


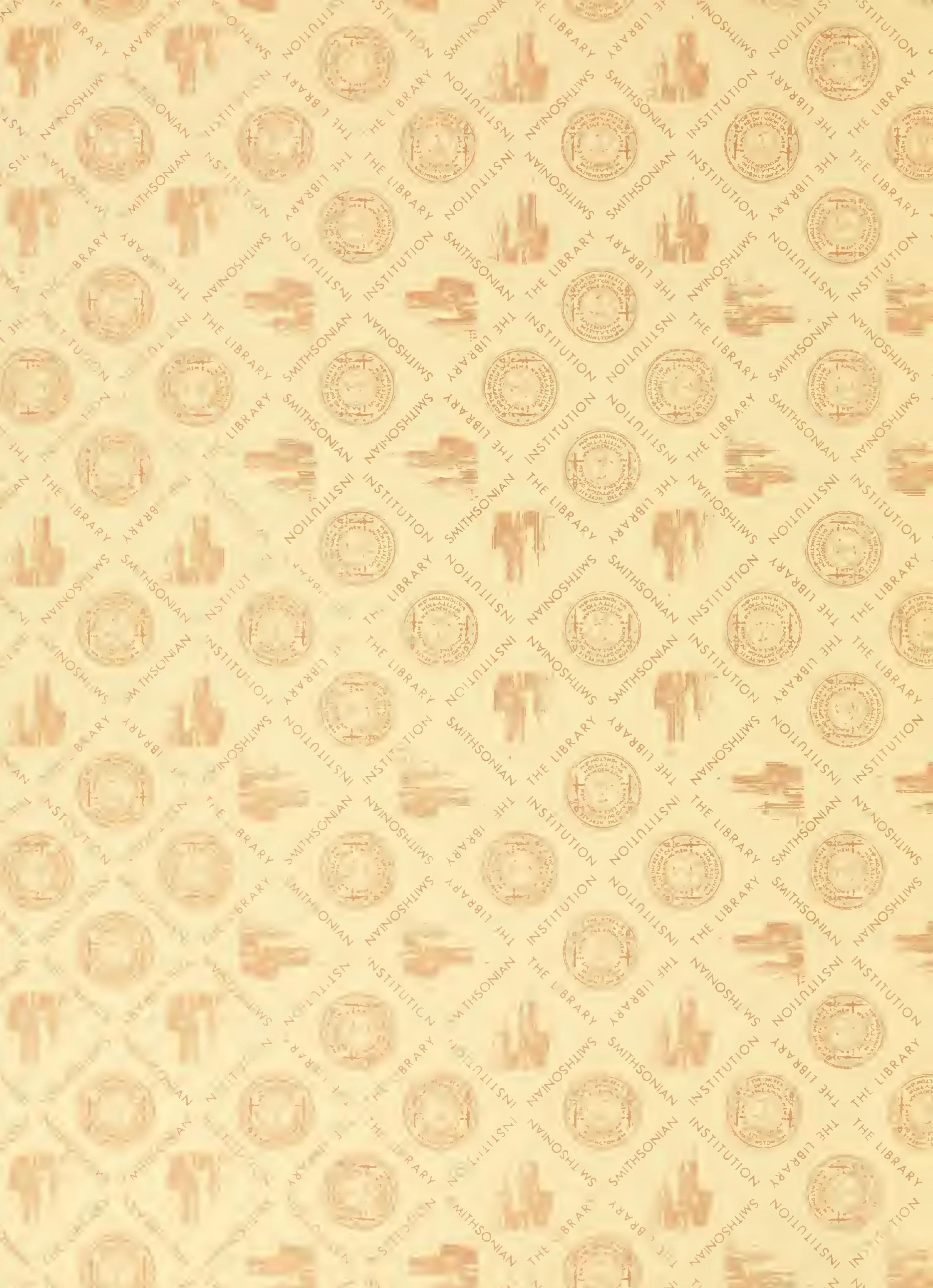


(1.) of

(1)
i)

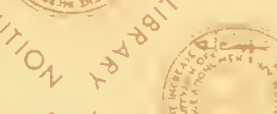

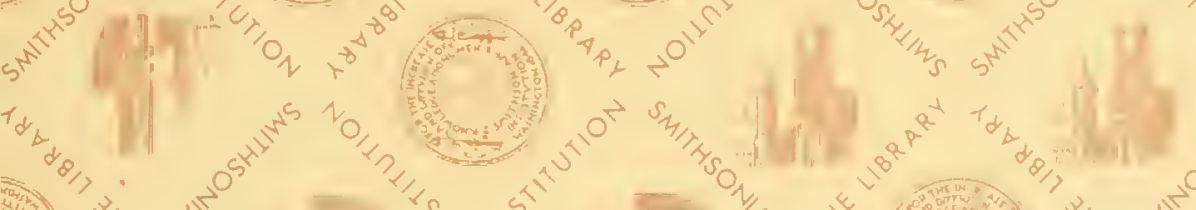

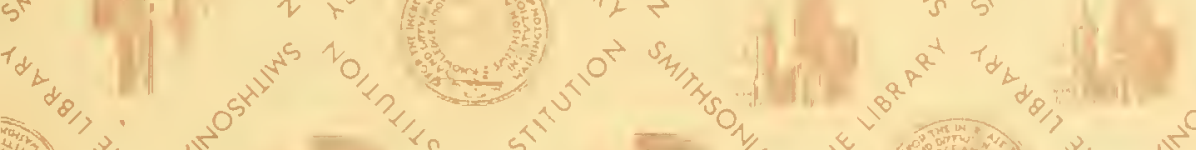

(1)

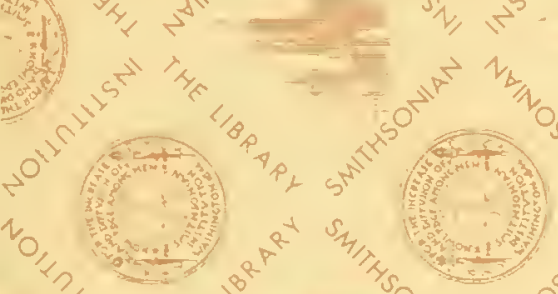

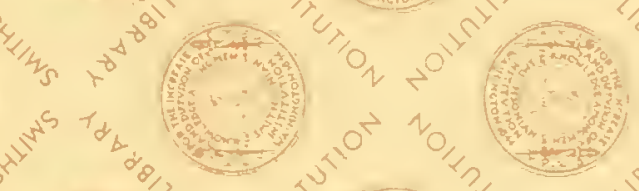

.

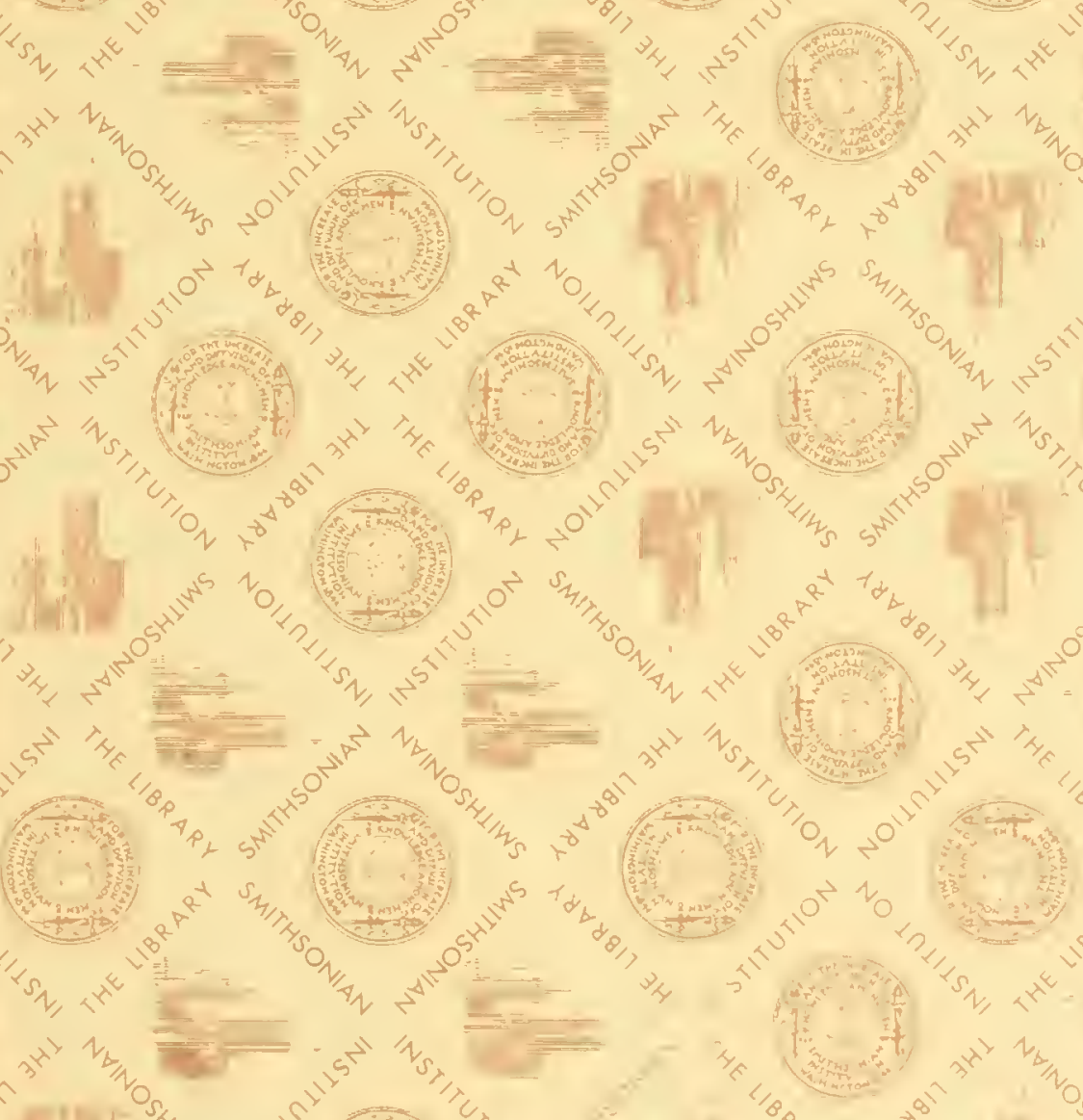

it

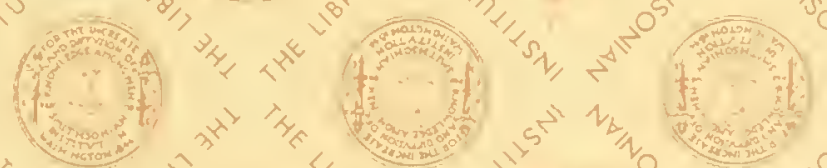

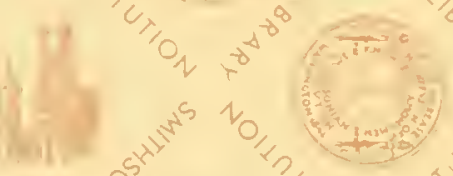

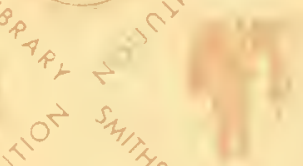

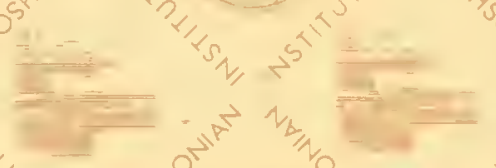
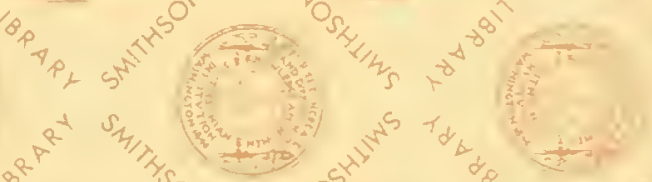

然-

(क)

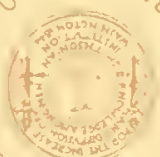

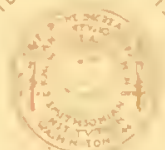

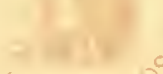

ti

s. 



\begin{tabular}{|c|c|c|}
\hline Adelolus n.g. & 124 & Lycomyra Bigot \\
\hline Amathomyia $\mathrm{n} \cdot \mathrm{g}$. & 34 & Megapoda Macquart \\
\hline Aphestia Schiner & 221 & Neophoneus Williston \\
\hline Atonia & 81 & Nusa Walker \\
\hline Atomosia $\mathrm{Mcq}$. & 135 & Oidardis $\mathrm{n} \cdot \mathrm{g}$. \\
\hline Atractia 'lacquart & 15.5 & Opeatocerus $n \cdot g$. \\
\hline Automolina $n \cdot g$. & 101 & Othoniomyia $\mathrm{n} \cdot \mathrm{g} \cdot$ \\
\hline Bathropsis $n \cdot g$. & 68 & Pholidotus n.g. \\
\hline Cenochromyia $\mathrm{n} \cdot \mathrm{g}$. & 114 & Pogonosoma Rondani \\
\hline Cerotainia Schiner & 38 & Pronomopsis $\mathrm{n} \cdot \mathrm{g}$. \\
\hline Clariola & 111 & Protichisma n.g. \\
\hline Cyanonetys $\mathrm{n} \cdot \mathrm{g}$. & 128 & Pseutorus Walker \\
\hline Cyphotomyia Williston & 65 & Rhopalogaster Macquart \\
\hline Dasylechia Williston & 239 & Smeryngolaphria n.g. \\
\hline Dasv1lis Low. & 235 & Strombocodia $n \cdot g$. \\
\hline Dasythrix Low. & 271 & \\
\hline Dissmeryngodes $n \cdot g$. & 75 & \\
\hline Doryclus Jannicke & 10 & \\
\hline Eni gmomorphus n.g. & 272 & \\
\hline Epaphroditus n.g. & 117 & \\
\hline Eumecosoma Schiner & 70 & \\
\hline Goneccalypsis $\mathrm{n} \cdot \mathrm{g}$. & 108 & \\
\hline Hybozelotes $n \cdot g$. & 197 & \\
\hline Lampria & 218 & \\
\hline Lamprozona & 98 & \\
\hline Laphria Meigen & 218 & \\
\hline Lophoceraea n.o. & 193 & \\
\hline Lowinella & 104 & \\
\hline
\end{tabular}



NOVA A CT A.

Abh. der Kaiserl. Leop.-Carol. Dentschen Akademie der Natturforscher. Band XCVI. Nr. 1. mleduch

\section{Beiträge zur Kenntnis}

\section{der \\ siidamerikanischen_Dipterenfauna.}

aul' Grund der Sammelergebnisse einer Retise

in Chite. Per'u und Bolivia,

Moñosia zuelauafrom ansgefihht in den Jahren 1902-1904 ron ans Jexas, for 144 .

A. muda, Jrunitad

W. Schnuse.

p.147.

alinctin Fam. Asilidae. $p, 183$

Bearbeitet ron

Professor Dr. F. Hermann-Erlangen.

Mit 5 'Tafeln Nr. I- $\mathrm{V}^{r}$ und 87 Figuren im T'exte.

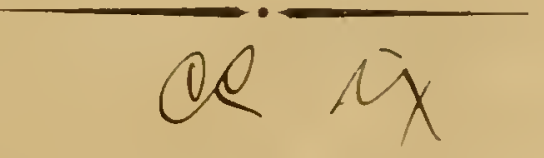

I A I, I, E.

1912 .

Drdek von Ehrhardt Karras, Hallea. S. 



$$
\text { NOVA A C T A. }
$$

Abh. der Kaiserl. Leop.-Carol. Deutschen Akademie der Naturforscher. Band XCVI. Nr. I.

\section{Beiträge zur Kenntnis}

der.

\section{sürdamerikanischen Dipterentauna}

auf Grund der Sammelerobniso siner Reise

in Chile. Peru und Bolivia.

ausgefiihrt in den .Jahren 1902-2-19(04 von

W. Schnuse.

switisugheng

JAN 231989

LBRANIES

\section{Faml. Asilidae,}

Pearbeitet von

Prolessor Dr. F. Hermann-Erlangen.

Mit 5 Tafeh Nr: I - Y und 87 Figuren im Texte.

Eingegangen beí der Akademie am 25. Oktober 1911.

I A I, I, I:.

1912.

Druck von Ehrhardt Karras, IIalle a. S. 



\section{Eimleitıll!g.}

Der Aufforderung, die Asiliden der Schnuseschen Reiseausbente zu bearbeiten, bin ich gerne nachgekommen; gewithr schon an und fuir sich die Beschäftignng mit einem Material, das mit so weitgehendem fachmännischen Verständuis zusammengetragen und in so tadelloser Weise konserviert wurde, wie dies ron dem leider zu frih verstorbenen Her'n W. Schnuse geschehen war, eine gewisse Befriedigmig, so zeigte schon die erste fliichtige Betrachtung der reichen Vorrïte, dafs ein detailliertes Studium dieser für die Kemntnis der siidamerikanischen Asilidenfauna ron allergrörstem Interesse sein miifste. Die fleifsige Sammeltätigkeit Schnuses erstreckte sich anf Chile, Peru und Bolivien, also im wesentlichen auf transandinische Gebiete, deren dipterologische Fauna im ganzen noch relatir wenig, jedenfalls weit weniger erforseht ist, als dies fiir das cisandinische Gebiet Siidamerikas, vor allem fuir die weit ansgedehnten Gefilde Brasiliens der Fall ist. Ein näheres Bekanutwerlen mit der transandinischen Fama diufte aber in tiergeographiseher Hinsicht nicht ohne Bedentung sein. Herr Dr. Lutz in Sĩo Paolo, der wohl beste Kenner der siidamerikanischen Tabaniden, macht nämlich darauf aufmerksam, dafs die transandinische Tabanidenfauna von der cisandinischen ganz rersehieden ist und dal's es zweifelhaft sei, ob beide iiberhanpt nur eine Art gemeinsam haben. Soweit meine Erfahrmgen reichen, diurfe diese Ansicht von Lutz anch fur die Asiliden einigermafsen Geltung besitzen, und so kam es, dafs meine Bearbeitung des Schnuseschen Asilidemmaterials nicht blofs in einer Determinierung, in einer Identifikation mit schon bekamten Formen, sondern vielmelır in der Aufstellung einer relativ grofsen Anzahl ncuer Arten bestehen 
mufste. Bekommt schon dadurch die vorliegende Arbeit einen etwas grö̈seren Unfaug. so wurde dieser noch darlurch ausgedchnter, dafs zufolge einer mit Herrn Schnuse getroffenen Verabredung eine grö́sere Reihe neuer Arten der siidamerikanischen Fauna, die mir im Laufe der Jahre aus meiner eigenen stattlich herangewachsenen Asilidensammlung, sowie aus gelegentlich geworlenen Zuwendungen vou seiten versehiedener Fachgenossen bekannt geworlen sind, Beridcksichtignng fanden. Noch aus einem anderen Grunde glaubte ich dieser Arbeit cine breitere Ausdehnung geben zu missen. Die langjährige Beschäftignng mit der formenreichen Familie der Asiliden legte mir nimlich mehr und mehr die Notwendigkeit einer Revision der Asilidengenera nahe. Lis will mir scheinen. dals die dipterologische Systematik in bezug anf die Defuition nnd die gegenseitige Abgrenzung der Asilidengenera mit viellejeht iibertriebenem Konservatismus allzusehr anf den Arbeiten aus der Mitte des vorigen Jahrhunderts stehen geblieben ist. Man lıat einerseits - da nul dort vielleicht mit zu wenig Kritik — nene exotische Species Gattungen subsummiert, die lediglich anf Grund palaiarktischer Formen mit vollem Rechte errichtet worden waren, und hat andererseits an Gattungen festgehalten, deren von Autoren wie Löw, Schiner usw. gegehene Iefinition und Abgrenzung eingehenderer Kritik nicht standzuhalten vermag. Mit diesen Ausstellnngen liegt mir niehts ferner als ein herbes Urtei] iiber dic Arbeiten vor allem der beiden genannten Antoren, im Gegenteil, wer, wic ich, immer wieder Gelegenheit lıat, sich iiber das Unzulingliche Ma cq wartscher oder Walkerscher Asilidenbeschreibungen zn ärgern, wird sich mit ganz hesonderer Anerkenummg del Prägnanz nud des Formenverstindnisses schinerseher und besonders Löwseher Arbeiten erfrenen. Aber man möge bedenken, in wie richlichem Mafse ms seit ihren \%eiten nenes. namentlich exotisches Untersuchungsmaterial zugeströnt ist und da und lort eine Ïnderung unserer Ansichten iiber die Ansilehunng der Gattungsbegriffe mit sich gebracht, hat. vor allem jedoch möge man dic Vervollkommunng muserer optisuhen Hilfsnittel in Rechnung ziehen. Die herrlichen nach Greenough schem Prinzip konstrujerten Binocularinstrunente, wie sie von den Firmen Zeifs, Leit\%, Scibert usw. gebaut werden, grestatten uns ein weit intensiveres nud miiheloseres Studium plastischer Verhältnisse, als dies unseren Vorfahren möglich war. Fin solches infimeres Studium 
plastischer Merkmale in bezug auf Reliefiermig des Kopfes, der Fiihler usw., anf Verhältnisse der Behaarung und Beborstung liel's ich mir fiir die Revision der Asilidengenera angelegen sein und möelte zunächst meine gewnnnenen Erfahrungen iiber die hauptsiehlich der siidamerikanischen Fauna zugehörenden Formen niederlegen. Voranssetzung fiir eine solehe Revision war freilich eine möglichst unfassende Autopsie der vorhandenen Typen. Mit freudiger Genugtnung kam ich konstatieren, dafs meine Bitto un Überlassung kostbaren 'Typenmaterials von seiten staatlicher und privater Sammlungen in weitestgehendem Mafse Entgegenkommen gefunden hat und ich betrachte es daher als eine angenehme Pflieht, anch an dieser Stelle fiir diese Liberalitït meinen verbindlichsten Dank anssprechen zu diirfen.

Ans äufseren Grïnden möge die Bearbeitmng des Schunseschen Asilidenmaterials mit ten Laphrinen begimen, ilmen sollen dann die Dasypogoninen, Leptogastrinen und Asilinen folgen und erst am Schlnsse werde ich vielleicht Gelegenheit haben Stellung zu nehmen zu der Frage, ob und wieweit die Einteilung der weit ansgedehnten und formenreichen Asilidenfamilie in diese vier Unterfamilien aufreeht erhalten zu werden vermag.

Eine Zusanmenstellung der Fundorte findet sich in der Vorrede, die seinerzeit Herr Schunse der Bearbeitmg der Empididen (Bezzi, Fam. Empididae, Nova Acta Acad. Leop. Carol. Bd. XCI) voransgestellt hat. 

I.

Laphrinae. 



\section{A. Tibiae anticae calcaratae $=$ AC ANTHOCNEMINAE.}

Die erste Horie laphrienartiger Raubfliegen setzt sich ans den Genera Therentria, Dorychs, Psendorus und Megapoda zusammen, denen ich eine neue Gattnng als Pronomopsis anfiigen werde. Ton diesen scheidet fiil unseren vorliegenden Zweek die Gattung Therentriu von volnherein ans, weil sie einerseits, soviel wil wissen, aussehliefslich der australisehen Fauna angehört, andererseits deshalb, weil bei Therentriu die Torderschienen lediglich mit einem einfachen uagelartigen Fortsatz ansgestattet sind. Die vier anderen Gattungen aber sind ansschliefslich Bewohuer Amerikas und zeichuen sich vor allem dadurch ans, dal's die Torderschienen nicht nur mit einem langen Endnagel (Fig. 1) versehen sind, sondern dafs anch der Metatarsus an seiner Wurzel mit einem lappenartigen Chitinfortsatze bewelnt ist, wodurch sie sich ummittelbar an gewisse Formen del Dasypogoninen

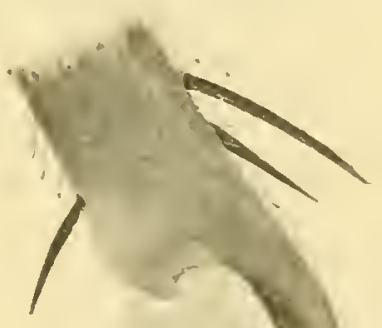
(Neolaparus usw.) anlehnen. Auch im Habitusbild, in der Kahlheit des Körper's usw. liegt mancher, nicht zu verkennende Anklang an diese Formen.

Is wird sich nun darmm hamdeh, die Grenzen der einzehen Gattmoen in strikter Weise zu entwickeln! und diejenigen Merkmale herauszuschälen. welche die Differenzierung der Formen zu ermöglichen imstande sind. Eine solche diirfte aber, wie ich glaube, schon durch die l3enutzung der folgenden kleinen analytischen Tabelle nicht die geringsten Srhwierigkeiten finden. 
1. Gesichtsfiache iiber dem aufogeworfenen Mundrande zu cincr Querrinne eingekerbt

- Gesichtsfläche gileichmaissig gewölbt

2. Gesicht ganz kahl. Torlersehienen olne circumskripte Terdickung, lagegren Metatarsus und die folgenden 'Tarsenglieder der Hinterbeine anffallend rerkiirzt und verdickt Doryclus Jännicke.

- Gesicht mit einigen lïngeren Borstenharen. Torderschienen in ihrer Nitte mehr oder minler spindelfömig erweitert mol an der Hinterseite mit sehr dichter, knrzer Borstenbeharmo kissenartig besctzt. Metatarsus mil T'arsen dej Hinterbeine vou normaler Länge mol nicht verdickt. 'Thorax rorne vorgetrieben und den Kopf mehr oder minder kajuzenartig iiberlagend

Pseudorus Walker.

3. Wangen vollständig nackt, die Mitte des Mundrandes liegt der Grenze des unteren Drittels der Angenhöhe gregeniiber, die Mundöffumng fällt steil naeh linten ab. Ober'and des dritten Fiilılergliedes beharst. Beine, namentlich die Vorderbeine stark verlängert Megupoda Maequart.

- Wangen dicht behaart, Mundrand in der Mitte nasenartig naeh abwiirts verlaingert; (Oberrand des Aritten Fühlergliedes nackt, Beine nicht verlaingert

Pronomopsis 11.8 .

\section{Toryclus Jünnicke. $\left.{ }^{1}\right)$}

Die von J Jïnieke gegebene Gattungsliagnose trifft im grofsen und ganzen vollstiindig das richtige, so dafs ich mieh hier auf cinige ergänzente und beriehtigende Angaben beschränken kann.

Die un sehr wenig beharte Stirne springt sockelartig iiber die Angen vor ('laf. Fig. 1), das kurze, viillig kahle und bartlose Gesicht ist unter den Fiilılern linnenförmigg gehölılt, der aufgeworfene Mnndrand spring t aber zu cinem schwach nasenförnigen Mundhöeker vor. Der grofse aber flache ()ellenhïrker entbehrt cigentlicher Borsten, sondern ist mur an seiner linteren Ablarhmog mit lingeren, na.l vorne iilsergebogenen Hasuen besetzt.

1) Da in dem Catalogus Dipterorum usw. ron Kertésez die Literatur in sehr sorgfältiger Weise beriicksichtigt ist, werde ieh nur dann Literaturangaben machen, wenn es fur meine vorliegrenden $Z$ recke notwendig erelieint. 
Auch eigentliche Oecipitalborsten fehlen vollkommen, beim $q$ ist das Hinterhanpt lediglich mit reicher, lingerel Beharung versehen, beim ơ findet

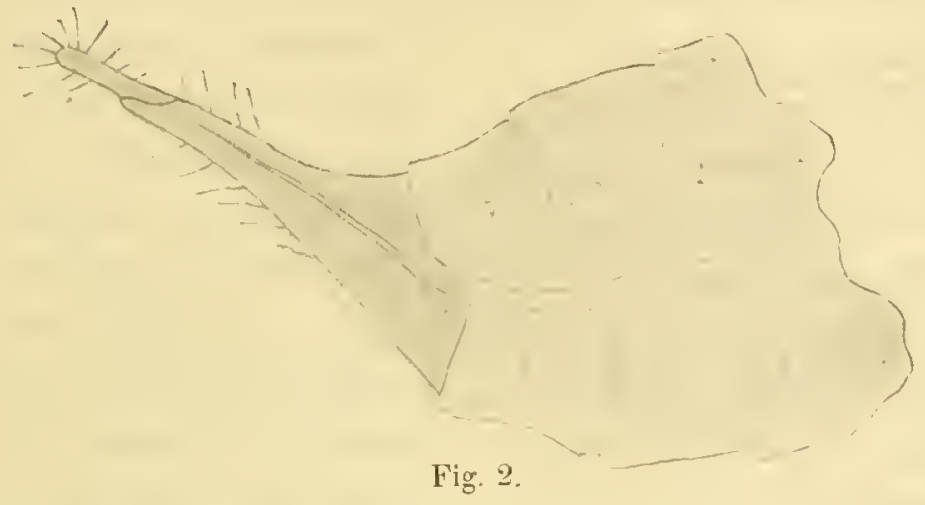
sich zwischen dieser jedersejts ein Buisehel etwas derberer, nach voriue umgebogener Hatre. Auch neben den Fiihlern steht bei ihm ein Biisehel gröberer Haare. Das erste Filhlerglied ist ein wenig länger als das zweite, das Endglied nicht ganz 11/2 mal so lang als die beiden Basalglieder, birı- oder ku'z keulenförmig, und an seiner Spitze mit ciner kleinen narbenförmigen Delle rersehen, in deren Tiefe ein ganz kuzer Stift nur schwer zul sehen jst. Die beiden Basalglieder sind mit starken Borstenhaaren besetzt, die namentlich anf der Oberseite des zweiten Gliedes erhebliche länge besitzen. Das Mesonotum besitzt an scinem Vorderrande eine thache, durch benlenförmige Vorlagungen (nicht die Schulterbenlen!) Hankierte Rimne ' und ist mit knrzer abstehender Behaa'tung versehen. Die Beborstung ist mu selwwach entwickelt: prifsutural 1, supraalar 1, postalar 1, Notopleuralborste fehlend; anch der Metapleuralschirm fehlt, es findet sich hier nur kurze Behaarmug. Ebenso ist das kleine, gewisscrmafsen in das riesig entwickelte Jetanotum mit einbezogene Schildehen kaum behaart. I)as siebenringlige Ablomen entbehrt der Discalborsten, das zweite Segment besitzt einen lincaren "neren Eindruck. Die Genitalien des oł sind klein, die lange Legeröhre des $q$ ist in ähnlieher Wreise,

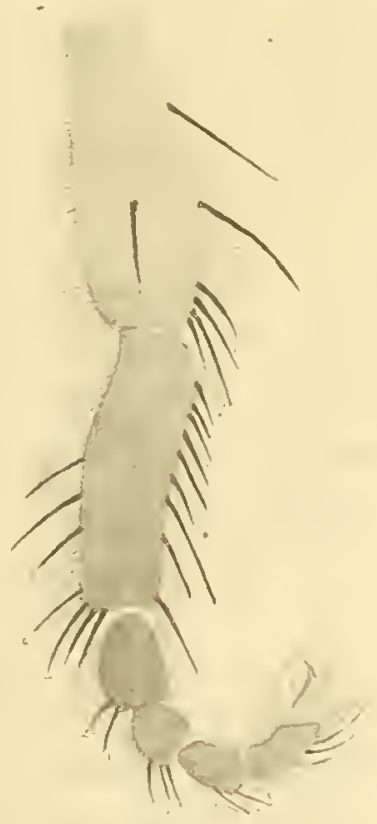

Fig. ::. wie bei gewissen Schlupfwespen (z. B. Pimplu) schict nach aufwirts geriehtet (Fig. 2). Auf die von Jïnnicke und von v. Rïder erwähnte Terdickung 
del Schienenspitze und des Metatarsus ler Hinterbeine sei auch hier noehmals aufmerksum gemacht und beigefiigt, dal's der Metatarsus an seiner Unterfliche zweircihige, ungenein grobe, kurze Beborstnng trägt ('Textfig. 3).

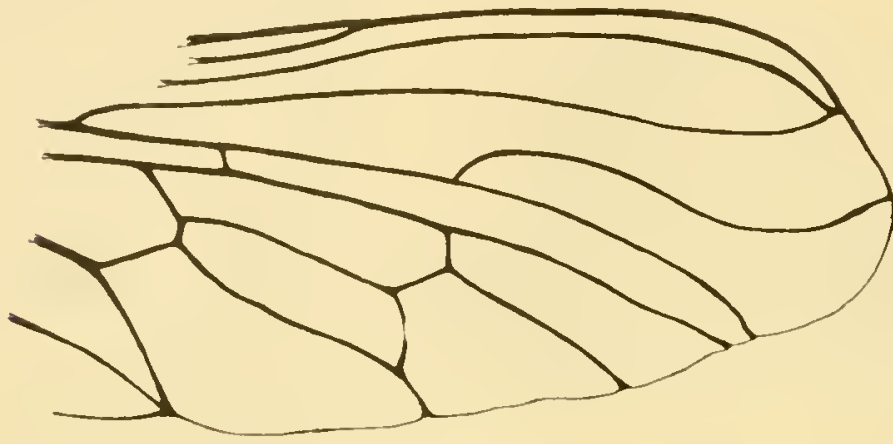

Fig. 4. Beziiglich der Fliigelidlerung stimmen die Aıgaben .Jännickes nicht vollkommen. Die Sulbcostalzelle ist entweder ganz am Fliigelrante geschlossen oder mit einem sehr kurzen Stiel versehen ('lextfig. 4). Es sind fiinf Hinterrand-

zellen vorhanden, von denen die vierte gestielt ist. Die kleine Querader steht iiber der proximalen Hälfte der Discoidalzelle. Im ïbrigen müehte ich noch auf tie sehr ausführliche, von einigen im allgemeinen gaten $\mathrm{Ab}$ bildungen begleitete Genusbeschreibung v. d. Wulps (Tijdschrift voor Entomologie XTII, 18\%0, p.9. Sep.-Abz.) aufmerksam machen.

Als typische Art gilt lokantlich

Doryclus distendens Wied.

Die Synonymie ist von v. lïider, wie ich sche, in vollständig richtiger Weise festgestellt worden (vgl. Kertéscz, Catalogus). Ich besitze die Art in vier Exemplaren (Brasilien) beiderlei Geschlechts in meiner Sammlung und kenne sie anclı aus del Sammlung Lichtwardt und dem k. k. Hofmuseum in Wien.

Ferner gehört hierher

\section{Doryelus Gïntheri Arribalzaga,}

den ich in zwei ebenfalls ans Brasilien stammenden o Exemplaren in meiner Sammlung besitze. Dieselben stimmen mit der Beschreibung rollständig iiberein, wobci ich benerke, dafs es sich um einen cehten Doryclus handelt; Arribalzaga hatte utr versäiunt, auf die Verdickung der Schicnenspitze und des Metatarsus an den Hinterbeinen aufmerksan zu machen, die bei spec. Gramlheri in gleirher Weise wie hei der typischen Art vorhanden ist. 


\section{Pseurlomus Walker.}

Das Genus Pseudonus wurde von Walker iu den Diptera Saundersiana (1850) errichtet und zwar auf Grund der brasilianischen Species piceus, der dann Bellardi (1859) eine zweite Art ans Mexico als Ps. bicolor anreihte. Üher die Auffassung der Gattung herrselıt noch eine gewisse Unklarheit, die sich seinerzeit schon dadurch manifestierte, dafs Schiner (1866) dis Genus zu den Dasypogonimen stellte, während es von Bellardi nnd allen folgenden Autoren den Laphrinen subsummiert wird; dabei möchte ich nebenbei bemerken, das anch Walker sein Genns Pseudorus in der Abteilung. "Dasypogon" unterbrachte. Sehen wir nun zu, woranf sich diese Diskrepanz der Meinnngen zuriickfiihren lälst, so wird eine solehe L'ntersuchung zunichst mit dem Fliigelgeäder zu beginnen haben. Von Pseudons piceus Wlk. liegen mir aus dem k. k. Hofmuseum in Wien zwei $o^{T}$ Exemplare vor. wohl dieselben, die seinerzeit Schiner untersucht hatte, und da fällt, wie nebenstehende Textfig. ó ersehen

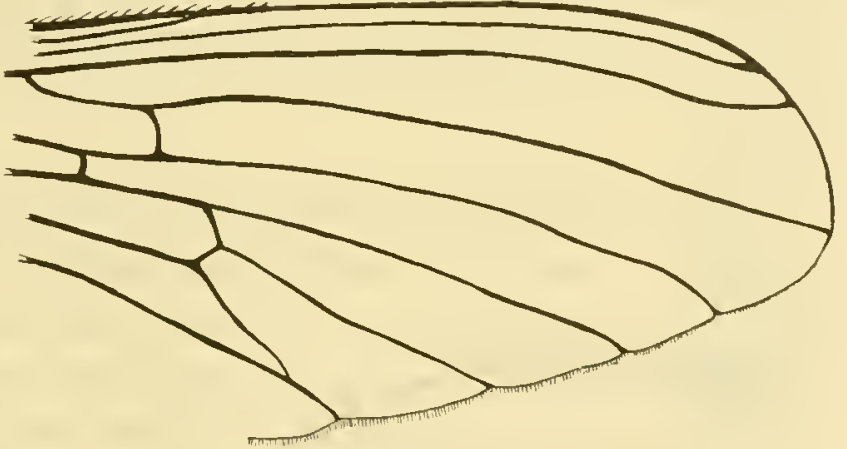

Fig. 5 .

lärst, vor allem auf, dafs wirklich die Subeostalzelle breit offen in deu Fliigelrand ausmindet. Danach bestände also die Ansicht Schiners. das Gen. Pseudorus den Dasylogoninen einzureihen, vollkommen zu Recht. Andererseits ist aber die Subcostalzelle auf der trefflichen West wo odschen Zeichnung, die die Beschreibung Walkers begleitet, mit aller Deutlichkeit als geschlossen dargestellt, mol anch Williston (Psyche $T^{\top}$ ) bestitigt dies nach Untersuchung eines Exemplars, das er fuir Ps. piceus Wrk. hielt. Walker gibt fernerlin für seine Species das Torhandensein von drei Submarginalzellen an und ich finde diese auch an den beiden mir rorliegenden Exemplaren in der nämlichen Weise ausgeprägt. Da auf der zitierten Westwondschen Zeiehnung die in Frage kommenden Aderu nicht mit der nitigen Klarheit dargestellt sind, so seien hier folgende Angahen 
gemacht. Der vordere Ast der Cubitalater entspringt scheinbar aus der Radialader und zwar riemlich genan iiber der kleinen Querader; die die beilen muteren Submarginalzellen vomeinander tremmende Querader (Wurzel des vorderen Cubitalastes) steht genau in der Mitte zwischen der kleinen Qnerader und den distalen Versehlul's der Disroidalzelle: die äufsere untere Submarginalzelle ist daher doppelt so lang als die imere. Die sie einrahmenden C'ubitalaiste verlanfen einamler vollkommen parallel und divergrieren nur am äufsersten Fligerrande ganz wenig. Der Angabe Villistons iiber das Vorhandensein von nur zwei Snbmarginalzellen möchte irolı keine besondere Bedentung beimessen, beobachten wir ja doch bei den Asiliden relativ häutig, dals die Zahl der Subunarginalzellen weg*en ilurer Tariabilitit kaum zum Definieren der Speeies, geschweige denn der Gattung Terwendung finden kann. Endlich sei noch iiber das Geäder von Ps. picens die Angabe gemacht, dals die kleine Querader ziemlich iiber der Mitte der Disenilalzelle steht mul dal's die vierte Hinterrantzelle und die Amalzelle lang gestielt sind.

Betrachten wir um zum Tergleich das Geidler von Ps. bicolor Bellardi ('lextfig. 6), so stofsen wir auf relativ recht betrichtliche Differenzen. Hier

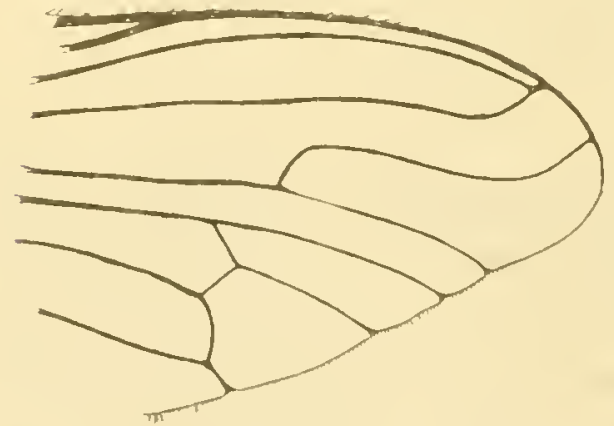

Fig. 6. ist dic Subeostalzelle wirklich geschlossen und, wem anch kinz, so doch deutlich gestielt. anclu sind nur zwei Subuarginalzellen rorlianden. Der vordere Ast der Cubitalatel steigt in steil S-firmigem Zug noch gegen den vorderen Fliigelrand empor, seine Trurzel licgt ziemlich in gleieher Linie mit der rlistalen Begrenzung der Discoidalzelle, mud lie kleine Querarler steht iiber dem proximalen Y'iertel letzteres Zelle. Dagegen verhalten sich die erste mol vierte llinterrandzelle, sowie die Analzelle genau so wic bei del species piceus.

Halten wil nun tas Gesargte noch cimmal zusammen, so miissen wir eingestehen, dass bei nem Gen. Pseulorus einlseitliche Ziige in Fliggelgeiiler vermilst werden mul dals dieses iiberhanpt nicht instande wïre, die systematiselıe Stellung nur einigermalisen zu sichern. Es ist dalıer recht gout, 
dafs uns hieriiber eine ganze Reihe anderer plastischer Merkmale sicheren Aufschluls zu geben vermag. Schon der Bau des Kopfes. Zug um Zug sehen wir hier die gleiche Linienführung wie bei Dorychs, und es kann แแน eine einzige Differenz konstatiert werden: wïhrend nämlich bei Doryclus das Gesicht völlig kahl ist (Taf. Fig. 2), besitzt es bei Pseudorus sowohl seitlich einige Haare, als anch auf dem nasenartig vorgeworfenen Munclrande einige den Knebelbart reprësentierende Borsten, wie sich dies auch an den versehiedenen in der Literatur nierlergelegten Zeichnmgen rou Westwood, Bellardi und Williston (Mfanual of the North American Diptera, III. el. 1908) in einigermalsen befriedigender Weise dargestellt findet. Ebenso kam ich im Ban der Fïhler keine irgendwie in Betracht fallenden Unterschiede erkemnen. Auch in der Beschaffenheit des Thorax stofsen wir auf den gleichen Typus, daran vermag anch der Umstand nichts zu :indern, dafs bei Pseudorus piceus der Prothorax zu jenem seitlich beborsteten, geradezu abentenerlichen Höcker aufgeworfen ist. weleher den Kopf kapuzenartig iiberlagert. Bei der Bellardisehen Spec. bicolor ist die Höekerbildung; wenn auch vorhanden, so doch bei weitem schwächer ausgebildet und es ergibt sich anch dadurch wieder cine Annäherung an Doryclus. Ich bemerke dabei, dals die verschiedene Gestalt des Thorax bei den beiden Species an den oben

Fig. 7 . zitierten Figuren recht gut zum Ausdruck

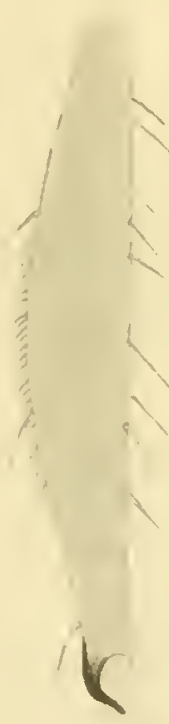

Fig. 8.

kommt. Aneh das Abdomen scheint, soweit ich auf Grund meines wenig. ausgedelnten Untersuchungsmaterials urteilen darf, keine irgendwie bedentenden Unterseliede gegeniiber Doryclus \%u besitzon.

Ist nun vorliegende vergleichende Untersuchung imstande gewesen. in einwandfreier Weise dic verwandtschaftliche Znsammengehörigkeit zn erweisen, so gibt uns anf der anderen Seite die betrachtung der Beine 
Merkmale genug, die leieht und ïbersichtlich eme generisehe Trenmung beider Formen erunöglichen. Fs genight sehon ein Blick auf die 'Textfig. 3 und 7, แm die total versehientene Bildung der Hinterbeine von Pseudorus und Dorychus zu erkennen; bei diesem die schon oben erwälnte anfallende Verkiurzung und Verdickung des Metatarsus und ner folgenden 'Tarsenglieder, wähnend diese bei Pseudorus schlank und diinn gestaltet sind ('Textfig. 7). Andererseits zeigen bei ilicsem letzteren die Torderschienen eine auffallende Reliefierung, die hinwiederum dem Genus Dorychus vollstïndig fehlt. Die seitlich komprimierten Torderschienen besitzen nämlich eine oblonge, an die Innenseite iibergreifende Verbreiterung, welehe äulserst dicht mit knrzen Borsten besetzt ist ('T'extfig. 8).

\section{Megceporle Macquart.}

Die von MIacyuart gegelsene Gattungsdiagnose ist nicht genügend, un die Gattung von Doryclus zu trennen; daher kommt es auch, dafs der Autor die Spec. distendens WVied. unter verschiedenen Namen (crassitarsis, cyaneiventris) seiner Grattung Megupola subsummierte. Unter diesen Umständen erscheint mir eine ausfiihrliche Genusbeschreibung notwendig, die auf Grundlage der bekannten brasilianischen Species labiata Fabr. gegeben werden soll.

Bei l'rofilbetrachtung' ragt die Stirne nicht iiber die Stirne vor (Taf. Fig. 3), dagegen zieht sich das Gesicht sngleich unter der Fühlerwurzel nasenartig ror. Die Spitze dieser Nase, die ungefäh der Grenze des unteren Inittels der Augenhöhe gegeniberliegt, trägt aufser zwei langen, starken Borsten einige wenige kurze Borstenlaare und anch in einiger Entferumng von dem Mundrande finden sich solehe ganz vereinzelt auf dem im iibrigen völlig kahlen Gesicht. Die Umrandnng der grosen Mundüffinung füllt steil nach hinten ab. Rủssel und 'l'aster lang' und von gleichem Bau wie bei Doryclus. I) Stirne trägt zerstreute borstenartige Behaarung, der grolse aber Hache Ocellenliöcker entbehrt ter Borsten und ist ebenfalls nur an seiner hinteren Abdachung mit zalhlreichen, nach rorne gebogenen kurzen Burstenharen besetzt. Anch das Hinterhaupt ist mit solehen versehen, eigentliche, I. h. in Reihen gestellte Occipitalborsten, find(n sich jeloch unr in mittleren Partien. Das Grundglied der Fiiller ist etwa $1^{1}$. 2 mal so lang 
als das zweite, beide besitzen borstenfömnige Behaarung, die namentlich auf der Riiekenflïche des zweiten Gliedes sehr lang ist. Ins spindelförmige, an seinem Oberrande mit cinigen borstenfürmigen Haaren versehene Endglieil ist etwa doppelt so lang als die beiden Basalglieder zusammengenommen und hesitzt einen deutlichen, schief abgestutzten Endgriffel, ans dessen Spitze ein kurzes Stiftchen lerrorragt. Der Thorax ist an seinem Vorderrande wie bei Doryches, nur weit schwiicher rinnenfirmig gehïhlt. Die gewissermafsen zweispitzigen Schulterbenlen sind mit einem Büischel knrer, teilweise gribberer Haare besetzt, im iibrigen abcr ist das Mesonotum rollstindig kahl. Peborstmng: priisutural 1, supraalar 1, postalar 1, Notopleuralborste fehlend, der Metaplenralsehirm besteht nur ans schwachen Haaren. Anch das Schildchen ist vollständig kahl, lagegen triight das Metanotum seitlich ein Biisehel

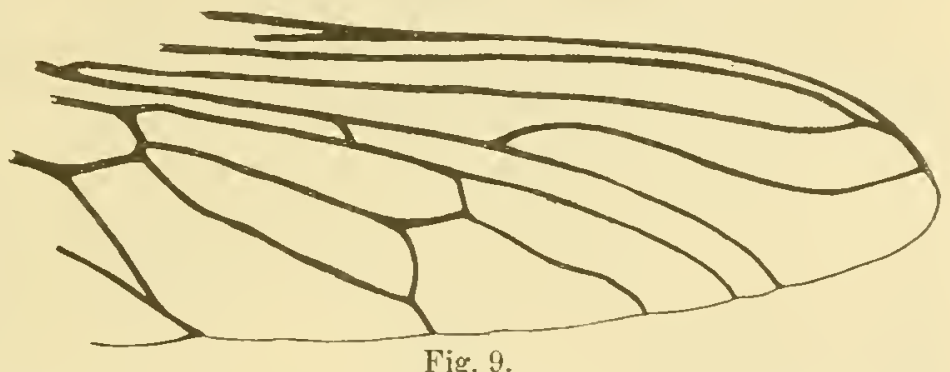
kiirzerer Haare. Das Abdomen ist bei dem ơ arht-, dem $q$ siebentinglig, etwas schmäler als der 'Thorax und mit zerstrenter. teilweise reihenfömig' angeorheter anliegender Beharung versehen. Das zweite Segment besitzt einen leichten Quereindruck, Discalborsten finden sich nur auf dem ersten Segment. Die Genitalien des or sind ziemlich grols, fast kolbig. mul ranh behart, die Legeröhre relativ kurz, gerade ausgestrerkt. l)ie exzessive Lïnge der im ganzen kahlen Beine, namentlich der Torderbeine, ist bekannt. Über las Flïgelgeitder ggenïgt die Angabe, dafs der Stiel der Subcostalzelle sehr kurz ist, ja manchmal fast fehlt, und dals die kleine Querader distal von der Mitte der Discoidalzelle steht (Textfig. 9). Analzclle und vierte llinterrandzelle sind wie bei den vorhergehenten Gattungen lang gestielt, die erste Hinterranizelle ist anffallend lang und schmal.

Als trpische Art hat lie altbekannte spee.

$$
\text { Megapoda labiata Fabricius }
$$

zu gelten, die in Brasilien nicht selten zu sein scheint. 
Nach rler Versirhermog v. Rioders wiurde sich als zweite Art anreihen müissen

\section{Meyaporla rufientivis v. liabler}

¿lls Manes am Amazonenstrom.

Ich kenne die Art nicht und la sich in ler Beschreibnng auch nicht ule mindeste Hinweis auf plastische Merknale fiudet, so kann einstweilen die Zugehiorigkeit dieser Art noch nioht als ganz sicher gestellt gelten.

\section{Promomomolsis 11. 20.}

J)as gleichförmig gewölbte Gesicht springt nasenartig vor und ist in ler Mitte zu einem fast riisselförmigen Fortsat\% verlängert, lessen Spitze jederseits \%wei lange Knebelhorsten trägt ('laf.' Fiug.4). In del Mitte ist das Gesicht vollstiindig kahl, seitlich jedoeh mit locker stehender, zicmlich langer Behaarung versehen; auch die Stime und die Soheitelgegend sind lang und dicht behaart. Der Hache Orellenhiokser enthehrt ebenfalls del liorsten und ist nu an seiner hinteren Abdachung mit einem Büschel vorwäits gebogenel Haare ansgestattet. Auch dem Hinterlaupte fehlen eigentliche Occipitalborsten, lagegen besitzt es gleiehniafsige dichte Behaarung; die sich umnittelbar in dic Behaarung des Kinns mud del hiisselwumel fortsetzt. lïn eigentlicher Backenbart fehlt jedoch. Riissel mul 'Taster zeigen in Ban und Behaarmug die gleichen Verlältnisse, wie bei den benachbarten Gattungen. An den Fiihlern ist das erste Gilied etwa 1'a mal so lang ali des zweite, das kenlenfïmige lindglied, 11, mal so lang als die beiden Basalglieder zusammengenonmen, trïgt an seiner Spitze einen in einen nagelartigen lorn auslanfenlen, kräitigen lindgriftel. Die beilen

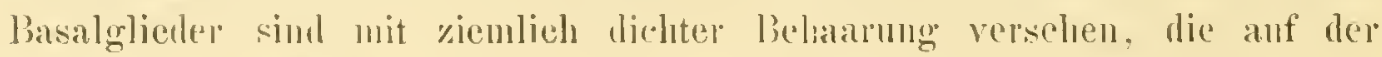
(Herseite des \%weiten Gliedes erhebliche Linge annimmt: las Fudglied ist vollstandigg kahl. leer märsig gewölbte 'T'horax lälst die rinnenörniget Delle an Torderrande nur wenig dentlich erkenuen und zeichnet sieh vor

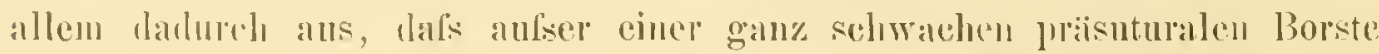
wohl jerle weitere beborstung fehlt. Ial's lagegen das Mesouotum. namentlir.lı

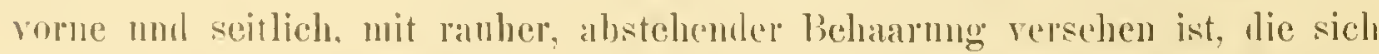
zerstrent anch anf dem Sohildehen fimbet. Der Metaplenralsehim ist deutlich 
entwickelt und aneh das Metanotum triggt scitlich lïngere Haare. Das abgeplattete siebenringlige Abdomen ist nach hinten etwas verbreitcrt mnd hiel breiter als ther 'Thorax. Das zweite Segment tright vorme einen sehr dentlichen lineäiren Quercindruck. Jiscalborsten fehlen anch anf dem ersten Segmente vollstiondig, dagegen ist der Seitenrand des ganzen Abdomens dicht behaart mul anch lie Ritckenflit·he ist mit lockerer anliegenter Behaarung rersehen. Die wic gewilmlich zweigliehlrige Jegeröhre ist mälsig lang, nach abwiirts gebogen, an der Spitze fein behaart mnd aufserdem an ilurer Unterscite mit zwei ('hitinhakchen versehen. Die Beine sind unt wenig verlängert, jeclenfalls bedentend kiirzer und plumper als bei Meya-

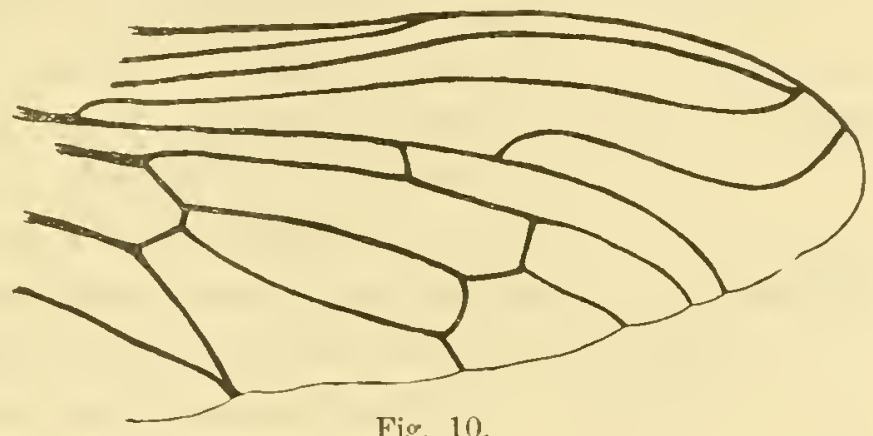
poda: simtliche Schienen gegen ihre Spitze schwach keulfürmig rerdickt. Dichtere Behaarnug tindet sich nur an der Unterflache ler Srlienenspitzen mul an den Tarsen, lagegen sind saimtliche Abschnitte der Beine mit riemlich kurzen, zerstrenten Borsten rersehen. Die Fliigel sind relatir kiirzer als bei Megapoda, zeigen aber in wesentlichen den sleichen Arlerverlauf ('Textfig. 10). Die kleine Querader steht anf der Grenze des distalen Drittels der Discoidalzelle, die a'ste mul zweite Hinterrandzelle ist relativ rerkiuzt, der rortere Ast der gegabelten ('nbitalader stark S-fïrmig gekriimmt.

Als typiscle Art betrachte ich

$$
\text { I'ronomopsis chalyball n. sp. ?. }
$$

Ich besitze thei Stïcke aus Mestargentinien (Mendoza).

Kopf. Witte rles l"ntergesichtes zitronengell, die seitlichen l'artien siml ebenso wie die Stirne, der Seheitel und das Hinterhanpt dunkelbram bis sehwarz: nur an ler oberen Iugenecke findet sieh ein kleiner, bramgelber Scheiteltleck. Anch die Fiihler, die 'Taster mul tler Rüssel sim schwarz, ebenso die gesante Behanrung des Kopfes, nur der liissel traght an seince sipitze ein Biischel gellser Haare. 
Thorax sehwarz mit Spuren striemenförmig angeordneter graugether Bestäubung anf lem Mesonotum; die Schulterbeulen und die Gegend zwischen den Postalarlüekern und dem Sehildehen diister rotbraum. Die Behaarmig des Thorax ist ansschlicfslich schwarz, ebenso die der sehwarzen Hüften.

A bdomen lebhaft blan metalliseh glinzend mit kurzer ansschliefslich schwarzer Behan'ung. Nur die Spitze der Legeröhre trïgt ein Biischel zarter gelber Haare.

Beine durchaus dunkelpechbram bis sehwarz, anch die gesante Behanrung und Beborstung besitzt die gleiche Farbe. Klanen diister rotbraun mit schwarzen Spitzen, Pulvillen braun.

Dic Flïgel sind an der W'urzelhïlfte und am Vorderrande lebhaft rostgelb, an cler Spitze und am Hinterrande sehwarzbraun mit lebhaft blanen Reflexen. Die Farbe der Adern richtet sich nach dem Untergrunde.

Long. (orp. 17 - $26 \mathrm{~mm}$ long., alar. $16-22 \mathrm{~mm}$.

Als zweite Art ist mir bekannt geworden

$$
\text { Pronomopsis rubipes n. sp. of, }
$$

1 f aus P'er'u. Juliaca $4000 \mathrm{~m}$ iiber dem Meere.

Kopf. Das Mittelfeld des Gesiehtes ist lebhaft zitronengelb, die seitlichen Partien sind ebenso wie die Stirne, das Hinterhanpt, der Riissel und die 'laster llurchaus schwar', die gleiche Farbe besitzt anch die gesante Behaarung des Kopfes. Erstes lihhlerglied schwarz, das zweite gelbrot, das dritte fehlt; dic Beharmug der beiden Basalglieder ist schwarz.

Der gesamte 'Thorax ist schwarz und schwarz hehatart, ebenso die Schwinger.

l)as schware Abdomen zeigt lebhaften grinen Erzglanz, die kure Behaarmug ist gleichfalls schwarz, nur die kurze Legeröhre ist gelb behaart.

Beine. Oberschenkel glianzend schwarz mit gleichfarbiger Beharmug, die Schimen, T'arsen. Klanen und P'ulvillen jedoch lebhaft rot und mit zarter goldschimmernder Behaarung versehen; die groben Borsten ler ganzen liene sind jedoch ausmahmslos schwar.

Die stark glinzenden F'liigel sind durehans dunkel-rostbrann mit leichtem violetten Schimner und zeigen gegen den Fliigelrand lichtere Zehlkerne. Lomg. corpe. $233 \mathrm{~mm}$, long. alar. $18 \mathrm{~mm}$. 


\section{B. 'Tibiae anticae non ealcaratae = EREMOCNEMINAE.}

\section{Atomosinae.}

\section{Einleitung.}

Untcr den im allgemeinen grolsen, häufig genug grob pelzartig behaarten laphrienartigen Raubfliegen fiillt eine Horde zierlicher. meist relativ kahler läuber auf, die nur selten die Länge von $10-12$ mm iiberschreiten, meist noch kleiner sind, häufig eine dureh punktfïrmige Gribchen bedingte Skulpturierung am 'Thorax und Abdomen erkennen lassen und mit ganz geringen Ausnahmen an den Fliigeln eine Eigentiimlichkeit des Aderverlaufes zeigen. Die die Discoidalzelle und die vierte Minterrandzelle distal absehliefsenden Queradern verlaufen nämlieh in der goleichen Riehtung, häufig genug sogar in der gleichen Linie. Maequart hat besonders anf dieses eigentiimliehe Terhalten der Fliigeliderung hin sein Gen. Atomosia anfgestellt und ich möchte daher für die ganze, vorlerland ganz flichtig gekennzeiclnete Grupue deu Namen Atomosinue testgehalten wissen. Wiederun ist es ein beredtes Zeichen fiil das fachmämische Terstiudnis und Interesse, mit dem Herr Sehnuse auf seinen Reisen zu sammehn pHegte, dals seine Ausbeute gerade reeht reich an diesen kleinen, in allgemeinen recht schmucklosen und wenig anffallenden Atomosinen ist. Sehr ball stiefs ich bei deren Determinierung auf bïse Schwierigkeiten und sah zugleich ans der. Literatur, dals diese auch meinen Torgäugern nicht erspart geblieben waren. Und so waren sie selbst an eine Aufteihng der versehielenen Atomosinenformen in gewisse Genera gegangen: von Schiner wurlen die Genera Aplestia. Cerotainia. Eumecosoma, von Lüw Letmprozone, von IV'illiston Atonia und C!photomyiu, von Arribalzaza Rihathimomyia. von Kertésez 
emllich Cluriolu errielstet. Selon friher hatte Macynart las Gen. Atractia anfgestellt, lasselbe aber aus spiter genamer zn besprechenden, mugenigenden Grimlen bei den Asilinen mergebratht. Zum 'Teil waren wohl diese verschedenen Genera, wenn ich so sagen darf, mit unzmreichenden Witteh errichtet worden mul es blicben dementsprechend die schwierigkeiten fiil die ststematische beabeitung der Atomosinen nach wie vor bestehen. Gerade diese Schwierigkeiten aber reizten mich; so habe ich dem mit ainen wahren Fenereifer diese klemen, schmucklosen Riuber stuliert, aber bahl einsehen miissen, dafs das Stmdimm lediglieh sibd-und nordamerikanischer Formen nicht die gewiinschte Finsicht in die Systematik der Atomosinen vermittelı kann, somleru dafs diese sich nur dureh eine monographische Darstellung der Fornen aller Fannengebiete erreichen läfst. Mit dicser monographischen Jarstellung habe ich freilich — ich weifs das wohl die Grenzen der gestellten Aufgabe, die Asiliden der Schunseschen Reiseausbente zu bearbeiten, $n m$ ein erhebliches iibersehritten, aber ans der langjihrigen Komespondenz mit dem leider zn frïh verstorbenen Herru Schnuse glanbe ich wohl zu wissen, dals er einer solchen Überschreitmor seine Billigung nicht wïrde verweigert haben. L'nmöglich aber haitte ich eine solche Monographle zum Abschlnsse bringen kömnen, wäre ich nicht ron den versehiedensten Seiten in nieht genug dankenswerter Liberalitit mit Untersuchungs- ma namentlich kostbarem Typemmaterial nuterstiitzt worken; so lernte ich ein Atomosinemuterial von ciner Vollstindigkeit kemurn. wio es wohl kamm je cincul Lutersurher vorgelegen haben mag, und ich kann wohl sagen, lal's es nur recht wenige formen sein werden, dir mir nicht durelı Antojsic bekannt geworden sind. Lnd gerale der mir ermiiglichte Vergleich der 'T'yen hat meinen ganzen I'ntersuchungen dis gewiinschte feste Rasis gegeben. Dak ich unter diesen giinstigen Lmstänlen bei der systematischen Aufteilumg der Atomosinenhorie immer eine golickkliche IJand gehabt Iaittr, will ich trotzdem nicht behaupten, im Gegrenteil, ich bin mir wohl bewulst, yon einer völlig restlosen Lisung der gocstellten Aufugabe ila und dort doch noch weit cutfernt $z u$ sein; ncben manchem anderen. ist daran, so paralox das klingen mag, gerate die grolse Ansdelunng meines Untersnchmosmaterials Schuhl. Ans kleinerem Material

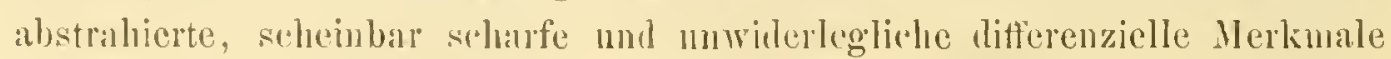


zerrinnen dem Untersucher nur allzu häufig muter den Händen, wemn ihn die Kenntnis eines ansgedehnteren Materials mit den mannigfaehen Übergangsfolmen bekannt gemacht hat. Trotz den mir wohl bewulsten Mäingeh darf ich aber doch vielleicht von der vorliegenden monographischen 1)arstellumg elhotten, dafs sic ordnend und klärend die systematische Kenntnis der Atomosinen zu erweitern vermag und dals sic durch stete Hervorhebung der jeweils einenden und trennenden plastischen Merkmale zeigen kann, in welchem Formenreichtum diese Horde zierlicher lianbfliegen unseren gesamten Lrdkreis bevölkert.

Gilt es mun, die Atonnosinen gegeniber den anderen Laphrienformen scharf abzugrenzen, so wird man sich wohl zunäehst an die oben bereits erwähnte Eigentiimlichkeit des Fliigelgeäders halten. Wenn diese aber in den verschiedenen analytischen 'l'abellen, die wir fuir Bestimmmg del Asilidengenera in der literatur vorfinden, als ein oder vielmeln als das die Atomosinae kennzeichnende Merkmal angegeben wird, so ist das nicht richtig. lhem zunäehst finden sich gewisse Formen der Atomosinen, allerdings ausmahmsweise, bei denen die beiden Queradern nicht in der gleichen hivolutung verlanfen, anderersejts gibt er echte Laphrinen, die die Figentimlichkeit des Atomosinenfliigels besitzen. Hierher gehören zunächst einige gennine Laphrien, die indomalayischen Species scamlaris Wied., obliguistriga W]k. und nigrocoeveles v. d. Wulp, weiterhin die Genera Lamyra und Amppodetus. afrikanische Formen, dic mit den Atomosinen nicht die geringsten rerwandtschaftlichen Beziehnugen lesitzen. Da demuach das F'liigelgeaider kein spezifisches Merkmal für die Atomosinen abzugeben relmag. wirl man sich nach anderen Merkmalen muzusehen laben. Ein solehes labe ich in der Beschaffenheit der seitlichen flachen Hörkerbildung des Netanotum anfzufinden vermocht. Lini allen Atomosinen besitzt dieser Metanotalliicker entwerler cin Biischel feiner Haare. oder weit häutiger eine Anzahl grober und kurzer. dorn- oder stiftehenartiger liorsten, die nieht selten eine reihenfirmige Anordumng zeigen. Aber anch die Behaarung mul Beborstung des Metanotum stellt kein Specificum der Atomosinen dar: wir finden Belatarung z. B. hei den Nusaarten, Borstenbiischel anch bei llem von mir errichteten Gen. Smeryngolaploria, wenn anch hier die Borsten nie die lonantige Beschatfenheit haben wie bei den Atomosinen. Nun habe ich bei diesen noch ein weiteres 
Merkmal als konstant grefunden, eine eigentiimliehe bildung an den Fiihlern, lice ich Zahngriticl goenamut habe. Es handelt sich dabei $n$ m eine stiftoiler Jornartige lixkreszenz des dritten Fiihlersegments - also nicht um eine eingelenkte liorste -, die sirh, meist anf ler Kante einer mehr oder minder ansgresporhenen Finkerbung auf der distalen Hälfte des Oberrandes befinlet. Bui lenjenigen Atomosinen, deren Fiihler eines Endgriffels entbehren, ist dur 'sahngriftel mehr oder minder weit von der Fiilılerspitze entfernt. wihlurend er bei den mit einem Endgriftel ansgestatteten Formen all die Basis dessclben verlagert ist. Fin soleher Zahngriffel ist schon von Śchiner bei seinel Sp. ancylurere und anch von Vtilliston golegentlich "rwihnt worken, ich kamn aber die Angaben dahin erweitem, lafs er bei allen Atomosinen ohne alle Ausmahme angetroften wird. Soweit meine ansgedehnten Erfahrungen ausreiehen, finten sich nmr recht wenige Asililenformen, deren Fühler ubenfulls mit einem Zahngriftel ausgeristet sind, das sind die l)asypogoninengenera Taracticus und Dioctiva; anch bei Pseudoholopogon finclet sich etwas ihuliches.

Aus dem Gesagten mulis gefolgert werilen, dal's es ein cinziges, die Atomosinen spezifisch kemzeichnendes Merkmal iiberhampt nicht giht, hält man sich aber an the Arei l’unkte: Flïgelgeäler, Beharung und Beborstung des Metanotum mul Vorhamlensein eines ,Zahngrifiels", so wird eine absolut reinliche Abtrenmung ler Gruppe von den ibrigen laphrienartigen liaubthegen sich jelerzeit ermöglichen lassen. I'nterstitzt wird eine solche dureh eine l'ntersuchung tè sonstigen, mehr sekundiren Merkmale, die den Atomosinen eigen sint. Jer meistens, in manchen Fiillen sogar exzessiv verbreiterte, mejst abgeplattete liopf zeigt in seinem liau die C'harakteristika ler ibrigen Laphrinen. Das stets bestiiubte Gesicht ist entweder ganz plan, olel im ganzen melı oller minter gewölbt, lailst abel ın ausmalmuswuise die Andentmog abes eigentlichen Mundhöckers erkennen. Fine in iler Hijhe der Fiihlerwurzel begrimende Ausrandung der inmeren Orbitalrainder führt entweler zu einer gleichmifsigen Verbreiterung von Stirne mul Scheitel, oder läist nur erstere verbreitert erseheinen, wiihrend del Scheitel wieler eine Verengerung erfahrt. Stets ist diescr stark eingesattelt, wodurch ier entweder mit $2-4$ oder mit einem biischel von Borsten versehene Ocellarhörker stark vorspringt. l)er Kuebelbart 
besteht aus läıgeren Borsten und dazwischen stehenden kilrzeren Härohen, ist nur ausmahmsweise dicht buschig, häifig sogar recht diim und spärlich. Anch die Behaarung des Gesichtes, der Stime und hes Scheitels ist nie pelzartig' dicht, selten buschig angeorhet, beschrankt sich viehneho meistens nur anf Reihen zarter Borsten und Härchen. Die Occiphitalborsten sind meist relativ recht derb, beschriuken sich aber bei vielen Formen mu auf die oberen Partien des bestäubten Hinterhauptes. Del liiissel ist in allgemeinen mu von mittlerer Länge, judenfalls nie verlängert, lagugen sind die 'laster liainfig sehn klein, gerudezn atrophisch, sie sind damn ganz in die Mundiiffunng zuriickgezogen und hier nur recht schwer der Betrachtung zugänglich. Die tiilıler sind meist, bei grewissen Gattungen sogar sehr beträchtlich verlängert; hier allgemeine Angaben iber ihre Fornverhältnisse zu machen, erscheint zwecklos, da wir uns bei der Definition der verschiedenen Genera noch genugsam mit den Fiihlern werden zu beschïiftigen haben.

Dorl fïr gewiihnlich nur mälsig gewölbte Thorax zeight häufig eine lureh feine Gribchen bedingte Sknlptur und ist in allgemeinen mit kurzer, anliegender. meist lichter Behaarung besetzt, zwischen die sieh nicht bei allen Formen längere abstehende dorsocentrale borstenlaare in freilich wechselnder Menge zn mischen pHegen. Selten kommt es anf dem Mesonotun auch zu Andentungen der bei den Asiliden so häufigen Striemenzeichmmg. Die Randbeborstmog des Thoraxrickens ist im allgemeinen nicht besonder's stark, präisnturale, supraalare und postalare Borsten sint in begrenzt wechsehnler Anzahl wohl immer vorhanden. Joch lïlst sieh nach meinen Frfahrungen mit ihnen in systematis.luer Richtung nicht riel anfangen. Der freie Schildchenrand verhält sieh recht verschienten: er entbehrt anfallender Beharmug ganz oder ist mit langen Haaren besetzt, el triagt partiell oder in ganzer Anslehnung grobe Beborstung, oder cr ist bei gewissen Formen mit zwei auffullend langen, spiefsfirmigen borsten bew ehrt. Die P'lemen tragen dichte, vorwiegend lirhte Bestänbung, hänfig nit Ansschluf's der Mesoplenra, die daun entwerler kahl und göinzend ist, oder aber das kurze anliegende Harkleid, oder endlich die Skulptur des Mesonotum zeigt. Die Peharung der 'Thoraxflunken ist nur in Ausuahmefällen dicht, fiil gewiihnlich nur seh" zerstrent und zart. Notopleuralborsten sind 
whlu stets rorhandru. der Metapheuralschirm ist meistens lang. Das Collare triigt meistens eine Reihe recht derber Borsten, die jedorh auch durch frinere hehar'ung ersetzt sein kimnen. Der fiir die ganze Gruple der Itomosinen so charakteristischen, konstanten Behanrmig resp. Beitormung des Metmuotalhöckers wurde oben bereits geedacht.

bas relativ kur\%e, streifenförmige, nur selten verliingerte und kolbenförmige Abdonen besteht bei vielen Atomosinen bei Betrachtung von oben mur alls sechs: Segmenten. Der freic Rand des sechsten Segmentes ist dam meist deutlich abgekantet, glatt poliert und stellt, ron unten betrachtet, eine halbkieisförmig gebogene Spange dal, welehe die ventral verhagerten kaudalen Segmente und die Genitalien unfalst. Bei anderen Formen seizt sich das Mbdomen hei Betrachtung von oben ans sieben oder anch acht Segmenten zusammen und es können dam allenfalls anch die Genitalien sichthar werten. Sehr hälufig zeigen die Ablominalsegmente die gleiche durch Griibchen bedingte, nur gröbere Sknlpturicrung wie das Mesonotum und anch die gìeiche, meist lichter gefärlute, anliegende Beharmug, die eventuell zur Bilhung binlen- nder fleckenartiger Zcichnungen Veranlassung gibt. Aneh zeigen sich die Segmentaleinschnitte häufig mit feiner lichter Bestäubung bedeckt, die mehr oder minter entwickette, schmale Binden erzengt. Die Seitenbehatrung ist oft abstehend und verlingert und anfserdem sind bei vielen Formen wenigstens die vorderen Segmente mit mitunter recht derben Discalborsten lewehrt. Die (icnitalien sind unit geringen Ansuahmen sehr klein: dies und ihre eventudl schr rersteckte Lage lassen eine Definierung der Geschlechter nicht immer möglich erscheinen.

Die kräftigen, relativ langen lieine bieten nur äulserst wenig Charakteristisches. Ihre sperrige, meist wenig dichte Allgemeinbeharung nimmt nur bei einzelnen formen cinen locker pelzartigen ('harakter an. 1)agegen findet sich bei den $\sigma^{-7} O^{-1}$ einzehner speries an den Hinterbeinen als sekmulibrer sexualeharakter schr dichte, meist silberschimmernite Behaarung, auch kommen jeweils bischelartige Harbbildungen an den Ilinterbeincu der $0^{-1} \sigma^{7}$ zur Beobaclutung. Kraftige, eventuell recht lange Borsten kommen an allen $\mathrm{Abschnitten}$ der beine vor, doch vermochte ich ans ihrer topographischen Anordnung keine fiir die systematik branchloaren Jerkmale auf\%utinden. libe Tarsen und die Schicnen tragen an den Torderbeinen fast 
ansnahmslos, manchmal anch an den Hinterbeinen, häufig lebhaft goldgelb gefïrbte biirstenfïmige Behaarung, die eventnell an dem Metatarsus der Hinterbeine eine äufserst zicrliche Reihenanordnung zeigt. bullich siml die Hinterschienen nul -schenkel an ihren einander zusehenden Flïchen

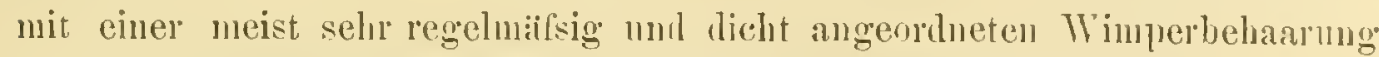
begabt, Pulvillen sind bei allen Atomosinen vorhanden.

Der Aderverlanf der meist mehr oder minder hyalinen oder schwach getribten, nur selten bunten Fliigel lälst sich am besten dureh eine Abbildung verdentlichen (vgl. Texttig. 48). Fiir die Systematik der Atomosinen besitzt er nur recht ggeringe ITertnng; die Länge und Richtnng des Stieles der Sulcostalzelle, sowie die topische Stellung der kleinen Qnerader zur Discoidalzelle ergeben norh einigermafsen branchbare Nerkmale. Cagegen lialst sich ans dem vershiedenen Verhalten der ersten nut zweiten Hintermandzelle, da lasselbe eine grofse Neigmg zur Tariabilität zeigt, absolut uichts entnehmen und ans den goledhen Grunde ist auch die gegenseitige Lage und Stellung der beiden Qneradern, welche die Discoidalzelle und die vierte Ilinterrandzelle distal abschliclsen, in systematischer Hinsieht nicht verwertbar.

WTas nun die allgemeinen Fïrbungsverhältnisse betrifft, so wurde bereits oben anf die Sehmucklosigkeit der Atomosinen anfmerksam gemacht. Dunkle Töne in Brann und Schwarz herrschen vor, in die nur durch die anliegende meist messinggellse Kïrperluehaarmng. sowie die hïuffo weilse Bestäulnug der Sogmentaleinsehnitte eine gewisse, wenn anch geringe L'nterbrechnng kommt. Jeweils kommen anch metalliselıe Färbungen in 13lan und Griin zur Beobaclitung', lebhaftere 'Tänmugen alher in Gelb- oder Tiotbraun lassen sich nur als seltene Ausmahmen feststellen. Die Beine sind hä̈nfig heller — gelb bis rotbraun - gefïrbt, aber auch dam fiilıren fleckenartige, ring- oler striclffirmige Zeielunngen zu einer gewissen Verdiisterung: onler aher die leine sind ganz dunkel gefïllot und hesitzen nur an den Knien uml den Schienen wenig ansgetlehnte hellere Stellen.

Endlich sei dieser Allgemeinbeschreibung anch noch eine Angabe ijber die allgemeine geographische Verbreitung der fruple beigefight. Am reichsten an $\Lambda$ tomosinen ist entsehieden die amerikanische Fanna, iln schlielist sieh damn die indo-malayisehe resp. australisehe an, während die 


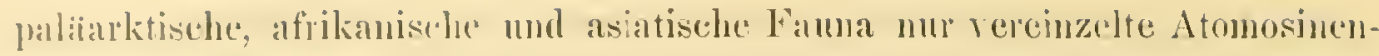
sjeries boherbergen. Die genanere geographisehe Verteihng der rinzchen Ficnera soll erst an späterer Stelle dureh eine Tabelle dargestellt werlen.

\section{Analytische Tabelle zur Bestimmung der Gattungen.}

1. Kopuf sturk in die Quere gedehnt, uler Querturchmesser mehr wie dopprelt so grols als der Höhendurehmesser: Auggen meist brillenartig* vorgeyuollen: Rand dos Schildehens stets nur mit geringer Beharmug verschen.

- Kopf nie auffallent in die Quere gedehnt, der Querdurehmesser hörhstens doppelt so grol's als der llöhendurchmesser; die Augen nie brillenartig vorgeruollen; das erste Glied iler Fiihler nie anffallend verlingert. sondern so lang; oder doppelt so lang, mr in Ansmahmefällen ilreimal so lang als das zweite, das Endglied mindestens doppelt so lang als das Grundglied: Srhildeheurand kurz behaart. oder mit langen Borstenharen, oder mit dornartigen oder spielsfümigen Borsten versehen.

2. Dis erste fiihlerglied etwa zweinal so lang als das zweite, das Endglied nicht ganz doppelt so lang als die beiden basalglicder zusammen. Nin vier Hinterrandzellen rorhanden.

Amathomyia n. g. 34

- Das erste Gilied rler verlängerten Fiihler mindestens $3-4$ fach so lang als das kurze zweite, das Eudglied so lang, oder höclistens dopjelt so lang als das verlängerte Gruntglied. Fiunf Ilinterrandzellen vorhanden.

3. Das streifenfuinnige, ofler $\left(O^{\prime}\right)$ nach hinten zu etwas verjiingte Ahdomen besteht bra betrachtung vou oben un ans sechs Segmenten. 4.

-_ Jas expuisit keulenförmige Ablomen besteht ans sieben Segumenten.

$$
\text { l'otichisma n.g. } 35
$$

4. Mesmutum mäilsig gewilht, olne cireunskripte auffallente Vorwälbung; die kleine (puerater steht etwas distal von der Mitte der Discoilalzelle:

$$
\text { Cerotainia Schiner. } 38
$$

- Das Mesonotum bexityt an seinem Vorderrande iiher dem Prothorax einc halbkugelformige, durh tlache Rinnen begrenzte Vorwöbung, die 
kleine Querader steht etwas proximal ron der Vitte der l)iscoidalzelle.

Cyphotomyia Williston. 65

5. Erstes Fühlerglied dreimal so lang als dias zweite, die verlïngerten Fiihler stehen anf einem auffallenden kanzelartigen Vorsprung und sind mit einem zapfenartigen Endgriffel versehen. Bathropsis n. g. 68

- Frstes Fuihlerglied nie dreimal so lang als das zweite.

6.

6. Stime gegen den Scheitel zu mehr oder minder verbreitert, d. h. eine Terbindungslinie der medialen Orbitalränder ist unter dem Ocellenhöcker kleiner als iiber demselben.

- Stime gegen den Scheitel zn mehr oder minder verengert, d. h. eine Verbindungslinie der medialen Orbitalränder ist unter dem Ocellenlücker gröfser als ii ber demselben.

20.

7. Das dritte Fiihlerglied ist mit einem kindgriftel versehen, onler in einen Dorn auslanfend, orler eiufach zugespitzt, auf alle Fälle steht der 'Zalhnstift 11 mittelbar neben der Spitze des Endgliedes.

- Das dritte Fiihlerglied meist ohn e Endgriftel, anf alle Fälle steht der Zahnstift weit entfernt von der Spitze auf dem Oberrande des Endgliedes. 16.

8. Die 'laster normal entwickelt, so dafs sie stets deutlieh zu sehen sind. 9.

- Die Taster sehr klein, fast rudimentär, vollkommen in der Mundöffinung. verborgen, so dafs sie nur undentlich, manchmal nur als kileine Torspriinge zul sehen sind.

9. Das kenlenförmige, siebenringelige Abdomen unpunktiert; Gesicht mit dentlichen, warzenförmigen Inndhïcker; drittes Fühlerglied in einen Dorn auslaufend, iiber ihm auf eckigem Yorsprung der Zahnstift; Sehildehen mit langen liandborsten.

- Das nicht keulenförmige Abdomen punktiert.

10. Hinterschenkel an ihrer Unterseite mit derben, spielsartige Borsten tragenden C'hitinhö̈ckern versehen; das dritte Fiihlerglied iiber doppelt so lang als die beiden Basalglieder zusammengenommen, mit deutlichem Eudgriffel; Schildchenrand mit zwei durch ihre Länge und Dicke anffallenden spiefsfïrmigen Borsten.

Dissmeryngodes n. g. 75

(Nota. Hierher gehört wahrseheinlich auch das Gen. Rhathimomyiu Arribalzaga, das ich nicht kenne.) 
- llintersehenkel ohne Borstenhiveker; das dritte Fiihlerglied weniger wie dopjuelt so lang als die beiden basalglieder zusammengenommen; Schildehenranl mu mit kuren Haaren besetzt. Oidarlis n. g. 76

11. Abrlomen aus sechs Segmenten bestehend; Gesicht mit deutlichem, rondlichem Mundhöieker, untel der Fiblserwurzel mit linearer, narhenartiger limne; die derben Ocripitalborsten anf den oberen T'eil des Hinterhanptes beschrinlit: Fiihler relativ kur\%, die boiden basalglieder gleichlang, das lublglied mit dentlichem, meist nach abwïrts geknickten Fulgriffel; Randbeharmug des Schildehens kurz: Metmotum mit stiftfiilnigigen Borsteu.

Atonia Williston. 81

- Abdomen ans sieben resp. acht Segmenten bestehend.

12.

12. Abrlomen 1 mumnktiert.

Ablomen punktiert.

14.

13. Gesicht und Fiilıler mit ungemein dichter und langer Behaarung; auch das Hinterhaupt sehr dicht behart; Mesomotum mit durehaus abstehender dichter Behaarmng; Mctanotum mit einem Biischel kurzer, steifer Borsten: Abrlomen metallisch glänzend, aus sicben Segmenten bestehend. Genitalien ventral verlagert; Fufskrallen auffallend stark harkenförmig gekrimmt, Empolialhorste sehr stark entwickelt.

Lampro:ona Lijw. $9 \gamma$

Gesicht und livihler zart behant; Mesonotum mit kurzer, anliegender Beharmug. der dorsocentrale abstehende Haare beigemengt sind: Metanotum ohme stiftfïmige Borsten, mur fein behant: Abdomen aus acht Segmenten bestehend, anch die Genitalien von oben sichtbar.

Automolina n.

14. Histes Fiilılerglied doppelt so lang als das zweite. 1)er Beharmug les Gesichtes siml beim or schimmernle Schuppenhare beigemeng't. Mesonotmm glatt, poliert, l'muktierung tritt mu fleckenartig immerhalh kleimer Areale anf, Schildehen vollstiindig unpunktiert. Jas zangenartige Hypopginm und die Legeröhre freistelenel.

Gomecralypsis 11. g. 10X

Wrstes und zweites Fiillerglied gleichlang, oder das zweite Glied etwas liinger als das erste. Srlublelien punktiert. Genitalien rentralwairts verlagert.

15. 
15. Gesicht gegen den Mundrand höckerförmig vorspringend. ơ Genitalien kolbig vorspringend, Legeröhre ron seitlichen, aufallend bedornten Klappou besehirmt. Lörinella n. g. 104

-- Gesicht rollkommen plan. Genitalien seh. klein, ohne besondere IIerkmale.

Opeatocerus n. g. 106

16. Drittes Fiihlerglied mit dentlichen Endgriffel; Gesicht namentlich unter der Fuihlerwurzel auffalleml verengert, Knebelbart ans vier Borsten bestehend, Occipitalborsten fehlend; Thorax und Abdomen metallisch glianzend; Schildchen mit zwei langen, spielsfürmigen Randborsten; Metanotum mit mehreren dornartigen Borsten; Abdomen siebenringelig; Genitalsegmente ventral verlagert; Hintersehenkel unl -schienen verdickt; die kleine Qnerader steht nur ganz wenig proximal von der Mitte der Discoidalzelle, Flügellappen fehlend. Cluriola Kertésez. III Drittes Fiihlerglied ohne Endgriffel; Gesicht unter der Fiihlerwurzel nichit rerengert.

17. Die kleine Querader steht iiber dem proximalen Drittel der Discoidalzelle.

- Die kleine Querader steht iiber iler Mitte der Discoidalzelle.

18. Tordere Basalzelle länger als die hintere; der Knebelbart besteht ans einem Biischel niedergedriickter Hanre und vier langen Borsten, von denen zwei neben, zwei über jenem Haarbiisehel stehen, Stirne und Scheitel kahl; der Zahnstift des dritten Fiihlergliedes stelıt distal von der Mitte des Oberrandes; Schildehenrand nit zwei änlserst langen, spiefsförmigen Borsten; Abdomen kahl, ohne durch längere Behaarung gebildete seitliche Torderrandtlecken; Fliigel einfarbig oder an der Spitze mit dunklem Fleck.

Cenochromyia n. ‥ 14

- Jie beiten Basalzellen von ghleicher Läinge; der Kobelbart besteht ans einem Biischel niedergedrïckter grober Borstenhanre und einigen wenigen, nur an seitlichen Mundrande stehenden, lingreren Borsten. Stirue und Seheitel behaart; der Zahnstift des dritten Fiihlergliedcs steht in proximalen Drittel des Oberrandes; Schildehenrand mit langen. aufwärts gebogenen Haaren besetzt; das siebenringlige Abdomen besitzt durch lïngere lichte Beharung gebildete scitliehe Torderrandflecken: Fliigel hỵalin mit schwarzen Querbinden. 
19. Dar Knebelbart besteht ans wenigen, in zwei lieihen angeordneten Borsten, Gesicht mit deutlichem Mundhöcker und zarter behamrung; Mesonotun stark gewiibt, rorne buckelartig aufgeworfen: Abdomen nicht punkticrt, olne J)iscallorsten. Hypopygium klein, in deutliche Zangenarme gesplalten; Fligel durch anfallende Terschmälermng des Fliigellappens exquisit dreierkigr; kleine, schlanke Art.

Othoniomyia n. g. 114

- Her Knebelbart ist sehr dieht und besteht aus kiirzeren. etwas abgepulatteten und langen, den Mundrand auch seitlich einnehmenden Borsten, Gesicht olne Mundhöcker, ebenfalls dicht und lang behaart; Mesonotmm flach gewölbt; Abdomen grob punktiert, Hypopygimu garnls, kolbig. Discalborsten rorhanden; Fligel von gewöhnlicher Gestalt; griilsere, plumpere Arten.

Alelortus $11.8 \cdot 124$

20. Drittes Fiillerglied lang spindelfürmig. nu' in Ausnahmefillen an seiner spitze scliwach verjiingt.

- Drittes Fihlerglied in eine scharfe Spitze ausgezogen, oder in cinem langen gefiederten oller jubseenten oder nackiten borstenfümmigen Fortsat\% endend.

21. Untergesicht in ganzer Flaiehe sanft konvex, olue Mundhöckel; relativ grofse Arten rou minlestens. $10 \mathrm{~mm}$ Liange.

- Intergesicht sanft konkar oder plan, am Mundrande dentlich rorgezogen; kleinere Arten von höchstens 10 mm Länge.

22. Frstes Fiblerglied etwa doppelt so Jang als das zweite, das verliunerte Fulglied Areimal so lang als die beilen Basalglieder zusammengenommen; die an ihrel Spitze mit divergenten Borsten besetzten Taster relativ selur grofs; Collare mit groben Borsten bewehrt, das Schildehen mit vier derben Randborsten; Abdomen aus scchs Segomenten bestehend; Grundfarbe des Kïrpers diister, nie metallisch gäinzend; die vorderen Beinpare olne anfiallende, sibcrschmmernde Wimperheharung: erste Hinterrandzelle stets mehr oder minder rerengert. manchual beinahe geschlossen.

Apliestia Seliner. |2|

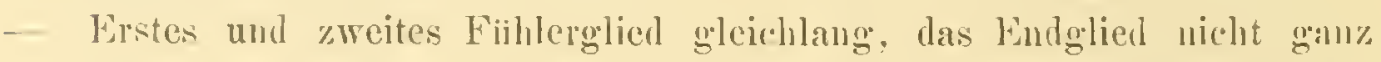
$1^{1}{ }^{2}$ mal so lang als die Basalglieder zusammengenommen; T'aster nicht anfallend grofs; Collane ohne Borsten, nur uit feiner Behaarung verselıcu, Selildelicurand in gan\%er Ausdehumug mit langen Haren mul Borsten 
besetzt; Abdonen ans sicben Segmenten besteliend; Grundfarbe des Körpers lebhaft metallisch blau oder griin, anf lem Abdomen mit durch silberschimmernde Behaarung gebildeter Flecken- oder l3indenzeichnung; die Sthienen und Tarsen der vorderen Buinpare tragen an ihrer Aufsenseite lange wimperartige, siberschimmende Belaarung erste Hinterandzelle nirht verengert.

Cyanonedys n. g. 128

23. Kopf mälsig abgeplattet. jedenfalls nicht halbkuglig, das Gesicht elseheint in Profil deutlich gehoihlt, am Mundlande betrichlatlich rorgezogen: Knebelbart ans lïngeren Borsten nud kïrzeren Haaren bestehend, die sich bei den meisten Arten in der Mitte des Mundrandes zu cinem niedergedriickten Büischel rerdirhten; Schildchenrand jederseits mit wenigen derben Borsten: Metanotum mit kurzen stiftartigen Borsten: Disealborsten an den ersten drei Abrominalsegmenten stets rorhanden: die kleine Qucratler steht auf der Mitte der Discoilalzelle oder wenig proximal davous.

Atomosia Macruart. 135

- Kopf im Profil halbkuglig, das schmale Gesicht plan, am Mundrande nu. wenig vorgewiilbt, Ḱnebelbart nur aus wenigen, den Mundraud einnehmendeu Borsten bestehend; Schildehemrand mit kurzen abstehenden Haaren, ohne Borsten, anch das Metanotum eutbehrt der kurzen. stiftartigen Borsten rollstiondig; 1)iscabborsten fehlend: die kleine Querader steht an der Crenze des proximalen Tiertels her Discoilalzelle.

$$
\text { strombocodian. n. Ko }
$$

24. Auffallend kleine, höclisteus 5 mm lange und schlanke Arten rum durchaus schwarzer Kïperfïrbung.

- Nittelgrofse, stets iiber a mm lange Arten ron nicht durchaus schwarzel Kïpertïrbung: Abdonen rotbraun mit ủukler Flecken- oder Bindenzeiclnumg oder schwarz mit dentlirhen weifsen Bestiubungsbinten. 2à.

25. Kopf stark verbreitert und namentlich die Stirne lurch Ausrantung. der Orbitalriuler dentlich erweitert. Drittes Fiihlerenlied entweder spindelfömig verbreitert oder mehr lineir, nackt niler pubescent, die mehr oder minder lange Endborsto stets nackt.

Atractia Macruar. I 65

- Kopf mälsig verbreitert, die Stime kaum elweitert. 1)rittes Fiilulerglied deutlich beharet und namentlich die Endborste nit langer federbuschartiger Beharung rerselıen. 


\section{Spezielle Beschreibung der Genera und Arten.}

\section{Amerthomelyiar n. g.}

Koplf stark in die Breite gedelunt (T'af. Fig. 5 u. (j), der Querdurehmesser meh" wie hoppelt so ganls als der Höhendurehmesser. Das loreite, gegen den 11 umlrand ctwas vorgerogene Untergesicht verbreitert

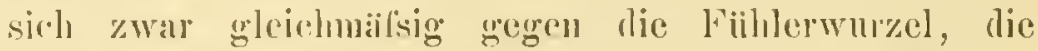
medialen aingekerbten Orbitalrïnler divergieren aber im Bereich der Stime bei weitem nirblit so stark wie bei Cerotcimu. Her Knebelbart bestelit jerlerseits aus einer leihe griblerer borsten und dazwischen stehenden kiirzeren Hancen, dic hanptsichlich den Mumband eimehmen. Das Gesicht trïgt jelerseits eine Rrilse kurzer, alswirts gebogener llaare, lie Stime besitzt am Angemande und in der Mitte iiber der Fiilılerwurzel kurze Teharmug. Silleitel nackt. Der relativ niedere Ocellenhöker ist mit zwei divergenten Borsten bewehrt. Das Hinterhaupt besitzt nur in der oberen Hälfte cinige wenige Borsten, anch dor Backenbart ist verhailnismälsig schwach entwirkelt. liiissel kur\%, 'l'aster sehr kleil. Fiilıler rerlingert ('lextfig. 11); erstes Glied lopuelt so laug als das \%weite, das seitlieh kompresse, bamlartime, rines Eulgriftels

Fig. 11 contbehrende Eudghied, Iessen kleiner Zahnstift im l'rofil mur schwel sichthar ist, ctwa $1 \%$ mal so lang als die beiden Grumblieder zusammengenummen. Das ku\% behante erste Segunent triggt an seiner

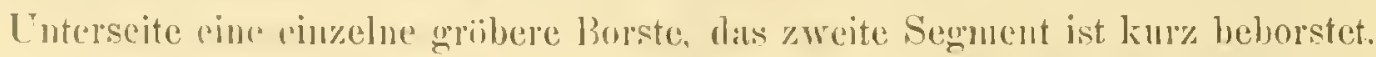

'Tholax. has mälsig grewölbte Mesonotmm mol das Sichildchen netallisch gäinzend, deutlich punktiort und gleichmälsig nit kurzer, anliegender lichter Behaarmog versehen; längere, abstehende Behaarmo fohlt

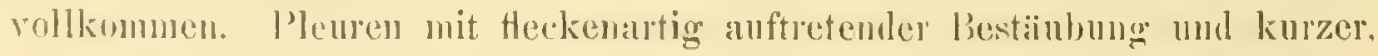
im Bereiche der Mesnoleura anliegender Behatrung. Behorstumg: präsutmal 1, supualar 1, postalar 1, notoplental fehlend, Metanotum trigt seitlich einige kur\%c sitarhelborsten. 
Das metallisch-glänzende, sehr grob punktierte Abdomen ist gleichmäfsig mit anliegender kurzer Behaarung von lichter Färbung versehen und liifst bei Betrachtung von oben auch den ïufsersten Rand les siebenten Segmentes erkennen. Die Seitenbehaarunng ist nur wenig verlingert, ilas erste Segment ist mit 2-3, die iibrigen mit je einer Discalborste versehen. Banch nackt.

Beine relativ kurz und ziemlich plump, die Endtarsen jedoch auffallend verschmächtigt. 1)ie Behaarung uml Beborstung bietet nichts Charakteristisches, nur auf der Ilinterseite der Vorderschienen fallen zwei Borsten (Huch erhebliche Länge auf. 1)ie biirstenförmige Beharmug ist nur wenig: entwickelt, die Wimperbehaarumg auf die Torderfliche der Hinterschienen beschränkt. Klanen lang, Pulvillen verhïiltnismäísig klein.

An den Fliigeln failt das Vorhandensein vou nur vier Hinterrandzellen besonders in die Angen, indem die zweite und dritte Hinterrandzelle miteinander verschmolzen sind. Stiel der Subcostalzelle lang. Die erste Hinterrantzelle deutlich verengt, lie kleine Querader steht iiher der Grenze des distalen Drittels ier Discoidalzelle. Das nene Genlls Amathomyia besitzt nm deswillen erhöhtes Interesse, als es den ersten paläarktischen Vertreter des bis jetzt nur ans Amerika bekannten, un das Genns Cerotuiniu sich gruppierenden Formenkreises darstellt.

Als typische Art betrachte ich Amathomyiu persiuna Becker,

von der mir die ans beludschistan stammenden Typen ans der Sammlung. Th. Pleske zur Untersuchung vorlagen.

\section{Proticheismare n. g.}

Kopf stark verbreitert (Taf. Fig. 7 u. 8), melı wie doppelt so breit als hoch. Das breite Gesicht ist nach oben gegen Stirne nurl Seheitel gleiehmailsig verbreitert nunl zeichnet sich dadurch ans, dafs es sich von der Fuihlerwurzel nach abwirts ziemlich gleichnifsig iiber die Augen vorwülbt: ein eigentlicher Gesichtshïcker fehlt, oder ist wenigstens nur ganz wenig angedentet. Der Kuebelbart besteht aus ziemlieh zahlreichen lïngeren $n$ mb 


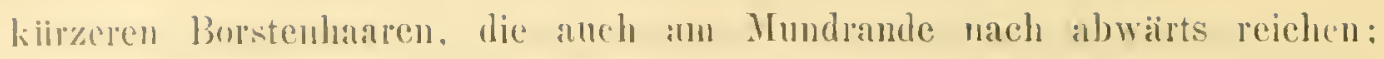
surh die behaarung des Gesichtes setzt sich aus abwälts gebogenen lingeren Bursten und kiirzeren Halren zusammen. Stime und Seloeitelgegend zart behalart, erstere tragigt an Augrenrande ciuse einzelne liugere Borste. Orellenböcker klein mit zwei lelativ kurzen Borsten. 1)as bestainbte Hinterhaupt

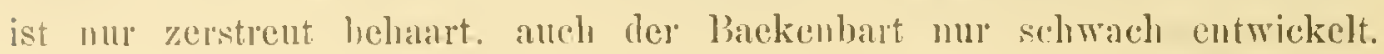

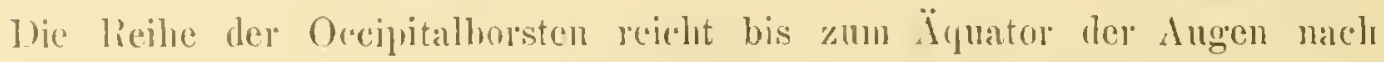
abwïrts. Jer derbe, seitlich kompresse liuissel ist relativ lang: an sciner Vuterseite biischelartig behalrt, auch ein scharf abgesctzter Hicker der Kinngegend ist mit einem Har büischel besetzt. Die Fiihler, relativ lang; ihre lainge ist etwas groblser als der Läingsdurehmesser der Augen - erinnern in ilnem Ban ctwas an die Terhältnisse bei Atomosia. Das dielst belaarte, an der Interseite nit einer einzelnen Borste versehene erste Glied ist etwa heimal su lamg als das kurze, behorstete zweite Gliel, das ungefähr spindelfirmige dritte Segment ist etwa $1 \frac{1}{2} 2 \mathrm{mal}$ so lang, als die beilen Grumbglieder zusammengenommen, ohne Eudgrifíel, gröfstenteils leicht pubescent und trïgt auf einem Vorsprung einen dentlichen, wenn anch kurzen Zahngriffel.

'T'holax. Mesonotum matt, mit fuinel lichter J'unktierung und sehl' kurzel Beharmug, die an den hinteren Partien nach vorwith gerichtet ist: ilı sind mamentlich vorne und an den susten anliegende groldgelbe Hatre beigemengert, welche anch tas der liandbeharmug röllig entbeluende Schildehen eimnehmen. Laingere dorsocentrale Hare fehlen und anch die beborstumg ist uu kur\%: prisutural 1, supraala 1, postalar 1, notopleural 2.

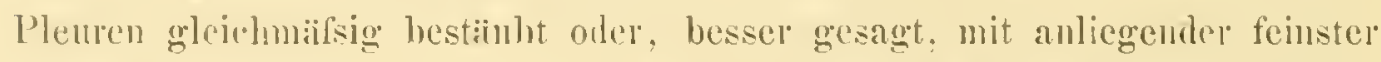
liehatrung berleckt. Zerstrente lïngere Behaarung funlet sich iiber den Hiften. am obereu liamle der Mesopleura und in der Notopleuralualit. Das Collare ist fein heborstet, das Metanotun trïgt eine Grupue derher. stiftartigner borsten.

A bdonen ans sieben von oben sichtharen s̈egmenten bestehend. matt, utu fuin punktiert und ron exquisit keulenfölunger Gestalt: die liuschniirung betrifft das zweite nud die vordere IJälfte des dritten Segmentes. Jas ganze Abdonen ist mit langer, anliegrender Behaarung bedeckt, eigentliche Diseal-

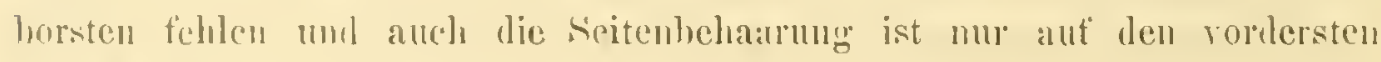

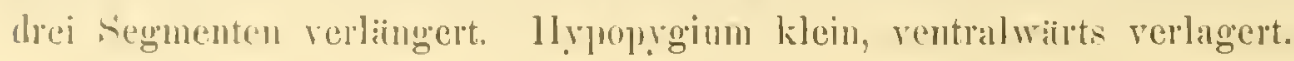


Beine lebhaft gefärlot mit spärlieher Beharming und Beborstung. An den beträichtlich verlängerten Hinterbeinen sind die Schenkel und Schienen gleichmälsig rerdickt. ])ie Unterfläche sämtlicher Tarsen und die Innenseite der Vorderschienen besitzen die gewöhnliche biirstenförmige, die einander zugekehrten Flächen der Hinterschenkel und -schienen grleichmïilsige wimperartige Beharumg.

Die grofsen Fliigel iiberagen die Spitze des Abdomens. Stiel der Subcostalzelle von anffallenler Lïnge (wie bei Cerotainia), die kleine Querader steht etwas distal von der Mitte der Diseoidalzelle, die erste Hinterrandzelle erweitert, die zweite schwach verengert. Die die vierte Hinterrandzelle und die Discoidalzelle distal abschliefsenden Queradern stehen nicht vollständig;, aber doch annïhernd in gleicher Richtung. Der Stiel der vierten Hiıterrandzelle und der Analzelle lang.

Als typische Art beschreibe ich:

$$
\text { Protichisma longimanus n. sp. ot. }
$$

Ein einzehnes $\sigma^{\top}$ aus Peru (Callanga) in der Sammlung des k, ungar. Nationalmuseums in Budapest.

Kopf. Gesieht, Stirne und Hinterhaupt mit ockerbrauner Bestiiubung beleckt, Seheitel unbestäubt, schwarz. Am hinteren Orloitalrande nimmt die Bestäubung mehr weifsliehe Fürbung an. Knebelbart in der obereu Hülfte sehwarz, gegen den Mundrand gelb. Auf den Gesicht sind die Haare unten schwarz, gegen die Fithlerwurzel gelb, elsenso wie die Beharrung der Stime, des Scheitels und les Hinterhauptes. Anch der diinne Backenbart, die Beharrung der Kinngegend, des Riïssels und der schwarzen 'Taster ist gelb. Ocellar- und Occipitalborsten schwarz. Auch die schwarzen Fiihler sind ausschliefslich schwarz behart.

Thorax mattschwarz; die äufserst kurze abstehende Behaarung ist schwarz, die stellenweise, anch anf dem Schildehen, anftretende anliegende Beharung dagegen goldgelb. Schulterecken in geringer Ausdehnung rotbraun. Die präsuturalen und supraalaren Borsten schwar\%, die postalaren gell. Pleuren und Hiiften grleichmialsig mit ockergelber Bestïubung unt gelber Behaarung rersehen. Notopleuralborsten und der vor den gelben 
Schwingern stehende Metapleuralschirm gelb, ebenso die Behatrung des ('ollare und die Borsten des ockergelb bestiiubten Metanotum.

Abrlonen mattschwar\%, die thelite und lange anliegende Behanmmg allenthalben goldgelb, so dals das ganze Abdomen bei gewisser Belenchtumg einen goldenen Schimmer bekommt. I) mittleren Segnente besitzen an ilen Finschnitten feine brame siinue. Bauch braun mit zerstrenter lichter Behaaling.

1)ie langen Beine sind mit Ansuahme der Endtarsen lebluft gelb, dic schenkel mehr rotgelb. Anch die Beharung und Beborstung ist ausschliefslich grelb. Katuen schwarz, Pulvillen gelb.

lic Fliigel sind gleichmälsigg gelb tingiert und allentlalben nit ziemlich grober mikroskopischer beharung versehen. Nur die hintere Basalzeile entbehnt derselben, ist völlig hyalin und erscheint ladurch leblatfter gelb. Die Costalzelle und die Fliigelspitze sammartig getriilut. Die Älerumg ist dumkelbraun.

Long. colp. 11 mm, long. alal. 9,5 mm.

\section{Crovotrinir Solliner.}

Die Diagnose, die Seliner dem in den Terhandhngen der Zool. lot. Gesellschaft Bd. 1li. sowie in der .,Tocarareise" aufgestellten Genus gregeben hat, kann keineswegs als eine besonders gliickliche angesehen werilen. Schon die Angabe: .Koplf wie bei Atomosiu gebildet", entspricht den 'latsachen durchans nicht, da wir gerade in der eigentiinlichen Kopfform mit das beste Merkmal zur Charakterisicrmg der Cerotainien gegeniber den benachbarten Formen besitzen. Wem daher Osten-sacken Bbioloyia centruti-americuna

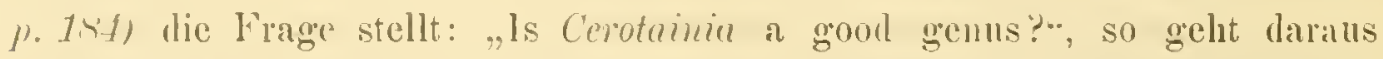
hevor, dals er sich ans der Schinerschen Gattungsbeschreibung nicht die nitige Klarheit hatte erholen kinnen. Erst Williston (1'syhe 1Ga9) verlanken wir eime klane und bindlige Auffassung des Gattmosbegriffes, aber auch scine Diagnose ist mur kury, so dals ich hier eine ctwas ausfuhlrlichere Beschreibung für \%weckmilisigg halte. 
Kopf stark in die Breite gedehnt (Taf. Fig. 9 n. 10), sehr nieder, die grofsen Angen brillenartig vorgequollen, wolurch die Kopfform lebhaft an Holcocephala erimnert. Was breite Gesicht erweitert sich gleichmälsig gegen die Scheitelgegend, so dals ter Querdurchmesser der letzteren das doppelte der Gesichtsbreite beträgt. Der Mundrand ist nur ganz wenig anfgeworfen, lagegen wölbt sich das Gesicht oben zu einem sockelartigen, die Fühler tragenden Höeker vor. Der Knebelbart besteht ans mehr older minder zalıreichen langen Borsten, denen sich namentlich an Mundrande anch kïrzere Hare beimengen; anch iiber dem Knebelbart erseheint das Gesicht mit meist reihenweise angeordneten, abwärts gebogenen, ziemlich langen Haaren besetzt. Die Stirne trägt über der Fiihlerwurzel mul am medialen Augenrande je eine Gruppe borstenartiger, teilweise relativ langer Haare. Der Ocellarhöcker ist mit zwei, oder auch mit 4-6 Borsten bewelırt. Auch der Scheitel ist stark behaart. Die Reihe relativ derber Occipitalborsten besitzt eine bei den einzehnen Arten verschiedene Ansdehmung; der Backenbart ist gut entwiekelt. Riissel kurz, derb, die 'Taster klein. Die Fiilıler' sind lang, das verlängerte erste Segment stets mindestens viermal so lang, als das kurze zweite, mur bei einer Species (argyropus) nur ron theifacher Länge, oben und unten mit ziemlich langer borstenartiger Behaarung; an der Unterseite finden sich aufserdem eine oder zwei lange Borsten. Das zweite Segment ist nale seinem Vorderrande mit einigen kurzen Haaren und läugeren Borsten bewehrt. Das spindelfürmige, mehr oder minder pubescente dritte Segment ist liöchstens 1'2 mal (nur bei der Spec. argyropus (loppelt) so lang als das verlängerte erste Glied. Die Pubescenz liafst den immer vorhandenen, kurzen Zahngriffel bei der Profilbetrachtung schwer erkemnen, bei der Betrachtung von oben aber ist er, stärkere Vergröfserung vorausgesetzt, stets zu sehen.

'Thoraxrïken milsig' gewölbt, fein mond hänfig' nicht in ganzer Ausdehmung punlitiert, mit dichter, meist mehr oder minder abstehender Behaarung versehen. Das Sehildehen trägt an seinem freien Rande feine Behaarung, aber keine Bossten. Die Pleuren sind bestänbt und mit relativ lichter Beharung versehen, die anf der Mesoplenra erentuell biischelfïrmige Anordmung zeigt. Beborstung: prïisutural 1, supraalar 1, postalar 1, notopleural 3-6. Der Metapleuralschirm besteht ans langen Borstenhaaren. 
Tas ("ollare trïgt eine heilıe langer Borsten, das Metanotum ist seitlich mit einem Biischel kurzer, stiftartiger Borsten besetzt.

Ablomen aus scchs ron oben sichtburen Segmenten bestehend, dus siebente mul die kleinen Genitalsegmente sind ventral verlagert. Die ejuzelnen Siegmente, die durch tiefc, eventuell sclunal gesỉmute Segunentalcinschulte getrennt werden, sind derb punktiert, mit meln oder minder dichter anliegender Behasumg versehen und entbehren der Disealborsten rollständig: un an den Seiten des ersten Segmentes findet sich eine Inzalı] gribiberer Borsten.

1)ir, Beine sind kräftig und ziemlich dicht belaart, die Hinterbeine stets etwas verlängert unl melr oder minder rerdickt. Auch der Metatarsus der Hinterbeine, der in allgemeinen die Läinge der drei folgenden 'Tarsenglieder besitzt, ist lainfig verdickt. Dic Beborstmng der Beine ist nicht anffallend. Bei gewissen Arten findet sich bei den ơ $\sigma^{7}$ an den Vorderund Mittelbeinen anffallende silberweilsc Behaarung:

An den Fiigelu fiilt die Liinge des Stieles ler Subcostalzelle besonilers anf, die kleme Querader steht etwas distal ron der Mitte der Discoirlalzelle. Die gegenseitige luge der beiden die Discoilal- und die vierte Hinterrundzelle distal abselnliefsenden Queraden zeigt eine gewisse Variabilitit, doch liegen beile Aleru stets wenigstens in derselben Richtumg: Aurh der Sticl der vierten Iinterrandzelle ist variabel insofern, als (J) rudimentiir cutwickelt sein mol manchmal ganz fellen kam, so dafs damm die dritte und die fïnfte Hinterrandzelle gar nicht voneinander geschieden sind.

IVas endlien den Gesamthabitus betrifft, so treten die Cerotainiaspecies in zwoi formen, einer sthlankeren mul einer plumperen, mehr gedrungenen anf. Bei dor elsteren ist das streifenfömige Abdomen t-5 fach so lang" als der Thorax, bei den plumperen Formen dagegen ist der 'Thorax selbst beit und das breite Abdomen mur $2{ }^{1} \cdot 2$ mal so lang wie lieser. Fine strenge 'Trenumng läst sich freilich ans diesem Verhältnis nicht anfstellen. Zwei neu zu beschreibende Arten (leominu und dlesythrix) zeichnen sioh dureh besmiters godrungenen Ilabitus ans, so dals sic eigentlich aus dem Gesantbilile der ('erotainianten etwas herausfallen. Da sich aber, abgesehen von lichterer liehaanung; nach keiner likehtung' plastische 1)ifferenzen feststellen 
lielsen, glanbte ich von emer generischen Absonderung der beiden Species absehen zn mïssen.

Die gegenscitige Abgrenzung der einzehen Arten begegnet zienlichen Schwierigkeiten, die in einer gewissen Tariabilität, in eventuellen sexnellen Differenzen, ror allem aber darin begriindet sind, dafs die C'erotainien anscheinend ziemlich selten sind. so dal's nur von einer Art grö́sere Reihen untersueht werden konnten. Mit Ausnahme ron sp. mignipenmis Bell. haben mir sämtliclıe bekannten Arten, gröstenteils als Typen rorgelegen, so dafs ich glauben möehte, bei leren Identifizierung wenigstens stïrkere Irrtimer vermieden zu haben. Die beiden Bigotschen Arten tubia nud nigra konnten keine Beriicksichtigung fimlen, da sich den mangelhaften Beschreibungen nicht entnehmen liefs, ob sic iiberhaupt dem Genus Cerotainic angehören.

Als typische Art wird von Schiner die

$$
\text { Lupleria xanthoptera Wied. }
$$

bezeichnet.

Die mir bekaunt gewordenen Cerotainiaspecies lassen sich ilurch folgende analytische 'labelle bestimmen:

1. Arten von gedrungenem Habitus, Abdomen etwa 2\% mal so lang als ler relatio breite 'Thorax.

- Arten von schlankem Habitus, das streifenfömmige Abdomen bis viermal so lang als der relatir sclmmale Thorax.

2. Occipitalborsten auf rundlichen Chitinwarzen cingelenkt, auf den oberen Teil des Hinterlauptes beschrïnkt. Vorderer Teil der Mesopleura vorgewïlbt.

- Occipitalborsten nicht auf Chitinwarzen eingelenkt, weiter nach abwäits reichent. Mesopleura nicht vorgewölbt.

3. Fliigel gleichmailsig braun.

marroceru Sar.

- Fliigel grleichmailsig gelb. xanthoptera Wied.

4. Behaarung des 'Thorax und iles Abdomen kurz, anliegend.

bella Sehin.

- Behaarmug des Thorax und des Abdomen pelzartign, ungewöhnlich dicht: Arten vou auffallend gelrungenem Habitus. 
5. Behaamug volwiegend schwarz, Wurzelhälfte der Fliigel stark gebräunt, Ailern sceliwar\%. dasythrix n. sp.

_ Belaaıung ausschliceslich gelb, Fliggel völlig lıaliu, Arlern gelb.

leominu n. s]).

6. Fiiller auffallend kurz, das erste Segment nu dreimal so lang als las zweite. Die vorderen Beinpare des or besitzen an der Aulsenseite in ganzer Ausiehumg silberweilse Bcharung. urgyropus Sehin.

- Fiilıler von gewïhlieher Liange, das erste Segment mindestens viermal so lang als das zweite.

7. Auf den Mesonotmm finden sich immer, freilich in wechselnder Menge, helle (weifsliche orler häufiger goligelbe) Haare.

- Mesonotum ausschliefslich schwarz behart. unicolor H. sp.

s. Hic Seiten der Abdominalsegmente rotbraun gesaiumt.

- Abdomen cinfarbig schwarz.

9. Ocellenhioker mit sechs Bolsten, Mesonotum mit goldgelber Beharung; Beine diister gellbbramn. violaceithorax Arribalzaga.

- Ocellenhïcker mit zwei Borsten, Mesonotum mit weifslicher Behaarung, Beine selı lebhaft gelbrot. rhopalocera A ribalzaga.

10. Flïgel lıalin, Spitze mit rauchgrauer, auffallender, fleckenartiger Siiumullg. marginata n. sp).

- Fliigel lıvalin oler gleichmảlsig bräunlich tingiert. 11.

11. Beine mit Ansnahme der gelbbraunen Knie gleichmaỉlsig schwarz oder tief dunkelinamm.

- Beine stets an den Schienen und 'Jarseu, mindestens der vorderen Beinjare in gröfserer Ausdehnung gelb oder gellbbaun.

12. Fiihler schwar\% Jehaart, Borsten iles Hinterhauptes und des Mesonotum schwar\%, die Vondersehienen besitzen in beiden Geschlechtern an ihred Innenseite aufser ller gewöhnlichen Biirstenbeharung eine eigentimulieh weilslich bestiatute Iaingsbinde. Bei dem or sind die Schienen und 'Tasen der beiden rorderen lieinpare, sowie der hand des siebenten Segmentes mit anffallender silberglänzender Belaarmug versehen. 
- Fiihler mit vorwiegend heller Behaarung, Bolsten des Hinterhauptes und des Mesonotum gelb; Vorderschienen an ilner Innenseite nur mit der gewönlichen Biirstenheharung. propinqua Sehin.

13. Auf dem Abdonen wird die schwarze Grundfarbe in gröfserer oder geringerer Auslehnmug durch besonders dichte silbergliinzende oder golilgelbe Behaarung verdeckt.

- Auf dem Abdomen wird die schwarze Grundfarbe nie durch die lichtere Behaarung verdeckt.

14. Die zwei ersten Abdominalsegmente mit silberglänzender dichter behar'ung bedeckt, Ocellarlö̈ker mit zwei Borsten.

$$
\text { argyropusta n. su. }
$$

- Das dritte, vierte und fiinfte und der Hinterrand des zweiten Adominalsegmentes mit leuchtend goldgelber Beharmng bedeckt, Ocellarhörcker mit vier Borsten.

aurata Selin.

15. Schienen und Tarsen lebhaft gelb, das Wurzeldrittel der Fliigel besitzt hellbranne Adern und aufserilem beim or milchweifse 'Tribung.

$$
\text { flaripes n. s1). }
$$

- Schienen und T'arsen höchstens diister gelbbraun, Fligelarlern durchans dunkelbraun oder scliwary.

16. Relativ grofse Art von $8-9 \mathrm{~mm}$ Länge mit stark verlängertem Abdomen. Bancl gelb. Behorstung der Hinterbeine schwarz.

$$
\text { brasiliensis Sehin. }
$$

- Kleine Art von 5-6 mm Länge mit relativ kurzem Abdomen. Banch nur durch die ockergelhe Bestiubung etwas lichter erscheineud. Beborstung der Hinterbeine gelb.

debilis n. sp.

A. Arten rom mehr gedrungenem Habitus, Ahdomen rotwa "2 2 mal so lane als der l'elatir breite 'Thorax.

Cerotainia macrocera Say.

Anfser den funf Exemplaren Wiedemanns aus dem k. k. Hofmusemu in Wien liegen mir vier Exemplare ex coll. Bezzi mol fünf ex coll. Hermann, simtlich aus Norr-Amerika, ror. 
Dic Ant ist, trotzden sie in der mehr oder mimler dichten Beharmug des 'Thorax, des Abdomen und der Beine stark variert, an einer lieihe plastischer Merkmale leicht kenntlielı.

Kopf. Gesicht, Stime mul Scheitel gleichmälsig mit weilser: granweifser orler auch gelblicher l3estänbming bedeckt. Der recht dichte Knebelbart hesteht aus relativ kiirzeren und feimen Haaren und setzt sich lach oben in die bis zur Fihllerwurzel emporreichende Behaarung des Gesiehts, lie dasselbe allenthalben dieht bedeckt. fort. Die Farbe wechselt ebenfalls zwischen weils und einem lichtem grelbbraun. lie Beharung der Stirne null des Seheitels ist cbenfalls dicht und lang, und reicht namentlich auf letzterem bis an die Basis les Occllenliockers heran. Die Farbe ist gewöhnlich licht, doch kamm sie aneh ausuahmsweise (ein or ex coll. Bezzi) dunkelbraun bis scbwarz sein. Anch die Farbe der Bestiubung des Hinterhauptes, die iibrigens in den oberen Arealen nur recht diimn liegt, schwankt zwischen hellgran und ockerbrann, ist aber am Angenrande, sowie in den unteren Partien konstant weifs. Die Borsten sind anf den oberen 'Teil des Hinterhauptes besehränkt und hören schon ïber dem Äquator des Auges vïllig auf, erstrecken sich dagegen in einer Schicfreihe bis gegen die Basis des Ocellenlörkers. Sämtliche Borsten sind anf rundlichen Chitinwärzchen eingelenkt, eine Anordnung, lie mit Ausuahme von C . xanthoptera Wied. (vgl. miten) bei keiner der mir bekannt gewordenen C'erotainien vorkommt. Die recht dichte Beharming des Hinterhauptes Fig. 12. gelst marh abwärts in len relativ langen baekenbart ibber und besitzt wie lieser konstant weifsliche, oder höchstens ganz bleichgelbe farbe. Riissel mud T'aster dunkelhraun, ebenso wie die kinngegend mit reichlicher, weifser bis lichtgelber Behanung verschen. Der Ocellenhücker ist mit 4-6 mogleich langen, aher rehativ schwachen, lichten Borsten (schwarz bei einem ot ex (onll. liezzi) bewehnt. An den ulunkelbranen Fühlern ist das dritte Segment nu wenig ]änger als las erste Glied und gegen dic Spitze zn dentlirls spindelfirmig verdickt (Textfig. 12, betrachtet von oben). Das erste Segment trägt dichte, schwarze Behaarung und anfseriem anf der Mitte seiner Tnterflidhe aine einzelne steife Jorste von konstant golblicher Farbe. 
Thorax. Der vordere obere 'Teil der Mesoplenra ist eigentiimlich vorgewiilbt und wird dadurch in das mälsigg gewölbte Nivean des Mesonotum mit einbezogen, ein T'erhalten, das sich ebenfalls von allen untersuchten Cerotainien nur noch bei Spec. ranthoptera Wied. findet. Diese Partie ist ehenso wie das ganze Mesonotum und das Schildchen dieht und grob punktiert und mit bleiehgelber, seltenel weifslicher, sehief alostehender, fast pelzartiger Beharung versehen. Die Intensität dieser Behaarung ist freilich eine individnell reeht rerschiedene nnd anscheinend sowohl anf die Lïnge der einzehnen Haare, als anch wohl anf deren verschiedene Dichtigkeit zuriickzufiihnen. Die gröberen Seitenhorsten des Mesonotum sind weifslich bis lebhaft gelbbraun, unter allen Umständen aber hell. Der Schildchenrand trïgt kurze, braune Behaarumg. Peuren mit weifslicher bis gelbgraner Bestaubung und Behaarung, Notopleuralborsten und der vor den zitronengelben Schwingern stchende Metaplemalschirm fahlgelb. Die auf dem grau bis ockerluram bestäubten Netanotum stehende Borstengrupe ist liehtbraun, das Collare ist mit schwachen, lichtbrannen Borsten besetzt. Hiiften schwarz mit schwacher grauer Bestïubung und lichter Beharmug.

Abılomen schwarz, glänzend, mit dichter und grober Punktierung, die jedoch die Hinterrïnler der Segmente freiläfst. dic Segmenteinschnitte. ganz schmal durch branne Bestaubung gesäumt. An der Seite sind die Segmente in mehr oder minder grofser Ansdehnumg rotbram und zwar macht sich diese rothrame Färbung anch bei ilen dunkelsten Exemplaren, und sei es nur als kleine Maekeln, bemerkbar. Die stets anliegende Behaarung ist weifslich oder bleich messinggelb und zeigt in ilurel Linge die gleiche individuelle Variabilität wie auf dem Thorax: sie kam so lang sein, dafs das Abdomen dem unbewafỏneten Auge grau erscheint, während sie ein anderesmal so kur\% ist, dafs sie sich erst bei recht starker Vergriblserung bemerklich macht. Dabei möehte ich betonen, dafs für diesen versehichenen Grad der Behaarung sexnelle Differenzen nicht in Frage kommen. Banch lederhranu mit zerstrenter lichter Behaarmng.

An den relativ plumpen Beinen sind die Schenkel schwarz, die Schienen und 'Tarsen jedoch mehr oder minder lebhaft rot; bei den dunkelsten Fxemplaren können die Hinterschienen anch gresehwiirzt scin. Sehr beträchtlich ist wieder die Tariabilitiit der Behaarung nach Farbe, - weifs bis gelb- 
brann. - rol allen aber mach der I,ïnge, so dal's die Beine eventuell pelzartign behaart erscheincu. Die Borsten sind in allgemeinen gelb, doch machen sich bei den dunkelsten lixemplaren an den Selienen un 'Tarsen der llinterbeine vereinzelte Borsten vou dunkelbranner Farbe bemerklich.

Flï g el mit ziemlich intensiver, gleichmailsig branner 'Triibung. Spitze ler Subcostalzalle anfallend stumpf, die erste Hinterrandzclle gegen den Fliigeliand clweitert: die zweite Hinterrandzelle betriiblitlich verengert. Wer Stiel der vierten Hinterrandzelle erreieht den Fliigelrand nicht.

Long. corp. $6,5-8 \mathrm{~mm}$, long. alar. $5,5-7 \mathrm{~mm}$.

\section{Cerotainia xanthoptera Wied.}

Es liegt mir das typische Exemplar Wiedeman musenm in Mien vol; im iibrigen scheint, wenigstens den Literaturangaben mach zu schliefsen, nichts mehr über die Species bekannt geworden zu sein. Fine vergleichende Tutersuchung hat, wie oben bereits bemerkt, gewisse recht eigentiimliche plastische Merkmale als gemeinsam mit $C$. macrocera Say crogeben und es liefsen sich anch im iibrigen keine Lntersehiede zwischen C. xanthopter und den weniger dieht beharten Varianten von $C$. macroceru entrlecken, so dafs mir die Selbstänligkeit der Wiedemannschen Speries in bohem Glanle unwahrscheinlich ist. Fis $\mathrm{ist}$ ja rientig, dafs die Fäbung ver Fliigel meln einen Stich ins Gelbe besitzt, aber sollte dieses Merkmal allein geniigen, 1 m die Artrechte der Spec. nanthopter zu sichern? Ich betone noch in Korrektur einer Angabe des Kertésczschen Kataloges, dafs die Wickeman noche 'lype mit der Tatelandsangabe ,America " bezettelt ist.

\section{Cerotainia bella Sehin.}

Die typischen Fxemplare ans lem k. k. Hofmusenm Wien sind mit .Brasilien, Beske* bezettelt.

1)ic Beschreibung Schines beschrimlit sich auf eine Ingabe del Unterschicule gregeniiber $C$. husitiensis schin. Als ler wichtigste dicser Untersehienle mag die kiluzere und plumpere Gestalt der Hinterbeine grelten; ich fiige aber bei, das las ganze 'Tier breiter und geelrungener gebaut ist 
und dals es sich dadurch schon in seinem Habitus mehr an die Sppec. macrocera, xanthoptera usw. anschliefst. Das Abdomen ist wenig mehr wie doplelt so lang als der 'Thorax. Ich stelle aufserdem noch folgende speziellere Angaben für dic Kenntlichmachung der Species zusammen:

Kopf. Gesicht, Stime und Scheitel gleichmarsig mit goldbranner Bestäubung bedeckt, Knebelbart und Beharung des Gesichts schwarz, diejenige der Stirne und des Scheitels jerloch gellbbraun. Das ockerbramue. am Augenrande grau bestäubte Finterhaupt ist oben gelb, unten schwarz behaart und behorstet mul zwar erstrecken sich die Borsten bis efwas unter den Äquator des Auges. Auch der Backenbart ist dunkel. Riissel und 'Taster mit hauptsächlich lichter Beharung. Der Ocelleuhücker träg't sechs gelbe Borsten von verschiedener Länge. An den schwarzen Fiillern ist das dritte Segment etwas länger als das erste, die Peharmug ist schwarz.

Thorax. Das dicht, aber fein punktierte Mesonotum ist schwarz, violett glänzend und gleichmälsig ron ziemlich langer, vorne etwas abstehender, nach hinten zu anliegender Behaarung von inessinggelber Farbe beleckt, die sich auch auf lie obere Hälfte der Mesopleura fortsetzt. Die Borsten an dem Seitenrande iles Mesonotum und auf dem schwarzen Collare sind gelbbräunlich. Schildehen ebenso wie das Mesonotmm behaart, mit aufwairts gebogenen lichten Haaren am Rande. Pleuren, Prothorax und Hiiften ockerbraun bestaiubt und zart behaart. Das ebenso bestiinbte Metanotum trägt eine Gruppe stiftartiger Borsten von schwarzer Farbe. Notopleuralborsten und Metapleuralschirm gelblichbraum.

Abdomen schwarz mit gröberer Pmktierung mo der goleichen messinggelben, anliegenden Behaarung wie das Mesonotum. Auch die längere Behaarung am Seitenrande ist durchaus licht. Tie Segmentaleinschnitte schmal aber dentlich mit ockerfarbener Simmung versehen. An dem einen Exemplar ( $f)$ sind die Seitenränder der einzelnen Segmente rotbraun gesäumt. Banch lelerbramn mit zarter heller, nach hinten zu dunklerer Behaarung.

Beziiglich der Beine und Fliigel habe ich den Angaben Schiners nichts beizufiigen. 


\section{Cerotainia dasythrix n. sp. or $q$.}

Serlis Fxemplare aus Peru (Pachiteamiindung $150 \mathrm{~m}$ ii. d. MI.) und lolivia-Japuri (Sarampioni $700 \mathrm{~m}$ ii. d. M.) ex coll. Schnuse.

Hic Art fiillt durch den iiberaus gedrungenen Habitus nud die dichte nul lange Behatuug des Kïrpers nnd der kurzen Beine sehr auf, lälst sich aber trotzden durch die iibrigen plastischen Merkmale olme weiteres dem Genus Corotaimin cinorinen.

Kopf. Gesicht mul Stirne gleichmaifsig mit ockergelber, fast goldgoliuzender Bestäubung bedeckt. Dem mïlsig dichten gelben Knebelhart sind 1110 iiber dem Mnndrande cinige wenige schwarze Haare beigemengt, anch die Beharung des Gesichts und der Stin'n ist gelb. Scheitel mul obere Partie des Hinterhauptes unbestäubt, selıwarz mit gleichfarbiger dichter Behaarung. Die gleichfalls sehwarzen Oceipitalborsten erstrecken sich bis iiber den Äruator der Augen nach abwärts. An diesen, sowie auf scinen unteren Partien ist das Hinterhaupt grau bestiubt, der Backenbart ist gelb. Taster mul Riissel glänzend schwal'z, jene mit gelber, dieser mit dichter schwarzer Behaarmug, die auch die Kinngegend eiunimut. Der Ocellenhiicker trägt andsel zwei langen Borsten rier kürzere Hare von schwarzer Farbc. An den selwwarzen Fuilılern ist das schlanke erste Glied lïnger als das gegen die Spitze kolbenfürmig rerdickte dritte Glicd (T'extig. 13), schwarz beharit und an seiner Unterseite mit einer einzelnen cbenfalls schwarzen Borste rersehen. Auch das zweite

Nig. 13. Seg'nent ist relativ etwas liinger als bei clen verwandten Arten nud schwarz beborstet.

'Thorax. Mesonotum nnd Sehildehen schwarz mit dunkelgriunem Elyglanz, fein punktiert und goleichuälsig mit dichter, abstehender, nach hinten zu linger werdender Behaarung von suhwarzer Farbe besetzt. Hinter den S'chulterbenlen befindet sich ein nicht immer goleichstarkes Quer)and grolischimmernder Hare. Die griiberen Seitenborsten des Thorax unl die 
dichte Randbcharung iles Sehildehens sind schwarz. Pleuren mit ockerbrauner Bestüubung nul langer, biischelfürmig angeordneter schwarzer behaarung. Auch die Notopleuralborsten sowie ler dichte, vor den brannen Schwingern stehende Metapleuralschirm sind sehwarz. Das Collare triigt eine Reihe starrer Borsten von scliwarzer Farbe, ebenso ist die Gruppe kurzer Borsten auf dem Metanotum schwarz. Hiiften ockerbraun bestaiubt mit langer schwarzer Behaarung.

Das kurze und breite Abulomen schwarz, mit braungrinem bis violettem Metallglanz, grob punktiert, die Segmenteinsehnitte sehr fein braun gesäunt. Die schwarze Beharung ist auf dem Hinterleibsriicken sehr kurz, nach hinten zu wird sie lïnger und bleich messinggelb. Die lange abstehende Seitenbehaarung ist an den vorderen Segmenten stets schwarz, kann aber auf dem letzten Segment eine messinggelhe Farbe amehmen. Der schwarze Banch ist leicht ockerbraun bestïubt und schwarz bchaart.

An den relativ kurzen und plumpen Beinen sind die Schenkel schwarz, die Schienen und 'Tarsen aber rotbraun. Die sehr lange und lichte, abstehende Behaarmo ist ebenso wie die Beborstung allenthalben schwarz. Die biirstentünnige Behaarmug der Tarsen ist rotgehl bis bram. Jas eine $\mathrm{O}^{\top}$ trïgt an der Oberseite der 'Tarsen der Mittelbeine lange, silberschimmernde Beharung. Klauen schwarz, Pulvillen gelblich.

Fliigel lang, den Hinterleib iiberragend, an der Wurzelhälfte mit starker Bräunung. Die Adern schwarz. Erste Hinterrantzelle nur sehr wenig verbreitert, der Stiel der vierten Hinterrandzelle erreicht den Fliigelrand.

Das o unterscheidet sich hauptsächlich dadurch, dals das Mesonotum mit zarter, brauner Bestäubung bedeckt ist. welche eine geteilte Mittelstricme und fleckenartige Seitenstriemen wenigstens andentungsweise erkennen liifst.

Long. corp. 6,5 mm, longr. alar. 7 mm!.

\section{Cerotainia leonina n. sp.}

Znei q aus Mendoza (Argentinien) in coll. Hermann.

Die Art gehört durch den gedrungenen Habitus und durch die lange und dichte Behaarung in die unmittelbare Telwandtschaft ron C. Alasythrix und ist durch den Nangel jeglicher schwarzer Behaarmg leicht kenntliclı. 
Kopf. Gesicht, Stime, Scheitel mul Hinterhaupt gleichmaifsig mit graugeller, diinner liestiilbung bodeckt, der bleichgelbe Knebelbart geht ummittelhar in die dichte Behaarung' les Gesichtes iiber, die zahlleichen IIaare der Stirne und des Scheitels, sowie die sechs Oeellarborsten sind weifslich. Die gelben, relativ zarten Oecipitalborsten lassen sich bis zum Ïquator les Anges nach abwiilts verfolgen. die Beharung des Hinterhauptes und der Backenbart sind weifs. Riissel, Taster und Fïhler dunkelbraun mit gleichfalls durclaus lichter Behaarung (Textfig. 14).

T'horax. Mesonotum und Schildchen gläizend schwarz, fein punkticrt und gleichmälsig mit pelzartiger, fahlgelber Behaarmng verselsen. Auch die Randborsten, sowie die Haare am freien Rande des Schildchens sint gelb. Plenren gleichmailsig gran bestiiubt mid mit namentlich iiber den V'orderliiften und auf der Mlesopleura selır dichter, weifslicher Behaarung. Notol]leuralborsten und der ror den gelben Schwingern stehende Metapleuralschirm weisslich. Die auf dem grau bestäubten Ifetanotum stehende Borstengruppe liehtbraun.

A bromen plump und gedrungen. glänzend selswarz und mit dichter. relativ feiner Punktienung versehen. Dic anliegende, lange und diclite, licht messinggelbe Behaarung geht auf dem fünften und sechsten Segmente mehr in Iteifs iiber. Banch dunkelbraum mit lochler Beharming, die kurze Legeröhre gelbs und goleiehfarbig behart.

An den relativ kurzen lieinen sind die Schenkel und die Endtarsen glimzend schwarz, die Schienen und 'Tarsen lebhaft gelb ohe dunklere Zeichnungen. Die liehanrung und Beborstnng ist anssehliefslich weisslich odcr gelb. Klanen schwarz, P'ulvillen fahlgelb.

Die vollstaindig hyalinen Fliigel sind länger als das Abdomen und durchans mit gelben Adern rersehen. Stiel der Subeostalzelle relativ kurz, die erste Hinterrandzelle an Fligelrande kaum erweitert, die Hinterrandzelle nicht verengert.

Long. cor]. $6.5 \mathrm{~mm}$, long. alar. 6,5 $\mathrm{mm}$. 
13. Arten ron schlankerem Habitus, das Holomen etwa $4-5$ fach so lang als der relatir schmale Thorax.

\section{Cerotainia brasiliensis Schiner.}

Ieh konnte die typischen stitcke aus dem k. k. Hofmuseum in Wien mutersuchen und besitze in meiner sammlung ein cinzelnes Exemplar aus Bolivien. Der ansfïhrlichen Beschreibung Sehiners habe ich nichts beizllfigen.

\section{Cerotainia argyropus Schin.}

Es liegen mir die beiden typischen Stideke $\left(O^{\top} f\right)$ Schiners aus dem k. k. Hofmusenm in Wien ror, fernel besitze ich in meiner Sammlung ein + aus Peru. Dạ dic Schinersche Beschreibung die 'Trennung der spec. rigyropus ron einer nahe rerwanten, weiter unten zu beschreibenden nenen Art uieht gestattet, sollen hier iiber die Speries etwas ausfïhrlichere Angaben gemacht werlen, die ror allem gewissen plastischen Merkmalen Rechnung tragen.

Kopf. Gesicht und Stirne mit der iiblichen goldgelben Bestäubung. Der aus zahlreichen langen, schwarzen borsten bestehende Knebelbart reicht weit nach aufwiirts, so dars fiir lie feine, ebenfalls schwarze Beharmug des Gesichts nur wenig Platz iibrig bleibt. Die Behaarung der Stirne ist ebenfalls schwarz und namentlich am Augemrande ron erheblicher Lainge. Der Ocellenhücker träigt sechıs Borsten von ungleichel Liinge. Hinterhanpt nur nach abwiirts mit weifsgraner Bestäubung: Dic schwarzen Occipitalborsten dehnen sich bis unter den Augenäquator nach alwärts aus. Dic Behaarung ist der Hauptsache nach, ebenso wie der Backenbart, gelb. Riissel und Taster schwar", jener mit dunklen, diese mit bräunlichen Haaren, dic Behaarung der Kinngegend gelblich. Fiihler relativ kurz, namentlich das Basalylied anffallend kiirzer als

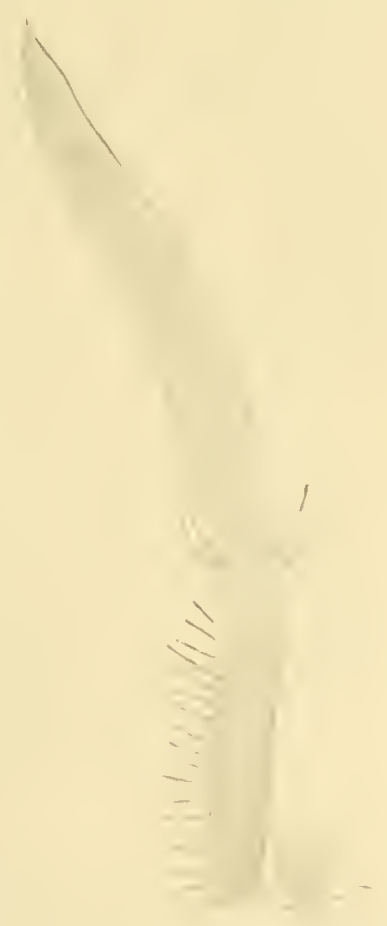

Fig. 15. bei den iibrigen Cerotainiarten, plump (Textfig. 15). Das dritte Segment $1^{1 / 2}$ mal lainger als das Grundglied, an der Basis etwas nach abwiilts ver- 
hreiert, nach der spitze sich rerjïngend. Behaarung der beiden Basalglieder schilian.

Thorax glainzend schwal\%, fein punktiert. Wer schwarzen, namentlich in der Vitte und hinten riemlich langen, abstehenden Bchaarung sind nur vorne wenig auffallende goldgelbe anliegende IJärchen beigemengt. Die Seitenborsten des Mesonotum, die Randhaare des Schildchens, sowie die stiftartigen liorsten auf dem orkerbranu bestäubten Jletanotum sind schwarz. ('nllare mit einer lieihe starker. schwarzer borsten bewehrt. Die gelbe Bestäubung der Plenren läl'st die Mesopleura frei, die rorne ein auffallendes Bitschel langer, schwarzer Hare trägt. Notoplenralborsten schwarz, der ror den gedben Schwingern steheude Metapleuralschirm gelblich.

Abdomen giliinzend schwarz mit dichter Punktierung, die aber die glattpolierten Segmentrïnder freilälst. Die änfserst kurze Beharmng des Hinterleilssiickeus ist schwarz, die liungere seitliche Behalrung lichtgelb. Banch mattschwar'z mit dunkler zerstrenter Behaarung.

l’ezüglich der lieine sei betont, dafs die silberschimmernde Behaarung der vorderen Beinpare in greicher Weise die Schenkel, die Schienen und die Tarsen cimimmt. Die Borstenhare der Hinterbeine sind der llanptsache nach schwarz, die biirstenförmige Beharung der Tarsen der Hinterbeine gelbhraun. Klanen schwarz, l’ulvillen schneeweils.

Das o stimmt in den plastischen Nerkmalen nul der Fübung vollstiundig mit dem o $o^{T}$ iberein. so dafs es geniigt, die Lnterschicile anzugeben. l) silberschinmerude Beharung der vorderen Beinjaare fehlt rollstïndig. und wird dureh forkere im wesentlichen weifsliche Beharmug und Beborstung. crstzt, lie Borsten der Hinterbeine sind fast ansschliefslieh fahlgelb. Die P'ulvillen sind liclitgelb.

long. corp. 8 mu, long. alar. $7 \mathrm{~mm}$.

$$
\text { C'erotainia argyropygu. ot } 7 \text { H. sle }
$$

Lin $\Im^{-1}+$ ex roll. Hermann ans Peru, ein $q$ gleicher Provenienz. findret sich in der Sammlung les Herrn Abtes leander in Kremsmiinster.

Lie Art steht im Allgemeinhabitus mol im Einzelnen der vorigen species schr nahe. lisfst sich aber durch eine heihe plastischer lifferenzen leicht und sicher auscinanderhalten. 
Kopf. Gesicht und Stime mit der gerröhnlichen gelben Bestäubung. Der ans wenigen sehwarzen Borsten bestehende Knebelbart reiclit nicht bis znr Hälfte der Hähe des Gesichtes empor, die iiber ihm stehende kiirzere Beharmg ist gell). Die Stime trägt in der Mitte kiirzere schwarze Behaarung, am Augenrande zwei oder drei lange Borstenhare, anch die Scheitelgegend schwarz behart. Hinterhanpt gläizend schwarz, am Angenrande und weiter nach abwiirts gran bestïnht, die schwarzen Occipitalborsten reichen ïber den Angeníiquator nach abwärts. 1)ie feine Behaarmg gelblich, ebenso der Backenbart. Der Ocellenhöeker trägt zwei lange Borsten. Riiissel und Taster schwarz, beide mit bleichgelber Behaarung. Fiihler schwarz, das erste Glied schlank und fast so lang als das dentlich pubescente dritte Segment ('Textfig. 16), auch das zweite Glied ist länger als bei spec. argyropus. Die Beharung der beiden Basalgiieder ist schwarz, am zweiten Segment borstenförmig.

Thorax. Mesonotum glänzend schwarz mit feiner Punktierung. Die kurze anliegende schwarze Behaarung ist namentlich nach riickwïrts reichlich mit messinggelben Haaren gemengt, die sich zum Teil anch auf das Schildelien fortsetzen. Die Seitenborsten ies Iesonotum, die Randhaare des Sehilichens sowie die kurzen Borstenstifte des Metanotmm schwarz, ebenso ist das Collare mit einer Reihe sehr derber, schwarzer Borsten bewehrt. Pleuren mit graner bis gelbliclier Bestänbung und gleiehfarbiger zarter Behaarung heileckt, auf der'Mlesopleura finden sich mur einige wenige kurze Haare, die cbenso wie die Notopleuralborsten nnd der vor den fahlgelben Schwingern stehende Metapleuralschirm gelb sind.

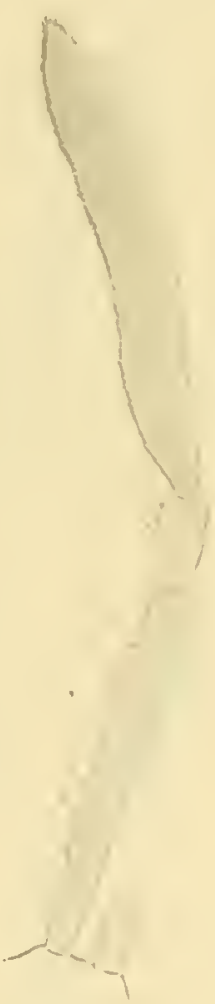

Fig. 16.

Abdomen schwarz, dicht punktiert. Die kurze anliegende Behanrung ist gröfstenteils gelblich mud steht so dicht, dals das ganze Abdomen bei gewisser Beleuclıtung einen leichten Erzschimmer erhält. Dic lïngere Behaarung an den Seiten ist ebenfalls gelb, die Segmenteins'hnitte sind wenigstens an den Seiten durch weilse liestäubung gesäumt. 1)as schon ventral verlagerte sicbente Segment ist mit sehr auftallender biirstenförmiger, sclmeeweilser Behaarung licht besetzt. Baluch mattseluwarz mit zerstreuter heller Behaarmg. 
Dic relativ gracilen Beine sind mit Ausuahme der gelhbrammen Knic schwar\%. Die Schienen der beiden vorteren Beinpare sind auf ihrer Aufsenseite weils hestiabt und aufserden mit diehter silberschimmeruder Belıarung rersehen, die sich anch auf die 'Tarsen fortsetzt, die Schenkel abel freilitist. Die lïngere Belaarung und Beborstung der Beine ist fast alsschlief'slich weifs bis gelblich, die Tarsen der Hinterbeine sind mit ganz bleichgelber. fast silherweilser biirstenförmiger Behaarung besetzt, die Winuperhatare der Hinterselienen sind gelblielı. Klanen schwarz, Pulvillen fahlgelb.

Dic Flïgel sind fast hyalin, nur an dem Torderrande und gegen die Fliigelspitze findet sich eine etwas deutlichere 'Tribung. Hrste Hinterrandzelle nur sehr wenig erweitert, zweite Hinterrandzelle kaum rerengelt.

Das $q$ entspricht in allen wesentliehen Punkten dem or, nur fehlt die silberweifse Beharung an den beiden vorderen Beinpaaren und an Rande des sicbenten Segmentes, anch ist die goldgellue Beharung des Mesonotum nud des Abdomen weniger diclit.

Long. corp. $7 \mathrm{~mm}$, long. alar. $6 \mathrm{~mm}$.

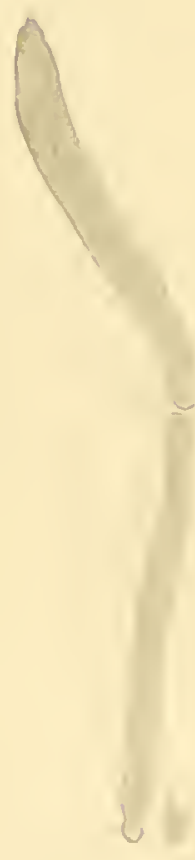

Cerotainia violaceithorax Arribalzaga.

Fin einzelnes $q$ aus Brasilien ex eoll. Bezzi stimmt vollstimlig mit der ansfiilulichen Beschreibung Arribalzagas, so dafs ich iiber die Identifizierung keinen Zweifel habe.

\section{Cerotainiu rhopalocera Arribalzaga.}

Ich besitze diese leicht kenntliche Species in fünf Exemplaren aus Mendoza (Argentinien). Die vïllig ausreichende Beschreibung giht zu weiteren Bemerkungen keinen Anlafs ('Textig. 17).

Cerotainia aurata Schin. Or.

Es liegt mir die aus Venezucla stammende 'Type aus dem Fig. 17. k. k. Hofmuseum in Wien ror. 
Die Schinersche Beschreibung genügt wohl zur Erkemnung der Species, gleichwolıl möchte ich hier einige ergänzende und berichtigende Znsätze machen. Tor allem sei darauf aufmerksam gemacht, dafs der goldene Schimmer, der den Kïrper zum 'Teil bedeckt, nicht, wie Schiner sagt, auf eine 'Tomentierung, sondern vielmehr auf Behaarmig zuriickzufiihren ist. Der 'Thoraxriicken ist durchans mit dichter, fast pelzartiger Behaarung bedeckt, die am vorderen Rande, sowie hinter der Quernaht schwarz ist, wïhrend dazwischen ein Querband lebhaft goldgelber, besonders dichter Behaarung gelegen ist. Schildchen schwarz behaart. Die Borsten des Collare, des Thoraxrandes mul die Randhaare des Schildchens sind schwary.

Ähnlich liegen die Verhältnisse auf den Abdomen, nur ist hier die Behaarung anliegend. Das erste und die Torderhälfte des zweiten Segmentes, sowie das sechste Segment ist schwarz behaart, während alle iibrigen ron goldener Beharmug bedeckt sind, die so dicht liegrt, das bei Untersuchung mit mbewaffinetem Ange die schwarze Grundfarbe vollkommen versehwindet. Die lïngere seitliche Beharming besteht anf dem ersten Segmente teils aus braunen, teils ans hellen Haaren, auf ilem zweiten und dritten Segmente ist sie gelblich, auf den folgenden durchaus schwarz. Die Segmentaleinschnitte sind schmal weifs ges:ïunt. Die Schienen der Torder- und Mittel-

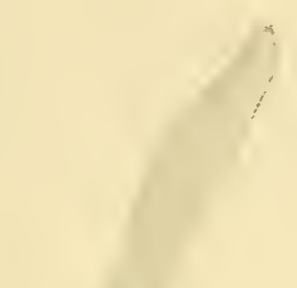
beine sind mit Ausnahme ihrer Hinterfläche lichtbraun, weifs bestäubt und mit fast silberweifser Behaarung bedeckt, ilie sich auch etwas auf die 'Tarsen fortsetzt. Auch die 'Tarsen der Hinterbeine besitzen an ihrer Aufsenseite solche silberweifse Behaarung. Das dritte Fühlerglied ist wenig, aber dentlich kiirzer als das erste Segment ('Textfig. 18). Der Ocellarhöcker trïgt vier Borsten, die schwarzen Occijitalborsten erstrecken sich nuter den Äquator der Augen naeh abwïrts. 


\section{Cerotainia mopinqua Sollin $q$.}

Die Art, ron lel ieh die ans Tenezuela stammende Type ans dem k. k. Hofunsenm in löien vol mil habe, läfst sich nach der kurzen Besuhreibung Schiners iiherhant nicht definieren. Demn gerale dic Unterschienle, dir Schiner beziighlich des Geäiler's gegeniiber auratu angibt, besitzen nach der oben gegebenen Gattungsbeschreibung iiberhanpt keine Bedentung. Andererseits entsprialt die Angabe Schiners: „diese Art gleicht in ter Firbmug ganz der vorigen Art"6 der Wirklichkeit absolut nicht, so dafs ich es vorziche, hier eine ausfiulurlichere Beschreibung der Soluinerschen Type zu geben.

Kopf. Gesicht und Stime gleichnäl'sig mit fahlgelber liestaiubung bedeckt. Wer ziemlich diinne Kuebelbart ist ıler Hauptsarhe nach gelb, nur oben sind ihm einige dunklere Borsten beigemengt. Anch die Behaarung des Gesichtes ist teils gelb, teils schwarz, dic Behaarung der Stirne brïunlich mit einzehnen dunkleren Haaren. Das ghlänzend schwarze Hinterhaupt ist am Augemande und den abwirtigen Partien mit fahlgelber l3estïubung bedeckt, die bis unter den Augenäuuator herabreichenden Oreipitalborsten sind ausschliefslich gelb. Auch die vier ()eellarborsten sind hell. Oceipitalbcharung und Backenhart gleichfalls gelblirh, ebenso die Behaarung der Kimngegend, des líissels mul der 'Taster. Frstes Fihlerghlied mit gelben Borsten, und ron

Fig. 19. gleivher Länge wie das dritte Segment (Textfig. 19).

'T'horax gränzend schwarz, die wenig dichte Punktierung findet sich hanptsichlich rorn und in einem schmalen Streifen neben der Medianlinic. J) Behaarnng ist gelhlich, volne mud am Seitenrande dichter nnd goldgelb. Anch das Schilldehen zeigt einzelne gonlisehimmernde Haure, die Randbehalung ist jedoch schwarz. 'Thorakahborsten ausschlicfslich grelb. l'leuren mit nekergelber Bestaimbung nnd gelber liehatrung, die namentlich an rer Mesopleura zicmlich alicht ist. Notopleuralborsten und der vol den gelhen Schwingern stehende Mctaplenralschirm gelb. Das grau bestäubte Mctanotum triagt ebenso wie das Collare schwarze Borsten. 
Abdomen glänzend schwarz mit dichter Punkticrung. Die feine, anliegende Behaarung ist allenthalben bleichgelb, aber so fein, tals die Grundfarbe nicht veraindert wirl. Auch die längere seitliche Beharung ist allenthalben bleichgelb. Die Segmenteinschnitte sind nur seitlich in selır gneringem Manfse weifs gesäumt. Banch lederbraun mit lichter zerstreuter Behaarung.

Beine glinzend scluwarz mit gelben Knien. Die Behaarung und Beborstung ist ausschliefslich gelb, die gelbliche Wimperbehaarung der Hinterschienen wenig dicht; die biirstenfümige Behaarung der Tarsen, sowie der Innenseite der Vorderschienen licht messinggelb.

Flïgel blafsluriunlich, an der Basis heller, am Forderrande und an der Spitze dunkler. Tierte Hinterandzelle olne Sticl.

Trotz der mannigfachen Färbungsdifferenzen ist bei der Älnnlichkeit des Gesamthabitus die Vermutung, dafs C. propingue nur das $q$ von $C$. uurata sei, nicht abzuweisen: ein lintscheil ist, da beide Arten nur in je einem Stiicke vorlanden sind, nicht zu treffen und wir werden die beilen Tiere deshalb vorderhand noch als getrennte Arten zu behandehn haben.

\section{Cerotainia flavipes n. sp. ot?}

3 o 1 q aus Peru (Chanchamajo $800 \mathrm{~m}$ ii. d. I.) ex coll. Schunse, 2 o aus Paraguay (Assuncion) aus der Sammlung des k. mngar. Nationalmuseums in Budapest.

Man wird diese nene Species an iler lebhaft grelben Färbung der Beine, die in dieser Weise bei keiner ter mir bekannt gewordenen Cerotainien vorkommt, leicht erkennen.

Kopf. Gesicht und Stirne gleichmailsig gelblich bis grau bestiiubt. Der Knebelbart besteht ans teils schwarzen, teils grelben Borsten und Haaren, die feinere Behaarung des Gesichtes und der Stirne ist schwarz. Der glinzend schwarze Scheitel mit dicher gelber Beharung. Auch das Hinterhaupt ist in den oberen l'artien gliinzend schwarz, am Augromande jeiloch und nach abwairts mit gelber Bestäubung beleckt. Die Occipitalborsten sind schwar\% und erstrecken sich weit unter dem Augendiquitor nach abwärs, die feinere Behaarung jedoch gelb, der dünne Backenbart 
weisklich. ])er Orellenhïrkel trägt zwei relativ kurze scluwarze Borsten. líissel und 'l'aster dumkrlbraun mit lichter Behaarung. Fiihler ('Textfig. 20) schwar\%, mit gleichfarbiger Behaarmng der beiden Basalglieder, das dritte Segment, an der Inmenscite gran bestänbt, und mamentlich an der Aufsenseite sehr deutlich pubescent, ist linger als das Grundglied.

'Thorax. Mesonotum glïnzend scluwar\%, mit Aus-

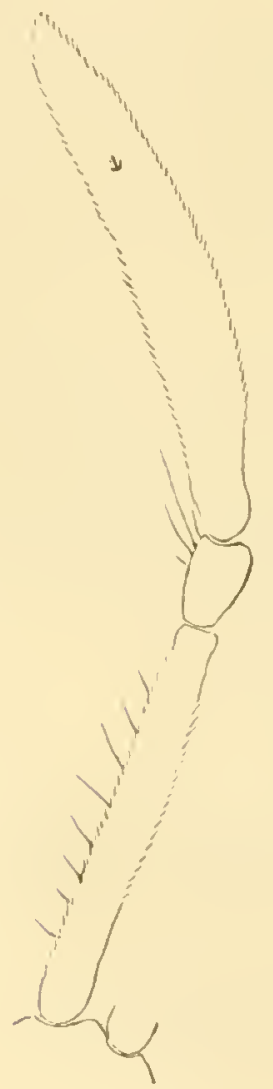

Fig. 20. nabme ier Schultergegend gleichmälsig punktiert und mit anliegender Beharung ron goldgelber Farbe bederkst, die sich anf dic Mesopleura mud auf das ebenfalls junktierte Schildchen fortsetzt. Die kurze hanibeharung des letzteren schwarz. Das glänzend sehwarze Collare träigt eine dichte Reihe sehr derber schwarzer Borsten, anch die kurzen stiftartigen Borsten des dunkelbraum bestiubten Metanotum sind ebcnso wie die Seitenborsten des Thoraxiickens schwarz. Plenren mit bindenartig angeorineter goldgelber Bestäubmug und zerstreuter grelber Behar'ung bodeckt. Notopleuralborsten und der vor den zitronengelben Schwingern stehende Metapleuralschirm gelb. Hiiften schwarz mit zarter gelber Bestäubung und Behaarung.

Abdomen schwar\%, mit leichtem branem Fir. schimmer und gleichmaissiger grober l'unktierung. I) feinc anliegende Beluarung ist lichtgeelb, an den Seiten etwas lainger, abstehend und mehr goldgell,. An dem zweiten, dritten mul vierten Segment sind die Segmenteinschnitte seitlich durch ganz feine, gelbliche Härchen gexsiumt. Bauch ockerbraun bestiubt und zart behatrt.

Beille. 'Tlochanteren und Obersehenkel gönzend schwarz, die Kinie, die schienen und die 'lasen lebhaft gelb. Jie Eudtasen mit den Klanen, sowie die sipitze der Hinterschienen geschwärzt. Die Behnarung ist lebhaft gelb, die Wimperbehartug Ale Hinterschienen meho weilsheh. Auch die Beborstung ist getb und nur an den 'Tarsen der Hinterbeine machen sich cinzelne schwarze Borsten bemerklich. 
Flitgel. Das W'urzeldrittel ist durch mikroskopische Beharmug milchweifs getrübt und besitzt gelbe Älerung, die iibrige Flïgeltiaiche ist schwach bräunlich tingiert und mit schwarzen Adern verschen. Die abgerundete vierte Hinterrandzelle entbelurt eines Stiels, so dafs die dritte mid fuinfte Hinterrandzelle nicht roneinander geschieden sind.

Das f nuterscheidet sich nur wenig ron dem ơ , so dafs die Angabe der Differenzen geniigt. Die Bestiubung des Gesichts und der Stirne ist mehr goldgelb, ihre Beharung vorherrschend gelb. Die Fligel entbehren der milehigen Triibung, doch sind in Wurzeldrittel die Adern ebenfalls gelbbrann. Die Spitzen der Hinterselienen sind nur in geringer Ausdehnung geschwärzt.

Long. corp. 6 mun, long. alar. 5 mm.

\section{Cerotainia debilis 11. sp. ort.}

Es licgen mir ror 49 Exemplare aus Peru (Pachiteamiindung, $150 \mathrm{~m}$ ii. d. M. und Chanchamajo $800 \mathrm{~m}$ ii. d. M.) und ans Bolivien (Sarampioni) ex coll. Schunse und 2 o aus Peru (Vileanota) aus dem k. ungar. Nationalmuseum in Budapest.

Kopf. Gesicht, Stirne und Scheitel gleichmïlsig mit goldgelber Bestäubumg bedeckt. Der Kunebelbart besteht ans milsig dicht stehenden gelben Borstenhaaren, auch die Behaarung des Gesichts, der Stirne und des Scheitels ist gelb. Das Hinterhaupt ist mit Ausnalıme einer grofsen, glänzend schwarzen Quermakel gelb bestäubt mit gleichfarbiger Behaarung, die in den etwas helleren Backenbart iibergeht. Die relativ feinen, gleiclifalls gelben Borsten reichen bis unter den Augenäunator nach abwärts. Riissel, Taster unl Kinngegend dunkelbrann mit bleichgelber Behaarung. Der Ocellarliöcker trägt zwei grobe Borsten und zwei kiirzere Haare von gelber Farbe. Fiihler (Textfig. 21) dunkelbraun, das erste Glied träigt an seiner Unterflïche vorwiegend gellue, an seiner Oberseite sehwarze Behaarung und Beborstung. Das zweite Segment besitzt ansschliclslich schwarze. relativ sehr lange Borstenhaare, das dritte Glied zeigt sehr deutliche Pubes- 
ren\%, welche an der Innenseite gelb, an der Sirtze fast weifslich ist, mud ist wenig kiumer als das Grumlglied.

'Thorax. Jas Mesonotmu ist an rorleren laumle gläinzend schwarz mul kahl, weiter narl hinten zeight es fleckonatig anftretenden fahlen Er\%schimmer, griifstentrils aber ist es ghinzend sehwarz mit blanen mud violetten lieflexen. Die dichte anliegende Beharung ist goldgelb, die Randborsten siml ausualumslos geelb. das violettschwarge Schildchen ist ebenfalls goelb behaart, am Ranle aber mit schwarzen Haaren besetzt. Dic Pleuren sind grleichmålsig mit gelber liestiubung berleckt, dic sich am Prothorax emporzicht. unl bleichgolb belaart. Auch lie Notopleuralborsten, sowje tler vor den ritronengelben Schwingern stehende Metaplenalsehim sind gelb. l)as in der Mitte fleckenartig golılgelh bestäubte Metanotum trägt seitlich eine Gruppe starrer Borsten von sehwarzer Farbe. Collare schwarz und ebenso belorstet. Iliften gell, bestainbt und behaart.

Abromen schwar\% mit sehr feinen weifslichen Segmenteinschnitten, goldehmälsiger derber Punktierung und kurzer ausschliefslich gelber Belıarung: Anch die lïngere Behaarung am seitenrande ist bleichgelb. Bauch lederbraun mit zerstreuter lichter Beharung.

Beinc. Schenkel dunkelbraun bis schwar\%, glänzend, nur an der äulsersten Kiniegegend dister lotbraun. Ebenso sind an den Hinterbeinen die simtliclıen Tarsen nnd die Schicnen mit Ausmahme ihrer rotbraun gefaibten Wurcl schwar\%. An den beiden vorderen Beinpanen sind jedoeh die 'larsen unit Ausualnne ihres Endgliedes mol lic Suhienen lichtbrann; letztere busitzen anfserlem an ilner Innenseite einen fahlgelben Liangswiselu. Die Behanrung nud Beborstung ist im wesentlichen gelb, nur an den vorderen lieinlalaren findet sich an der (Oherseite der Kinie schwarze Beharung, auch die 'Tarsen der IJinterbeine tragen fast ansschliefslich schwarze liolsten. bie hiirstenfurmige Theharung Acr Tarsen unl der Hinterseite ist goldgelb, die 11 imprerbehaarung der IInterschienen gelb.

Flïgel gleichnaifig schwach, aber leutlich hrann tingiert. am Vorderande ctwas intensiver. Erste Hinterrandzelle an! Fligelrande etwas verbreitert, dic zweite Jlinterandzelle nur wenig rerengert.

Das + unterseheidet sirh nur sehr wenig ron dem ot. Die Behaarung des Mesonotum ist kürzer, der Knebelbart besitzt cinige dunkle Borstenhaare, 
dats erste Fiihlerglied ist beiderseits schwarz behart, auch an den Beinen finlen sich schwarze Borsten in gröfserer Menge. Die Borsten anf dem Collare sind bald schwarz, bald gelb, anch die Aushlehnung der hellgefürbten Partien an den Schienen und Tarsen zeigt individnelle Schwankungen.

Long. corp. $6 \mathrm{~mm}$, long. alar. $4,5 \mathrm{~mm}$.

\section{Cerotainia argyropasta n. s]). ot.}

Ein einzelnes Exemplar aus Peru (U'cajaliflufs) ex coll. Schnuse.

Kopf. Gesicht, Stirne und Seheitel mit der gewöhnlichen goldgelben Bestäubung bedeckt. Der wenig dichte Knebelbart besteht ans vorwiegend dunklen Borsten, denen gelbe kiirzere Haare beigemengt sinl. Die sehr zarte Behaarung des Gesichts ist gelb, Stirne und Scheitel dagegen schwarz behaart. Der Ocellarhiieker ist nit zwei langen sehwarzen Borsten bewehrt. Das Hinterhaupt ist in den oberen Partien glänzend sebwarz, am Augenrande unl nach abwäits mit gelber Bestüubung bedeckt. 1)ie rorwiegend gelben zarten Borsten erstrecken sich bis unter den $\ddot{I}_{\text {quator }}$ les Auges, die ziemlich lange Beharrung ist ebenso wie der Backenbart und die Haare der Kinngegend gelb. Der ebenfalls lichten Behaarung des dunkelbraunen Riissels sind einige lïngere sehwarze Borsten beigemengt. Die beiden Basalglieder der dunkelbrannen Fiihler sind ausschliefslich mit schwarzen, relativ langen, zum Teil borstenfürmigen Haaren besetzt, das dritte Segment fehlt.

Thorax. Mesonotum glänzend schwarz mit sehr feiner Punktierung. Am vorderen Rande findet sich kurze. abstehende Behaarung von branner Farbe, der Hauptsache mach aber ist das Ifesonotum mit anliegender goldgelber Bekaarung bedeckt, die hinter der Quernaht länger wirl, besonders dicht liegt und allmihlich fast silberschimmernde Farbe ammimmt. Anch das Schildchen ist völlig von dieser dichten silbersehimmernden Behaarung bedeckt. Die Seitenborsten anssehlielslich schwarz. Pleuren gleichmälsig von fast goldgelber sich auch auf den Prothorax hinaufziehenter Bestïubung bedeckt und zart behaart. Auf der M[esopleura ein Biischel längerer gelber Haare. Notoplenralborsten seliwarz, anch der ror den zitronengelben Schwingern stehende gelbe Metaplenralschirm schlielst oben einige dunklere Borsten ein. Collare schwarz mit derben gleichfarbigen Borsten. Auch lie 
kulzen Borstenstifte des Metanotum sehwarz. Hïften goldgelb bestäubt und lang behaart.

Abdomen glanzend schwarz mit depber Punktierung. Die beiden ersten S'egmente sind mit diehter anliegender silberschimmernder Behaarung bedeckt, die sich anch anf der vorderen Hälfte des dritten Segmentes Heckenartig ausbreitet. In iibrigen ist das Abdomen mit knuer und zarter gelblichel, nach hinten zu schwarzer Beharmug beleckt. An den Sciten ist die lichtgelbe beharmug nur soweit lang und abstehend, als die Segmente mit der silberschimmernden Beharung bedcekt sind; weiter nach hinten wird anch an den Seiten die Beharung kurz mud richtet sich in der Fiirbung: nach dem Terhalten auf der Rüickenflichc. Banch glänzend bram mit ziemlich breiten ockerbraun bestäubten Hinterrandbinden nnd zarter licliter Behaarung.

An den Beinen sind die simtlichen Sehenkel goanzend dunkellurann, an den vorderen Beinparen sind die Knie, die Schiencn nud die Tarsen mit Ausnahme ilnes geschwärzten kndgliedes gelbbram. An den Ilinterbeinen aber beschränkt sich die helle Fïrbnng lediglich anf die Wrurzel ler S'chienen. Die Behaarung und Beborstung ist fast ansschliefslich gelb, nur an den Tarsen, namentlich der Hinterbeine machen sich anch dunkle Borsten bemerkbar. Die biisstenförnige Beharnng der Tarsen ist goldgełb und zeigt an dem Metatarsus der Hinterbeine exquisit reihenfiomige Anordunng. Klanen schwar\%, Pulvillen bleichgelb.

l)ie Flïgel sind gleichmälsig schwach bräunlich tingiert und besitzen lobhaft irisierenden Glanz. Die Adern sind dunkelbraun. Die erste Hinterrandzelle an Fliggelrande leicht elweitert, die zweite Hinterrandzelle etwas verengert.

Long. corpl. $4,5 \mathrm{~mm}$, long. ałar. $4 \mathrm{~mm}$.

$$
\text { Cerolaimia marginala } 11 . \text { sp. OT. }
$$

Fin einzelnes Exemplar aus Peru (Pachiteatluls, Lnimi.) cx. coll. Sclıul use.

Die Alt ist an der schwar\%en Säumung der Fliigelspitze leicht kemntlich. 
Kopf. Gesicht, Stirne und Scheitel mit der gewïhnlichen goldgelben Bestäubung g’leichmärsig berleckt. Der Knebelbart besteht aus gelben Borsten und dazwischen stehenden kiirzeren IIaren, die mmittelbar in die ziemlich dichte, gleichfarbige Beharung des Gesichtes iibergehen. Auch die anf der Stirue und namentlich anf dem Scheitel diclıt stelıenden Haare - sind anssrhliefslich gelb. Das Hinterhaupt ist am Augenrande mud anf der unteren Hälfte mit gelbgraner Bestäulung bedeckt, in iibrigen galiinzend schwarz. Die relativ zarte Beborstung reicht bis zum Äyuator der Angen nach abwärts, die feinere Beharung ist ebenso wie der Backenbart bleichgelb. Der Ocellenhöcker trägt vier gelbe Borsten von ungleieher Läinge. Aueh die Beharmmg des gäüuend dnnkelbramen Riissels ist bleichgelb. Die beiden Basalglieder der schwarzen Fiihler sind auschlielshich schwarz behaart und beborstet, das iritte Segment fehlt.

Thorax. Mesonotum schwarz mit erzgrinen und violetten Reflexen und deutlicher, dichter Punktierung. Die anliegenule Beharung ist goldgelb. die Seitenborsten ausschliefslich grelb. Auch las schwarze Schildchen ist mit anliegenten goldgelben Haaren bedeckt, die schwarzen Haare an scinem freien Rande sehr kurz und spärlich. Plenren und P'rothorax głeichmäisig graugelb bestäubt mit lichter, zerstrenter Beharung, die auf der Mesopleura gröbere Länge gewinnt. Notopleuralborsten. Borsten des C'ollare und der vor den licht gelbbraunen Schwingem stehende Metapleuralschin goclb, die Borsten des graugelb bestäubten Metanotum aber schwarz. Hiiften grangelb bestäubt mit langer, bleichgelber Behaarung.

Abdomen schwarz mit derber Punktierung. Die anliegende Behaarumg ist auf den drei ersten und der vorderen Hïlfte des vierten Segmentes goldgelb und ziemlich dicht, weiter nach riickwärts bedentend zarter mud dunkel, am Hinterrande des sechsten Segmentes bleichgelb. Der Seitenrand des Abdomens träigt in ganzer Anslehnung lïngere, abstehende Behaarung von gleichfalls bleichgelber Farbe, auch das fast kugelig vorspringende Hypopyg ist dicht mit bleichgelben Haren besetzt. Der gleichmälsig oekergelb bestäubte Banch trägt lange bleichgelbe Behaurung.

An den Beinen sind die Srhenkel mit Ausnahme der gelbbramen Knie gläinzend schwarz. Die Schienen sind dunkelbram, an deu beiden vorderen Beimparen ist die Vorderfläche, an den Hintersehienen das basale 
1) rittel ringsum gelhbraun. Die 'l'arsen sind an den rorderen Beinpaaren mit Ausnahme ler Endglieller diister gelbbrann, an den Hinterbeinen beschränkt sieh die lichtere Firbung auf lie Wurzel des Metatarsus und der iibrigen 'Tarsenglieder. Die Beharung und Beborstung ist allenthalben gelb, un' auf len 'Tarsen, numentlich der Hinterbeine, funden sich zahlreiche schwarze Borstenlaare. Die bürstenfürnige Behaarung der 'Tarsen ist fast gohlgelb, dic Wimplerbehaarung der Hinterschenkel und -schienen bleichgelb. Klanen schwarzbrau mit gelblichen Pulvillen.

Die graulich hyalinen, lebhaft irisierenden F'li ggel besitzen an der Spitze einen verwaschenen, saumartigen, dunkleren Flecken. Die Adern mit Ausunlume der aulsersten Pasis dunkelbrann. Die erste Hinterrandzelle am Fliigelrande dentlich erweitert, die zweite Hinterrandzelle etwas verengert.

l.ong. cor'1. $5 \mathrm{~mm}$, long. alar. $4,5 \mathrm{~mm}$.

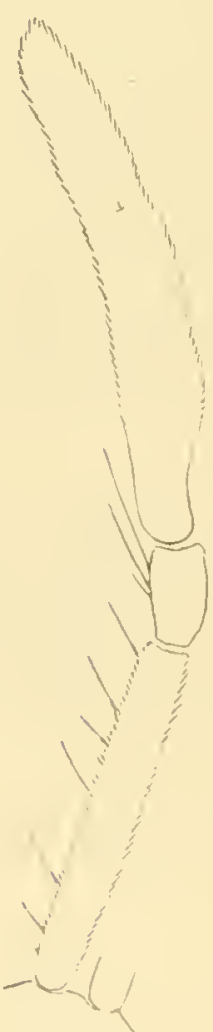

Fig. 22.

\section{Cerotainia unicolor n. sp. ?}

Je ein $q$ aus Peru in der. Sammlumg Lichtwardt mul Leander Czerny.

Kopf. Gesicht, Stime mnd Scheitel mit der gewöhnlichen goldgelben Bestaiubung. Der Knebelbart besteht ansschliefslich aus schwarzen Borsten und dazwischen gemengten kiirzeren gelben Haaren. Die Beharmug des Gesichtes ist zum Teil, diejenige der Stirn und des Scheitels ausschliefslich schwar. Das Hinterhanpt ist nu in den unteren Partien mit grangelber Bestäubung beleckt mul hicr mit bleichgelber Behaarmg versehen. Backenbart ebenfalls bleichgelb. Die schwarzen Oc(ipitalborsten erstrecken sich bis unter den İquator der Augen naeb abwärts. ()cellarlö̈cker mit zwei langen Borsten mnd zwei kurzen Haaren von schwarzer Farbe. Die Kinngegend und der schwarze Riissel bleichgelb behaart, letzterer mit zwei langen schwarzen Borsten. Fiihler (l'extfig. 22) selıwarz, dic beilen Basalglienler mit anffallend langer mol dieliter schwarzer Beharmmg und lieborstung. 
Thorax. Mesonotum und Sehildchen glïnzend schwarz mit gleichmälsiger, feiner Punktierung und ausschliefslich schwarzer anliegender Behaarung. Seitenborsten des Mresonotum und die auffallend lange Randbehaarung des Schildchens schwarz. Pleuren und Prothorax ockergelb bestäubt und bleichgelb behaart. Notopleuralborsten und der vor den zitronengelben Schwingern stehende Metapleuralschirm gelb. Collare mit kräftigen schwarzen Borsten, anch die kurzen Borsten iles Iletanotum schwarz. Hiiften gelb bestïubt und behaart.

Abrlomen glänzend schwarz mit grober Punktierung. Die änfserst kurze und feine Beharmug ther Rückenfläche ist schwarz, nimmt aluer gegen die Seiten und auf lem letzten Segmente allmählich lichteren Schimmer an. Die bleichgelbe Behaarung an Seitenrande ist nu an den ersten drei Segmenten lang und abstehend, nach hinten aber kurz und anliegend. Auf dem ersten Segmente sind ihr eine Gruppe langer schwarzer Borstenhaare beigemengt. Bauch glïnzend bram mit ockergelber Bestiubung und langer gelber Behaarung.

Beine gleichmälsig gläinzend schwarz, nur an der äulsersten $T^{\top}$ urzel der Schienen gelbbraun. Die Beharung" und Behorstung ist an den beilen vorderen Beinparen bleichgell, an den Hinterbeinen sind die Schienen und T'arsen vorwiegend schwarz beborstet. Die biirstenfürmige Behaarung der T'arsen und der Innenseite der Vorderschienen ist bleich messingrelb, die Wimperbehaarmıg an den Hinterbeinen bleichgelb. Klanen schwarz, Pulvillen weifslich.

Fliigel. Die gleichmälsig braune Färbung ist am Yorderrande nur wenig intensiver. Erste Hinterrandzelle nur wenig erweitert, zweite Hinterrandzelle kaum verengert. Ailern sehwarzbraun.

Long. corp. $6 \mathrm{~mm}$, long. alar. $6 \mathrm{~mm}$.

\section{Cymllotomyice Williston.}

Das Genus Cyphotomyia wurile anf Grund einer westbrasilianischen Species von Williston (I'syche $\mathrm{T}^{\prime}, 1889$ ) errichtet. Ans der Schnuseschen Sammlung liegt mir ein Exemplar vor, iiber dessen Zuggehörigkeit zu diesem 
Cienus ich keine Bedenken labe. I Her Angabe und ligäuzung der ron milliston groghenen Gattungsmerkmale will ich hiel cine etwas ausführlichere beschreibung des Genus grelıen, bemerke aber, dafs das mir rorliegende lixemplar in lex Beharmug und Beborstung des Kopfes anscheinend nicht tadellos konserviert ist, so dals ich lieriber keine vollständigen Angalren zu machen in der Lage bin.

ler Kopf zeigt die fiir alle Cerotainien charakteristische Form (laf. Fig. 11 n. 12). Has Gesicht ist etwas nash oben rerbreitert, am Mundrande ganz wenig aufgeworfen und in seinen oberen Partien mit einigen kurzen Haaren versehen. Der Kuebelbart seheint armborstig zu sein. Die stark mach oben elweiterte Stime trägt cinige kurze Härchen, die Scheitelregion ist kahl. Der relativ kleine Ocellenhöeker träg't an dem vorliegendem Exemplar zwei kurze Borsten. 1)as Hinterhaupt entbehrt an scinen oberen Partien anscheinend der Beloorstung, gegen den İquator des Anges aber machen sich einige sehr kurze steife Oceipitahborsten bemerkbar. Die Behaurung des Hinterhauptes und der Backenbart sind selı spirlich. Riissel und 'Taster kul'z, beide nur mit geringer Behaarung. I)ie langen Fibiler zeigen die fiir die Cerotainien charakteristischen gregenseitigen Längenverhailtnisse der einzelnen Segmente. Das Grundghied erseheint durch änfserst kurc Behanmug pubescent, an seiner Oberseite behant und seiner Unterseite mit wenigen Borsten versehen. Das nicht pubescente kurze zweite Segment trägt bejilerseits an seincm Vorderrande kurze Borsten, das griffellose Endglied ist so lang wie las erste Segment. Gegen seine Spritze ist es etwas erweitert und ebenso wie das erste segment deutlich pubescent.

An dem im iibrigen mälsigg gewïlsten 'Thorax fiilt zunähst eine eigentiinliche fast lıalbkugelige Vorwijbung der vorderen Randpurtie anf, lie sich durch seitliche schwache Rimmen ziemlich bestimme gregen die iilurige 'lhoraxtäche ahsetzt. Hïchst eigentiomlich verhailt sich anch die groble l'unkticrung. Zunäichst fiilt auf, dal's die die ticfe Punktiermug bildenden Griihchen an ihren Rïndern aufgeworfen sind, wodureh die ganzen punktierten Flïchen ein exyuisit chagriniertes Ausschen hekommen. Aufserlem erstreckt sich die Punktieru!g nicht gleichmaisig iiber das ganze Masonotum, sondern ist anf gerisse Areale heschrainkt, welche die den meisten Asiliden eigene Zeichnung in eine längsgeteilte Mittelstrieme mul 
Heckenartige Seitenstriemen zwischen sich fassen nud so deutlich erkennen lassen. Die eninent kurze, schwarze Behaarung des Mesonotum ist rollständig in die Tiefe jener Gribchen versenkt und macht sich dadurch auch bei stäkerer Tergriblserung nur recht wenig bemerkbar. Nur vor den Schildehen sind die Itaare etwas länger und werden auch durch ihre goldgläızende Fiirbung deutlicher bemerkbar. Gleiche goliglänzende Behaarung* findet sich auch im Bereich der Mesoplenra, sowie auf dem ebenfalls chagrinierten Schildchen, dessen Rand grïberer Haare vïllig entbehrt. Die Seitenborsten des Thorax sind sehr kurz und schwach entwickelt: prïsntural ?, supraalar 1, postalar 1. notopleural 1. Die Pleuren sind mit ghleichmäfsiger Bestäubnng bedeckt, die auch den Prothorax iiberzielt. Das Collare ist mit einer dichten Reihe dormartiger Borsten bewehrt, der Mretapleuralschirm ist märsig lang. Das gleichmälsig bestäubte Metanotum trägt seitlich eine Gruppe stachelartiger liurzer Borsten.

Das nath hinten verjüngte $A$ bdomen besteht aus sechs ron oben sichtbaren Segmenten und ist gleichmilsig sehr derl punktiert. Die kurze Behaarung ist ebenfalls gröfstenteils in die Punktgribbhen versenkt, so dafs sie sich nur anf den beiden letzten Segmenten deutlicher bemerkbar macht. Auch an den Seiten fehlt längere Behaarung vollstaindig, ebenso fehlen anch mit Ansnahme des ersten Segmentes alle Discalborsten. Das siebente Segment sowic die selı kleinen Genitalsegmente sind vollkommen an die Ventralthiiche verlagert.

Beine relativ kurz, die sämtlichen Schenkel, an den Hinterbeinen anch die Sehienen etwas verdickt. An diesen ist die Wimperbehaarmg sehr dieht, im übrigen bictet die Behaarmng und Beborstung der Beine nichts Charakteristisches.

Anch die Fliigel:idlerung besitzt keine besonderen Merkmale. Der Stiel der Subcostalzelle ist lang, die erste und zweite Hinterrandzelle sind distal gleichweit offen, die kleine Queraler steht etwas juroximal von der Mitte der Discoidalzelle. Ob der unvollstiindige, den Fliigelrand nicht erreichende Stiel der vierten Hinterrandzelle als charakteristisches MIerkmal anzusehen ist, erscheint nach den bei den echten Cerotainiaspecies gemachten Erfahrungen fraglich. 
Als typische Species grilt

$$
\text { Cyphotomyiu Lynchii Will. }
$$

Fin einzelnes Fixmplar aus Peru (Urubambathus, Umahuakiali. $500 \mathrm{~m}$ ii. d. M.) ex roll. Sclunuse.

\section{Buthlopsis n. ב..}

Kopf nur relativ wenig rerbreitert ('Taf. Fig. 13 u. 14). Das milsig verbreiterte Gesicht verengert sich etwas gegen die Fiilılerwurel zu, ron hier aber weichen dic ansgerandeten Orbitalrainder wieder so weit auscinander, dafs die Scheitelregion die Breite des Gesichtes, am Mmndrande gemessen, crlïilt. An der Fïllerwurzel ist das Gesicht erkcrartig vorgebnchtet, im iibrigen länft es, etwas riickwïrts geneigt, vollkommen plan nach abwirts. 1)er Knebelbart besteht jederseits ans einer lieihe weniger

, Borstenhaare, dic am Mnndrande nach abwairts reichen und zahluejchere feinere Haare zwischen sieh fassen. Die gleiehe Anorinung zeigt anch die Beharung des Gesichtes. Stime und Scheitc] tragen seitlich ziemlich lange, borstenartige Behaarung. Der stark vorragende Ocellenhöcker ist mit vier Borsten ron nngleicher Tainge hewelırt. Am Hinterhanpte reivhen die Borsten his gegen den Ïquator der Angen mach ahwiirts. Backenhart nur mairsig lang. Der ziemlich kurze liissel ist an seimer Unterseite djoht behart, die an ihrer Spitze mit cinigen Iaaren besetzten Taster sind klein. Fïhler verlïngert, ungefiiln so laug als der Breitendurchmesser des Kopfes. Ins erste Glied ist rtwa dremal so lang als das kurze zweite, das Endglied ('l'extfig. 23) ist ungef:̈hl doppelt

Fig. 23. so lang als die beiden Basalglieder zusammengenommen, griifstenteils zart puhescent nul mit einen kurzen, zapfenfirmigen, ebenfalls pubescenten Endgriftel ausgestattet. Der unch in apioaleu Drittel stehente Zahngriffel ist schr kurz und nur schwer wahruchmbar. I)as zweite Fiihler- 
glied ist apical beborstet, das erste Segment trïgt aufsel einer längeren Borste an seiner Unterseite ziemlich dichte, aber zarte Beharmung.

Thorax. Das mälsig gewölbte Mesonotum ist grleichmilsig mit anliegender kurzer Behaarung und jederseits mit einer Reihe kurzer abstehenter. dorsocentraler Borstenhaare versehen. Beborstung: präsutural 1, supraalar 2. postalar 1, notoplenral 2. Schildchen mit kurzer, anliegender Beehaarung und kurzen, aufwärtsgebogenen Randhaten, aber ohne Borsten. P'leuren mit Ausnahme einer ohrörmigen glänzenden Mackel gleichuaifsiy bestäubt. Metapleuralschirn ans sehr kräftigen Borstenharen bestehend. Coulare nur behaart, das Metanotum aber mit einer Gruppe derber Borsten bewehrt.

Abdomen aus sechs ron oben sichtbaren Segmenten bestehend. derb, aber nicht besonders dicht punktient und allenthalben mit anliegender, auf den vorderen Segmenten kurzer Behaarung bedeckt. Dic Seitenbehaarmug ist nicht besonders viel länger, Discalborsten finden sich nur auf den liei vordersten Segmenten.

An den mälsig beharten und beborsteten Beinen sind die sämtlichen Schenkel, sowic die Hinterschienen gleichmälsig rerdickt. Die äulserst dichte und regehnäsige Wimperbeharung nimmt nicht nur die einander zusehenden Flächen der Hinterschenkel und -schienen ein, sondern findet sich anfsertem noch auf der apicalen Hälfte der Mittelschienen.

Fliigel hyalin. Die kleine Querader steht über der Mitte der Discoidalzelle. Anal- und vierte Hinterrandzelle lang gestielt. Erste Hinterrandzelle etwas verengert, zreite wenig erweitert. Sticl der Subcostalzelle sanft nach aufwilts gebogen. Die die Discoidalzelle und die vierte Hinterrandzelle distal abschlicfsenden Queradern stehen nicht in der gleiehen Linie, vielmehn ist die Abschlufsader der vierten Hinterrandzelle etwas distal rerschoben.

Als typische Art beschreibe ich:

$$
\text { Bathropsis peruviuna or ns. sp. }
$$

Ein einzelnes aus Peru (Tilcanota) stammendes or ex coll. He run an 11.

Kopf. Gesicht, Stirne und Scheitel silberweifs bestïubt. Die Borsten des Knebelbartes und des Gesichtes sind schwarz, die feineren Haare weifs. Stirne und Seheitel schwarz behaart, anch die Ocellarborsten schwarz. 
Hinterhaupt oben gelblich, nach abwiirts weifs bestiiubt und ebenso behart. Die Oceipitalborsten sind gelbbram, der Backenbart weifs. Behalarung der Kimmgegend, der 'Taster mo des Riissels fahlgell). Die Basalgliedel' der schwarzen Fiihler ockerbraun bestäulst mod durchaus schwarz behaart, nur die Pubestenz des Eurlgliedes briumlich.

'Thorax. Mesonotum und Schildchen sehwarz mit anliegender gonldgelher Beharung, dargegen sind die dorsoeentralen Börstehen ebenso wie die Seitenborsten des Mesonotum schwarz. Die Randbehaarnng des Schildchens ist goldgell. Pleuren mul Hüften granweils bestänbt und ebenso behaart. Notoplenralborsten und der vor den weifsgelben Schwingern stehende Metapleuralschirm schwarz, die Behaarung des Collare gelb, die Borsten des gell, hestäulten Metanotum schwarz.

Abdomen schwarz. Die anliegende Beharung ist in der Mitte und an den vorderen Segmenten schwarz, im iibrigen gleichmälsig goldgelb. Iiscallyorsten gelly. Bauch braun mit sehr zerstrenter gelber Behaarnng.

Beine gleichmä́sig lmann, etwas durchseheinent. Die gesante Behaarung und Beborstmug ist mehr oder minder lebhaft grelb, nur die Oberscite der Hinterschenkel ist gröfstenteils mit sehwarzer anliegender Behaarmng versehen und die Tarsen tragen teilweise sehwarze Borsten. Klanen schwarz. Pulvillen gell,lich.

Flügel lỵalin mit schwarzen Aderu.

Long. corp. $6.5 \mathrm{~mm}$, long. alar. $5,5 \mathrm{~mm}$.

\section{Eumerosoma Schiner.}

Zur Ergainzung der sehr kurzen von Schiner (Terhandl. d. zool. boten.

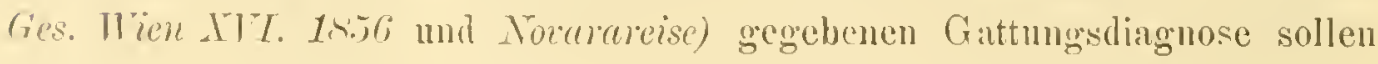
folgende ansfiilırlichere Angaben dienen, die mir um so nötiger erscheinen, als eine einheitliche Auffassung des Gattungsbegriffes gewissen Schwierigkeiten begernet. Gerade die typpische Art pleuriticum Wied. zeichnet sich nämlich in manchen P’unkten niclit muwesentlich von den iibrigen vier mir bekannt gewordenen Species ans. Gleichwohl möchte ich vorderhand eine generische Tremung remeiden, schon deshalb, weil die mir vorliegenden Wiedemannsehen 'Typen der Spee. pleuriticum sich in einem keineswegs 
idealen Konservierungsznstande hefinden. Ich begniige mich daher mit der Angabe der jeweiligen Differenzen.

Kopf beträchtlich hreiter als hoch (Taf. Fig. 15 แ. 16); lyei der Sp). pleuriticum Wied. exynisit abgeplattet, anch sind hier die in der Mitte des Angenfeldes gelegenen Facetten sehr grols und scharf von den den seitlichen Angenrand streifenfümig umfassenden kleineren Facetten geschieden. Das mäfsig breite Untergesicht besitzt einen warzenfürmigen, ungefähr eiu Viertel bis cin Drittel der Gesichtshöhe einnehmenden Höcker, der bei der Sp. metallescens die grörste Austehmmng besitzt. Nath oben ist das Untergesieht ebenfalls etwas vorgewölbt, bei Sp. metallescens stehen die Fiihler sogar auf einem deutliehen Höcker. Die starken Borsten des Kuebelbartes setzen sich anf den seitlichen Mundrand fort, anch iibur dem Gesichtshöcker ist das Gesicht mit nach abwiirts gekrimmten Borstenharen reihenweise besetzt. Stime nach oben gleichmisisig erweitert, seitlich mit einer Gruple von Borstenharen. Ocellarborsten und Beborstmng des Hinterhanptes lang; Backenbart jedloth relativ schwach entwickelt. Fiihler von mäisiger Länge, das spindel- oder tomnenfömige erste Glied verhältnismälsig wenig länger als das zweite, das dritte $1 \frac{1}{2}$ —2 mal so lang wic dic beiden Wurzelglieder zusammengenommen, seitlich komprefs, leieht keulen-oder (Sp.pleuriticum) mehr spindelfümig, ohne Endgriffel, jedoch an seiner Spitze in einen kurzen. scharfen Dorn anslaufenu, über den sich anf eckigem Torsprung ein selı dentlicher '/ahngriffel befindet. Das dritte Fühlerglied zeigt bei den einzelnen Arten in seiner relativen Iainge und seiner Gestalt Differenzen, iiber welche dic den Artbeschreibungen angefiigten Zeichmungen am besten zu oricntieren rermögen. Die Belıarung der heiden Basalglieder erreicht vor allem an dem zweiten Gliede erhebliche Linge, das erste Segment besitzt an seiner Unterseite eine cinzelne durch ihre Linge auffallende Borste. Riussel von mälsiger Lïnge, gerale, 'Taster klein.

Del mäsig gewölbte 'Thoraxioken mit Bestaibungstlecken, welche die Mittel- mol die Seitenstriemen in Form einer krenzförmigen /eichnung dentlich vortreten lassen, mit mehr oler minder lichter, anfechtstehender Behaarung. Beborstung: prisutural 1, supraalar 2, postalar 3, notopleural 2: Metaplemalschirm lamg. Pleuren mu mit zerstrenter und zarter Beharung. Schillchen mit langen Randborsten; bei Sp. liventum besitzen diese gleiche 
Lënge, bei den iibrigren Arten sind die lateral stehenden hiir\%cr, musonehr fallen zwei näher der Mitte stehende Borsten dureh ihre Lïnge und Dicke auf. Metanotum seitlich mit biischelförniger zarter Behaarung:

A bronen expuisit keulenförmig, nicht punktiert, glïnend, von oben betıalitet aus sicben Segmenten bestehend; anch die lang beborsteten Genitalsegmente sind von oben siehthar und zwal sowohl das in zangenartige Arme gespaltene Hypopygium, als auch die stumpfe mud kurze Legerible. Belıarung zart, nach hinten etwas lïnger weriend. An den Seiten des Abloncu findet sich längere, abstehende, weiche Behaarung; ragegen fehlen im allgemeinen l)iscalborsten. Bei der Sp. metallescens finden sich solche nul auf den ersten drei Segmenten, bei der Sp. pleuriticum jedorh ist jedes Segment mit Discalborsten bewelnt.

Die ziemlich langen Beine ohme besondere charakteristische Merkmale, die Hinterschenkel nur seh" wenig verdickt, an meisten noch bei iler Spec. pleuriticum.

Fliigel lang, den Hinterleib iiberragend. Sticl der Subeostalzelle mälsig lang, sanft nach oben gebogen, erste und zweite Hinterrandzelle nicht verengt, die die Discoidal- und die viereckige, kurzgestielte vierte Hinterandzelle distal abschliefsenden Adern nur anniliernd in der gleichen linie, wohl aber stets in der gleichen hielitung verlaufend. Analzelle kurz gestielt. Die kleine Querader steht iiber đem Basaldrittel der Discoidalzelle.

Als typische Art gilt

Eumecosoma pleuriticum Wied.

Fs liegen mir die drei typischen Exemplare Wiedemanns aus der Sammlnug des k. k. Hofmusemms in Wien vor, die freilich in ihrem Konservierungszustand durch die Länge der Zeit stark gelitten haben ('l'extfig. 24). Wic ich glaube, diirfte die IViede-

Fig. 24. malnusche Beschreibung zur Kenntlichmachung der Art genügen.

In die niahere V'erwandtsohaft dieser Art gehört auch Eumecosoma dichroma Big.

ans Brasilien, die nach Untersuchung aler Bigotschen 'Type sicher als selbstainlige Species betrachtet werilen kann. 
Eumecosoma staurophorum Sehin.

Es lagen mir vor die Type Schiners aus der Sammlung des k. k. Hofmuseums Wien, 57 Exempläre aus Peru (Pachiteaminndung etwa 150 m ii. d. M.), Bolivia-Mapiri (Sarampioni $700 \mathrm{~m}$ ii. d. M. und Chipata $650 \mathrm{~m}$ ii. d. MI.) ex coll. Schnuse, drei Exemplare ex coll. Hermann, die rollständig mit iler Beschreibung Schiners iibereinstimmen (Textfig. 25).

Eumecosoma metallescens Schin.

Aufser den drei typischen Exem-

Fig. 25. plaren Schiners knunte ich zwei Fig. 26.

Stiicke aus Pern ex coll. Hermann, sowic ein Exemplar ex coll. Prof. Bezzi untersuchen, die mit den Typen Schiners völlig iibereinstimmen (Textfig. 26).

Aulsertem beschreibe ich als neve Art:

\section{Eumecosoma hirsutum n. sp.}

Zwei Exemplare aus Bolivia-Mapiri (Sarampioni $700 \mathrm{~m}$ ii. d. M.) ex coll. Schnuse, ein Exemplar ans Peru ex coll. Hermann.

Die Art ist nïchst verwandt mit Eumecosomu metallescens Schin., von ihr aber schon durch die allenthalben dichtere Behaarung leicht zu unterseheiden.

Kopf. Untergesicht mit weilslicher bis bleichgelber Bestïubung bedeckt, in der oberen Hälfte mit einigen längeren, weifslichen Haaren. Dem dichten weilslichen Knebelbart sind oben in wechselnder Ansdehnung schwarze Borstenhare beigemengt. An der Stirne nimmt die weifsliche Bestäubung gegen den Scheitel zu mehr ockergelbe Färbung an. Die borstenfürmige Beharung an dem medialen Augenrande ist schwarz. Ocellarhöcker braun mit langer schwarzer Fig. 27. Beborstung. Fithler ('Textfig. 27) schwarz, die Basalghieder mit sciwarzel Nova Acta XCv1. Nr. 1. 
Bchaarung und l3eborstung. Das dritte Segment ist an seiner Innenseite namentlich gegen die Spitze graugelb bestaubt. Hinterhaupt gleichmälsig. gratu bestïnlst, Borstenkran\% und Beharung in lev oberen Hiilfte schwarz, nach abwills weils, cbenso wic der kurze Backenbart. Riissel und die selu' kleinen 'Taster' schwarzbraun, beide mit lichter Beharung.

'T'hnl'axrïcken mit der für die Gattung charakteristischen Zeichunng. ber Solillerfleck neben den Sehulterbeulen, sowie der bis zur Flügelwurzel zichende Samm lichtgelb; die Flecken der Scitenstriene nufsbram, matt, die selwwarze, durch eine lichte Medialinie geteilte Mittelstrieme liort in gerrisser Entfernung vor dem Schildchen auf und macht hier branner Bestäubung Platz. Jie abstelende, dichte Belıarung des Thoraxuickens ist wie dessen Beborstung ausschliefslich schwarz. Schildchen mit brauner Bestäubung, aber unbestainbtem Rand, ler von einer lieihe anfwirtsstehender Borsten eingenommen wird. Metanotum brann bestäubt und gelblich behart. Pleuren gran bestiubt, an der Mesopleura mn iiber der Vorderhiffe mit dichter gelblicher Behaarung. Metajleuralschirm in der oberen Hailfte ans schwarzen, in der unteren aus lichten langen Borstenhaaren gebildet. Hiiften grau bestiubt, weifslich behart. Sehwinger graugelb.

Abdomen mit lebhaft blaugrünem Metallglanz. Die kurze, aber ziemlich dichte Behaarung ist auf dem Hinterleibsriicken schwarz, an den Seiten jedoch, sowie anf den boiden letzten Segmenten ist sie länger und weifslich mol erstreckt sich an den Hinteräudern auch der iibrigen Segmente bindenartig gegen die Mitte. Banch schwarz mit zerstrentel dichter Behatarung.

Beine durchaus schwar\%, glän\%end, die feine ziemlich dichte, abstehende Beharung der Schenkel mol Schiencn im wesentliehen weifs, die langen Borsten der Srhienen vorwiegend selwarz. 'Tarsen an der Oberseite ansschliefslich schwar\% behaart und beborstet. Die Hinterseite der Torderschicuen, sowie die Lnterseite der 'Tarsen ist mit fast gooldglinzenler, bürstenartiger lBehaarnng versehen. Krallen schwarz, Julvillen buau,

I*liige] gleichförmig rauchgran, lebhaft irisierend, Adern schwarz. Long. ('or']), 7,5) mm, long. alar. $7.5 \mathrm{~mm}$. 


\section{Dissmerymgorles $11 . \mathrm{g}$.}

Kopf unr wenig in lie Breite gedehnt (Taf. Fig. 17 n. 18), Untergesicht schmal, ohne Gesichtshïcker, nur an Mnndrande schwach aufgeworfen. Stirne relativ wenig, doch dentlich nach oben verbreitert. Knebelbart auf den ILundrand beschränkt, etwas unter der Fühlerwurzel stehen zwei nach abwärts gebogene Borsten. Hinterhanpt, abgesehen von den starken Borsten, ziemlich kahl, auch der Backenbart schwach entwickelt. Fihler ziemlich lang, das erste Segment melır wie doppelt so liug, als das kurze, napffirmige zweite, das dritte Segment iiber doppelt so lang als die beiden Basalglieler zusammengenommen. Das dritte Segment trïgt nalse seiner Basis an seinem unteren Rande eine höckerartige Verbreitermng und ist gröfstenteils leicht pubescent (Textfig. 28). Der Endgriffel ist deutlich abgesetzt mid dentlich pubescent, der Zahnstift stelit an der Basis des Endgriffels. Die beiden Basalglieder kurz behaart, das erste an sciner Unterseite, das zweite an der Oberseite mit einer lïlngeren Borste.

Thorax ohne auffallende Wölbung, relativ kahl. Be-

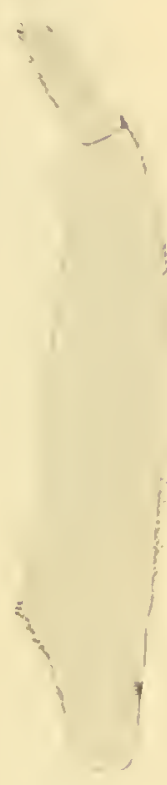

Fig. 28. borstung: prisisutural 1, smpraalar 1, postalar 1, notopleural 2, der Metapleuralschim besteht aus langen Borsten. Das Schildehen trïgt wahe ler Mitte seines freien Randes zwei durch ihre liange und Dicke auffallende, fast spielsförmige, aufwiirts gebogene Borsten. Metanotum seitlich mit dichter Beharrung.

Abdomen grob aber wenig dicht punktiert, kahl, beim $q$ nach hinten etwas verbreitert. Von oben gesehen sind sieben Segmente sichtbar, anch das $O^{7}$ Genitale tritt noch etwas vor. Das erste Segment trïgt seitlich drei, der zweite zwei, die folgenden vier Segmente je eine Discalborste.

Beine. Hinterschenkel an der Unterseite mit derben, in dornartige Borsten endigenden Hörkern versehen und aufserdem dicht bewimpert.

Fliigel. Der Stiel der Subcostalzelle mifsig lang, leicht nach anfwäits gebogen, zweite Hinterrandzelle gegen den Fliggelrand verhreitert. die die Discoidal- und die vierte Hinterrandzelle distal abschliefsenden Adern 
nicht immer in gleicher linie, dorh stets in gleicher Richtung rerlaufent. Vicrte Tlinterandzelle lang gesticlt, anch die Analzelle gesticlt. Die kleine (Juerader liegt noch iiher ther Basalhailfte der Discoilalzelle.

Als typische Art luetrachte ich

\section{Dissmeryngoles (Laphria) anticus Wied.}

Ieh konnte die Wiedemannsche Beschreibung mit der freilich nicht hesonders gut konservierten (es fehlen die hinteren Abdominalsegmente) 'Type vergleichen, die mir ans der Sammlung des Mnseum Senkenberg in Frankfurt a. M. Vorlag. Dic Beschreibung geniigt vollstiondig, so kurz sie ist, um die Art zu erkennen, tie sich in zwanzig Exemplaren in der Sammlnng Schunse aus Pern (Pachiteamiindung, $150 \mathrm{~m}$. ii. d. MI.) vorfindet.

Auch gehïrt hierher

$$
\text { Dissmeryngoles (Atomosia) dispar Wik. }
$$

Drei Exemplare ex coll. Hermann ans Surinam, 24 Exemplare ex coll. Schnuse aus P'eru (Pachiteamiindnng $150 \mathrm{~m}$ ii. d. М.).

Dic Walkersche Beschreibung (List Dipt. Brit. Mus. F pag. 5ro) geniigt, wenu man die liezeichmung der Körperfarbe als ,purpureo-cuprea* nicht zu wïrlich nimmt, vollkommen, un die Art zu erkennen.

\section{Dirlrorlis n. g.}

Kopf breiter als hoch, Untergesicht ron mäfsiger Breite, plan, nur iiber dem Mfundrante zu einem ganz wenig vorspringenden Höcker anfgewnrfen ("l'af. Fig. 20 n. 21). Knebelbart ans wenigen $(8-10)$ in zwei Reihen angenrdneten Borsten bestehent, iiber diesen zwei Reihen feiner llärchen. Stirne gegen ilen Scheitel gleichmailsig aher nicht beträchtlich erweitert, an dem Orbitalrande mit einigen wenigen feinen Hïrchen. Fiihler relativ kurz ('Textfig. 29). I)as rrste segment nur wenig liuger als ilas kurze zweite, beide mit del gewïhnlirhen borstenfümigen Beharmug. Das dritte Segrment ist höphstens $1 \frac{1}{2}$ mal so lang als die beilen Basalgalieder zn-

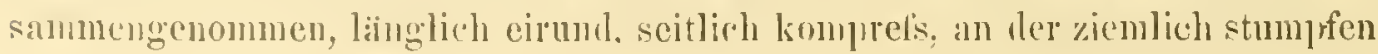


Spitze sehr zart pubescent, iber ihr findet sich in flacher Grube der Zahmgriffel. Hinterlaupt aufser dem Borstenkranze mit zertrenter, zarter Behaar'ung, anch der Backenhart mu' schwach entwickelt. Riissel gerade, an der Wurzel mit feiner Behaarung mol zwei langen Borsten. Taster klein, aber entschieden etwas läinger als bei den verwandten Formen.

'Thorax mit ziemlich hetriehtlicher Wöbung, die namentlich vorne stark in die Augen fällt, so dafs der Abfall gegen das nur mit feinen Haren besetzte Collare cin recht steiler ist. Thoraxriucken gleichmäfsig dicht punktiert und mit kurzer, dichter, absteheuder Behaarung bedeckt. lbeborstung: präsutural 1, supraalar 1, postalar 1. notopleural 3. Heuren bestäuht, iiber den Vorilenhüiften und anf der Mesopleura nit dichter, feiner Beharmug. Schildchen ebenfalls junktiert. konvex, kurz behaart, der Hinterrand wulstig abgesetzt und

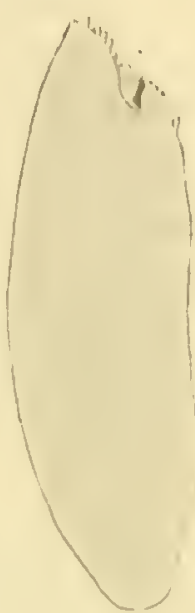

Fig. 29. mit relativ kurzen Haaren hesetzt. Metapleuralschirm ziemlich lang, Metanotum mit einem Biischel zarter Hare.

Abdomen gleichmiifsig dicht grob punktiert, alygeplattet, bei dem of nach hinten etwas verbreitert, iiberhaupt breiter als beim ot. Ton oben sind sieben Segmente, beim $\sigma^{r}$ auch die Spitzen der zangenartigen Fortsätze des ziemlich grofsen Hrpoprgiums sichtbar. Die Behaarung auf dem Hinterleibsrieken ist äufserst kurz, an den Seiten jedoch länger, das erste Segment mit 3-4 Discalborsten, die den folgenden Segmenten aber vïllig felılen; die beiden letzten Segmente, sowie das Genitale sind mit einigen schwächeren Borsten bewelnt.

Beine nur von mälsiger Länge, ohne besondere charakterisierente Merkmale. Die hellgefïrbten Teile sind fast glasartig durehschimmernd. An der Lnterseite des Metatarsus und den beiden folgenden 'T'arsengliedern der Hinterbeine steht die bürstenfürmige Behaarmg in regehnälsigen Reihen, so dafs sie wie geringelt anssehen.

Fligel lang, den Hinterleib iiberragend. Stiel der Snbcostalzelle ziemlieh lanı. Eiste und zweite Hinterantzelle nicht verengert. llie kleine Querader steht noch proximal ron der Mitte ler loiscoirlalzelle. Die die vierte Hinterrandzelle distal begrenzende Querader stelit bald ror, bahl 
hinter der Begrenzungsader der Discoidalzelle und besitzt auch nicht völlig Ieren lichtung. Vierte Hiuterrandzelle und Analzelle ziemlich lang gestielt.

Zunächst glaubte ich, in der Luphriu musilla Wied., von der Wiedemann angibt, dafs sie sich Iurch thas eirunde dritte Fïhlersegment anszeichne, die typische Speeies des neuen Genus erblicken zu niirfen. In der ('oll. Winthem des k. k. Itofmuseums findet sieh die Type Wiedemanns; dieselbe ist aber stark ansgebleicht, recht schlecht konserviert und gerade das dritte Fiihlerglied ist verloren gegangen. Die Untersuchung des Tieres ergab aber, dals es dem neuen Genus Oidam is nicht eingereiht werden kann, und so beschreibe ich als typische Art:

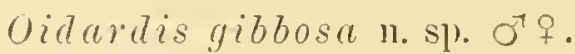

Sechs of $q$ aus Peru (Umahnankiali $500 \mathrm{~m}$ ii. d. M. und Pto. Bermudes $700 \mathrm{~m}$ ii. d. M.) und Bolivia (Chimate $650 \mathrm{~m}$ ii. d. M.) ex coll. Schnuse.

Das Ther aihnelt in seinem Habitus lebhaft an gewisse Arten des Genus Pipiza (Syrpleidarum).

Kopf. Gesicht mit gelblich grauer Bestäubung; oder besser gesagt. sehr' feiner, angeprefster Beharung versehen, welche jedoch am Mundhö̈ker die schwarze Grundfarbe freilïlst. Die wenigen Borsten des Knebelbartes schwarz mit helleren Spitzen, lie zwischen nnd iiber ihnen stehente Beharung weifslich. Stirne und Scheitelgegend mit dünner, grauer Bestiubung" und schwarzen Borsten; die feine Behar'ung und der Backenbart weifslich. Riisscl und Taster schwarz mit weifsheher Behaarung.

Thorax schwarz mit schlackenblauem Schimmer. Die Schulterbeulen rotbram gerandet, anch die Postalargegend ist in beträchtlicher Ausdehuung rotbraun. Die kurze Behaarung ist rorne weifslich, nach hinten mehr braiunlich. An den Seiten des Prothorax finden sich gelblich-graue Bestäubungsflecke. Schildchen schwarz, wie der Thorax sehwarz beborstet. Pleuren gelblich-gran bis weifs bestäubt und weilsich behaart. Die Notopleuralborsten bei lem ot schwarz, bei dem of weifslich, ler ghleichfarbige Metapleuralschirm enthält nur bei dem or einige schwarze Borsten. Metanotum mit ockerfarbener Bestainbung und gleiehfarbiger feiner Behaarung. Schwinger lichtgelb. Hüften bei den or liranngelb, bei dem o schwarz, teilweise mit grauer liereifung und heller beharmug. 
A bdomen gleichmälsig schwarz, matt glänzend, mit durchaus weifser Beharmung, dic auch den honiggelben Bauch bedeckt. An den Genitalien finden sich einige läugere Borsten yon schwarzer Farbe. Die Discalborsten der ersten beiden Segmente sind weilslich.

Beine. 'Jrochanteren hell gelbbrann. or Schenkel durelscheinemi bell gelbbraun, an den Torder- und Mittelbeinen in grö́serer Ausdehmung geschwirzt, an den Hinterbeinen und an der Olserseite mit einem rotbrannen Längswisch. Schienen durchscheinend hichtgelb, an den Hintcrbeinen mit Answahme der Wurzel schwarz. Tarsen lichtgelb. q Schenkel mit Ausnahme der gelbbraun gefürbten Wrurzel und Kiniegregend göinzend dunkelbraun. J)ie Schienen sind an den vorderen beinparen durchscheinend lichtgelb, an den Hinterbeinen jedoch mit Ausnahme der Wurzel mo Spitze gebrïunt. 'Tarsen braun. Die Beborstung' und Beharung ist bei beilen Geschlechtern ammihermd die gleiche. An den Schenkeh ist die Beharung im wesentlichen schwarz, nu' die Hinterschenkel tragen an ihrer Enterseite weifsliche Wimperbeharung: Die Schienen besitzen hauptsächlich gelblichweifse Behaarung. anch dic dichte Wimperbehaarung an der Innenscite der Hinterschienen ist weilslich. Jie Tarsen fast durchaus mit selıwarzer Behaarmg. Biirstenformige Behaarung von fast goldgelber Farbe findet sich an der Unterseite der Schienen und Metatarsen der Torderbeine, vor allem aber auf der Unterseite der Metatarsen mnd der zunäclst folgenden Tarsenglieder der Hinterheine, die beim $\sigma^{\top}$ an ihrer Aufsenscite noch knrze weifse Wimperbeharung tragen. Dic nicht eben auffallende Behorstmog der Beine ist sehwarz, nur an der Wurzel der Mittel- und Hinterschenkel finiten sich noch cinige gelbliche Borsten ron anffallenderer Lainge. Kilauen gelbhraun mit schwarzen Spitzen. Pulvillen lichtgelb.

Flïgel mit gleichmälsig ranchbramacr 'T'ribung. Dic Randzelle mit deutlich dunklerer 'Trübung', die sich anch um die Fliigelspitze herum bogenförmign anshreitet. Adern dunkelbram, einzelne derselben mit dunkleren Adersiimmen.

Long: corl. 7,5-8mm, long. alar. $7-7,5 \mathrm{~mm}$. 
Als zweite Art ist mir bekimnt geworden:

$$
\text { Oidardis wenescens n. sp. q. }
$$

¿wei f atus Peru (Ueayaliflufs, Unimi) ex coll. Schnuse.

Am Kopfe ist die Anorduung und Firbung der gesamten Bestiiubung, Beharung und Beborstung ganz die gleiche wie bei O.gibbosu.

Thoraxricken und Sehildehen schwarz, stark glïnzend; mit sehr feiner Punktierung. Postalarhöeker diister rotbraun. Die feine Behaarung ist lurchaus gelblich, die Beborstung des Thoraxrandes und thes Schildchens jedoch schwarz. Plenra mit fast messinggelber Bestiubung, die an der Mesopleura besonders dicht ist. Notoplenralborsten und Metapleuralschirm gelb. Netanotum mit leichter, oekergelber Bestäubung und hellbrauner Behaarung. Schwinger lichtgelb. Hiiften gelb mit gleichfarbiger zarter Beharming.

Abdomen schwarz mit erzbranem Glanze und ziemlich grober Punktierung. Die Behaarung ist durchaus gelb, auch die Discalborsten an den Seiten der beiden ersten Segmente besitzen die gleiche Farbe. Banch lederbraun mit zarter, gleichfarbiger Behaarung.

Beine durchans gelb, die Schienen durchscheinend und namentlich an den vorderen Beinparen gelblichweils. Die Eudtarsen sämtlicher Beine leicht gebriimt. Auch die Behaarung und Beborstung ist allenthalben gelblich. Nur auf der Oberseite der 'Tarsenglieder finlen sich anch vereinzelte dunklere Borsten. Klauen gelb mit schwarzen Sjitzen, Pulvillen lichtgclb.

Flügel mit leicht brauner 'Triibung und lebhaft irisierendem Glanz. Die Flïgelwurzel ist gelb, auch die Wurzeln der im iibrigen braunen Adern sind gelb.

Long. corp. $4,5 \mathrm{~mm}$, Long. alar. $4 \mathrm{~mm}$. 


\section{Atomire.}

Das Genus wurde von Williston anfgestellt mul (Psyche T, 1s-9)

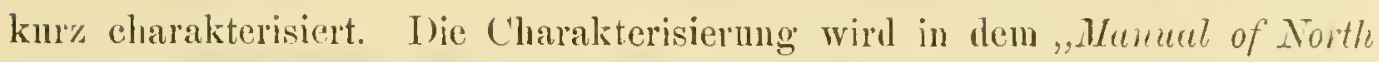
American Diptera, Third ellition 1908" wiederholt mul durch eine Abbildung des Kopfes unterstiitzt, so dafs ich iiber die Auffassmng des Genus keine Bedenken habe. 1)a die Untersuchung des reichen mir zu Gebote stehenlen Materials ergab, dafs einige sclon lange bekamte Atomosinen, sowie eine Reihe neuer Arten diesem Genns eingereiht werden miissen, so soll eine ansfiilurliche Darstellung des Gattungsbegriffes gegeben werden. Ist der Name Atonia (vgl. Kertéscä, Cutalogus) prïukkupiert, so mulste er in Atoniomyja umgeändert werlen.

Kleine, dureh anliegende meist gollgelbe Behaarung leicht erzschimmernde Arten vom Aussehen der echten Atomosien, von denen sie aber durch eine ganze Reihe plastischer Merkmale leicht zu unterscheiden sind.

K opf (Taf. Fig. 22 u. 23) verbreitert, ungefïhr doppelt so breit als hoeh. Das breite Gesicht ist am Mnndrande zu einem schwiicher oder stiirler vorspringenden rundliehen Ḧ̈eker aufgetrorfen und unter der Fïhlerwurzel mit einer lineiiren, narbenartigen Rimne verselıen. Der ziemlich dichte Knebelbart besteht aus langen Borsten und dazwisehen stehenden kilrzeren Haaren oder lediglich ans Borstenharen und erstreckt sich auch am Mrundrande nach abwïrts. Unter ler Fiihlerwurzel steht jederseits eine einfache oler mehrfache Reihe ziemlich langer, nach abwïrts gebogener Haare. Die Stirne erweitert sieh durch Ansbiegung der Orbitalrinder gegen den Scheitel zu betrïchtlich und ist am inneren Angenrande mit einer lieihe fast borstenartiger Haare besetzt. Der Scheitel triigt diehte, weiche Beharmug; nur bei einer einzigen Art fehlt aliese und wird durch eine Gruppe kurzer, starrer, stiftartiger Borsten ersetzt. Der stattliche Ocellarhücker ist mit 2-6 langen Borsten bewehrt. Das Hinterhan is ist oben mit zerstreuter, nach abwiilts mit lichter liehaarmug versehen, die in den langen und diehten Backenbart iibergeht. Iie Oecipitalborsten beschränken sich auf den oberen T'eil des Hinterhauptes und reichen kamm iiber die obere orbitalecke nach answïrts. Die medial stehenden Borsten sind in kurze, starre Stifte ungewanlelt, lie nur bei 
cincle Art fichlen und durclu zarte Haare ersetzt werilen. Der an seiner Wurel lang behaute hiissel iiberragt in anfocklapptem Zustande den Mundland nicht, die an der Spitze behaarten 'Taster sind klein mu mansehnlich. Ile Fibler sind relativ kurz, namentlich gilt dies fiil die beiden gleichlangen wenig beharten Basalglieder. Das erste Segment entbehrt an seiner Coterseite ler cinzelnen, bei den meisten Atomosinen vorhandenen langen Borste, lagegen trigut das zweite Glied distal einige längere Borsten. Das ungefailır keulenfïmige, seitlich leicht kompresse dritte Segment ist mgetaihr doppelt so lang als die beiden Basalglicder zusammengenommen und mit cincm stattlichen, meist nach abwärts abgeknirkten Endgriffel rersehen. an dessen oberem hande ler sehr dentliche, häufig anf stumplf liegrelförmig erweiterter Basis steliende Zahngriffel eingelenkt ist.

'T'hol'ax mur seluwacl gewölbt mit dichter aber feiner Punktierumg' und gleirhmil'sig mit knrzer, anliegender meist heller Behaarmg bedeckt. Unter diese mischen sieh bei den meisten Arten längere, abstchende, fast borstenfömige Haare, die bei einer Art ganz besonders ausgebreitet und lang sind. Rei einigen Arten besitzt der lintere Land las Mesonotum ror dem Srhildchen eine durch helle Bestiubung gebildete Saiumung. Beborstung : prisutural 1-2, supraalar 1-2, postalar 1, notopleural 1-2. Metapleuralschirm lang. Anch das Schildehen ist mit anliegenden Haren besetzt, die liamilueharmug ist meist kur\%, oder fehlt ganz; nur bei einer Art zeichnet sie sich durch besonele I äinge aus. Borsten feblen rollstindig. Das collare entbehrt ebenfalls der Beborstung und ist nur mit feinen Haaren besetzt. Ilagegen ist hei zwei Arten der Prothorax mit mehr obler weniger alusgebreiteten stiftchenartigen, kurzen Borsten hesetzt. Das Metanotum

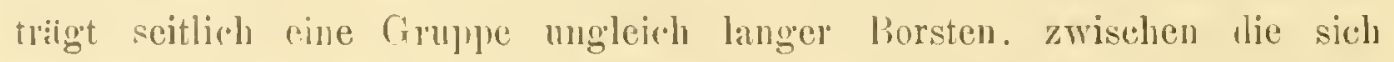
eventucll zarte Hande mengen. Jie l'lenren sind mit Ausnalume einer anf der Mesoplema stehenten ohrförmigen, gäunzenden Makel gleichnälsig mit dichter bestaiubmo versehen, die sich anf ilun Prothorax fortsetzt mul hei cinigen Arten auf die Srhultergegend des Mesonotmu iibergreift. Die Mesopleura hesizt bei gewisecn Arten in den oberen I'artien die griibehenfumige

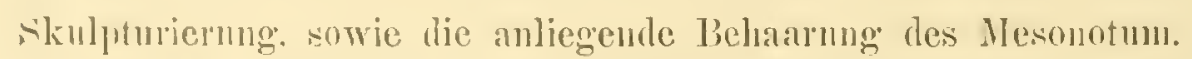

lhas entwerler hreite aler mehr streifenfömige $A$ bolomen setzt sich ans sechs von ohen sichtbaren Segmonten zisammen, das sicbente und die 
kleinen Genitalsegmente sind ventral verlagert. Die Segmente sind durch relativ tief eingreifende Finschnitte roneinander getrennt, erscheinen dadurch gewulstet und sind an ihrer ganzen Fliiche mit dichter und grober Punktierung versehen. Dic dichte, anliegende, meist lichte Beharung bedeckt das Abiomen entweder gleichmaisig oder fuihrt zu binden- oder fleckenartigen Zeichnungen. Die Seitenbehaarung' ist knrz, Discalborsten an allen Segmenten vorlanden. Bei einer Art ist die Seitenbehtarnng lang, fast schopffürmig abstehend und finden sich Disealborsten nur auf den vorderen Segmenten.

Die schwarzen, höchstens an den Knien helleren Beine besitzen in ihrem Ban keine besonteren Merkmale. Die anliegende oder abstehende Behaarung ist vorwiegend weilslich, die 'T'arsen sind an ihrer' Unterfliche, die Vorderschienen an ihrer Innenseite mit der gewöhnlichen bürstenförmigen Beharung versehen, die lichte Wimperbehaarung nimmt die Vorderseite der Hinterschienen in gröfserer oder geringerer Ausdehnung ein und findet sich eventuell auch auf der Unterseite der Hinterschenkel. Die zahlreichen Borsten fallen namentlich an den Schienen und Tarsen durch ilıre erhebliche Liinge und Stiirke auf. Bei einigen Arten finden sich an dem Metatarsus der Mittel- oder Hinterbeine bei den or eigentiumliche Haarbildungen. Die Empodialborste fillt oft durch ihre Derbleit auf.

Die meist schwach grau tingierten Fl iigel sind hyalin. Der mälsig lange Stiel der Subcostalzelle ist nur wenig nach oben gebngen, die kleine Querader steht iiber der Grenze des basalen Drittels der Discoidalzelle oder ist auch etwas mehr gegen deren Mitte versehoben, die die Discoidalzelle und die vierte Hinterrandzelle distal abschlielsenden Queradern zeigen in ihrer gegenseitigen Lage ziemlich weitgehende Varianten nach Art und Individuum. Der kurze Stiel der vierten Hinterrandzelle erreicht den Fliggelrand nicht immer, die Analzelle ist kurz gestielt, die erste und zweite Hinterrandzelle nur wenig gegen den Fliigelrand verbreitert oder verengert.

Als typische Art gilt

\section{Atonia Mickii Williston}

alls San Domingo. 
In der Biologia Centrali-Americana beschrieb der gleiche Autor eine zweite Art

\section{Itomia brevistylata Williston}

aus Mexico.

Keine der mir vorliegenden Arten konnte icls mit diesen beiden W'illistonschen Speeies identifizieren, die zugleich das nördlichste Torkommen des Genus Atomia angeben, das im ïbrigen nach unseren bisherigen Jifalıungen ausschliefslich auf die siilamerikanische Fauna beschränkt ist.

Die mir bekannt gewordenen Atonianarten lassen sich durch folgende amalytische 'Tabelle bestimmen:

1. Gesichtshöcker nu' sehwach angedeutet, Endgriffel des dritten Fiihlergliedes lureit zapfenfïmign, nicht abgelnickt, Prothorax mit kurzer, dornartiger Beborstming.

- Gesichtshïcker schr dentlich, Fndgriffel schlank, konisch, nach abwiats abgeknickt, Prothorax olne auffallende Beborstung:

2. Die Beharung des Scheitels ist durch einige stiftartige, kurze Borsten ersetzt; Ocellenlı̈eker mit zwei Borsten. viduata Wiel.

- Der Srheitel mit langen Haaren besetzt: Ocellenhöcker mit sechs Borsten.

$$
\text { setigera n. sp. }
$$

3. Occipitalborsten schwarz, in der Mitte jederseits eine Gruple kurzer stiftehenartiger, ebenfalls schwarzer Borsten.

- Occipitalborsten gell, stiftchenartige Borsten nicht vorlanden.

mollis n. sp.

4. Mesonotum ausschliclislich mit kurzer, anliegender Behaarung ron messing- bis goldgelber Farbe versehen. Abrlomen nit durch anliegender, auswärts gekimmter Behanung erzengter auffallender wiirfelartiger Schillerzeichnung. Scalarata n. sp.

- Zwischen die anliegende Behaanng des Mesonotuin mischen sich in griifserer oder geringerer Menge nach linten lïnger werlende abstehende Borstenliare von schwarzer Farlue.

5 .

5. Jie anliegende lichanung des Mesonotum ansschliefslich dunkel. 
- Die anliegende Behaarung des Mesonotum aussehliefslich messing- oder goldgelb.

6. Die abstehenden Borstenhare des Mesonotum sehr lang und dieht, Schildehenrand mit auffallend langen, aufwärtsgebogenen Haaren. Seitenbehaarung des Abdomen lang, Discalborsten mit Ausnahme des ersten Segmentes fehlend. hispidella n. sp.

- Die abstehende Beharmng nur wenig dicht und von mä́fsiger Länge, Randbehaarung des Schildehens kurz oder nur maifsig lang. Seitenbehaarung des Abdomen kurz, Discalborsten vorhanden.

7. Behaarung des Gesichtes und die kürzeren Haare des Knebelbartes weifs. Das Abdomen gleichmärsig von anliegender heller Beharung: bedeckt. albifacies n. sp.

- Behaarung des Gesichtes durchans schwarz, auch die kürzeren Haare des Krnebelbartes sind vorwiegend schwarz, nur ausnalımsweise stehen am Mundrande einige hellere Haare. Die anliegende helle lBeharming des Abdomen verdichtet sich zu Binden oder Flecken. 8.

8. Randhehaarung des Schildchens sehr kurz. fast fehlend. Die ansschliefslich goldgelbe: anliegende Behaarmng des Abdomen breitet sich auf den Segmenten bindenartig ans. Metatarsus der Hinterbeine des $O^{7}$ an seiner Spitze mit einem Pinsel langer Haare. Plumpere, grö́sere Art.

ancylocera schiner.

- Das Schildehen trägt wenig'stens seitlich längere Haare. Die Abdominalsegmente besitzen seitlich aus silberweifser Beharung bestehende Hinterrandtleeken. Der Metatarsus der Hinterbeine beim ơ ohne auffallende Behaarung. Kileine, schlankere Art.

laterepunctata n. sp.

Atonia (Laplevia) viduata Wied.

Es liegen mir die Typen Wiedemanns $\left(1 o^{7} 4 q\right)$ aus dem $k . k$. Hofmuscum in Wieu vor. Schiner stellte die Wiedemannsche Species viduatu zu Atomosia, machte jedoch (Terk. d. zool. bot. Ges. Wien 1867) darauf anfmerksam, dafs sie durch den Besitz eines Endigriffels von allen iibrigen 
Atnmosianten abweiche. Hie nähere Untersuchung des 'lypenmaterials

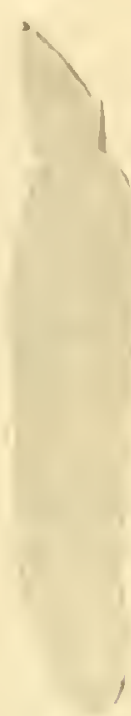

Fig. 30 . ergal, mun, dals die Spec. vinuatu dem Genus Atonia subsummiert werden muls, zu dem sie nieht nur dureh das Vorhamlensein eines Eudgriffels (Textfig. 30), sondern auch durch den eharakteristischen Ban des Kopfes und alle anderen plastischen Merkmale mit aller liestimmtheit gehört. Aber unter ilnen Gattungsgenossen nimmt die Spec. viduata doch insofern eine Ausnahmestellnng ein, als bei ihr die heharmng des Srheitels vollstindig fehlt und durch einige wenige dicke, nagelartige Borsten ersetzt wird. Solche finden sich auch anf dem Hinterluant, wo sie eine iiber die Mcdianlinie linübergehcnde Reihe bilden. Eudlich kommen auch in der Mitte des Prothorax einzelne derbe, kurz stiftfürmige Borsten zur Beobachtung. Durch diese Beborstungsverhailtnisse ist die Spec. viluata in so kurzen Beschreibung Wiedemanns ausfiblichere Angaben beiznfiigen.

\section{Atonia setigera n. sp. + .}

In der Wrinthemschen Sammlung des k. k. Hofnuseums fand sich ein cinzelnes Exemplar cincr etwas eigentimlichen Atomosine mit der Bezettchung: Atomosia nigripes Meq. Diese Bestimmung ist sicher nicht rielitig; da das Tier mit der Macquardschen Beschreibung' mmöglich in Einklang gebracht werten kann; dagegen ergab sich, dafs es sich dabei mu eine Atomia handelt. die in die mäichste Nachıarschaft vou A. viluata ggehört, von dieser aber sich unschwer dnrch gewisse plastische Merkmale unterscheiden liifst.

Das Gesicht ('Thf. Fig. 24 u. 25) ist entschieden schmiler als bei Spec. viduata, der Scheitel trïgt lange Iaare, der lerbe, zapfenfümige Endgriffel dev Fühler ist durchaus pubescent, der Ocellenlücker ist mit sechs livergierenden borsten bewehrt, besonders aber fiillt auf aler Mitte des Prothorax ein mit kurzen stiftförmigen Borsten von schwarzer Farbe besetztes Areal auf.

Kopf. Gesicht, Stirn uml Seheitel ockergelb bestïulıt; die gesaute Behaarung und Beborstung des Kopfes und der Fiilıler ist schwar\%, nur 
der Backenbart und die Behaarmng der Kinngegend, des Rüissels und der Tister weils. Auch die Bestänbung am linteren Angenrande ist weifs.

'Thorax. Mesonotum glänzend schwarz, sehr derb punktiert und mit gellber anliegender Behaarung besetzt, lie am Seiten- und Vorderrand derber ist und Goldglanz besitzt. Die längeren dorsocentralen Haare sind schwarz, ebenso wie die gesante Beborstung. Pleuren grangelb bestiubt, die Mesopleura ist kahl und glänzend, in ihren oberen Partien punktiert und mit anliegender gelber Behaarung versehen. Metapleuralschirm bräunlich, die Schwinger hellgelb. Das ockerbram bestäubte Jetanotum besitzt eine Schiefreihe grober schwarzer Borsten.

Abdomen glänzend sehwarz und schr grob punktiert; die anliegende Behaarung ist lichtbram, an den Seiten etwas länger und weifs, so dafs an den einzelnen Segmenten ziemlich ausgedehnte Vorderrandflerken entstehen. Discalborsten falligelb.

An den schwarzen Beinen ist nur die äufserste Kniegegend diister rotbrann. Ije kur\%e, wenig dichte Behaarmug ist lichtbrïunlich, an den Tarsen schwarz. Die büirstenförnnige Behaarung letzterer, sowie der Vorderschienen lebhaft goldgelb, die Wimperhare bleichgelb. Die zahlreichen groben Borsten sind vorwiegend schwarz, nur die Unterseite simtlicher Schenkel ist mit langen, weifslichen Borstenhaaren besetzt. Klanen schwarz, Pulvillen lichtgelb, die kräftige Empodialborste rotbrann.

Flïgel gleichmilsig bräunlich tingiert mit grober, dunkelbrauner Ïderung. Erste und zweite Hinterrandzelle breit offen, nicht verengert.

Long. eorp. $8 \mathrm{~mm}$.

Nota. Die beiden Species viduata und setigera bilden eine kleine Untergruppe des Genus Atonia, die sich von den ïbrigen Gattungsgenossen

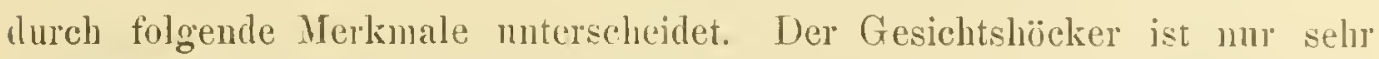
schwach angedeutet, das dritte Fühlerglied besitzt einen zapfenförmigen, eventuell pubescenten, nicht abgeknickten Endgriffel, der Prothorax ist in seiner Mitte mit einer grö̈seren oder geringeren Anzahl kurzer domfürmiger Borsten bewehrt. Eine generische Abtrennung der beiden genannten speries schien mir trotzdem nicht notwendig zu sein. 


\section{Atonia ancylocera Schin.}

Auch von dieser Art komute ich die Typen ans dem k. k. Hofmuseum untersuchen. 1)ie Beschreibung Schiners ist ausfiihrlich genug, um die, sich durch ihren breiten, gedrungenen Habitus auszeichnende Species zu erkemen. Ich mache hier nur anf einige llastische Verkmale anfmerksam, die Schiner anscheinend entgangen sind. Die Gestalt des dritten l'iihlergliedes ergilst sich ans Textfigur 31. Anf dem Hinterhanpte findet sich anfser den gewöhnlichen Occipitalborsten neben der Medianlinie jederseits eine Gr'ulpe kurzer, stiftchenartiger Borsten. Fine Reihe solcher befindet sich anch auf dem Metanotum. Die Mesoplenra ist oben punktiert und mit anliegender heller Beharmng verselien. Sehr eigentimmlich ist endlich der Ban des Metatarsus (Textfig. 32) an den Hinterbeinen der ot.

Fig. 31. Er ist an seiner IInrel verdickt und hier mit einer Floeke biirstenfürmiger, goldgelber

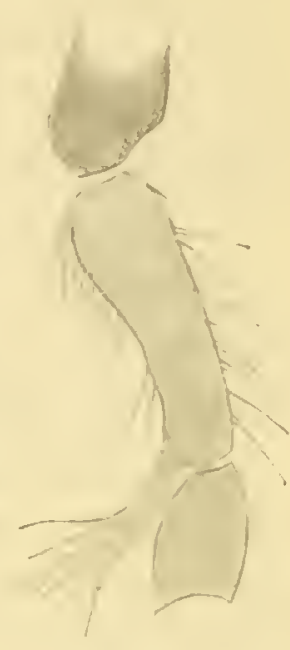

Fig. 32.

Behaarmng versehen, verjiungt sich dann und triagt an seiner Spitze auf einem derlon Höjker einen Pinsel langer, gelber Hiare.

\section{Atonia mollis 11. sp. Ot.}

Fünf Exempline ans l'eru (Ueayalithls, Unimi $300 \mathrm{~m}$ ï. d. M.) ex coll. Schnuse und ein Fxemplar ans Peru (Vilcanota) ans der Sammlung des k. 1ungan?. Nationalmuseums in Budapest.

Kopf. Gesicht mit weilshicher, an Angensande gelber Bestäubung. 1)er Knehelhart besteht aus wenigen schwarzen oler bleichgelben langen Borsten, lie sich dazwisehen mengenden feineren Haare, sowie die Behaarmug des Gesichtes ist ansschliclsich hleichgell. Stirne, Scheitelgegend und Hinterhanpt weilskich bestïulst und bleichgelb behart. Anch die zarten, nie spicfisartigen Uceipitalborsten, sowie die beiden Borsten des Ocellar- 
höckers sind gelh. Der Backenbart, die Behaarung der Kinngegend, der pechbramen Taster und des Riissels weifslich. Die schwarzen Fiiller (Textfig. 33) erscheinen dureh gelbliche Bestïubung etwas heller, die beiden Basalglieder sind knrz sehwarz behart, ter dentliche Zahngriffel ist an der Anlsenseite les Endgriffels befestigrt.

Thorax schwarz mit kaun wahrnehmbarer Punktierung und gleichmälsig mit ziemlich dichter, kurzer, anliegenter Beharung von goldgelber Farbe belcekt. Dieser mengen sich anf der Mitte abstehende, namentlich vor dem Schildchen lïngere bleichgelbe Haare bei. Dic prisuturale Borste ist schwarz, die iibrigen Randlorsten jeduch sind gelb. Das Sehildehen ist ebenso wie das Mesonotum goldgelb behaart und an seinem Rande mit einer Reihe nach aufwärts gebogener, ziemlich langer gelber llare hosetzt. Tor dem Schildehen ist der hintere Rant des Mesonotum durch weilse. fast silberglänzende Bestänbung goesiinmt. Pleuren und Hiiften gleichmäfsig mit gelblicher Bestiubung bedeckt, die nur anf

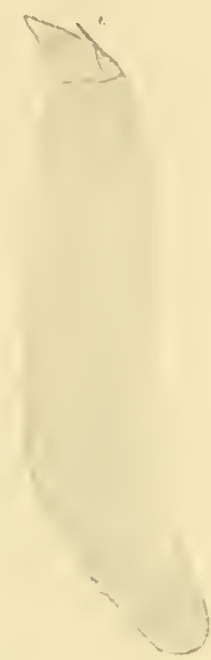

Fig. 33. iler Mesopleura die Grmulfarbe in Form einer olnfürmigen, glinzend sehwarzen Stelle freilifst. Die Notoplemralborsten sind ebenso wie der ror den brännlichgelben Schwingern stehende Mctapleuralschirm bleichgell, die gleiche Farbe besitzt anch tie zarte und zerstrente Beharmig der Pleuren und Hiiften. Das fast silberweils bestiunbte Mctanotım trägt seitlich einige wenige brïunliclıe Borsten und weil'sliehe Behaarung.

Abdomen. Die sehwarze Grundfarbe verschwinlet mit Ausnahme der Segmenteinschnitte fast vïllig unter dichter anliegenter goldgelber Behaarung, so dals das Abdomen, von oben betrachtet, einen matten Goldbronzeton zeigt. Betrachtet man aber den Hinterleil schief von linten. so wird die dunkle Grundfarbe sichtbar, von ler sich matt goldgefurbte Hinterrandflecken abheben. An den Seiten wird die Belnarung länger und abstehend, und nimmt fast silberweifse Fürbung an; Discalborsten von bleichgelber Farlo finden sich nur auf den ersten vier Segmenten. banch mattbraun mit dichter, anliegenter, gelblicher Bchaarung.

Beine schwarz, lie Kniegegend, das proximale brittel simmtlieher Sehienen und die Wurzeh der 'Tarsenglieiler gelbbraun. Die Beharung Nova Acta XCVI. Nr. 1. 
ist ansmalmslos 1) leirhgelh his weifslich, aneh die Borsten besitzen mit Ausnahme einiger weniger schwarzer an der $\lambda$ ufsenseite der 'Tarsen die gleiche Farbe. lie hiirstenfïmige Rehaarung der 'T'arsen ist gelb, die Wimperhehaarmug der Ilinterschienen weifslich. Kianen schwarz, Pulvillen bleichgelb.

Flitgel hyalin, die Arlem dunkellorann. Der kurze Stiel der Analzelle erreicht den Fligelrand nicht ganz.

long. copp. $7.5 \mathrm{~mm}$, long. alar. $7 \mathrm{~mm}$.

Atonia pinguis n. sp. ?.

Zwei Exemplare ans Peru (Pachiteamiindung, $150 \mathrm{~m}$ ii. d. M.) ex coll. Sohnuse.

Gesanthabitus ziemlich geilungen.

Kopf. Gesicht, Stime und Seheitel gleichmilsig mit gelber, am Mundrande etwas hellerer Bestäulung bedeckt und durehans sehwarz hehaart.

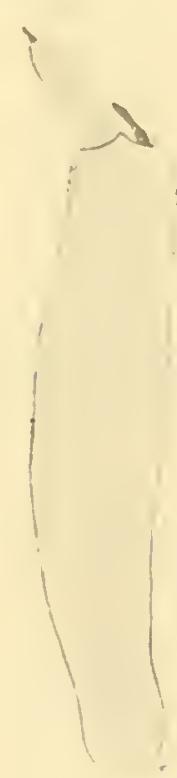
Aneh der Knehelhart hesteht ausschliefslich aus schwarzen Borsten. Ilinterhaupt grangelb hestaiulot und oben zart schwarz behaart. Die Oecipitalhorsten. deren am weitesten medial stehende kurze Stifte darstellen, sind durchaus schwarz. Nach abwärts wird bestänbung und Behaarung des Hinterhauptes weils, ebenso ist der Backenbart weifs. Riissel und Taster dunkelbram mit rorwiegenl sehwarzer Beharung, anch die Kinngegend trïigt im wesentlichen dunkle Haare. Dic zwei Borsten des Ocellenhöckers sind schwarz. Die schwarzen Fiihler (T'extfig. 34) sind tcilweise ron ockerbramer Bestimbung bedeckt, das erste Glied ist etwas liiirzer als das zweite, das gegen sein distales Ende leicht puheseente, schwach kenlenförmige dritte Segment ist mugetäh doppelt so lang wie die heiden basalglieder zusammengenommen. ler relativ lange, an seinem linde dornfürnigg zn-

Fig. 34. gespityte lindgriffel ist sehief nach ahwiirts gerieltet, der lange, trommelschlegelförmige Zahngriffel inseriert ciner belle des driften Segmentes. Die behanrung der Fiihler ist schwarz.

'Thorax. Mesomotum und Schildehen ggleichmälsig ziemlich groh junktiert und mit kurzer, anliegender, hinten nu wenigg lingerer Beharung 
vou brauner Farbe beleckt, der, wenigrstens bei dem einen Exemplare. sehr zerstrent anch goldgelbe Haare beigemengt sind. I) Seitenborsten iles Mesonotum und die kurze Behaarung des Schildchemrandes schwarz. An ler Basis des Schildchens ist das Mesonotum sehmal silberweifs gesäumt. Die Plenren und der Prothorax sind gleichmälsig mit reilser Bestiubung bedeckt, die anf iler in ihren oberen Partien punktierten und hell behasten Mesoplenra eine oluförmige stelle freiliist. Die Beharmug ist weilslich, die Notopleuralborsten un der ror den gelben Schwingern stehende Metapleuralsehirm sind bleichgelb. I)ie Borsten und Harre les weifsbestäubten Metanotum sind sehwarz. Die feine Beharmng des Collare ist brïunlich.

Abdouen glinzend schwarz mit sehr derber Punktiermng und knrzer, auliegender, hauptsïrhlich schwarzer Behaarung. Die mittleren Segmente (3-5) besitzen seitlich aus silberweifsen mul einzelnen goldgelben Haaren bestchende Flecken. die bei gewisser Belenchtumg breite, in der Mitte muterbrochene Binden bihlen. Auch das scchste Segment ist in seinen liuteren Hailfte mit silberweilsen Haaren besetzt. Die lïngere Seitenbehaarmg ist weifs, die Disealborsten (1. Segment 4-5, 2. Segment ? die Segmente $3-5$ je 1) sind bleichgelb. Das scelste Segment trägt seitlich eine Grupue teils bleichgelber, teils schwarzer längerer Borstenhaare. Der schwarze, teilweise ockerbran bestiubte Banch besitzt gröstenteils schwarze Beharung.

Die durchaus schwarzen Beine sind rorwiegend mit weifser Beharung versehen, die an der Anfsenseite der Schienen und der Oberseite der Tarsen besonters dicht liegt. Die biirstenförmige behaarung' der 'T'arsen, sowie der Innenseite der Vorderschienen ist exquisit goldgell, die dichte Wimperbehaarmng der Hinterschienen gुelblich. Die goroben und langen Borsten der Schienen und Tarsen sind Iurchans schwarz. Die Schenkel sind an ihrer Unterseite mit langen gelblichen Haren, die Mittelschenkel anfiserdem wahe ihrer Spitze mit einer einzelnen groben, schwarzen Borste rersehen. Klanen schwarz, l’ulrillen fahlgelb.

Flïgel lyalin; braune 'Trübung' schliefst sich wolkenartig' den schwarzen dicken Ailern an und füllt einzelne Zellen eventuell ganz ans. Long. eorp. 8 mm, long. alar. 6,5 mm. 


\section{Alonia scalarata ơ $q$ n. sp.}

33 Exemplare beiderlei Geschlechts ans J'eru (Rosalina, U'ubambaHuls $700 \mathrm{~m}$ ii. 1. М.) und Bolivia-Mapiri (Chimate $650 \mathrm{~m}$ ii. d. M.) ex coll. Silhuluse.

Kopf. Gesicht, Stine und Seheitel ghleichmärsig mit gellyliehweilser oder weifsgrater Bestiubung bedeckt. Der Kuebelbart, der aus ilerben

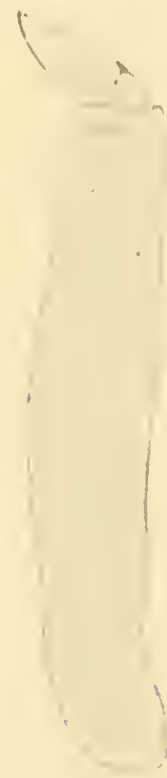

Fig. 35 . Borsten und dazwischen stehenden feineren Iaaren bestelit, ist ebenso wie die Beharmig des Gesichtes mod der Stime im allgemeinen schwarz; nu bei einigen Jxemplaren sind die Haare des Gesichtes nud des Kinebelbartes teilweise bleiehgelb. Die Oceipitalborsten und die beiden Borsten des Ocellenhöckers sind sehwarz; lie liehamung des Scheitels, des weifs bestimbten Ilinterhanptes, der Kinngegend, sowie der Backenbart weifs. Der braune Riissel ist mit wenigen hellen Haaren versehen. An den schwarzen Fiihlern (Textfig. 3j̃) sind die beiden Basalglieder an ihrer Anlsenseite mit weifsgrauer Bestänbung versehen, das zweite Segment und die Oberseite des ersten Segmentes schwarz belaart, an der Unterseite des letzteren fintet sicls anch weifsliche Behaarung. Der derbe Griffel des vome quer alggestutzten dritten Segmentes ist leicht pubescent, der auf kegelfirmiger Basis stehende Zahngriftel ist mur sehr kurz.

'Thorax. Mlesmotmm un Schildehen schwarz mit feiner, aber selir dichter Punktiermng und gleichmälsiger kurzer, anliegender liehaarmng von messinggelber Farbe, die sith seitlieh anch anf den oberen Teil der Mesopleura fortsetzt. l)ie Seitenborsten des Mesonotum, sowie die kure anfwairts gelongene Randbeharung des Schildehens schwarz. Pleuren und l'rothorax mit Ausmalme der ohrförmigen Seitemakel gleiehmifsig mit melir oder minler gelbgraner liestänbung nud zerstrenter, bleichgelber Beharangon bedeckt. Notopleuralborste schwar\%, der vor den lielitgelben Schlovinger'n stehende Jetapleuralschirm bleichgelb. Das grau oder weilshich bestinlbte Iletanotum trägt eine Schiefreihe schwarzer Borsten. Hiiften ug(t)grau, bestäul)t und hell behaart. 
Abdomen sehwarz, dicht pmiktiert und allenthalben mit dichter, anliegender Behaarung von teils goldgelber, teils weifser Farbe besetzt. Diese Behaarung ist in der hinteren Hälfte der Segmente von der Mitte aus seitwärts gekïmmt; dadurch bekommt der Hinterleib eine Riickenlinie nud es entsteht cine wiirfelfürmige Schillerzeichmung, deren Ausdelnnung nud Anordnung ganz von der Riclıtung der cinfallendeu Beleutltung abhängt. Die kaum längere Seitenbeharung ist im wesentlichen weifs, auch die Spitze des sechsten Segmentes ist hauptsïichlich mit weilsen Haaren bedeckt. Die Discalborsten sind fahlgelb. Der braune Banch ist teilweise ockerbram bestäubt und mit zerstrenter gelber Behaarung versehen.

Beine dunkelhraun bis schwarz, olme jede hellere Zeichunng, mit allenthalben weilser Behaarmg bedeckt. Die krïftigen Borsten sind an den Schienen vorwiegend fahlgelb, an den Tarsen hauptsäellich schwarz. Die bïrstenförmige Behaarmng an der Innenseite der Vordersehienen und der Unterseite der Tarsen ist mehr oder weniger lebhaft goldgelb. Auf der Mitte des Metatarsus der Hinterbeine fehlt sie vollständig, so dafs dieser dadureh seheinbar eine Einschniirung erhält. Die kurze Wimperbehaarung der Hinterschienen ist fahlgellb. Klanen schwarz, Pulvillen lichtgelb.

Die kaum merklich rauchgrau tingierten Flïgel sind hyalin, die hintere Basalzelle glasartig durchscheineml. Die Äderung ist schwar', nur an der äufsersten Fligelwurzel teilweise lichtloram.

Sexuelle Differenzen sind nicht zu beobachteri.

Long. corp. $8,5 \mathrm{~mm}$, long. alis. $6,5 \mathrm{~mm}$.

\section{Atonia laterepunctata. ot o n. sp.}

52 Exemplare beiderlei Geschlechts ans Peru (Pachiteaniindung $150 \mathrm{~m}$ ii. d. M.. Urubambaflufs - Umaluuankiali $500 \mathrm{~m}$ ii. d. M., P'uerto Yessup $300 \mathrm{~m}$ ii. d. M.) und Bolivia-Mapiri (Sarampioni $700 \mathrm{~m}$ ii. d. M.) ex coll. Schunse und zwei Exemplare aus Peru (Tileanota) aus der Sammlung des k. ungar. Nationalmuseums in Budapest.

Kopf. Gesicht, Stirne und Scheitel gleichmailsig mit goldgelber Bestïubung bedeckt. Der Knebelbart besteht aus schwarzen Borsten, denen in relativ geringer Menge gleichfarbige kürzere Haare beigemengt sind. 
Lnter ler Fihhlerwurzel steht jederseits eine einfarhe Längsreihe schwarzer, abwirts gelongener Haare. Die Stirne besitzt aussehliefslich schwarze, der Scheitel teils schwarze, teils gelbliche Behaalung. Der ()ecllenlï̈ker trïgt zwei lange liorsten und zwei kiirzere Halare voll schwarzer Farbe. Hinterhaupt oben mit goldgelber, unten mit weifser Bestïnbung bedeckt und weifslich behart. Die Oecipitalborsten sind schwarz. Backenluart, Behaarung der Kinngegend, der pechloramen Taster und des Riissels weilslich. Die relatir kurzen Fiihler sind schwarz (Textfig. 36), das dritte Segment sowie lessen Endgriffel zeigt sich bei starker Vergrörfserung stellenteise leicht pubescent, der lange Zahungriffel

Fig. 36. steht auf einer kegelfürmigen Terbreiterung. Die Jeilen Basalglieder siml schwarz behart und beborstet.

Thorax. Mesonotum, Sehilddien und obere Partie der Mesoplenra schwarz mit leichtem Eirglanz und dichter, feiner Punktierung. Der dichten, anliegenden. mehr oder minder golilgelben Bcharung mischen sich nach hinten zu länger werdende, aufrecht stehende llaare von schwarzer Farbe bei und anch das Sehildehen trïgt auf seiner Fliiche sowohl wie an seinem freien liande solche längere Behaarung. Randborsten des Mesonotum schwarz. Die Plenren sind granweifs, vorne und am Prothorax goligelb bestäubt, die Notopleuraluaht ist durch silberwei'se Bestäubung gesiiumt. Beharmug ler I'leuren gellulich. Notopleuralborste meist schwary, der vor den gelben Schwingern stehente Metapleuralschirm fahl. Die Borsten des weilslich hestäubten Metanotum schwarz; Hiiften mit weilslicher bis goldgelber I3estainlung und lichaarung.

Ablomen schwarz, leicht erzglänzend mit sehr dichter groher Punktierung. I)ie anliegente Behaarung zeigt nach Dichtigkeit und Farbe bräunlich lis goldgelh - weitgehende indiviluelle Schwankungen, stets finden sich aher am Seitenrande der Segmente ans silberweifsen, längeren Haaren gebildete Hinterrandtlecken. Die Seitemheharmug ist im uibrigen, mit Ausnahme des crsten Segmentes, kurz, die Discalborsten sind fahlgelb. bameh dunkelhrann mit dïmer grauer bereifung und gelher Behaarung.

lieine nit Ausnahne der gelbbrannen Knie selwwarz mit weilslicher

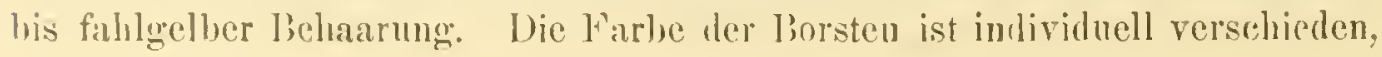


doch ist sie wenigstens an den vorderen Beinparen meist rorwiegend schwarz. Jie bürstenfürmige Behnarung ist messing- bis gohlgelb und an ten T'arsen der Vorderbeine meist nm spärlich rorhanden. Die zarte Wimperbeharung der Hinterschienen bleichgelb. Klanen schwarz, Pulvillen lichtgelb.

Die nur sehr schwach braun tingierten Fliigel hyalin mit schwarzen Adern. Der Stiel der vierten Hinterrandzelle erreieht den Flïgelrand, die erste Hinterrandzelle ist schwach erweitert, die zweite Hinterrandzelle etwas verengert.

Sexuelle Differenzen sind nicht vorhanden.

Long. corp. 6 mm, long. alar. $5,5 \mathrm{~mm}$.

Atonia hispidella n. sp. ơㅇ․

Fïnf Exemplare dieser sich durch ihre Selłlankheit und die ungewöhnliche Länge der Behaarmng anszeichnenden Art ans Brasilien (Sa Paulo) ex coll. Bezzi.

Kopf. Gesicht, Stirne und Scheitel gleichmälsig mit grangelher bis goldgelber Bestäubung bedeckt. Der dichte Knebelbart besteht ausschliefslich ans langen Borstenhaaren mud ist ebenso wie die lange Behaarung des Gesichts, der Stirne und des Scheitels schwarz. Das Hinterhanpt ist in den oberen Partien ockergelb bestäubt und mit einzehen schwarzen Haaren besetzt, nach abwärts wirl sowohl die Bestänbung wie die dichtere Behaarung weils und geht in den gleichfarbigen langen Backenbart iiber. Die Reihe der schwarzen Occipitalborsten breitet sich etwas weiter seitwärts ans als bei den iibrigen Arten. Der Ocellarhüeker triigt vier lange Borsten. Lie lange Behaarnng der Kimngegend, des Riissels und der 'Taster ist weitslich. Die beiden Basalglieder der schwarzen Fïhler sind weifsgran bestiäubt und schwarz beborstet und behart, anch der sehr kräftige, in eine kleine spitze zulanfende Endgriffel des dritten Segmentes ('Textfig. 37) ist medial hell bestänbt.

Thorax. Mesonotmu und Sehildchen schwarz mit sehr dichter aber feiner Punktierung; das Mesonotmm ist an seinem Hinterrante durch gelb- 
graue Bestäubung gesiumt. Zwischen der anliegenden, dichten gooldgelben Beharıng' breiten sich iiber den ganzen Thoraxrieken lange, abstehende, fast borstemartige Haare von soluwarzer Farbe aus und auch der Rand des Schildchens ist mit lungen selwwarzen, anfwäts gebogenen Haaren besetzt. Die Seitenborsten des Mesonotum ebenfalls schwarz. Die Plenren sind mit weilsgraner Bestäubung bederekt und zart bohart, ror der Fliigelwurzel, in den oberen Partien der Mesopleura und am l'rothorax ist die Bestäubung ockergelb und zieht sich vou hier iiber lie Suhultergegend etwas auf llas Mesonotum enupor. Notoplemalborste schwarz. der vor den gelben Schwingern stehende Metapleuralsrhim fahlgelb. Das weifsgrau bestäubte Mctanotum trägt seitlich zicmlich lange schwarze borsten und zwischen ihnen lielle feincre Haare. Hiiften grau bestainbt und weifslich behaart.

Das streifenfömige Abdomen schwarz mit diehter grober l’unktiermug. Die anliegende Beharung ist auf dem Abdominalriicken rorwiegend braun und äulserst fein, wird aber lateralwärts länger, goldgelb bis weifslich und legt sich an den Hinterrändern der Segmente zur Bililung von Halbbinden zusammen, deren Ansdehnumg freilich von der Richtung der jeweils einfillenten Belenchtung lecht abhängig ist. Das sechste Segment ist auf seinel hinteren Hälfte mit längeren weifsen Halren gleichmälsig beleckt und an seincm Rande mit langen fahlyelben Borstenlaren besetzt. 1)ie weifsliche Seitenbeharmug des Ablomen ist lang, abstehend und tast sehopfantig angeoldnet. Wigentliche Discalborsten finden sich lediglich auf ilen ersten Segmenten. Bauch schwarz mit diinner ockerbranner Bereifung und sehr zerstreuter gelber Behaarung.

beine mit Ausualnne der dister gelbluramen Knic schwarz. Die lehaarmng ist griofstenteils weilshich oder fahlgrelb, an der Unterfliiehe der Schenkel sehr lang, auf del Oberseite der 'Tarsen der Hintebeine schwarz. Dic beborstung ist vorwiegend schwarz, doch machen sich da und dort auch einzelne fahlgellue Borsten bennerkbar. Die biirstenförnige Behaarung ist goldgell); die fahlgelbe Wimperbehaarung, die nur die apicale Hälfte der Schienen einninnt, ist sehr lang. Kilanen schwarz, l’ulvillen fahlgell.

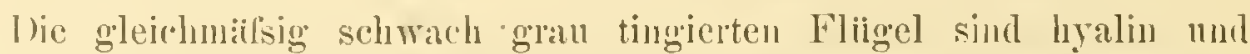
lebhaft irisierend. Ärlerung schwarz, die erste Initerrandzelle etwas erweitert. Long. corp. 7 mm, long. alar. 6 mm1. 
Atonia albiceps 11. sp. + .

Ein einzehnes $q$ aus Westbrasilien (Matto Grosso-Cuyaba) in der Sanmlung des k. ungar. Nationahmuscums in Bnlapest.

Kopf. Lie grangelbe Bestiinbung des Gesiehtes nimmt auf der Stirne und dem Seheitel rein weilse Farlue an. Der Knebelbart besteht ans relativ wenigen schwarzen Borsten und zahlleichen kïlzeren Haaren, die wie lliejenigen des Gesichtes und des Scheitels weifslich sind. Die Stime alber ist schwarz behaart. Das weifslich bestäubte Hinterhaupt ist gleichfarbig behart, ebenso lie Kimgegent, der Riissel und die Taster. Die Occipitalborsten siml schwarz. Au den schwarzen Fühlern ('Textfig. 38) sind die beilen Basalglieder schwarz behaart und beborstet, der ziemlich schmächtige Endyriffel des dritten Scgmentes ist stark mach abwärts gebogen, der Zahngriffel relativ plump.

Thorax sehwarz mit dichter feiner Punkticrung. Zwischen der kurzon, anliegenden fahlgelben Behaarung stelt jederseits eine Reihe vor dem Schildehen recht langer dorsocentraler Borstenhaare. die ebenso wie die kräftigen Scitenborsten des Mesonotum schwarz sind. Das ebenfalls mit anliegender Beharung ver-

Fig. 38. sehene Suhildchen entbehrt der Ranthare vollstaindig. Dic Pleuren reilsgran hestänbt mo zart behant, an ten oberen Partien ter Mesopleura unt auf dem Prothorax ist die Bestäubung ockergelb und zielıt sieh gegen die Sehultergegend empor. Notopleuralborste schwarz, der vor den brämlichen Schwingern stchende Metaplemalschim fahlgelb. 1)as weilslich bestïnbte Metanotnm mit den iiblichen schwarzen Borsten. Hüften granweifs bestäubt und behaart.

Das streifenförmige Abdomen ist schwarz, dieht und grob punktiert und gleichmiissig mit anliegenter, goldgelber leharmug bedeckt, die irgendwelche Binden- oder Fleckenzeichnung nicht erkemnen lisfst. Die Scitenbehaarung des Abdomen ist kurz, die Discalborsten sind fahlgell). Der dunkelbram bestäubte Banch ist gelb behaart.

Die schwarzen Beine sind nur an den Knien in sehr geringer Ansdehnung gelbbrann. Die Belıarmug ist gröfstenteils weifslich, die licborstung 
an den beiden hinteren beinparen und an simutlichen Tarsen rorwiegend sthwar\%, an den Vorlerschienen fahlgelb. Die biirstenfürmige Behaarung ist goldgelb, die Wimperbeharmug, die die Hiuterschienen in ihrer ganzen Ausdehnung und auch lie Unterseite der Hinterschenkel eimmimnt, ist fahlgelb. Klanen selwwar\%, l’ulvillen tast goldgelb.

Die rancligrane Färbung der hyalinen Fliigel ist am Torderrande etwas intensiver, die Adern sind sehwar\%. Die erste Hiuterandzelle ist etwas rerengert, die zweite Hinterrandzclle ganz schwach erweitert.

Loug. corp. 8 mm, long. alar. $6,5 \mathrm{~mm}$.

\section{Lamp)}

Die Gattung wurde von liöw (Bemertanyen ïber die Familie der Asiliden, 1651) anfgestellt und zwar hat Iaiw die Gattungsilignose mit der Artbeschreibung vereingt. Ich ziche es dalıer ror, hier nochmals eine Zusammenstellung der Gattungsmerkmale zu geben.

K opf (T'af. Fig. 26 u. 27) breiter wie hoch, nur sehr wenig abgeplattet. Untergesicht in beiden Richtungen leicht gewölbt, aber ohne Gesichtshöcker; Stime mud Scheitelgegend nach oben grleichmäfsig erweitert, so dals iler (fuerdurehmesser an der Scheitelhiihe das Doppelte der Gesiclitshreite beträigt. Innerer Angenrand ohue merkliche bogenfirmuge linkerbung. 1)er kräftig entwickelte, luschige Knebellant setzt sich unmittelbar in die lange, his zur Fiihlerwurzel emporragende Beharung des Untergesichts fort. Auch die Stirne trägt seitlich starke Belaarung; der knopffürmig vorspringende Ocellenhireker ist mit einem Biischel langer Borsten hesetzt. Ilinterhanpt mit dichter liehaarumg und Beborstumy, der Backenhart jedoch relativ zart. Riissel kur\%, gocrale, die 'Taster sehr' klein. Fiihler von maifsiger Lainge, las erste Glied doppelt so lang wie das kurze zweite, beide mit Ausuahme ihrer MedialHairhe mit langen und dichten IJaren besetzt. Das dritte Segment ('lextfig. 39) $1^{1}$ i mal so lang wie die beilen Basalglieder

Fig. 39. zassammengenummen, mit einem deutlichen Endgriffel, an dessen liasis der Zahnugrittel steht. 
Thorax mailsig gewoilbt, gedrungen, mit dichtel alsstehender Belaarung. Beborstung: prisutural 1, supraalar 3-4, postalar 2, notoplenral 5-6. Schildchenrand mit einer Reihe langer, aufwiirtsstehender Borstenhaare versehen. Das Metanotmm trïgt seitlich ein Biischel kurzer, diroht beieinander stehender, steifer Borsten.

Ablomen ungefih doppelt so lang als der Thorax, abgeplattet, unpunkticrt, sieben Segmente von oben sichtbar, die Genitalsegmente jerloch ventral verlagert. Bei dem or ist das Abdomen narlı hinten verjiingt, iiberhaupt schmäler wie beim + . Die Behaarung ist im allgemeinen anliegend, bei ler einen A th ist sic besonders dicht, goldgell, und crzengt auf den ersten fiinf Segmenten eine dentliche Bindenzeichnung. Die beiden ersten Segmente tragen scitlich eine Gruppe Jiscalborsten, die aber den iibrigen Segmenten röllig fehlen.

Beine. Sehenkel und Sehienen der Hinterbeine dentlich verdickt, die Krallen sind stark, fast hackenfürmig gekriimmt und besitzen eine schr stark entwickelte Empodialborste.

Flïgel. Stiel der Subcostalzelle kurz, scharf nach aufwailts gewendet; erste und zweite Hintertandzelle nicht verengt, die die Discoidalund die vierte Hinterrandzelle distal abschliefsenden Adern verlanfen genan in einer Flucht. Tierte Iinterrandzelle (beim of) und die Analzelle lang: gestielt. Die kleine Querader liegt noclı iiber der distalen Hailfte der ziemlich langen Diseoidalzelle.

Als typisehe Art gilt

$$
\text { Lamprozonu "uricincta Lw., }
$$

von der mir das aus Chile stammende, vou Schinel erwähnte or $q$ ans der Sammlung des k. k. IJofmuseums in Wien zur Untersuchung vorlag.

Irll bemerke dazu, dacs L. castamipes Bigot nach Veroleich del Typen vollstindig mit der Spec. auriciurta Lw. zusammenfïllt und dafs die von Bigot erwïhnte hellere Fiirlung der Beine — sie ist iiberhaupt nur bei dem einen Exemplar zu konstaticren - lediglich auf die mangelule Aisfuirloung zuriickzufiilnen ist. 
1)agegen hat die lintersuchung ler Bigotschen Typen ergeben, dafs Comansis cyanescens ohne allen \%weifel zu Lamprozona zu stellen und laher als

\section{Lamprosona cyanescens lig.}

zu bezeichnen ist. Da die Bigotsehe beschreibung recht mangelluaft ist, sollen liel croginzende Angaben gemacht werden. Die Art stamunt ebenfalls aus Chile nul befindet sich in der Sammlung V Terrall.

Kolıf. Gesicht nur unten mul an den Orbitalrändern mit gelbgraner Bestiubung bedeckt, so dafs nuter der Fithlerwurzel eine grofse viereckige, brame Makel von Bestäulonng freibleibt. Stirne, Scheitel und oberer T'eil des Hinterlauptes fast kaum luestiubt, schwarz, nur hinter den Oeellenhöcker findet sich eine gröbsere weifsbestäinte Stelle. Auch in den unteren Partien des Hinterhauptes ist die Bestäulung weifsgrau. Der Knebelbart, die dichte Behaarmg des Gesichtes, der Fiihler, der Stirn, des Sclleitels, des Hinterhauptes sowic dessen Belorstung schwarz, dagegen ist der lBarkenbart, sowie die Beharmug des Kinns und des hiissels weifslich. Die 'Taster tragen an ihrer Splitze einige lange schwarze Haare. Fiihler schwarz, das dritte Glich ist an seiner Innenseite briunlich bestïubt und trägt einen lanģen Zahngriffel.

'T'horax. Mesonotum schwarz mit leicht blanem Glanz. Die abstehende, schwarze, aber schwach grau schmmernde Behaarung ist etwas

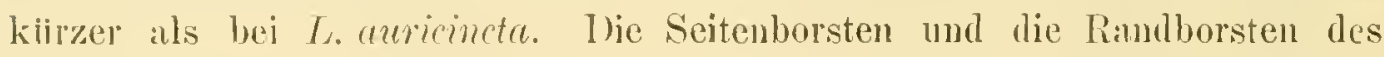
Sehildchens sind schwarz. Hiiften und Plemen mit Ansmahme einer olufïrmigen Makel auf der Mesoplenra grau bostainbt und zerstrent behaart.

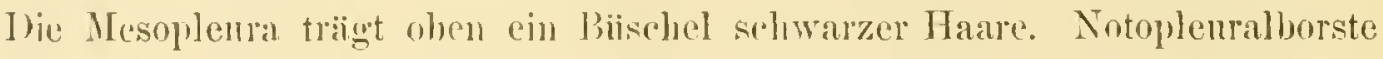
schwarz, der ror den gelben Schwingern stehende Metapleuralschirm fahlgelh. Collare schwarz behaart, auch das Biischel starer Borsten auf dem zart graubestiubten Metanotom ist selıwarz.

Abdonen riemlich lehhaft blanschwar\% uit leicht violetteni Glanz, naclı hinten zu diister rothraun. Die helle, anliegende Behaa'ung ist so fein und licegt so wenig dicht. dal's die Grundfurbe nirgends rerdeckt wird und auch keine bindenartigen Zeiohnungen entstelın. Die Segmenteinschnitte sind namentlich nach linten zu ganz fein luamu gesänunt. Jie Seiten- 
behaarung ist nur an den beiden ersten Segmenten länger und ebenso wie die Discalborsten bleichgelb, im ïbrigen aber kurz, anliegend und schwarz. Banch brann mit lichteren Hinterrandsbinden und weifslicher, langer, zerstrenter Behaarung.

lieine mehr oder minter dunkel pechbraun, fast schwarz mit hanptsächlich weilslicher Beharung, die namentlich an der Unterseite der beilen vorderen Schenkelpare selı lang ist. Anf der Oberseite sind sämtliche Schenkel mit kurzer, anliegenter, in wesentlichen schwarzer Behaarung bedeckt. Die Wimperbehaarung der Hinterbeine ist weilslich; die birstenförmige Behanrung der 'Tarsen und der Innenseite der Tordersehienen goldgelb. Die namentlich an den Schienen der vorderen Beinpare sehr langen und zahlreichen Borsten siud ansuahmslos schwarz. Klanen schwarz, Pulvillen gells.

Fliigel nur sehr wenig bräunlich tingiert, durchscheinend; Ädermug dunkelbraun. Jie die Discoidalzelle und die vierte Hinterrandzelle distal abschliefsenden Adem liegen nicht in der gleichen Linie, an einem Exemplatre anch nicht in der gleichen Richtung. Erste Hinterrandzelle ganz wenig verengert, zweite Hinterrandzelle kamm erweitert. Die kleine Querader steht iiber der distalen Hälfte des Discoidalzelle.

Long, corp). 7 mm.

\section{Antomolina n. g.}

Aus der Verwandschaft das Genus Atonia, von diesem aber dureh eine Reihe anffallender Merkmale verschieden.

Ko plf (Taf. Fig. 27 u. 28.) breiter als hoch, aber entschieden schmi:ler als bei Atoniu. Das mäfsig breite Gesicht verbreitert sich iiber der Fiihlerwurzel durch Ansrandung der Orbitalränder, so dafs Stime und Scheitel eine erluebliche, wenn anch betlentend geringere V'erbreiternng erleiden als bei Atonia. Bei reiner Profilbetrachtnng springt das Gesieht wohl ein wenig iiber lie Angenrïmler vor, ist aber im iibrigen völlig plan, so dals nicht eimmal die Andentmng eines Gesiehtshïckers vorhunden ist. Knebelbart, Behaarmng des Gesichtes, der Stime und des scheitels, anch 'Taster' 
und liuissel ganı wie bei Atomiu. Der Ocellenhöcker triggt ein Biischel divergierenuler Borsten; die Oreiphitalborsten lassen siclı, schwäieher werdend, bis zum Äruatol iler Angen nach abwïrts verfolgen. Die

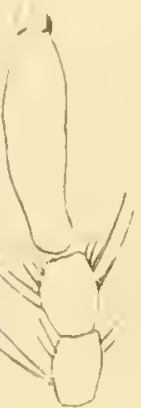

Fig. 40 . F“iilıler verhalten sich in Gestalt und der gegenseitigen Lïngenverhiiltnisse ihrer einzehnen Segmente ganz wie bei Atonia ('Textfig. 40), nur ist der Eudgriffel ganz bedeutend kiirzer.

Thorax. Das mälsig grewölbte Mesonotmm besitzt die iiluliche, anliegende lichte Beharung, aufserdem aber zalılleiche, namentlich vor dem Schildchen sehr lange dorsocentrale Borstenhare. Beborstumg: prïisutural 1, supraalar 1, postalar 2, notopleural 1, Metapleuralsehim seln lang und dicht. Das Collare ist mit einer Reihe sehwaeher Borsten besetzt, dagegen fehlen dem Metanotum die stiftehenförmigen Borsten völlig und sind durch ein Biischel sehr zarter Haare ersetzt. Die Pleuren sind mit Ansnalıme der goinzenden, kahlen Mesopleura bestainbt und mit zerstreuter Beharung verselien.

Abrlomen abgeplattet, unpunktiert, bei Betrachtung von oben aus acht nicht wnlstig voneinanler abgesetzten Segmenten bestehend, aueh die kurze zweizipfelige legeröhre ist von oben sichtbar. Die kurze, anliegende Behaarung ist an den Seiten der Segnente wirbelfïmig gekämmt, wodurch eine Andentung von Hinterrandflecken entsteht. Die Seitenbelaarmug ist nicht besonders verlängert, las erste Segment traigt seitlich einige laingere Borstenlaare, im ibrigen fehlen aber Discalborsten vollständig. Neben der Legerölıre stehcn einge lange Borstenlaare.

l)ie Beine bieten nichts eharakteristisches. Die Wimperbcharmng fehlt dem Wurzeldrittel der Hinterschienen, fundet sich dagegen in geringer Ausdehnung auch an der Spitze der Mittelschienen.

Flifgel. Stiel der Subcostalzelle ziemlich kurz, Anal- und rierte Hinterrandzelle lang gestielt. Die kleine Querader steht auf ler Grenze des distalen Drittels der 1)iscoidalzelle. Die diese Zelle und die vierte Hinterraulzelle distal abschliefsenden Quradern verlanfen weder in ler goleichen Linie noeh aber in ter gleichen lichtung. 
Als typische Art beschreibe ich:

$$
\text { Automolina chilensis n. spec. }+ \text {. }
$$

Ein einzelnes Exemplar aus Concepeion in Chile in ter Sammlung Hermann.

Kopf. Gesicht, Stirue und Scheitel gleichmälsig nit gelblicher Bestäubung bedeckt. Kunebelbart, Ocellarborsten, Behaarung der Stirne sowie die gräberen Iaare les Gesichtes schwarz, die feineren des letzteren jedoch falılgell). Hinterhaupt grangelb bestäubt mit weifslicher Behaalung. Occipitalborsten gelb; Backenlyart weifs. Fühler schwarz mit durchaus schwarzer Beharung. Riissel und Taster schwarz mit lichter Behaarmug.

'T'horax. Mesonotum mit Ausnahme der diister rotbrauuen Schultelund Postalarhöcker grainzend schwarz, die anliegende Beharung gelblich, gegen den Prothorax zu fast rein weifs. Die dorsocentralen Borstenhare. die Randborsten des Mesonotum und die Randhaare des Sehililchens selıwarz. Das Collare trägt bräunliche Borsten, das gelbgrau bestioubte Mletanotum fast weilshiche Behaarnng. P'leuren und Hiuften grau bestäubt und behaart. Notopleuralborste gelb resp. schwarz, der vor den fleischrötlichen Schwingern stehende Metapleuralschirm weilslich.

Abdomen gläinzend schwarz mit gewissem bramem Fraschimmer. Die anliegende Beharung ist im allgemeinen wenig dicht, an den Vorderrändern nud an den Seiten der Segmente aber liegt sie etwas dicliter, so dals bei gewisser Beleuchtumg zarte Vorderandbinden und Hinterrandflecken zustande kommen. Dic Borsten der ersten Segmente, die Seitenbeharmug: sowie die Haare der Legeröhre weidslich, dagegen sind die neben letzteren stehenden langen Borstenhare schwarz. Bauch pechbraun mit sehr zarter, licliter Behaarung.

Die Beine sind dunkelbraun, fast schwarz mit gelbbraunen Kunien nud an den beiden vorderen Beinparen, ditster rotbranen Schienen. Die im allgenteinen ziemlich spärliche Behaarung der Schenkel und Schienen ist weifslich und an der Unterseite ler Vorder- und Mittelschenkel sehr lang. Die ziemlich zalhleichen und langen Borsten sind im allgemeinen schwarz. doch finden sich an der Irurzelhälfte der Hinterschenkel sowie an der Aufsenseite der Vorler- und Mittelschienen anch Borsten ron fahlgelber 
Farbe. Die 'l'arsen sind an inrer Oberseite schwary behart und beborstet. 1) bie birstenfömige Beharmug ist an den Torderschienen, dem Metatarsus und den folgenten Tarsengliedern der Hinterbeine goldgelb, an den Tarsen der Vorderbeine weifs und an denen der Mittelbeine schwarz. Klauen schwarz, Pulvillen licht.

Die Flügel sind dureh sehr grobe mikroskopisehe Behaarung stark gratu getribt, nur im Bereich der hinteren Basalzelle und des Wrurzelteils der Randzelle hỵalin. Die sehr groben Adern sind durchans schwarz.

Long. corp. $7 \mathrm{~mm}$, long. alar. $5,5 \mathrm{~mm}$.

\section{L̈̈шinellı 11. 2..}

In dem zweiten Bande (1) 104) der ,Beschreibungen europäiseher Iipteren" beschrieb lïw scinerzeit eine Atomosic virescens ans Sarepta. Da zu vermuten war, dafs die Species wohl kaum dem Genus Atomosia angehüren wülole, war es mil von selbstverständlich grofsen Interesse, die Löwsche 'Type untersuchen zu kömen. Diese Untersuchung, die durch das von Herrn Dr. Griuberg in dankenswerter Weise vermittelte Entgegenkommen des K. Zoolog. Museums in Berlin ermöglicht wurde, zeigte demn auch, dals die I, ̈̈w sehe Species dem Gatungsbegriffe Atomosia sieh nieht einordnen lich mnl aurh mit kemem der iibrigen Atomosinengenera stimmte, so dal's ich fii sie ein nenes Genus anfzustellen genötigt bin.

Kopf (Taf. Fig. 29 u. 30) breiter als loch, das ziemlich breite Untergesicht ist, nach abwirts noch etwas verbreitert und zu einem statt-

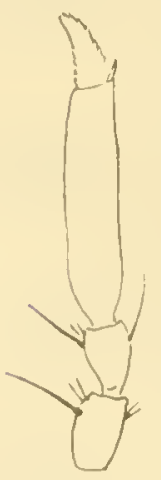
lichen querliegenden Wrulst aufgeworfen. Der aus Borstenharen bestehende diclıte, fächerförmige Kuebelbart erstreckt sich am seitlichen Mundrande nach abwiirts; iiber ihm wird das Gesicht teilweise von langen, nach abwiits gebogrenen llaaren eingenommen. Stime nach oben gleichmälsig, wem aneh nicht beträchtlich erweitert und am inneren Angenrande init einigen Borstenharen besetzt. An den Fiihlern (Textfig. 41) sind die beiden ersten Segmente nahezu gleichlang, mit der gewohnten, aher nicht

Fig. 41. dichten Behaarung und einer einzelnen Borste an der Unterseite 
des ersten Gliedes. Das dritte Segment ist 1/2, mal so lang als die beiden basalglieder zusammen, fast zylindrisch und mit einem etwas kolbig verdiekten Endgriffel versehen, an dessen Basis ein deutlicher Zahnstift sichtbar ist. Hinterhant mit relativ wenigen, aber dicken Borsten, im iibrigen kaum behaart, Backenbart lang, aber nicht besonders dieht. Riissel kurz, 'Taster ?

Thorax und Sehildchen gleichmilsig junktiert und mit kurzer anliegender Behaarung bedeckt. Beborstung: präsutural 1, supraalar 1, postalar 1, notopleural ? Schildchenrand mit wenigen kurzen Borsten, Metaplenralschirm diinn, das Metanotum mit einer Sehiefreihe kurzer starker Borsten bewehrt.

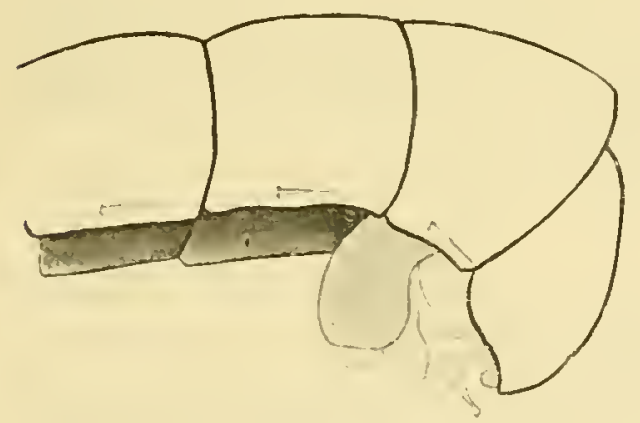

Fig. 42.

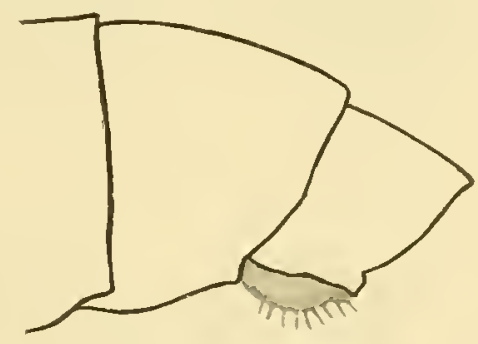

Fig. 43.

Das nach hinten eine Spur verbreiterte Abdomen besteht ans sieben von oben sichtharen Segmenten, deren Hinterrïnder (wenigstens beim ơ) gregliittet sind, während die iibrige Fläche gleichmälsig punktiert erseheint. Die anliegende Behaarung ist sehr kurz und fein, auch am Seitenrande ist sie nur wenig linger. Das erste Segment ist mit $3-4$, das zweite mit zwei, die folgenden Segmente mit je einer Discalborste bewehrt. Das Hyropyg ist ventral verlagert, relativ grofs und stark vorspringend; iilser seinen Bau vermag beistehende Figur (Textfig. 42) am besten zu mrientieren. Bei dem $q$ ist der freie Rand des ebenfalls ventral verlagerten achten Segmentes zn einer die kurze Legeröhre zwischen sich fassenten Klappe ungebogen ('T'extfig. 43), die mit einer Reihe kurzer innartiger Borsten bewelurt ist. 
Beine. IInterschenkel kolbig verdickt nnd ebenso wie die Ilinterschicuen etwas gebogen. Auch die Selienkel der Volrder- und Mittelbeine sinl kriftig entwickelt. Die Behaarmug und beborstung bietet keinc besonderen Merkmale.

Fliigel. Spitze der Subeostalzelle auftallend stumpf, ilu Stiel sehr kur, fist direkt nach aufwäts gebogen. Erste mo zweite Hinterrandzelle meht verengert, die dritte Hinterrandzelle viereckig und so breit wie die zweite. die vierte Hinterrandzelle ist relativ lang gestielt. Analzelle offen. die kleine Qnerader stelit iiber der apicalen Hälfte der Dicoidalzelle.

Als typische Art betrachte ich:

$$
\text { Lörinella rirescens Löw. }
$$

Die aus Sarepta stammende 'Yye or befindet sich in der Sammlung des K. Zoologischen Museums in Berlin, ein o rerdanke ich der Liebenswiurdigkeit des Herru Baurat 'Th. Beckel' in I iegnitz.

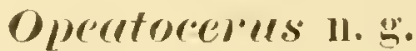

Ko lif ('laf'. Fig. 30 u. 32) mïisig verbreitert. Das Gesicht gleich breit, die Stirne gegen den Scheitel zu mur sehr wenig verbreitert. Der eigentliehe Knebelbart bestelıt nur aus zwei geschwungenen Borsten, aufserdem wird der Iundrand von einer lieihe Borstenharen und sich dazwischen mengenden kiirzeren Haaren eingenommen. Unter den Fiihlern stehen jederseits zwei abwiils gebogene Borstenlaare, die Stirne ist mu seitlich wenig hehart, der scheitel vollstindig kahl. Das Hinterhaupt trigt eine lieihe ungemein grober, dornartiger borsten, die sich jedoch mur bis zum erstrecken, Backenbart sehr schwach, auch die Beharung der Kinngegend, des hiissels und ler kleinen 'Taster ist um sehwach entwickelt. Das erste Glied del relativ kurzen Fiihler ('lextfig. 44) ist kiirzer als das zweite und wie dieses in der gewöhnlichen Weise behaart und beborstet. Das dritte Glied, mngefilh $1^{1}$ z mal so lang als die beiden liasalglieder zusammengenommen, ist mit cinen dolchartigen, leirht pubescenten lindgriffel versehen, der fast ${ }^{1}$ : so lang ist als das ludglied selbst; an seiner Basis ein dentlicher /almstift. 
Thorax. Mesonotum, Schildehen und obere Partie der Mesopleura mit sehr derber Punktierung und sehr zarter und kurzer anliegender Behaarung. Beborstung: prisutural 1, supraalar 1, postalar 1, notopleural ?; Schildchen ohne Randborsten. Die bestäubten Pleuren fast vollkommen kahl, auch der Metapleuralschirm nur sehr schwach entwickelt. Collare mit feiner Behaarung, das Mesonotum trïgt seitlich einige kurze Stachelborsten.

Abdomen. Das verhältnismälsig lange, metallisch glänzende und sehr derb punktierte Abdomen besteht bei Betrachtung von oben aus sieben Segmenten und ist gleichmailsig mit sehr kurzen und feinen anliegenden Harren bedeckt. Die seitlich verlängerte Behaarung ist wenig dicht, Disealborsten sind an allen Segmenten vorhanden. Dic kleinen Genitalien sind ventralwärts verlagert, ohne besondere Merkmale.

Beine ziemlich kahl. Oberschenkel, Spitze der Schienen, Metatarsus und erstes 'Tarsalglied an den Hinterbeinen etras verdiekt. Schenkel sämtlicher Beine an der Unterseite mit langen Haaren, Schienen und Tarsen mit wenig zahlreichen, aber kräftigen Borsten versehen. Die bïrstenförmige Behaarung der 'Tarsen erstreckt sich an der Innenseite der Vorderschienen hoch empor. Die Wimperbeharung an den einander zusehenden Flächen der Schenkel und Schicnen der Hinterbeine ist selır dicht.

Flïgel. Spitze der Subcostalzelle stumpf, der Stiel kurz unt anfwärts gebogen. Erste Hinterrandzelle breit offen, gar nicht verengert, die kleine Queraler steht etwas distal von der Mitte iler Discoidalzelle, die vierte Hinterrandzelle und die Analzelle sind lang gestielt.

Als typische Art hat zu geelten:

$$
\begin{aligned}
& \text { Opeatocerus purpuratus Westw. } \\
& \text { syn. Atomosia purpurata Westw. }
\end{aligned}
$$

(Diptera nonnulla exotica descripta, Trans. Entom. Soc. Lomion. V. 1849.) 
her Beschreibung 1 estwoods habe ich nichts beizufïgen, ich benerke nur, dafs die beigegebene sehr schöne Zeichnung Fig. 5 dic Art anf den eisten Blick erkennen läist und dafs die Detailbilder wenigstens soviel zuigen, dals die Species dem Gemus Atomosia nicht subsummiert werlen kann. Fin Exemplad wurte nir vou Herrn Poulton aus dem Museum in Oxford liebenswiirdigst mitgeteilt.

\section{Gomercellypsis $11 . g$ ğ.}

Kileine, leblaft metallisch griiu gefärlute Arten, welche im Habitus wohl eine weitgohende $̈$ Änlichkeit mit Lärinella virescens besitzen, sich aber iu Bau des Kopfes, des Thorax, der Beine und m Flïgelgeider doch zu bestimmt scheiden. als dafs man sie mit der genamnten Species generisch zusanmenwerfen kïnute.

Ko luf ('lat. Fig. 33 11.34) breiter als hoch. Das miifsig breite Gesicht nach abwiilts etwis verbreitert, am M[undrand nur sehr wenig vorgebuchtet. Der Knebelbart besteht aus einer den Mundrand einnehmenden

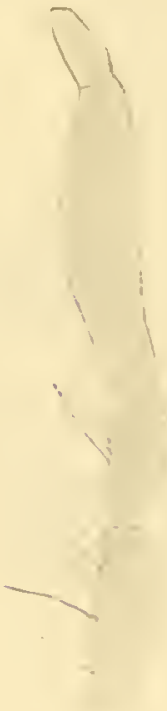

Fig. 45. Borstenreihe, iiber der kiirzere llaare bis fast zur Hälfte des Gesichtes emporreichen. 1)iesen sind beim ơ selimmernde schuppenhare beigemengt. [̈ber lem Knebelbart findet sich jedelseits eine Reile abwärts gebogener grüberer Borstenhaare. Stirne nach aufwälts gleichmäfsig, abel nicht betrïchtlich erweitert, seitlich mit wenigen Borstenharen. Ocellenhückel schr stark prominent mit vicr nicht gleichlangen Borsten. Die oben selur starken Borsten des Hinterhauptes lassen sich, freilich schwieher werdenul, bis gegen den $̈$ quator der Augen verfolgen; dic zarte Behaarumg geht unten in den schwach entwirkelten Backenbart iiber. liuissel kaum iiber den ILunirand rorragend, Taster klein. Histes Fiiblerglied ungefïlı zweinal so lang als das zweite ('Textfig. 4õ), an der Unterseite borstenartig, an ler Oberseite liurz belaart; auch an lem zweiten Segment ist dic Belaarmug an der Unterseite borstenartig und linger. Jas dritte schwach seitlich kompresse Segrment ist nach unten 
höckerartig erweitert, bei stiilkerer Tergrüfserung jubescent und mit einen kegelförnigen Endgrifie] versehen, an dessen Basis deutlich ein Zahnstift vorspringt.

Thorax. Das stark gewölbte, gegen das stachelig beborstete Collare steil abfallende Mesonotum ist stark glänzend, wie poliert, und kahl, Innktierung findet sich mu inmerhalb beschränkter, Heckenartiger Areale. Ein solehes von ilreieckiger Gestalt liegt jederseits meilial von ilen Sehulterbenlen, ein umpares, mehr quel rechteckiges findet sich hinter der Qnernaht. Diese Areale sind mit kiirzerer oler längerer beharmug ziemlich dirht bedeckt, stehen untereinander durch reihenweise, gestellte lälngere Haare in Terbindung, und endlich wird auch der seitliche Rand des Mesonotmm bis zur Gegend der Postalarhöcker ron Behaarung gesäumt. Beborstung: präsutural 1, supraalar 1, postalar 1, notoplemral 1. Die Pleuren bestäubt, auf der Mesopleura eine lïngliche unbestäubte. gläuzende Makel; Behaarung. zart und in einzelıen Flecken stehend, Metapleuralschirm diinm. Das gölänzente Schildehen trïgt seitlich einige zarte Haare, der wulstig abgesetzte freie Rand ist mit einer heihe verschielen langer, anfwärtsgebogener Borsten bewehrt, deren am meisten medial stehende durch besondere Länge anffallen. Das bestäubte Metanotum trägt eine je nach der Species verscliedene Anzahl steifer, kurzer Borsten.

Abdomen streifenfirmig sclmal, aus siehen von oben sichtbaren, seluarf abgegrenzten Segmenten bestehend mu mit Ausuahme der iulsersten Segmentränder gleichmälsig dicht punktiert. Anch das Hypogyl ist wenigstens teilweise ron oben sichtbas. Die dichte Beharung ist auf der Riiekentlaiche kurz und anliegend, an den Seiten länger und abstehend, l)iscalborsten anf sämtlichen Segmenten vorhanden.

An den Beinen sind die Hinterschenkel und -schienen leicht kenlenfïmig verdiekt, aber gerade, an ihren einunder zusehenden fiäichen mit wimperartiger Behaarung bedeckt. Auch der Metatarsus nud das zweite Tarsalglied ist an den Hinterbeinen leicht rerdickt nnd mit reihenweise angeordneter biirstenförmiger Behaarung versehen. J)ic Behaarung und Beborstumg der Beine ohne besondere Merkmale.

Flïgel ohme deutlichen Flügellappen. Spitze der Subeostalzelle relativ stumpf, Stiel derselben kurz, nach oben gebogen. Erste Hintelrand- 
zelle nicht verengert, zweite Hinterrandzelle nach aulsen etwas erweitert, vierte Hinterrandzelle lang gestielt, Analzelle gestielt. Die kleine Querader steht iiber ler Mitte der Ihiscoidalzelle.

Als typische Ait betrachte ich:

$$
\begin{aligned}
& \text { Goneccalypsis argenteo-viridis Herm. } \\
& \text { syn. Atomosia argenteo-riridis, Herm. }
\end{aligned}
$$

(Zeitschr. f. syst. Hymenopt. und Dipterologie. VIl. p. 68) ans Transvaal.

line zweite Art

$$
\text { Goneccalypsis lucidu n. sp. ot?. }
$$

ist mil aus Formosa bekannt geworden; sie befindet sich in der Sammlung des k. ungar. Nationalmuseums in Budapest.

Kopf. Gesicht gleichmäisiog weifs bestiubt, Knebelbart mit Einschlul's der Schuppenbeharung des $\sigma^{-1}$ weil's, dagegen die borstenfümingen Haare über ilım schwarz. Stirne und Scheitelgegend gelblich bestäubt und schwarz behaart. Der unbestïubte Ocellenhöeker trägt vier schwarze Borsten. Auch das Hinterhaupt ist mit dünner gelblicher Bestäubung bedeckt, Borsten schwarz, die zarte Behaarung und der Backenbart weifs. Riissel und Taster dunkelbraun mit weifshicher Behaarung. Fühler schwarz, die beilen Basalglieder mit sehwarzer Behaarung, das dritte Segment an seiner Medialfliche oekerbraun bestäubt.

'T'horax. Mesonotum und Schildehen lebhaft blaugrouin, stark glänzend, die Schulterbeulen in sehr geringer Ausdehung rotgelb. Die Beharmgg goligelh, nur neben den Schulterecken einige zarte schwarze Hürchen. Beborstung des Mesonotun und des Schildehens durehaus schwarz. Pleuren mit Ausmahme der lang ausgezogenen glänzend sehwarzen Makel anf iler Mesopleura gleichnilisig weifslich bestäubt und behart; ebenso die Hüten. Notoplenralborste und der vor den weirsen Schwingern stehende Metaplenralschirm bleichgell,. Das grau bestaiubte Collare schwar\% beborstet, auch die zahlreirheren Stachelborsten des grauweifs bestäubten Metanotum sind sehwar\%.

Abilomen dunkelerzgrin. Die kurze anliegende Behaarung ist gelblich; auf der vorderen Hiilfte der Segmente ist sie mehr weifs und steht 
dichter, so dals dadurel wenigstens bei gewisser lielenchtung breite Vorderrandbinden angedentet werden. Die längere Behaarung an den Sciten ist ebenso wie die I)iscalbeborstung weifslich. Hypogyl dunkelrotbraun mit gelblicher Behaarung: Bauch glänzend dunkelbrann, zart grelblich behart.

Beine sehwarz, die 'Trochanteren, die Knie und das Basaldrittel der Sehienen hell gelbbraun. Die Behaarmg der Schenkel und Schienen ausschliefslich weifslich, anch die diehte Wimperbcharmug dè Hinterbeine und der gröbste Teil der beborstung; nur an den Schienen finden sich stellenweise aneh einige scluwarze Borsten. Die Tarsen sind dunkelbrann und schwarz behaart und beborstet. Die biirstenförmige Behaarung del 'Tarsen ist an den Hinterbeinen dunkel, an den anderen gelb. Klanen dunkelbrann, Pulvillen lichtgelb.

Fliigel nur sehr wenig bram tingiert, fast rollkommen hyalin. A(lern gelbbraun.

Die Unterschiente des gröfseren q gegeniiber dem ơ sind nur geringe. Das Gesicht trägt mehl gelbliche Bestäubnng, der Knebelbart, dem die das $\supset^{-7}$ charakterisierenden Schuppenhaare vollständig fehlen, ist vorwiegend sehwarz. Der zarteren Beharung des Mesonotnm misehen sich, namentlielı am Seitenrande in gröfserer Menge schwarze Härchen bei. An den Beinen besitzen die lichter grefïrbten Partien eine geringere Austehnung; so dafs die Hinterbeine durchaus sehwarz sind, anch die verhältnismälsig längere Beborstmng ist an siimtlichen Beinen vorwiegend scliwarz.

Long. corp). $8 \mathrm{~mm}$, long. alar. $6.5 \mathrm{~mm}$.

\section{Clariola.}

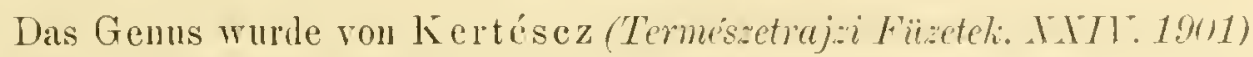
aufgestellt: ich fiige der Gattmusbeschreibmug folgende nähere Angaben bei.

Kopf (Taf. Fig. 35) u. 36) nur wenig verbreitert, Intergesicht namentlieh efwas unter der Fiihlerwurzel sehr sehmal, mit einem kleinen Inndhöcker, der von dem aus vier Borsten bestehenden Kuebelbarte eingenommen wird; einige schwaichere Borstenlatare nehmen den seitlichen Mundrand ein; ancl iiber diesem stehen feine Hate. Stirne gegen 
den scheitel zu verbreitert, kahı. 1) Hinterhaupt entbehrt der Beborstung

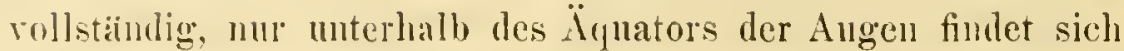
eine veroinzelte kurze B3orste; auch die Beharung fehlt in der oberen llïfte rollkommen, nur nach abwirts finden sich einige wenige zarte Haare. Der Backenbart nur seht schwach entwickelt, fast völlig fehlend. Der an ler spitze lang behaarte Riissel gerade, die kleinen 'Jastel an ihrer Spitze behart. Fiihler ('Textfig. 46) ziemlich lang, das erste Glied 1'2 mal so lang als das zweite, beide mit sparsamer Behaarung, die Unterseite des ersten Segmentes anfserdem mit einer einzelnen langen Borste bewehrt. Das dritte Segment, etwa $1^{1}$.2 mal so lang als die beiden Basalghlieder zusammengenommen, ist alleuthalben, besonder's aber an seiner eines Endgriffels entFig. 46. behrenden Spitze deutlich pubescent. Der auf einem kantigen Vorsprung stehende Zahngriffel befindet sich noch auf der distalen Hälfte des Oberrandes.

Der mälsig gewiilbte 'Thorax trïgt wenig dichte, anfrechtstehende, fast borstenförmige Behaarung. Beborstung: präisutural 1, supraalar 1, postalar 1, notopleural 1. Metapleuralsehirm aus relativ wenigen Borsten hestehend. Anch medial vor den Schulterbeulen findet sich eine starke Borste. Metanotum seitlich mit einigen, groben, fast nagelartigen liorsten bewehrt. Das dreieckige Sehilichen trägt aufser abstehender Behaarung an seinem Rande zwei sehr lange und dicke, spiefsartige, divergente Borsten.

Ablomen nach hinten etwas verbreitert, schwach keulenfömigr, fein nul dicht punktiert; ron oben sind sieben Segmente sichtbar, die Genitalsegmente jedoch nach unten verlagert. Auf dem Hinterleibsricken ist die Behnarung dicht aber sehr kurz, an den Seiten liinger und abstehend. Das erste Segment trägt seitlich einige steifere Borstenhare, das zweite und dritte Segment je eine Discalborste, und anch das siebente Segment besitzt an seiner Luterfläche einige Jorsten ron auffallender Läng’e, die iibrigen Segmente aber entbehren der Discalborsten vollstïnlig.

Jie Beine sind ziemlich lang, im allgemeinen schlank, nur an den Hinterbeinen sind die Schenkel sowohl wie die Schienen erheblich rerdickt. 
An den zwei ersten Tarsen der Hinterbeine steht die bürstenförmige Beharung in regelmailsigen Reihen, so dafs sie wie geringelt aussehen.

Die Flïgel entbehren eines Fliigellappens. Stiel der relativ etwas stumpf endigenden Subeostalzelle nur von mälsiger Läinge. Erste Hinterrandzelle nicht rerengert, zweite Hinterrandzelle etwas gegen den Fliigelrand erweitert, Stiel der vierten Hinterrandzelle lang. Analzelle relativ kurz gestielt. Die die Discoidalzelle und die vierte Hinterrandzelle distal abschliefsenden Adern stehen in der gleichen Richtung, aber nicht vollkommen in ler gleichen Flucht. Die kleine Querader stelıt nur ganz wenig. proximal von der Mitte der Discoidalzelle.

Als Type gilt

\section{Clariola pulchra Kertésez,}

von der sich ơ $q$ aus N.-Guinea (Huon-Golf) in der Sammlung des k. ungar. Nationalmuseums befinden.

In der gleichen Sammlung befinden sich fiunf Exemplare (ebenfalls aus N.-Guinea) einer zweiten Species, die sich ron Clariola pulchra sowohl durch plastische, wie durch Färbungsdifferenzen unterscheidet. Ich sehe in derselben die Laphria pipunculoides Wlk. und fïhre sie hier als

\section{Clariola pipunculoides Wlk.}

all.

Die Walkersche Beschreibung (Proc. Lim. Sor. London. TIII. pag. 110. No. 26. 1865) geniggt, um die Species zu erkennen. Ich kam mich daher begniigen, hier die Unterschiede anzugeben, durch die sich die Art von Clariola pulchire Kert. auszeichnet.

Die Beine sind mehr rotgelb, die Hinterschenkel erheblich stïrker verdickt, wie bei $\mathrm{Cl}$. pulchra, nnd an ihrer basalen Hialfte mehr oder minder gebräiunt, die Hinterschienen sind dentlich gekrïmmt und mit Ansnahme ihrer Spitze tief dunkelbraun, die 'Tarsen sämtlicher leine ebenfalls gobräunt. 


\section{Cemorheom!gia $11 . \mathrm{g}$.}

Kopf breiter als hoch. Das Gesicht relativ schmal, am Mundrande zu eincm schwachen Höcker aufgeworfen (Taf Fig. 37 u. 38). Del Kinebelbart bestelit aus cinem Biisclıel niedergedriickter kiirzerer Haare und vier langen Borsten; zwei dersclben stehen neben, die beiden anderen iiber jenem Haarbischel. Auch der seitliche Mundrand tragt einige kürzere Haare. Über dem Kinebelbart ist das Gesicht zweireihig zast behaart. Stirue nach oben gleiehmälsig verbreitert, so dafs der Scheitel betrïichtlich breiter ist als die Stirne; beille vollstinndig kahl. Die schwachen Borsten des Hintel-

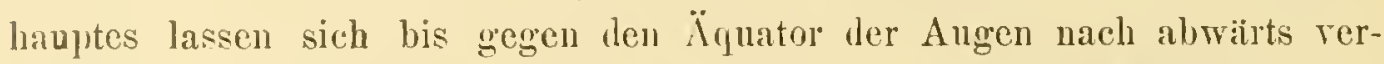
folgen; auch die feinere Beharung ist ebenso wie der Backenbart sebı kur\% und zart. Ríissel mîlsig lang, gerade, die 'Taster selır klein, beide nul schwach behaart. Die Fiihler besitzeu den nämliehen Bau wic bei den Atomosiaarten, nur ist die Pubescenz des Endgliedes sehr schwach angedentet; der Zahngriffel steht nugefähr in der Mitte des Oberrandes. Ocellenhöcker mit zwei, relativ kirzen Borsten.

Thorax. Das mäfsig gewïlbte Mesonotum zeigt nur ill der Gegend der Schultern und am seitlichen liande äufserst feine Punktierung und Behaarung, im iibrigen ist es glatt, metallisch glinzend. Beborstung: präisutural 1, supraalar 1, postalar 1, notopleural ?, der Metapleuralschirm besteht aus wenigen langen Borstenharen, das Mlanotum trägt aufser einer Gruple feiner Härelien eine einzige längere Borste. 1)as dreieckige Scluildchen ist an seinen freien Rande kurz behart und ualie der Mitte mit zwei aulsert langen spicfsfönigen Borsten bewehrt. Collare ohme Beborstung:

An dem ziemlich langen, gleichmälsig streifenfümigen, derb punktierten Abdomen sind bei Betrachtung von oben sieben Segumente siehtbar, auch der hinterc Rand des achten Segmentes, sowie die Legerïhe sind von oben eben noch sichthar. Am Seitenrande fehlt die liehaarung vollständig, und anch del Hinterleibsricken kann als vollständig kahl bezeichnet werden, da die feinen Ilärehen nur bei sehr bedeutender Vorgröfserung eben noch sichtbal sind. Die beiden ersten Segmente haben je zwei, alle folgenden je einc Discalborste. 
I)ie relativ langen Beine besitzen lange Beborstung, zeigen aber sonst keine charakterisierenden Merkmale; die Hinterschenkel unl -schienen sind nur wenig verilickt, aufserdem ist an den Hinterbeinen die Empodialborste sehr stark entwickelt.

Flügel von der läinge des Hinterleilss. Stiel der Subcostalzelle sehr lang, kaum aufwiirts gebogen. Erste Hinterrandzelle nicht verengert, die zweite nur ganz gering gegen den Flïgelrand erweitert. Die dic Discoidalzelle und die vierte Hinterrandzelle distal abschliefsenden Queradern bilden gegenseitig einen distal offenen stmmpen Winkel. Vierte Hinterrandzelle und Analzelle gestielt. Die kleine Querader liegt iilser dem Basaldrittel der langen Discoidalzelle; die vordere Basalzelle länger als die hintere.

Als typische Art beschreibe ich:

$$
\text { Cenochromia xanthogaster n. sp. } q .
$$

Ein einzelnes Stiick aus N.-Guinea befinlet sich in der Sammlung des Museo eivico di Genova.

Kopf. Gesicht mit silberweifser Bestäubung bedeckt; Knebelbart weifs. Yon den vier Borsten desselben ist das obere Paal schwarz, das untere ebenso wie die den scitlichen Mundrant eimnehmenden Haare gelbbraun. Die iiber lem Mundrande stehende zarte Behaarung ist weifslich. Stirne und die Mitte der im iibrigen sammetschwarzen Scheitchregion weilsgelblich bestäubt. Der unbestäulute Ocellenhöcker schwarz heborstet. Hinterhaupt mit ockergelber Bestäubung, liehtbraunen Borsten und gelblicher Behaarung. Riissel und Taster' dunkelbraun, gelblich behaart. Die beiden basalglieder der Fiihler braunschwarz mit gleichfarbiger Beharming, das zweite Segment ist vorne rotgelb gessiumt, das Endglied erscheint durch briunliche Bestäubung heller.

Thorax. Mesonotum blaugriun metallisch gliuzend mit roten und violetten Reflexen. Die Schulterbeulen sind in sehr geringer Ausdehnung, die Postalargegend und der hintere liand des 'Thoraxriickens in ausgedehnterem Mafse gelbrot; auch das Schildelien ist mit Ausnahme seiner schwarzen Basis gelhrot. Die zarte abstehende Beharrung des Mesonotum und des seitliehen Schildehenrandes brïunlich, die Seitenborsten des Thoraxriickens und die beiden spiefsartigen Schildchenborsten rotbraun. Pleuren 
und ('ollare galeichmälsiug mit graugelber Bestäubung bedeckt und zart gelblich behant. Der Metapleuralschirm und die Jiehaarung des ockergelb bestäubten Metanotmu gechbraun. Iliften grangelb hestaubt mul weifslich behart.

Abdonen mit Ausnahme des seehsten und siebenten gebrimuten Segmentes lebhaft gelbrot. Die aufserst kure Behaarung richtet sich in ihrel Farbe mach dem Untergrunde, die Discalborsten sind rotgelb. Das schmale achte Segment nnd die kurze gelbe J،geröhre sind mit lingerer bratuner Jehaarung verselien. Bauch gell).

Beine lebhaft gelbrot, zienlich kahl. An den vorderen Beinpaaren sind die Endtarsen, an den Hinterbeinen die Schienen und die sämtliehen 'Tarsen geschwärzt. Die Behaarung ist im allgemeinen gelblich, nur die Oberseite der Hinterschenkel, sowie die T'arsen der Hinterheine sind sehwar\% belatart. Die langen Borsten sind volwiegend gelb bis gelbrot, an den Vorder- und Mittelschienen, vor allem aber an den Sehienen mu Tarsen der Hinterbeine findet sich alser anch schwarze Beborstung".

Die gelbbraun tingierten Flïgel besitzen schwarzbraune Äderung. Long: corp. $11 \mathrm{~mm}$.

\section{Cenochrompia guttata n. sp. q.}

Eine einzelnes Fxemplar aus N.-Guinea, das leider namentlich am Kopfe durch Schimmelbildung sehr gelitten hat, befindet sich in der Sammlung des k. ung. Nationalmusenms in Budapest.

Die Art zeigt eine weitgehende Übereinstimmung nit C. ranthogaster, so dal's es geniigt, die Unterschiede anzugeben. Die vier Borsten des Kinebelbartes sind schwarz, die Seitenborsten des Mesonotmm rotbraun, vor allem aber besitzen die wenig tingierten Fligel an ihrer Spitze einen grolsen tiefbrammen l'leck, der sich bis zur 'Teilumgsstelle der Cubitalader erstreckt.

Long. corp. $10 \mathrm{~mm}$.

Als dritte Art grehört hierher:

Cenochromyia dioctroilles Whik. syn. Taphria dioctroides Wrlk. Celebes, von dler ich zwei ans Ceylon stammende Exemplare aus der Sammlung des Mr. Poulton in Oxford ror mir habe. Die Beschreibung W" lkers genitgt zur Erkemung der Art. 
Zu dem Genus Cenochomyia sind walurscheinlich anch die ron Walker beschriebenen Species zu zïhlen:

Laphria declarata Aru-Inseln

bipars Torey N.-Gninea

tripars Torey N.-Guinea.

\section{Eprophrorlitus n. :.}

Kopf (Taf. Fig. 39 n. 40) breiter als lıch. Das mälsig breite Gesicht springt bei reiner Profilbetrachtung nur sehr wenigg iiher die Angen ror, ist vollkommen plan, so dafs ein IIundhüeker völlig fehlt. Der Knebelbart besteht ans einem Biischel niedergedriickter grober Borstenhaare unl einigen wenigen längeren, den Mundrand sämmenden Borsten. Die zweireihige Behaarmug des Gesichts ist ziemlich grob. Die Stirne erweitert sich gegen den Scheitel deutlich, alser nicht beträchtlich, und ist seitwiirts mit eimigen kurzen Haaren besetzt. Der Scheitel und das bestänbte Hinterhaupt ziemlich dicht behaart, auch der Backenbart ist lang und dicht; die rclativ schwachen Occipitalborsten erstrecken sich fast bis zum Äquator der Angen nach abwärts. Der Ocellenhöcker trïgt zwei kurze, nach hinten gebogene Borsten. Der an seiner Unterseite mit langen Borstenlaaren besetzte Riissel von der gewöhnlichen Länge, die 'Taster sehı klein. Die Länge der Fühler entspricht fast dem Breitendurchmesser des Kopfes; das mit einer grö̈beren Borste an der Unterscite versehene erste Segment ist mehr wie doppelt so lang als das kurze zweite Glied. Das spindelfürmige Endglied ist etwa $2 \frac{1}{2}$ mal so lang als die beiden Basalglieder znsamnengenommen, seitlich komprels, fast handförmig, allenthalben fein pubescent und besitzt noch im basalen Drittel seines Oberrandes einen kurzen Zahngriffel.

Thorax. Das sehr wenig gewïlhte, schwach metallisch grlinzende Mesonotım ist fein punktiert und gleichmälsig mit abstehenden, nach den Seiten und nach hinten zu lïnger werdenden Haaren bedeckt. Beborstung: präsutural 1, supraalar 1, postalar 1, notopleural 1, Metapleuralschirm relatir sehr dünn. An dem ehenso wie das Mesonotum punktierten und behaarten Schildehen ist der freic Rand durch eine Furche deutlich abgesetzt 
und mit laugen aufwairtsgebogenen Haaren beset\%t. Die Pleuren sind mit Ausuahme einer kleinen glïnzenden Makel an unteren Rande der Mesopleura dicht bestäubt und mit relativ langen Haaren besetzt. Metanotum mit einer Gruplue riemlicl langer Borstenhare.

Das lange, fast yylimblische, metallglänzende Abdomen besteht bei lietrachtung vou oben aus sieben, wnlstig abgesetzten Segmenten und ist selı grob punktiert. Die Belaarung ist auf dem Hinterleibsricken äufserst kurz und fein, lagegen stehen seitlich an den Vorderecken les zweiten bis sechsten S'egmentes Büsthel längerer, dichter Haare, wolurch eine sehr in die Augen fallende Fleckenreihe entsteht. Das erste Segment triggt seitlich lange abstehende Behaarung, die an den iibrigen Segmenten wohl anch vorlınden, aber sehr dimn ist. Discalborsten sind an simtlichen Segmenten vorhanilen.

Die langen, kräiftigen Beine bieten kann irgendwie charakteristische Merkmale. Wie Hinterschenkel tragen an der basalen Hiilfte ihrer Unterseite cinige Borsten von sehr auffallender Läinge, anch die Beborstung sämtlicher Şchienen und 'larsen zeichnet sich durch erhebliche Lïnge aus.

Die relativ langen lyalinen F'liig*el sind mit sehwazen Querbinden geziert. Stiel der Subcostalzelle Iang; die erste und zweite Hinterrandzelle durchans nicht verengert, breit offen, die die Discoiclal- und lie vierte Hinteraudzelle distal abschliefsenden Queradern verlaufen in der gleichen Linie, die kleine Qneraler steht nalıe der W Vurzel der langen Diseodulzelle, so dals die vordere und lintere Basalzelle mahezu gleiche Läuge besitzen.

Als typische Art betrachte ich:

$$
\text { Epuphroditus placens Twlk., }
$$

von der mir zwei ans N.-Guinea (Huon-Golf) stammende Exemplare aus der Sanmlmug des k. ungar. Nationalmusemms vorliegen.

Die Walkersehe Beschreibung von Laplwia placens genight vollkommen \%ur Identifizicrung, anfserden besitzen wir noch eine ansfiihrliche

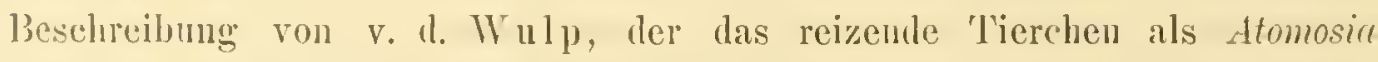
conspicuu besclurieben und abgebilıtet hat. Beziiglich der Zeichnumgen r. l. W ul]s möchte ich betonen, dals diese in l)etails sehr wenig genau sind. 
Aus der Sammlung des Museo Civico di Genora liegt mir ein etwas gröfseres Exemplar vor, bei dem die Fliigelspitze der schwarzen Säumung und der Körper der lebhaften blaumetallischen Fïrbung entbehrt. Es diirfte sich $u m$ das Exemplar handeln, dafs Osten-Sacken in seiner Enumeration of the diptera of the Malay Archipelugo (Amnali del Museo civico di storia naturale di Genora 1582) pag. $42 \%$ erwihnt. Ob es sieh dabei um cine eventucll neue Art handelt, rermag ich bei lem schlechten Konservicrungszustande des vorliegenden Exemplars nicht zu cutseheilen.

\section{Othomiomyia $11 . \mathrm{g}$.}

Kopf (Taf. Fig. 41 n. 42) breiter wie hoch, Gesicht riemlich schmal, iiber dem Ifundrande zu einem deutlichen Gesichtshöeker aufgeworfen, ter einen aus wenigen, in zwei Reihen angeordneten Borsten gebildeten Knebelbart trägt. Anch ïber dicsem findet sich jelerseits eine Reihe von abwiilts gebogenen Borstenharen, neben welchen das Gesicht eine leiehte Liingsfurche besitzt. Stirne gegen den Scheitel gleichmilsigr verbreitert, seitlich mit einigen wenigen Haaren. Das erste Fühlerglied zweimal so lang als das kurze, napfförmige zweite Segment. Das uritte Segment bandförmig, etwa zweimal so lang als dic beiden Basalglieder zusammengenommen, die mit der gewöhnlichen Behar'ung versehen sint. Ein Endgriffel fehlt. der Zahngriffel befindet sich anf einem scharfkantigen Vorsprung ungefiilur anf der Grenze des apicalen und mittleren Drittels (Textfig. 47). Der an seiner Spitze biischelförmig behaarte Rüssel ist relativ lang und trägt an seiner Wrurzel aufser der gewöhnlichen feineren Behaarung zwei lange Borstenhaare. Taster sehr klein, an ihrer Spitze mit einigen Borsten versehen.

Thorax stark gewölbt, vorne buckelartig anfgeworfen, so

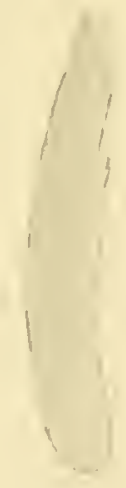

Fig. 47. dafs der Abfall zu dem Collare ein sehr steiler ist. 'Thoraxriicken mit dichter, aufwärtsstehender Behaarung. Beborstung: präsutural 1, supraalar 1 , postalar 1, notopleural 2. Schillchenrand mit langen, anfwiirtsgebrgenen Borsten besetzt. Metanotum hoch, seithich mit einem Buischel steifer Haare. Metapleuralschirm sehr lang. 
Abilomen streifenfurmig, nicht punkticrt, sieben Segmente sowic das in zwei beborstete Zangenarme gespaltene 11 yopygium vou oben sichtbar. Beharnng der Riickenfliche sehr zerstreut und kurz, Scitenrand lang behart, ohne Discalborsten.

Beine. Hintersolenkel sowie die gleichniifsig verdiekten Hinterschienen an den cinander zusehenden Flïchen mit Wimperharen versehen, Metatarsus der Hinterbeine ebenfalls etwas verdickt mit biirstenförmiger Beharmug. P'ulvillen eigentimlich gefranzt.

Fliigel durch anffallende Verschmailerung des Fliggellapens exquisit dreicekig ('lextfig. 48). Stiel der Subcostalzelle kurz, die die vierte Ilinter-

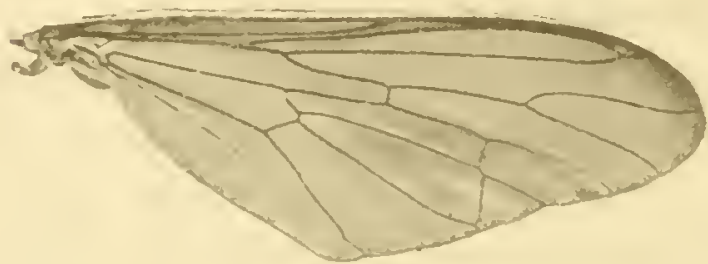

Fig. 48. rand- und Discoidalzelle distal abschliefsenden Adem nicht ganz in einer Linie, wohl aber in derselben Richtmng liegrend, im ganzen weit gegen den Fliigelrand verscliobèn, daher die Discoidalzelle und mamenttich die

vierkantige kurzgestielte vierte Hinterrandzelle sehr lang. Dritte Hinterrandzelle klein, dreieckig, Analzelle relativ schmal und lang gestielt. Die kleine Querader steht iiber ler Mitte der Discoidalzelle.

Als typische Art beschreibe ich:

$$
\text { Othoniomyia triangularis n. sp. or. }
$$

Zwei Exemplare ans Brasilien ex. coll. Prot. Bezzi. Ein Exemplar aus Blumenau (Brasilien) in der Sammlnng des k. k. Hofmuseums Wrien.

Ko],. Cutergesicht mit ockerbrauner; oder besser gesagt, bronzefarbener, an Mundranle mit weifser Bestiiubnng bedeckt. Knebelluart mud Behallung des Gesichtes sclıwarz. Stime schwarz, matt, anch das Hinterlaupt grörstenteils dunkelbram, in der Umgrebmg des Seheitels mit ockerloranner, mach abwäls teilweise mit weilsgrauer Bestäubung von schwarzer ljeborstung. Die gleiche Farbe besitzt anch der Backenbart. Behaarumg des liuissels und ler 'I'aster mit etwas lichterem Schimmer. Fihler schwarz, clonso die kurze Behaarung der beiden Basalglieder. 
Thorax schwarz, glinzend, mit riolettem Schimmer. Die aufreehtstehende Behaarmug ist wie die gesimte Beborstung ansuahmslos scluwarz, auch das schwarze Schildchen besitzt schwarze Randborsteu. Pleuren meilsgran bestänbt mit zarter, zerstrenter, im wesentlichen lichter Behaarung. Notopleuralborsten, sowie der gröfsere 'l'eil des Metaplenralschirms schwarz. Schwinger gelbbraun. Huiften schwarz mit graner Bestïnbung und weifslicher Behaarung.

Abrlomen dunkelbran glänzend mit sehlackenfarbenen Reflexen. Die äufserst kurze Beharmng des Hinterleibsriickens schwarz, die liingere Seitenbehaarung jedoch weissich. Die Zangenarme des Hypopygiums schwarz beborstet, dieses selbst ockerbraun behaart.

Beine dnnkel lederbrann, die Behaarmng ist in wesentlichen gelblich, die Beborstung sclıwarz; Klanen schwarz, l'ulvillen gelllich.

Flïgel gleichmälsig leicht ranchbraun getriibt, mit sehr lebhaft irisierendem Glanz. Adern schwarz.

Long. corp. 5,5 mm, long. alar. 5,5 mm.

\section{Aphestir schiner.}

Die Gattungsdiagnose stanmt bekanntlich ron Scliner und findet sich in seiner bekannten Abhandhng iiber die Wiedemannselen Asiliten (Tertandl. der zoot. botan. Ges. Wien. 1866). 1)ie Diagnose ist kurz, weshalb ich hier eine etwas ansfiilnlichere Zusammenstellung der Gattungmerkmale geben müchte. Ich werde dahei die von Scliner hetonten Merkmale durch Anfiihrungszeichen hervorheben.

Kopf (Taf. Fig. 43 u. 44) $m$ r milsigg verbreitert. "Untergesicht ohne Ḧ̈cker, aber der ganzen Ausdehnung nach erhaben und iiberall mit borstlicher Behaarung beileckt." Stirne mul Scheitelgegend nahezn goleich breit, Augenrand nur ganz wenig ansgerandet. Frstes Fühlersegment fast dopyelt so lang, wie das kurze zweite, ..drittes Fiihlerglied dreimal so ling als die beiden Basalglieder znsammengenommen, anf der Mitte oben mit cinem zahnartigen Fortsatz" (Zahustift), sanft geschwungen, von rundlichem Qnerschnitt ('lextfig. 49). Ile beiden Basalglieder ziemlich kurz behart, 
das erste Semment an scince Lnterseite mit einer einzelnen langen Borste. ., Riissel langow, die an ihrer Spitze mit divergenten langen Borsten besetzten Taster relativ grofs, wodurch sich Aphestia von allen bekamut gewordenen Atomosinen unterscheilet. Occipitalborsten stark entwickelt, anch das Collare ist mit kräiftigen Borsten bewelıt.

Thorax mur flach gewiilbt, das Mesonotum mit ganz kurzer, anliegenter Beharmug beleckt, anch die l'leuren mit relativ 1 zahlreichen, feinen Haaren besetzt. Metanotum seitliel mit einem Biischel feiner Haare. Das Schildehen traigt an seinem Rande vier Borsten, zwei stiirkere nahe der Mitte, zwei sehwiichere lateral. Beborstung: prisutural 2, supraalar 1, postalar 3, notopleural 4. An dem grob punktierten Abdomen sind von oben nur sechs Segmente zu sehen, das siebente sowie die kleinen Genitalsegmente sind an die Banchfläche verlagert. Die anliegende Behaarmog ist aufserst kurz und auch an dem Seitenrande des Abdomens ist sie

Fig. 49. weder lang noch dicht. Das erste Segment trägt eine Gluppe starker Scitenborsten, das zweite ist mit zwei, die folgenden mit je ciner, das letzte sichtbare Segment mit vier anliegenden Discalborsten versehen.

Die kräftigen Beine ohne auffallende Merkmale.

Fliigel. Erste Hinterrandzelle stets mehr oder minder verengt, manchmal beinahe geschlossen. Die kleine Querader befindet sich noch ïber dem Basaldrittel der Discoidalzelle. Der vordere Ast der gegabelten C'ubitalader ist ab und zu mit einem kmyen Aderrudiment versehen. "Hintere Qnerader nie in derselhen Linic mit der die Discoidalzelle abselliefsenden Querader, wohl aber in derselben Riehtmng verlaufend*, d. l. die die rierte Hinterrandzelle distal abschliefsende, leicht geschwnugene Ader ist stets etwas proximal verlagert. Die vierte Hinterrandzelle ist dreieckig und Iul kurz gresticlt.

Aphestia anmulipes Mer.

syll. Atomosia annulipes Mer. 1838.

Aphestia brasiticusis Schin. 1867.

lis diurfte keinem Z/reifel mnterliegen, dafs Atomosia ammlipes Meq. und Aphestia brasiliensis Schin. zusammenfallen. Da die Matulurtsche 
Beschreibung die ältere ist, mus der Schinersche Name eingezogen und kann lediglich als Synonym rerwendet werden.

Es liegen mir von dieser Art auser ler Type Schiners, elf ron Bischof determinierte Stïcke (Villa Oguapé, Brasilia) ans der Sammlung des k. k. Hofmuseums Wien vor. Der ausfïhrlichen Beschreibung Schiners ist nichts beizufiigen.

\section{Aplestiu calceata Schin.}

Es liegen mir die drei trpischen Stitcke schiners aus der Sammlung des k. k. Hofmuseums Wien rol:

Die Art steht der rorhergehenden Sipecies in allen plastischen Merkmalen, in Grölse und Fïrbung so nahe. dals es rielleicht passender wire, sie lerliglich als eine Tarietät der śpec. ammulipes anzuselıeı.

Als dritte Art fiihre ich

$$
\text { Aphestiu nigra Big. }
$$

an, deren 'Trpe mil zu' Lutersuchung vorlag' und die wohl sicher als eine sclbstaindige Art betrachtet werden kann.

Zwei Fxemplare aus Peru ex coll. Hermann, ein Exemplar aus S. Paulo (Brasilien) ex coll. Bezzi, stimmen mit der Tye und der Beschreibung bigots gnt iberein, welch letzterer ich folgende ergainzende Angaben beifiige.

Diese Art zeichnet sich gegenüber der Spec. ammutipes. Ireq. ron allem durch geringere Grüse und gracileren Bau, sowie durch hellere dichte Behaarung aus. Es genügt fïr die Kenntlichmachung die nähere Angabe der Unterschiede. Behaarung des Untergesichts und Knebelbart fahlgelb, letzterer olne jede Beimengung schwarzer Borsten. Lnterseite der beilen basalen Fiihlersegmente ebenfalls vorwiegend fahlgelb behaart. Der Thoraxriicken und das Sehildehen sind mit anliegender, goldschimmernder Beharung dicht bedeckt, gleiche Behaarung breitet sich auf dem Ablomen an ilen einander zuselıendeu Randpartien der Segmente bindenartig aus. Schulterbeulen und Postalarhïeker in grölserer oder geringerer Ausdelnung gelbbis rotbraun. Bestaiubung der P'lenren und Hiiften fast rein weirs. Schenkel 
sïmtlicher Beine brannselwwary, nur an den Knien und der Basis in geringer Anslehnung lellbraun. Schienen hellbrann, an den Torder- und Mittelbeincu an der Anfsenseite, an den Hintelbeinen in ihrem apicalen Drittel geschwäizt. Behaalung und Beborstmmg vorwiegend licht. Tarsen schwarz, an ihrer Oberseite schwarz, an der Unterseite fast fnehsrot behart und belonstet. Fliigel lichter, auch die Adern heller als bei der Spec. ammlijes. Long. corp. $11 \mathrm{~mm}$, long. alas, $10 \mathrm{~mm}$.

\section{Allelorlis $11 . \mathrm{g}$.}

Aus der Terwandtschaft des Gen. Aphestia Schin.

Ko pf ('Taf. Fig. 45 ı. 46) breiter als hoch, Untergesicht mälsig breit, schwach gewölbt, olme Gesichtshöeker. Die Behaarnng des Gesichts geht unmittelbar in den dichten Knebelbart iiber, der aus kiuzeren, etwas abgeplatteten, und langen, den Mundrand aurh seitlich eimnehmenden l3orsten besteht. Riissel ziemlich lang, grerale, Taster jedoch sehr klein. Stirne gleichmälsig, wenn aueh nicht sehr beträchtlich, zum Scheitel rerbreitert, am Angenlande mit längeren Haaren besetzt; der Scheitel zart behaart. Der Ocellenhöcker ist mit zwej, resp. mit sechs langen Borsten bewehrt. Die Occipitalborsten erstreeken sich bei den beiden bekamnt geworilenen Arten verschieden weit naeh abwälsts. An den Fiilılern ist das erste Glied nicht ganz doppelt so lang als das zweite, das dritte spindelfürnige Segment ist etwa $1 \frac{1}{2}$ mal so lang als die beiden Basalglieder zusammengenommen.

'T'horax mälsigg gewöbt und mit dichter, anliegender Beharung' bedeckt, die in der Schnltergegend sowie an den riickwärtigen T'artien des Mesonotum erlıblichere Iänge annimmt. Diesel anliegenden Belıarung mischen sich zahlreiche längere dorsocentrale Borstenhare bei. Anch das Sohildchen ist mit dichter, anliegenter Beliaarung bedeckt und an seinem lianle mit einer lieihe aufwaits gebogener langer Borstenhaare verselien. Bebolstung: prisutural 1, supraalar 3, postalar 3, notopleural 2 ron besonderer Liinge, auch der Metapleuralschim besteht ans sehr langen Borstenhaaren. Die Bestiabung der Wiiften und Plenen laist anf der Mesoplemra cine oblonge Makel frei. Das Metanntum besitzt aulsel feineren Haaren 
einige steife Borsten, das Collare ist mit einer Reihe recht seliwacher Borsten besetzt.

Abdomen fast so breit wie der Thorax, an den mittleren Segmenten eine Spur verschmälert; bei Betrachtung von oben besteht es ans sieben durch tiefe Einschnitte voneinander getrennten Segmenten, auch die relativ grofsen, kolligen Genitalsegmente liegen frei. Die einzelnen Ringe sind deutlich punktiert und mit kurzer anliegender Beharung bedeckt, die an den Seiten jedoch sehr lang und abstehend ist. Erstes Segment mit vier. die folgenden Segmente mit je einer Discalborste verselıen.

Die krïftigen Beine, deren Schenkel dentlich verdickt sind, bieten nichts Charakteristisches.

Fliigel. Stiel der Subcostalzelle zienlich lang, sanft nach aufwärts gebogen, erste und zweite Hinterrandzelle nicht rerengert, Analzelle gestielt, kleine Querader ïber der Mitte der Discoidalzelle stehend.

Möglicherweise dürfte die von v. Rüder (Stettiner ent. Zeitg. XTII. 1881) aus Australien beschriebene Aphestia chalybaea dem nenen Genus Adelodus angehören, wofür manche der von v. Röder erwähnten IIerkmale (Borsten am seitlichen Mundrande, die Siebenzahl der Abdominalsegmente usw.) spreehen wiirden. Andererseits bezeichnet der Autor seine Sp. chalybaea als .,eine echte Aphestia", die demnaeh anch das diese Gattung einigermafsen charakterisierende verlängerte dritte Fühlersegment besitzen wïrde. Da ich leider die v. Rödersehe Type nicht kenne, ist natürlich ein Entscheil in der Frage bislang unmöglich. Jedenfalls beschreibe ich als typische Art:

$$
\text { Adelodus rufipes } \text { in. sp. ot. }
$$

Ein einzelnes or aus Cairns (Queensland) ex coll. Hermann.

Kopf. Untergesicht und Stirne gleichmaisig mit lebhaft messinggelber Bestiuhung bedeckt; ،lieselbe Farbe besitzt auch der gesante Knebelhart sowie die feinere Beharung des Gesichtes. Die an seitlichen Mundrande stehenden Borsten sinil jedoch schwarz, Scheitelgegend und Hinterhaupt braun, dieses am Augenramle messinggelb, weiter abwiirts weil's bestäult. Die zwei Oeellarborsten sind schwarz. Die Behaarung des Hinterhauptes ist oben gelblich, nach abwïrts weifs und geht alhmählich in ten gleichfalls 
weifsen Backenhart iiber. Riissel, Taster und Fiihler schwarz mit g'leichfarbiger Behagrung:

'T'holax dunkelerzhraun, mälsig' glänzend, gleichmaifsig' mit hellbrauner, goldig schimmernder, anliegender, nach hinten zu lïnger werdender behaarung beleckt. Die lïngere Beharung der Schulterecken, sowie die grüberen liorsten schwarz. Schildehen elıenfalls erzbraun und hell behaart, Randborsten schwarz. Pleuren schwarz nit weifsel Bestiubung. Ton den Torlerhiiften bis zu der Fliigelwurzel erstreckt sich eine gebogene Binde messingogchber Bestiubung. Dic Mesopleura zeight einen länglichen nnbestäubten Fleck. Beharung der Pleuren weifs, die Beborstung schwarz, ebenso der Metajleura]schirm. Schwinger lichtbraun. Metanotum durch teils weise, teils messinggelbe Bestäubung schillernd, lichtbraun behart. Hiiften rot mit weifser Bestiubung und Beharung.

Abdomen lebhaft metallisch blaugriin mit violetten Reflexen und dichter Punkticrung. Der dichten, anliegenden schwarzen Behaarung des Hinterleibsrickens mischen sich an den Segmenteinschnitten weifse Hare bei, durch die wenigstens bei gewisser Beleuchtung eine unscharfe Bindenzeichnung entsteht. An den Seiten des Abdomens ist die recht lange, abstehende lieharung weilslich, die Discalborsten braun. Das kugelig sich vorwölbende, anscheinend kompliziert gebaute 1 y popygym ist rothram und mit einem Buischel goldgelber Haare hesetzt. Banch bram, mit zarter, weifslicher Behaarung.

Beine. Ilic verdickten, rotgelben Oherschenkel besitzen auf der Oberseite der Knie einc unregelmälsige brame Makel, ebenso sind die lebhaft rotgelben Schicuen an ilurer Spitzenhälfte gebriiunt. Nie nicht besonders dichte, nur an her Innenseite der Hinterschienen wimperartige Belaarung ist weifslich, die Borsten volwiegend schwarz. Die-schwarzen Tarsen tragen auf ihrer Oberseite anliegende Haare von teils schwarzer, teils lichter Farbe, auf der Unterseite ist dic biirstenfürmige Beharmug fuchsrot. Klauen schwar\%, Pulvillen gelb. Die recht lange Beborstung der 'Tarsen ist vorwiegend schwarz.

Fliigel leicht brïunlich tiugriert, mit ziemlich lebhaft irisierendem Glanz. die Adern dunkelbraun.

Long. corp. $12 \mathrm{~mm}$, long. alar. 9,5 mm. 


$$
\text { Adelodus nigro-coeruleus n. sp. ot. }
$$

Ein einzelnes bxemplar aus $\mathbf{N}$.-S.-Wales (Mt. Victoria) befindet sich in der Sammlung des k. ungar. Nationalmusemms in Budapest.

Kopf. Gesicht, Stirue, Scheitel und Hinterhaupt mit branner Bestäubung bedeckt. An dem dichten Kucbelbart sind die kiirzeren Borstenhaare weils, die dazwischen stehenden langen Borsten schwarz. Diese Farbe besitzt auch die Beharung des Gesichtes, der schwarzen Fuihler, der Stirne, sowie die Ocellarborsten. Die Hare des Scheitels und die Oceipitalborsten lichtbraun, die feinere Behaarung des Hinterhanptes, ler Backenbart, sowie die Haare der Kinngegend, ler kleinen schwarzen Taster nnd des Riissels weilslicl.

Thoras. Mesonotum uni Schildchen fein punktiert, gläuzend schwarz mit bramem Erzschimmer. Die dichte. anliegende Beharung ist gelb, die dazwischen stehenden dorsocentralen Hare dunkelbraun. Scitenbeborstung des Mesonotum und dic Randbehaarung des Schildchens durchaus schmarz. Die Plenren nnd die lebhaft gelbroten Hiiften sind mit weifser bis ockergelber Bestäubung und gleicllfarhiger zerstrenter Behaarung hedeckt. Notopleuralborsten und der vor den lichtgelben Schwingern stehende Metajlemralschirm schwarz. Die schwachen Borsten des Collare lichtbram, das ockergelb bestäubte Metanotum besitzt schwarze Beborstnng:

A bdomen grob punktiert, glänzend schwarz, an dem 2.-6. Segment mit lebhaft blanen, an den Seiten mehr griinen Reflexen. Die aiufserst kurze, anliegende Behaarnng ist gelb; lateral wird dic Behaarung länger und reifs und bildet ziemlich ansgelehnte Torderrandflecken, das siebente Segment ist durchaus mit weifser Behaarmng versehen. Die abstehende, mehr borstenartige Seitenbehaarung ist weifs lis gelb. ebenso die Discalborsten; an den Seiten des sechsten und siebenten Segmentes stehen einige schwarze Borsten, anch die Genitalien sind schwarz belıart. Bauch sclıwarz mit lichter bestäubten Hinterrandbinden und zarter lichter Behaarung.

Beine mit Ansuahme der gelbbramnen Trochanteren glänzend dunkelbraun bis schwarz. Die feine Behaarung ist nur auf der Oberseite der Schenkel teilweise ockergelb. in uibrigen aber weifslich. l)ie Oberschenkel tragen an ihrer Unterf́liche lang abstelıende Borstenlaare von weifslicher 
Farbe, die Borsten der Srlienen und Tarsen aber sind durhans schwarz. Die wenig auffallende bürstenfümige Beharung ist goldgelb, lie Wimperhaare an den Hinterheinen fahlgell, Klauen schwarz, Pulvillen lichtgells.

Die relatir kurzen filigel sind nur seluwach gran tingiert, hỵalin. Die C̈lerung ist durehaus sehwarz, einzehe Qneradern, sowie die Gabelung der Culitalader sind schattenartig dunkler gesiiumt, so dals eine ganz leise Audeutung von punktförmigen Flecken entsteht.

Long. corp. 11 mm, long. alar. $7 \mathrm{~mm}$.

\section{Cyanouredys n. $\stackrel{\text { g. }}{ }$}

Relativ grofse Arten von eclit laphrienartigem Hahitus; der lebhaft metallisch glinzende Hinterleil ist mit dureh weifse Behaarung gebildeter Fleeken- oder Bindenzeichnung versehen, die jedoch nur bei gewisser sehiefer Beleuchtung völlig dentlich sichtbar wird.

Koplf (Taf. Fig. 47 \%. 48) breiter wie loch, wenig alogeplattet. Untergesieht mälsig hreit, in heiden Richtungen sanft gewölbt, ohne Gesichtshöcker,

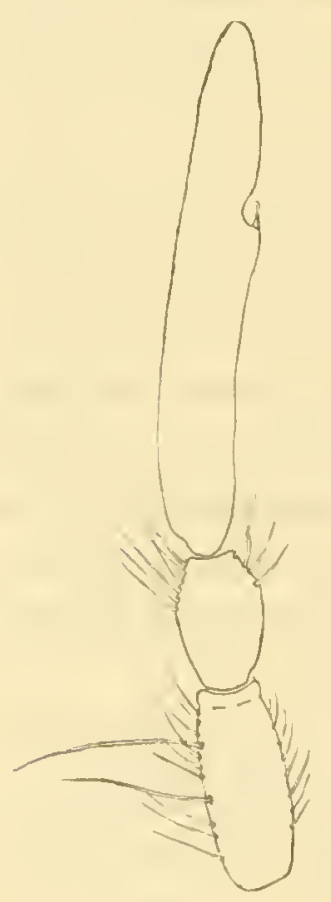

Fig. 50 . fast völlig von dem buschigen Knehelbart und grober Beharrung bedeckt. Tmerer Augenrand iiber den Fiihlern nur ganz wenigg ansgerandet, so dafs die an den Rïndern, sowie unter der Wurzel des Ocellenhöckers behaarte Stisne und die Schleitelgegend gegeniiber dem Untergesicht kaum verbreitert erscheinen. Fiihler ziemlich lang. das kurz behaarte, an seiner Unterseite mit einer oder zwei langen Borsten bewehrte erste Segment nicht ganz doppelt so lang wie das apical beborstete zweite Glied. Las streifenförmige dritte Segment ('Textfig. 50) ist nieht ganz doppelt so lang wie die beiden Wurzelglieder zusammengenommen, olne Entgriffel. Sein oberer Rant ist im apicalen Drittel mit einer selarten Kinkerbmg versehen, in ter ein kräiftiger Zahnstift steht. Kiiissel mälsig lang', gerale, von rundlichem Querschnitte, an der W'urzel dicht belatart; 'T'aster auftallend klein unl an der Spitze mit 
nur wenigen Borsten besetz. Hinterhaupt leicht gewiillst, nu1 wenig beborstet. aber dicht behart. Auch der Backenbart ist nicht dicht.

Thorax relativ schwach entwickelt, sanft gewölbt. Yesonotum mit diehter mehr oder minler abstehender, nach riickwïrts liinger werdender Behaarmug versehen. Beborstung: priisutural 4-5, supraalar 6-7, postalar 3-4, notoplenral 4-5. Eimzelne dieser Borsten sehr lang und kräftig. Auch der Metaplemralschirm ist selur lang und dicht. I'leuren teilweise mit Bestäubungsflecken und -ljinden, und mit zarter, zerstreuter Behaarung. Über den dicht behaarten und beborsteten Hiiften stehen lïngere Haarbiischel. Schildehen behaart und randständig mit langen Haaren und Borsten versehen. Metanotum mit einem Biischel langer Borstenhaare.

Abdomen lang und plump, metallisch glänzend, aus sieben vou oben sichtbaren Segmenten bestehend, fein aber dicht punktiert. Das ziemlich grolse, kugelige Hypouygium sowie die nicht rorstehende Legeriihre sind mach abwiirts gekelırt. Anf dem Hinterleibsriiøken ist die schwarze liehaarmg recht dicht, abjer kurz, melır oder minder anliegend, anfserdem erzengen weirse, längere, fast silberglïnzende Haare an einzelnen Giliedern binden- oder Heckenartige Zeichnungen, oder hetecken crentuell ganze Segmente. An den Seiten des Abdomen ist die Beharung abstehend mul lang. Das erste Segment trigigt seitlich ein Biisehel derler Borsten. auch die iibrigen sind mit starken Discalborsten bewehrt.

Beine kräftig und relativ lang, ohne besonders auffallende Jerkmale. Die Schienen und Tarsen der vorderen Beinpare tragen an ihrer Aulsenseite lange, wimperartige, silberweifse Beharung.

Fliigel. Sticl der Subcostalzelle ziemlich lang. nur wenig nach aufwärts gebogen, erste nnd zweite Hinterrandzelle niclut verengt, die dic Discuidalzelle sowie die dreieckige vierte Hinterrandzelle distal abschliefsenten dilern fast in einer Linie liegend, Anal- und rierte Hinterrandzelle lang gestielt, kleine (Gnerader iilser dem basalen Drittel der Discoidalzelle stehenul.

Alle bis jetzt bekamut geworlenen Arten gehiiren der australisehen Fama an und stammen aus Queensland. Als typische Art beschreibe ich: 


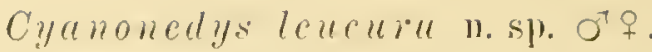

lin ort aus Kap lork in der Sammlumg des k. k. llofumseums in Wricn, ein or aus Australien ohne nähere Fundortsangabe ex coll. Hermann.

ơ Koj, Untergesicht mit dichter weilser Bestäubung, auch die gesante Beharmug, sowie der Kuehelbart sind rein weils. An der Stime ist lic Bestaubung leicht gelblich, lie Beharung ausschliefslich sehwar\%. Ocellenhörkel bramn, ebenso ist ein keilfürmiger, von dem inneren Angenrand sich medialwirts erstreckender Fleck anf lem Scheitel braun bestaubt, in iibrigen ist das Hiuterlaupt mit weifser, fast silberschimmernder Bestånbung bederkt. Auch dic Behaarung und die Borsten des Hinterhauptes, der Backenbart, die Haare des schwarzen K'iissels und der kleinen 'Tastel' sind weifs, die (cellarborsten jedoch schwarz. Fiihler schwar\%, das erste segment unten mit weifser, oben mit schwarzer, das zweite Segment iiberall mit schwarzer Behaarmug verschen.

'Thorax. Nesonotum und Schildchen schwarz, glänzend, mit leicht violettem Schimmer, die gesamte Behaarmug und Beborstung cbenfalls schwarz, nur auf dem Plotliolax, sowic dem Collare finden sich in grofserer Anstelumug anch weilse Haare. Pleuren violettschwarz, glïmzend, nur an nen die einzchen Abschnitte trennenden Nahtlinien funden sich wenig in lie Augen fallende ockergelbe Bestäubungssäume. Behanumg und Beborstung (ler Pleuren schwal'z, ebenso die Halteren. Hüften schwar\% mit ockerbraunce Beståmbung und lauger weifser Bchaarung. Metanotum dureh ockerbrame bastïnhung schillernd, scitlich mit eiuem Biischel schwarzer Hasre versehen.

J)as relativ gedrungene und plumpe Abdomen ist schwarz, mit leblaft blaugriinem und roten Metallschinmer und feiner aber dichter Punkticrung. Die dichte Beharumg les Abdomen ist schwarz und an den Seiten recht lang. Das erste und zweite Segment zeigen durch weilse Beharum gebildete ziemlich breite Hinterrandbindeu, das zweite Segment träigt anch seitlirh weifse Behanoung. Das sechste und las siebente segnent sind gleichmälsig mit ziemlich langer, abstehender, wie geschorener, licht schimmeruder beharung bedeckt. Das kugelige Hỵopygium schwary und ebenso behast. Auch der Bauch ist sehwarz. 
Beine mit lebhaft blaugrinem Metallglanz, die 'Tarsen melı schwar\%. Vorilerschenkel mit ahstehender, dichter, im wesentlichen schwarzer Behaarmng, aber ohne kräftigere Borsten. Die Torderschienen tragen an ihrer Imnenseite kurze. biu'stenförmige, fast fuchsiote Behar'ung', an der Torder- und Aufenseite sind sie mit langen, fahnenartig abstehenden, silberschimmernden Haren bekleidet. Jiese setzen sich anch anf der Oberund Anfsenseite der 'larsen fort, ebenso wie deren Unterseite mit fuehsroter' Biirstenbehaarnng versehen ist. 1)ie ziemlich dichtstehenden Borsten der Schienen und 'Tarsen simi schwarz. Die Mittelschenkel sind an ilırer Obernud Vorlerseite schwarz, an der Hinterseite jedoch lang weifs behart. Die Schienen und 'T'arsen besitzen die gleichen weilsen fahnenartig abstehenden Hare wie an den Vorterbeinen, entbehren jednch der fuchsroten Bebiirstung. Die Hinterschenkel sind mit im wesentlichen weilsen, namentlich an der Unterseite langen Harren besetzt und tragen antserdem in ihrem apicalen Drittel einige derbe Borsten von schwarzer Farbe. Die Hinterschienen sind an ihrer Torderseite äulserst dicht mit bleichgelblichen wimperartigen Haren besetzt. Die Tarsen sind in wesentlichen schwarz behaart und beborstet, nur die beilen Endglieder tragen anch kurze, weilse Haare. Netatarsus und Schienenspitze an der Unterseite mit bramer Biilstenbehaarung. Klanen sehwarz, Pulrillen hellbramu.

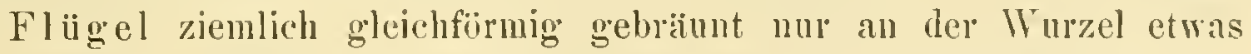
lichter. An der Gabelstelle ler Cubitalzelle findet sich ein kleiner, rerwaschener, dunklerer Flecken.

Das $q$ gleirht in wesentlichen den of. so dafs die Angabe del kleinen Unterschiede vällig' geniig't. Die weilse Pestainbung des Lintergesichts geht an den seitlichen Partien des IIundrandes in ockergelb iiber, lem weifsen Knebelbart mischen sich am Mnndrande in gröiserer Zahl schwarze Borsten bei, das erste Fiillersegment ist anch an seiner Unterscite schwarz behaart, die Fliigel zeigen ein gleichnäsig dunkleres Koln rit.

Long. corp $17 \mathrm{~mm}$, long. alar. $12 \mathrm{~mm}$.

Aufseriem sind mil noch folgende Arten bekannt geworden: 


\section{Cyanomedys luyubis n. sp. ort.}

Fin $\jmath^{T}+$ ans Cains (Queensland) ex coll. Ilermann, ein $q$ ebendahore ex coll. Jichtivalit.

Kopf. Untergesicht, Stirne, Scheitel und Hinterlaupt gleichmärsigo mit bleicligelber Bestäubung bedeckt und shenso belaart; mur auf der Stime finden sich auch einige wenige Haare von schwarzer Farbe. Knebelhart hleich messinggelb, Backenhart weifslich, anch die Behaarung des Jiissels. die ()cellar- und Occipitalborsten bleichgelb, die kleinen Taster dagegen schwarz beborstet. Die liihler sind durch dunkelbranue Bestälubung matt: die Bchaarung her beiden Basalg]ieder ist im allgemeinen schwarz, Joch finden sich auf aer Unterseite des ersten Segmentes auch einige grelbliche Hare.

Thorax. Mesonotum und Schildehen schwarz, glänzend, fein punktient mit nach riickwints länger werdender sehwarzer Beharrung, der sicl, jedoch im vorderen Drittel des Thoraxilickens auch weilssehimmernde Härchen beimischen. Die Borsten sind ausschliefshch sehwarz. l'lemen schwar" mit gleichfarbiger Behaarung und Beborstung, nur iiber den Hiiften stehen Biischel weifser, ziemlich langer Haare. Huften schwarz, matt, mit langer tejls weifser, teils schwarzer Behaarung. Schwinger schwarz mit dunkel rotbraunem Kinopf.

Abdonen plump, schwarz mit dunkel blaugriunem Metallschimmer nud dichter l'mukticlung. Die Beharrung ist auf der Riickenflache und an lem Seitemande selwar\%, aber merlilieh kiirzer als bei der Sp. leucuru. thie Discalhorsten ebenfalls ansmalnuslos scluwarz. Die Segmente drei, vier. funf. serhs und sieben besitzen dureh anliegende siberweifse Beharmug grobildete, nach riekwiats gröfser werdende Scitentleeken. Baurh schwarz,

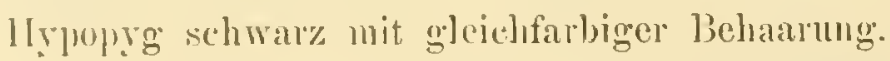

lieine schwar\%, mit violettem Metallglanz. Die Pehaalung und Jehorstung ist in wesentlichen von gleichel Beschaffenheit und Anorlnung wie bei der Spl. leucure, mur im gauzen etwas kïrzer. An der basis der llinterschienen steht ein Biisehel anliegender silberweifser llare.

l'liigel dureh sehr breite. verwasehene Adersilume sclıwar. An

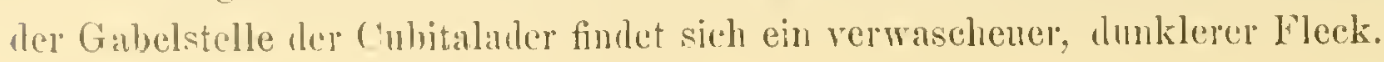


Die Unterschiede des $q$ gegeniiber dem of sind nur geringe. Die Hiiften tragen ansschliefslich schwarze Behaarung, an den Segmenten vier, fiinf, sechs mil sieben sind die weilsen Seitenflecken durch sehr zerstrente, kurze Härchen vou weilser Farbe iber die Mediane mitcinander in Verbindung, die Fliigel sind gleichmäfsiger mnd dunkler geschwirzt.

Loug. corp. $19 \mathrm{~mm}$. long. alar. $13 \mathrm{~mm}$.

$$
\text { Cyanonedys Hormii n. sp. of } q \text {. }
$$

Nem Exemplare ans ('airus (Rucensland) ex coll. Herman.

Kopf. Das sehwarze Lntergesicht ist dicht mit lichtgelber Bestäubung beleckt, auch seine Behaarmug. sowie der dichte Knebelbart sind messinggelb; die Stirne erscheint wegen der sehr diunen ockerfirbenen Bestäubmig dunkel mod ist ansschliefslich schwary behant. Fiihler schiwarz, die Basalglieder mit gleichfarbiger Beharung, anch die Ocellarborsten schwarz. Hinterhaupt weifsgran bestäubt, die Occipitalborsten gelblich, die Behaarung ist gegen den Scheitel zu selswarz, nimut aber nach abwärts lichtere Farbe an und geht allmählich in den weifsen Barkenbart iiber. Riissel sehwarz, weilshich hehaart, die schwarzen Taster mit schwarzer Behaarung.

Thorax schwarz, ziemlich glinzend, im vorderen Irittel mit diinmer schwarzer Behaarung, nach riirkwärts aber mit sehr dichten, anliegenden gelblichen Haaren bederkt, die sich in der L'mgebung del Postalarlöeker, sowie vor und anf dem Schildchen sehr verlängeru und fast schopfartig verdichten. Die Beborstung des Thoraxritckens und des Schildchens ist ausschliefslich schwarz. Pleuren schwarz mit duroh gelblichweifse bestïubung gebildeter Bindenzeichnung: Diese Binden steigen ron den Hiftwurzeln steil empor; wobei die beiden vorteren Binden durch eine von den Schulterbenlen zur F'liigelwurzel zichende Bricke untereinanler in Verbindung stehen. Die änfserst zerstrente Behaarung ler Pleuren ist cbenso wie die Notoplenralborsten und der Metapleuralschirm schwar\%, die ibber den Hüten stehenden Haarhischel sind dagegen weils, lliiften schwarz. an ilırer Vorderflaiche mit gelblichweifser Bestiubnug berlerkt und dicht weifs behaart. Metanotum duch grauweilse Bestïubung schillerud, seitlich schwarz behaart. Sehwinger gelbbraun. 
Abdomen schwarz, licht aber fein junktiert, mit an den Einschnitten selur lebhaft blangrinem Metallglanz. Die anliegende, kurze Beharung ist in allgemeinen sthwar'z; weilse silberglänzenle Behaarung billet anf dem ersten und zweiten Segmente ziemlich breite Hinterrandbinden. llie linde des zweiten Segrmentes verbleitert sich in der Mitte spitzwinklign nach volne, so dals die blangriine Grundfarbe nur in Form seitlicher halbrunler Flecken iibrig bleibt. Das vierte und fünfte Segment besitat lreievkige silberschimmernde Seitenflerken, das sechste Segment eine nach hinten dreicekig verbreiterte Vordermulsbinle, das siebente Segment ist durchaus mit weifser Behaarmng bedeckt. An den Seiten des Abdomen ist die länger werdende Beharung anf len heiden ersten segmenten weifs, im iibrigen schwarz, die kriiftigen 1)isralborsten sind auf jenen gelb, anf den folgenden Segmenten ansuahmslos schwarz. Hypoprgium sehwar\% und ehenso behart. Banch schwarz mit zerstrenter gleichfarbiger heharung.

Beine ilukelblangriu mit schwarzen 'Tarsen, die llinterbeine relativ lïnger als bei den beilen vorhergehenden Arten. An den vorderen Beinparen sind die Oberschenkel auf ilıer Oberseite schwarz, anf der Unterseite vorwiegend gelblich behart, die Schicuen und 'T'arsen besitzen die glciche franzenartige weifse lieharmug wic die iibrigen Speeies, an den Vorderbeinen sind sie ebenfalls mit Biirstenbeharmug von dunkelbrammer Farbe versehen. Die Hinterbeine besitzen in wesentlichen veilisliche Belaarung. I)ie Borsten sind an den beiden vorileren Beinparen an der Torlerseite hauptsaichlich schwarz, an der Hinterseite vorwiegrend gelblich, die Hinterbeine tragen mit Ansnahme der eigentlichen Tarsenglieler fast ausnahnslos gelbliche Borsten. Klanen sclıwar\%, Pulvillen lebhaft gelbrot. Flügel mit goleichnaifsiger, leicht branner 'l'ribung', die sich an der Gabelstelle ier Cubitalader zu einem zwar verwaschenen, aber doch recht dentlichen punktfömignen Flocken verilichtet. In der laasalhälfte sind die Arlern mit Ausnalnue der schwarzen liandader gelb, im ibrigren dunkelbram.

Auch bei dieser Art sind die Differenzen des $q$ gegeniiber dem $o^{7}$ mur greringe; sie sprechen sich wienlerum dadurch aus, lal's dem Knebelbarte, der Beharung les Gesichtes, der Scheitel- mu Occipitalgegend, sowie der Jliften und Beine schwarze Hare in gröfserer Anzalıl beigremischt sind und dal's lie Flügel ein entschieden dunkleres Kolorit besitzen. long. corp. $23 \mathrm{~mm}$, long. alar. $16 \mathrm{~mm}$. 


\section{Atomessire Heq.}

Die ron Macquart gegebene Gattungsdiagnose kann in ihrer urspriinglichen Fassung nicht mehr aufrecht gehalten werden, da sie sich auf die ganze Gruppe der Atomosinen mit alleiniger Ausnahme des Genus Atructic bezicht. Dementsprechend finden wir anch in der von Williston gegebenen kurzen Zusammenstellung der Atomosinengenera eine schärfere Fassung des Gattungsbegriffes Atomosia. Williston macht daranf anfmerksam, dafs der mediale Augenrand an der Stime ansgerandet ist, aber der Scheitel nach oben keine Terbreiterung zeigt; in vollkommen richtiger Weise hat der genamte Antor damit dasjenige Merkmal angegeben, das schon bei fliiehtiger Betrachtung mit einiger Sicherheit eine Trennung des Genus Atomosia von seiner Nachbarschaft erlaubt. Andere differenzierende Nerkmale scheinen ihm allerdings entgangen zon sein und ich möchte daher eine etwas genanere Beschreibung des Genus Atomosia geben.

Kopf (Taf. Fig. 49 u. 51) breiter als hoch. Das ziemlich breite, gegen die Fiihlerwurzel kanm verschmälerte Gesicht erscheint bei Profilbetrachtung dentlich gehöhlt, der Mnndrand ist beträehtlich vorgezogen, ohne aber einen eigentlichen Gesichtshïcker zu bilden. Der mäfsig dichte Kinebelbart besteht ans liangeren Borsten und kiilzeren Haaren, die sich hei den meisten Arten in der Mitte des Mundrandes zu cinem niedergedriickten Biisehel verdichten. Die Knebelborsten erstrecken sich auch an dem seitlichen Nundrande nach abwärts. In der zweireihig angeordneten Gesichtsbeharung machen sich ein oder zwei längere, abwïrtsgebogene Borsten durch ihre Länge bemerkbar. Über ter Fïhlerwuzel zeigen die Orbitalränder eine exquisite bogenförmige Ausrandung, welche zwar die Stirne erweitert, dic beharte und stark eingesunkene Scheitelgegend aber stark verengert erscheinen läfst. Die mit einer medianen, seiditen Rimne versehene Stime trägt zarte, zweireihig angeordnete Behar'ung: die eine lieihe befindet sich iiber den Fïhlem, die andere am Angenrande. Der ziemlich stark rorspringende Oechlenhöcker trägt hei gewiscen Arten zwei, hei anderen vier bis sechs kriftige Borsten. An den Fühlern ist das erste Segment stets etwas, manchmal erheblich lïnger als das zweite Glied; beide sind dicht 
behant und beborstet, die Vuturseite des basalghlierles ist aulserdem stets mit einel - seltencr mit zwei — lureh ilure länge und Dicke anfallende borste bewehrt. las melır oder minder spindelförmige bulglied ist unter allen Linständen lïnger als die beilen Grumdglieder zusammengenommen, entweder in ganzel Auslehumug. oder wenigstens an der Spitze dentlich pubescent und entbehrt eines lindgritfels. Der immer dentliche, in einer Ginkerhnng stehente Zahngriffel ist stets meh" oder minder weit von der Fiillerspitze entfernt. Jas Hinterhanpt triggt mur oben in beschuinliter Anzahl ausgesprochene Oecipitalborsten, meistens fehlen sie nach abwiits vollkommen oller sind wenigrstens ganz erheblirh schwiicher mul kiïzer. Die 'Tastel sind relativ gut entwickelt und gegen ihre Spitze mit sperrigen Borstenhaaren verselsen.

'Tlolax. Mesonotum und Sehildehen zart punktiert nud gleirhmälsig mit kurze, anliegenler, meist messinggelber Beharmug berleckt, zwisehen lie sich laingere, reilınweise gestellte dorsorentrale Borstenhare mischen. lie Plenen sind dicht bestïulst und zart beharet, mit Ausnalme del Mesoplcura, wolche meist der Bestäubung entbehrt und die gleiche anliegende, messinggelbe l3ehaarung wie das Mesonotum tıảigt. Beborstung: prisutural 1, suplaalar 1, postalar 2-4, notoplemal 1. Das Schildchen trägt an seinem Seitenranle einige kraftige Borsten, eine lieihe soleher fiulet sirh auf den bestäubten Collare, las Metanotum besitzt zwischen den kur"zen, stiftförmigen Borsten auch feinere Behaarung.

bas streifenförmige, jelenfalls nie verbreiterte derly punktierte, Abdomen bestelit aus sechs von oben sichtbaren Segmenten mul ist meist mit licht bestäulbten Segmentaleinschnitten geziert. Jer Ilinterrand

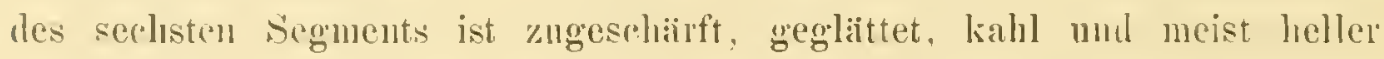
gefärbt. Die kleinen Genitalen sind ebenso wie las kurze siebente Segment ventralwiuts verlagert. Div Behuarumg ist anf dem Hinterleibsriicken kur\% und anliegend, auch an den Sciten relativ kurz. Die l)iscalborsten erstreckon sich weder bei den verschielenen Arten, noch bei den einzelnen Individun gleichweit nach hinten, sind jedoch auf den drei Segmenten immer vorlanden.

Die: kraiftigen, stark beborsteten Beine entbehren besonderer; charakterisierender Merkmale. Jie Wimperbeharmug der llinterbeine ist an ten 
Schienen besonders dicht. Bei einzelnen Arten besitzen die Hinterbeine der $\bigcirc^{\top} O^{\top}$ dichte, silbersthimmernde Behaarung.

F'liigel. Stiel der Subcostal-, der vierten Hinterland- und der Analzelle von miifsiger lainge. Histe Hinterrandzelle mehr oder minder verengert, ausuahmsweise geschlossen. Die die Discoidal- und die vierte Hinterandzelle distal abschlielsenden Queradern liegen stets in der grleichen Riehtung, aber nicht immer genau in gleicher Linie. Die kleine Querader steht iiber del Mitte ler Discoilalzelle, oder ist höchstens ganz wenig proximal rerschoben.

Geographisch betrachtet, gehören die Atomosiaarten ansschliefslich ter amerikanisehen Fauna an und diurften, soweit unsere Beobachtungen reichen, zwischen ılem $40^{\circ}$ nördlicher mu siddlicher Breite ziemlich gleichmälsig rerteilt sein. Dabei scheinen emzelne Arten iiber ganz Amerika verbreitet zu sein, während amlere mur auf die siidliche orler die nördliche Hälfte des Erdteils beschrinkt sind. Tie Behauptung der ausschlielshichen Zugehörigkeit des Gemus Atomosiu zur amerikanischen Famn kann festgehalten werden, trotzdem bekamtlich die Spec. A. Halictides IT alker aus Ostindien, die Sprec. plucens Wralker aus N.-Gninea beschrieben wurden. Letztere Art kemne ich unl es ist bereits an friberer Stelle gezeight worden. dafs sie dem Genns dtomosia nicht subsummiert werlen kanu. Aus der IV alkerschen Beschreibung ron A. Halicticles aber lailst sich wohl mit einiger Sicherheit vermuten, dals diese Spec. sicher nicht dem Gemus Atomosia zugehört.

Osten-Sacken macht in der Biologia Centrali-Americana die Bemerkung, das die Prïfung der vorliegenden Beschreihungen stets den Eindruck erweeke, als ob überhaupt nur eine und dieselbe Art volgelegen habe. und dels man trotzlem bei der Bestimmmmg einel beliebinen Atomosiaspecies stets das Gefiihl des Ungenügenden der betreffenten Artbeschreibung bekommt. Diese Bemerkung des erfahrenen 1)ipterologen diufte nach zwei Richtungen ihre Berchtignng ijesitzen. Zunächst vermag sie zu zeigen, dals die reinliche Auseinanlersetzung der Atomosianten an und fül sich auf grofse Schwierigkeiten stirfst, mnd ich will gleich cingestehen, dals es auch mir nicht gelang, diese zn besiegen, trotzdem mir cin ziemlich umfangreiches Untersuchuchnngsmaterial rorlag und mir lie lienutzung einer 


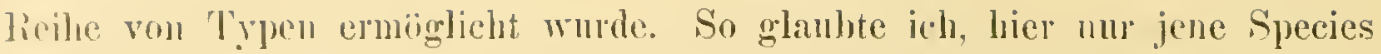
bedandelı zu diilfen, iiber deren ldentifizierung idh mir wenigstens einigesmalsen 'rwïnschte Klatheit verschaffen konnte. Diese Schwierigkeiten liegen zunaichst in lem relativ grolsen Mangel tinetorieller mul plastischer Merkmale, die tïr eine Ditferenzierung der im allgemeinen dister gefürlten Atomosianten zal Gebote stelen. Gileichwohl habe ich die Termutungr, dafs eine inteusivere Untersuchung namentlich der mämblichen Genitalien wohl eine schäifere Fassung der Artbegriffe erlauben diifte; ungliicklieherweise liegen aber gerale bei Atomosiu die kleinen Genitalen so versteckt an der Ventralfiache, dafs ihre Lutersuchung nur an durchsichtigen Kaliprỉluaten mighlich wïle. Eine solthe aljer liefs sich an meincu doch immerhin begrenzten, zum grofsen 'T'eil ans fremelem Besitz stammenten Material aus naheliegenden Griuden nicht 'ruöghlichen. Wie vorhandenen Srhwierigkeiten werden aber datureh noch vergroifsert, dafs nach meinen Erfahrungen die emzeluen Artes in ihren tinctoriellem Verhalten cine weitgelıende Variabilität besitzen, und ich glaube, dafs es sich häufig genug nur um Lokalformen liandelt, die in den Beschreilungen als eigentliehe Species getrenut wurden. Nun hat aber Osten-Sacken mit seiner oben zitierten Bemerkmug anch nach anderer Richtung liecht, _- ich meine die (1)alitait der in ler Literatur niedergelegten Beschreibungen. Zunaichst rivhtet sich das gegen Мacyuart. Schwer zu difterenzierende Arten lassen sich mit eingen wenigen, nichts ouler nur wenig sagenden Worten beim besten Willen nicht charakterisieren. Es war mir daher teìmeise nicht möglich, dic allzı kurzen, vïllig ungeniigenden Macyuartschen Beschreibungen zu bericksichtigen, zulem mir die Gelegenlueit fehlte, dureh cinen Vergleich der Typen die Berechtigung der von Macquart aufgestellten Arten zul prifen. Mutatis mutandis gilt diesel gegen Macqualt erhobene Torwurf anch gegeniber den Beschreibungen ron Walker, Rondani usw. Inls labe mich daher bemiht, vor allem unter Hervorhehung der allenfalls vorhandenen plastischen Merkmale die Beschreihungen der cinzelnen mir bekannt gewordenen sipecies sehr ausführlich, - mancher wird vielleicht golauben, allzi ausfihlichlich - zu gestalten, bin mir aher trotz aller aufgewendeten Miibe wolnl bewnlst, dals die Anseinandersetzung der mir bekannt gewordenen Atomosiaspecies doeh bislang nur als cin mehr oder minder 
nngeniigender Versuch anzusehen ist. Wenn ich mich gleichwohl entschlossen habe, eine Reihe nener Species aufznstellen, so kömnte dagegen vielleirht der Vorwurf erhoben werden, dafs schliefslich manche dieser nen anfgestellten Arten schon ron :ilteren Antoren beschrieben sein michte und dal's so mur eine Quclle nener Symonyma eröffnet wäre. Dieser Gefahr war ich mir natiirlich selbst bewufst, allein ich halte immer noch eine eventuelle Termelımng der Synonymie für das geringere Übel gegeniiber der Notwendigkeit, sich immer aufs nene mit Beschreibungen zu plagen, die schlechterdings z.n mngeniigend sind, um nach ihnen so schwer definierbare Species mit nur einiger Sicherheit auscinander zu halten. Vielleicht liifst es sich eimmal ermöglichen, die Typen Maequarts, Walkers, Roudanis usw. mit meinen ansfïhrlichen Beschreibungen zu rergleichen. dam wird es nirht schwer sein, in dieser Hinsicht Karheit in die Srstematik der Atomosien zu bringen und es wird dam immer noch Zeit sein, die ron mir vielleicht fiilschlich anfgestellten nenen Speciesnameu ruhigg wieder versthwinden zu lassen. Ich wende mich unmehr zu der Beschreibmig der einzehnen Arten. inlem ich derselben, soweit tunlich, eine analytisehe Bestimmungstabelle roransschicke; ich bemerke aber, dafs man sich bei der Ïhmlichkeit der rerschielenen Atomosianten nicht allzusehr anf liese Tabelle verhassen, sondern stets zur Sicherheit die ausfïhrlichen Beschreibnngen beriicksichtigen möge.

\section{Analytische Tabelle}

zur Bestimmung der mir bekannt gewordenen Atomosiaarten.

1. Der freie Rand des Schildehens ist durchaus mit langen Borstenhaaren besetzt. venustula Arribalzaga.

- Das Schildehen triigt nur seitlich einige wenige, derbe Borsten. ?.

2. Beine liellgelb mit geschwïrzten Endtarsen; eventnell findet sich an den Schenkeln und Schienen der beiden hinteren Beinprare wenig ansgedehnte, junkt- oder Heckenförmige Bräinnnng: Torderschenkel unil -schienen stets einfurbig hellgelb. rufipes Hcr. et varietates.

- Beine gelbbrann bis rotbrann mit ansgedehnterer Brïmmug oder dnukelbraun bis schwarz mit hellerer Kniegegend. 
3. Die Hinterbene der ơ an den 'Tarsen und der Aulsenseite der Schienen mit lichter silbersehimuernder Beharmug besetzt, die an den Sehienen anch beim $f$, nur weit weniger deutlieh, vorlitulen ist.

- Jie Hinterbeine der or ohe dichte silbersehimmende Beharung. 5 .

4. 1)ie zwisehen den Augen freiliegende Fliche des Kopfes (Gesicht, Stirne nnd Scheitel) gleichnälsig weifslich bestïubt: zwei Oeellarborsten.

tibialis Mey.

- Die zwischen den Angen freiliegende Flïehe des Kopfes abwechselnd durch weifse und goldgelbe Bestäubung quergebändert; 4-6 ()ellarborsten.

argyrophora Schin.

5. Der anliegenden, kurzen, lichten Behanrung des Mesonotum sind keine laingeren dorsocentralen, abstehenden Haare beigemengt.

6.

- Der anliegenden, kurzen, lichten Behaarmug des Mesonotum sind stets, freilich in wechselnder Menge, längere, abstehende dorsocentrale Haare beigemengt.

6. Relativ grofse Art ron $11 \mathrm{~mm}$ Linge. Beborstung des Hinterhauptes und des Collare sehr derb, dormartig. (1)mata $11 . \mathrm{sp}$.

- Kleinere Art von $7 \mathrm{~mm}$ Lïngc. Das Hinterhaupt trïgt jederseits nur Arci Borsten, Collare olme Borsten, nur mit feimeren Haaren besetzt. иuda $\mathrm{nt} \mathrm{sp}$.

7. Mesonotum und Abajomen dunkelerzgriin; Hinterschenkel einfarbig rot. an der Wurzel durehseheinend. metallescens $\mathrm{n} . \mathrm{sp}$.

- Mesonotum und Ablomen schwarz; Hinterschenkel dunkelbraun bis schwarz, oder gelbbraun bis rotbraun, dam aher stets mit ausgedehnter Brïunung.

8. Behaarung les Gesiehtes, der Taster und des Riissels schwarz. melanopogon $11 . \mathrm{sp}$.

- Beharmug des Gesiehtes, der 'Taster und des Riissels stets hell. weislich orter gell,lich.

9. Auffallend kleine Art von nu 4-5 mm Länge; Endglied der Fühler gegen die Spitze zapfenförmig verjïngt; Schildchen mit nur zwei borsten. similis Big. (?)

- Arten rom der ïhlichen Grölse; Hudglien der Fülıler gleichnälsig. spindelfürnig; Schildehen mit den gewöhnlichen vier Borsten. 
10. Hinterschenkel rotbraun mit schwarzer Zeirhmung auf ler distalen Hälfte.

- Hinterschenkel dlunkelbraun resp. schwarz, nur Wurzel und Spitze in geringer Ausdehnumg gellibraun.

11. Ocellenhöcker mit nur zwei längeren Borsten; Adern der Fluigel dunkelbran ; Endglied der Fiihler sehr deutlich pubescent, zart gefiedert. glabrata Say.

- Ocellenhöcker mit cinem Büschel langer Borsten; Adem der vollständig glashellen Fliigel durchans gelb; Fühler? Beclievi Jïnnicke.

12. Ocellarhöcker mit sechs divergierenden, langen Borsten: Randborsten des Mesonotum ausnahmslos gelb.

setosa n. sp.

- Ocellarhöcker nu nit zwei langen Borsten; Prïsuturalborste konstant schwarz.

puella Wied. geniculata Wied.

\section{Atomosia puella Wied.}

Aufser den beiden Typen Wiedemanns (coll. v. Winthenu) in der Sammlung des k. k. Hofmuseums in Wien liegen mir nocl 16 Exemplare (zehn ex coll. Bezzi, sechs ex coll. Hermann) vor, lie sïmtlich aus verschiedenen Fundorten N.-Amerikas stammen und sowohl mit den Typen, als auch, abgesehen von gewissen untergeordneten Färbungsvarianten, unter sich iibereinstimmen. Der Beschreibung Wiedemanns füge ich einige ergänzende Angaben bei, die es eventuell ermögliehen, die Species ron ihr recht nahe stehenden Formen bestimmt abzugrenzen.

Kopf. Gesicht weils oder leicht gelblich bestiubt. Der Knebelbart besteht aus einem medianen, lirekt über dem Mundrande stehenden, niedergedriickten Biischel kurzer und derber Haare und anfserdem ans lïngeren Borstenhaaren von ockergelber Farbe, die sich in einer Reihe an dem seitlichen Mundrande nach abwïrts erstrecken. Die zweireihig angeordnete, zarte, nach abwärts gebogene Beharung des Gesichtes ist wenig dicht und von weilser bis bleichgelber Farlue. Anch auf der weifs bestäubten Stirne ist die weifse Behaarung nur zart. Der Orellenhöeker ist mit zwei schwarzen Borsten bewehrt. Das graugelb bestäubte Hinterhaupt triigt nur oben jederseits 4--5 derbe, ockergelbe Oceipitalborsten; weiter nach abwïrts fehlen 
diese rollkommen und findet sich nur zarte, kur\%e Beharmug. An den relatir kurzen, schwarzen Fiihlem ('Textfig. 51 a u. b) ist das Basalglied an seiner L'uterseite entweder mit vorwiegend gell,licher, oder schwaryer Beharung, die Oberseite aber mol das zweite Segment sind ansschliel'slich schwarz beharart.

'T'holax. Das Collare trigt cine Reilie derber, ockergelber Borstell. Die gleiche Farbe besitzen anclı die supraalaren, postalaren und die Borsten des Schildehens, sowie die derben Borstenstifte anf rem Metanotum, dagegen ist die präsuturale 3orste koustant schwarz. Die Notopleuralborste ist lichtgelb, der aus diuneren Borstenharen bestehende Metapleuralschirm weilslich.

Anf dem Abdomen sind die Finschnitte

Fig. 51a. vom zweiten Segmente an weifs grerandet, dabei

Fig. $51 \mathrm{~b}$. sind sie an den vorderen Segmenten stets feiner und kïnnen altrly wohl cinmal in der Mitte mterbrochen sein. Das erste Segment triagt vier, das zreite drei, die folgenden zwei bis drei Segmente ein oder zwei bleichgellue Discallorsten.

Beziiglich der Beine bemerke ich, dals die Beharmug und Behorstung ansmalmuslos hell ist; weilslich oder gelblich an Schenkeln mul Schienen, ockergell, an den 'Tarsen. Biirstenförmige Behaarmng von glänzend ockergrelber Farbe fundet sich aufser an der Unterseite der Tarsen noch auf der Innenseite der Vorderschienen.

An den FlïgeIn ist die zweite Hinterandzelle kaum, die erste konstant verengert, aher stets mehr oder minder weit often. An der Gabel. stelle der Cubitaladel findet sich nicht sclten ein kurzes Aderrudiment.

L.ong. col1 1. 6.5-7,5 mm, long. alar. 5,5-6.5 mm.

\section{Itomosia geniculata Wiel.}

In der Sammlnug des k. k. Hofmusemms in Wien befinden sich ex coll. II intliem sechs durcli die liezettelung als 'Typen bezeichnete Fiemplare 
der Spec. geniculata. Ich bemerke, in Eräanzung der Angabe Wiedemanns, dafs von diesen sechs Exemplaren nur ein einziges den Fundzettel "Brasilien" trägt, während die anderen versehiedenen Gegenden Nord-Amerikas (N. York, S.-Carolina, Philadelphia usw.) entstammen. In der gleichen Samunlung finden sich nnter eigener Bezettelung und wahrscheinlich von Schiner bestimmt, neuu ansschliefsich sidamerikanische (Tenezuela, Brasilien) Exemp]are. Ich habe num diese sowohl, wie die sechs als Typen bezeichmeten Stiicke untereinander und die beiden Gruppen miteinander verglichen; ich habe đlabei zunächst eine völlige Übereinstimnung gefunden, aber anch feststellen können, dafs die Anortnung der schwarzen und gelbroten Partien an den Beinen einer ziemlich weitgehenden Variabilität unterliegt und dafs eine solche auch die Fiirbung der Behaarung und Reborstung an Gesicht, Knebelbart, Fiihlern, Beinen usw. beherrseht. Nun habe ich aber auch sehr eingehende T'ergleiche zwischen den beiden spec. geniculutu und puella angestellt, als deren hesnltat sich heransgestellt hat, dal's ich wenigstens aulserstande bin, die beiden Arten genigend voneinander zu trenuen. Dafs subtilere Färbungsdifferenzen hierfiir nicht die mindeste liolle spielen künnen, muls aus deren Tariabilität ohne weiteres zugegeben werden, aber auch die Prifung plastischer Merkmale macht mir eine 'Trennung' beider Arten ummöglich. Um davon nur einiges anzugeben, so finde ich bei der Spe. geniculata ilie greiche Anordnung des Knebelbartes, der Beharung des Gesichtes,

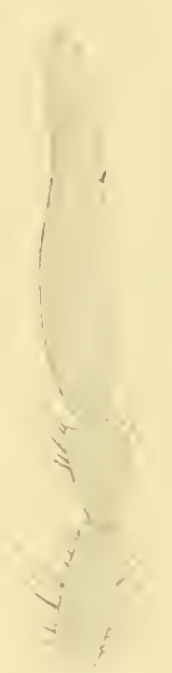

Fig. 52. der Beborstung des Ceellarhöekers, des Hinterhauptes usw., wic ich sie oben fiir die Spec. puella beschrieben habe. Andererseits lïfst sich freilich eine Verschiedenheit in dem gegrenseitigen Längenverhältnis des ersten und zweiten Fiilılergliedes insofern konstatieren, dafs bei A. puella das erste nur wenig fïllger als das zweite ist, wiihrend es bei A. geniculuta dieses bedeutend an Länge iubertriftt. Ich habe dieses Verhältnis in den 'Textfig. 51 und 5 ? kenntlich gemacht, bemerke aber, dafs diese Figmen gewissermalsen nur als Grenzwerte aufzufassen sind, zwischen tenen alle mïglichen l’bergänge beobachtet werden. Also aluch nach dieser Richtung erscheint mir eine Differenzierming der beiden Arten zurzeit noch numigglich. 'L'rotzdem mijehte 
ich sie beile einstweilen noch hier getrennt anfiihren, da bisher eine feinere Intersuchung der Genitalien an Kalipriparaten, die mir ans oben angefuilurten Grïuden nicht möglich war, noch anssteht. M̈̈ge daher solchen rein anatonischen Untersuchungen, die eventuell durch nähere Beriicksichtignug der geographischen Verbreitung cine gewisse Unterstiitzmng empfangen diirften, spaiterhin gelingen, wirklich einwandsfreic Unterscheidungsmerkmale zwischen beilen Formen anfzufinden, oder aber die Zusammengehörigkeit beider definitiv festznstellen.

\section{Atomosia melanopogon $\mathrm{ns}$ sp.}

Ein Exemplar ans Texas in der Sammlung Hermann.

Diese Art gehört in die unmittelbare Verwandtschaft von A. puellu, von der sie sich aber nicht nur durch die Firbonng, sontern auch durch die Anordnung der Beharrung des Kopfes unterscheidet. Vor allem sei daranf aufmerksam gemaeht, dafs der Ocellenhöcker ein Büschel vou sechs divergierenden Borsten trägt.

Kopf. Gesicht und Stirne gleichmaifsig silbergrau bestäult. Der Knebelbart, die Behaarung des Gesichtes und der Stirmmitte durchans schwarz; an den Seiten der Stirne finden sich aber anch vereinzelte weifse, auf dem Scheitel hräunliche Haare. Hinterhaupt lehmgrau bestäubt, die relativ sehwachen, bräınlichen Occipitalborsten finden sich blofs oben, weiter abwärts nur weifsliche Beharung, dic allmählich in den lichtbraun schimmernden Backenbart iibergelıt. Auch diesem sind aber, namentlich am unteren Augenrande, zahlreiche schwarze Haare beigemengt. Die Beharung ler pechbrannen Taster und der Wurzel des Riissels ist ebenfalls sehwar\% Auch die dunkelbraunen Fuiller ('T'extfig. 53) tragen ansschlielslich

Fig. 53. schwarze Beharmug.

Thorax und Abdomen vollstindig wie bei A. puella, nur fällt die Xotopleuralborste, deren Fir bung anf den beiden Seiten variabel (schwarz, hezw. lichtgelb) ist, durch ilne migewöhnliche Dicke anf. 
Anch die beine zeigen im wesentlichen die grleiche Färbung wie bei A. puella, aber die behorstung ist namentlich an den Torderbeinen der Hauptsache nach schwarz, anch die feinere Behaarmy hat an den Tordepschenkeln schwarze Fiilbung angenommen.

Fliigel durchscheinent, mit lichtbramner Älerung und einer geringen Sjur milchweifser Triibung. Die erste Hinterrandzclle ist gesehlossen resp. gestielt.

Long. corp. $7 \mathrm{~mm}$, long. alar. $6 \mathrm{~mm}$.

\section{Atomosia setosu n. sp.}

In ter Sammlung Bezzi befinden sich sechs ans brasilien stammende Stiicke; anch diese Art stelit A. mella nahe, liflst sich jecloch dureh eine Reihe plastiseher Iferkmale nicht schwer tremen.

Kopf. Gesicht mul Stirne breiter als bei den verwandten Arten. beirle gleichmilsig mit gelblichgraner Bestänbung dicht beleckt. Der dichte gelbliche Knnebelbart besteht aus anch den seitlichen Munirand einnehmenden Borsten mol zahldeichen dazwischen gemengten Haaren, die seitlich unnittelbar in die gleichfarbige dichte Behaarung des Gesichtes iibergehen. Die beiden unterhalb der Fiihlerwurzel stehenden langen Borstenhaare bleichgelb. Der gran bestänbte Ocellenhïcker trägt sechs gelhe divergierende Borsten von ungleieher Länge. Fiihler schwarz. Las erste segment ist namentlich an der Unterseite dicht behaart ('Textfig. öt); hier ist die Beharmug grö̈stenteils gell, an der (b)erseite jedoch sehwarz, doch mischen sich auch da einzelne lichtere Jä̈rehen bei. Das zweite Segment träigt beiderseits kïrzere schwarze Behaarung.

Fig. 54. An dem Endglied macht sich die Pnbesenz nur an der spitze bemerklich. Scheitel mud Hinterhaupt mit gellggrauer, an dem letzteren nath abwiarts mit weisslicher bestäuhung beleckt. I ic ziemlich lichte, aber feine gelbliche beharmog der scheitelgegend setzt sich inn hinteren (Orbitalrante nach abwärts fort nun gelit mit der gleichfarbigen lieharung des Ilinterhanjtes in den langen und dichten, fast weifsen Backenbart fort. Die gelben 


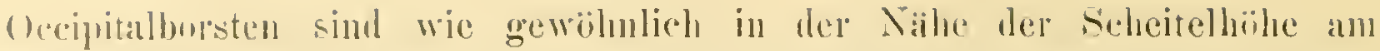
derlosten. lassen sich aher, freilich hedentend schwächer werilend, bis unter den Tínator des Auges nach abwiots verfolgen. Lie schwarzen Taster und der liiissel tragen lichte Behaarung.

'l'horax mul Schildchen sehwarz, gläinend, fein punktiert und mit der ïhlichen anliegenden, fahl messinggelben behaarung, die dem unhewaffueten Ange den T'loraxriicken leicht erzgriun ersclecinen liist. Anlserden trägt dieser aber reihenweise angeordnete, abstehende, hinten längel werdende dorsocentrale Borstenhare ron gelber l'arbe. Anch die starken borsten am Seitenramle des Mesomotum und am liamle des Schildchens sinul ausnahmslos @(cll). P'leuren mit weisgrauer Bestäubung bedeckt, die dic glänzend schwarze, mit anliegender messingogelber Beharmo berleckte Mesopleura treilairst. Dicse Bestäubung zieht sich auch gegen das mit einer licihe gelber borsten bewehrte collare empor. Die ziemlich diehte Behatung del l'leuren mul der gran bestiubten Hüfen ist weils. Notopleuralborste und der ror den hell zitronengellon Schwingern steliende Metapleurals(hirm gelb. liehorstung des Metanotun gelbbram.

Abdomen schwarz, dicht aber fein punktielt. mit weilsen Segmentaleinselnitten, die aber an den drei ersten Segunenten in ller Mitte breit unterbrochen sind. Lie anliegende. ïulserst kurze, messinggelbe Behaarung liegt all den Eimschnitten der hinteren drei Segmente etwas dichter mol gewinnt rol dem sohafen, rotgelben Rande des sechsten Segmentes erheblichere länga. An den Seiton des Abdomen ist die Beharmo linger um im allgeneinen hleichgelb. Ineh mischen sich ilı an uen hinteren drei Segunenten anch selowarze Hare bei. bie Discalborsten sind bleichwelb. Bauch dunkelgy'rau mit zerstreuter weilslicher Behaarung.

Beine durehats glänzend schwarz, nur die Kniegegend in geringer Auslehnung gelbbraun. l)ie Unterseite simtlicher Tarsen mit lebhaft gelber. tast goldghinzender hiirstenförmiger lieharung, die an den Vorderbeinen ancl dic Unterseite der Selienen einnimmt. An den Vorderschenkeln ist die Behaalumg ansschliefslioh lichtgelb, die Mittelschenkel besitzen gegen ihre spitze auch schwarze Haare, die Hinterschenkel sind an ihrer Oherseite fast ausschliefslich schwar\% hehaart. Auch der bleichgehben Wimperbehallung all der Untelseite sind vereinzelte schwarze Hatre beigemengt. 
An den Schienen der rorteren lieinpare ist die Behaarung im wesentlichen gelb, aber aud hier sind wenigstens an iler Vorderseite scliwarze Haare vorbinden. Die groben Borsten sind lebhaft rotgelb, an der Vorderseite aber stehen kiirzere Borstenhaare von schwarzer Farbe. An den Hinterschicnen ist die Behaarung und Beborstung der Ilauptsache nach schwarz. anclı der gelben Wimperbeharung an ilhrer Vorderseite sind in reicher Menge seluwarze Hare und Borsten beigemengt. Die groben Borsten an ler Innenseite alser sind rotgelb. Die Tarsen tragen auf ilırer Oberseite fast ansschliefslich schwarze kurze beharung und teils gelbe, teils sehwarze Beborstung. Klanen schwarz mit gelher Wurzel, l'nlvillen lichtgelb, Empodialborste geth). Bei dem $q$ tritt die schwarze Beharung der Reine allenthalben mehr in ten Hintergrunt, olne aher völlig zu versehwinten.

Fliigel fast vollkommen hyalin. Die Adern sind dminelbramn. Erste Hinterrandszelle dentlich verengert, aber immer offen.

Long. corp. $7,5 \mathrm{mmm}$, long. alar. $6.5 \mathrm{~mm}$.

$$
\text { Atomosiu nude n. sp. }
$$

Drei Exemplare aus Trinidad in der Sammlung des Herrn Leander Czerny in Kremsminster.

Kopf. Gesicht mit lichter siberweifs $\subsetneq$ Bestimbung und gleichfarbiger Behaarung. Auch der Knebethart, der im ibbrigen die ten meisten Atomosien eigene Zusammensetzung besitzt, ist ansschlielslich weifs. An der Stirne und dem scheitel ist die Bestäubung mehr gelblichgran und auch die sebr zarte hehaarung von gelblichweilser Farbe. Wie beiden Ueellarborsten sind getb. Das weilsgrau bestäubte llinterhaupt trägt nur oben jederseits drei gelle Occipitalborsten und ist im uibrigen nur mit reeht zarter kurzer Behaarmog von weifser Farhe verseben, lie nach abwärts in den weifsen, dichten Backenbart iibergeht. Auch die Behaarung der Kinngegend, der schwarzbraunen Taster und des Rïissels ist ansechliefshell weils. I Iic schwarzen teilweise gran bestiubten Fuihler (Textfig. 55) relativ lang, das Grundsegment anffallend gracil: der Zahmgriffel des schwach pmbescenten kinghiedes schwach entwirkelt. Die

Fig. 5.5. 
liehaarung der beiden besalen Segmente ist sehwarz, nur an der İnterfaiche des ersten Gliedes sind lie IJare und anch die cinzelne lange liorste fahlgelb.

'T'lopia. Mesonotum und Schildehen schwarz, glinzend, mit feiner P’unktierung und diehter, narh hinten zu länger werlender, anliegender beharung ron messinggelluer Farbe. Lïngere dorsocentrale Haare sind kaum vorhanlen. Pleuren mit Ansnahme der glänzend schwarzen, mit licht messingogelben Haren verschenen Mesoplenra sehr dicht weifs bestänbt und zart hehaart. Dic gresamte Beborstung des 'Thorax und des Schildchens mit Ausuahme der sehwarzen Präsuturalborste gelb. Der vor den gelben Schwingern stehende Metapleuralschirm falılgell,. Die dichte Borstenreihe des grauweifs bestaiubten Collare, sowic die Borsten auf dem gran bestäubten Metanotum, denen kurze, messinggelhe Härchen beigemischt sind, sind ebenfalls gelb. Hiiften reilsgran bestänbt und zicmlich lang behaart.

A bilomen schwarz, gränzend, mit grober Punktierung, gleichtörmiger, kurzer, anliegenter, messinggelber Beharmng und schmalen, wach hinten zu ctwas breitel werdenden, weifsen Segmenteinschnitten. Die nur wenig längere Seiteubehaarung ist weilslich, die Discalborsten fahlge!b. Baurh granbraun mit dister gelben Hinterrandsbinden und zarter grauer Belaarumg.

Beine. Schenkel und Schienen gyelbbraun göanzend. Die Selıenkel simtlicher Beine besitzen einen breiten, dunkelbraunen Ring, aler die gelhbranc Grundfarbe nur au der ITurzel und den Kunicn freilaist. Auch die "Truehanteren der Hinterbeine nnd das Spitzendrittel der Schienen ist schwach gebriunt. Die T'arsen sind durchaus dunkelbraum. Die feinere Behaarmugr ist weilslich, $1111^{\circ}$ auf der Oberseite les Metatarsus und der beiden folgenten 'Tarsenglieder der Hinterbeine teilweise sehwarz. Hier stehen aurh schwarze Borsten. wihrend sic im ibrigen teils weilslich, teils gelh sind. Die gewïhnliche hiirstenfümige Beharmug an der Unterseite der 'Tarsen unil der Vorderschienen ist dunkel goldgelb, was sich mamentlich an den Llinterbeinen recht auffillig benerklich nucht. Kilanen schwary, l'ulvillen fallogelb.

Flïgel durch mikroskopische Behaturung leicht getribt, die ahor in den beiden basalzellen. sowic in dem proximalen Drittel der Analzelle fehlt, so dal's dic lihgelwurzel lichter erscheint. Histe Hinterrandszelle melir oder minter verengert, aber stets offen. 
Man wird diese Art, trotz mancher $̈$ Änlichkeit, bei ciniger Aufmerksamkeit auf die Gestalt der Fühler, die Farbe und Behaarung der Beine usw. kaum mit A. puellu rerwechsehn kïmnen. Von A. setosu und melanopogon ist sie unter anderem schon durch den Besitz von nur zwei Ocellarborsten, sowie den fast vollkommenen Hangel lïngerer Dorsocentralhaare leicht zu tremnen.

Long. corp, $7 \mathrm{~mm}$. long. alar. $6 \mathrm{~mm}$.

Atomosia similis Big.

Enter diesem Namen befuden sich in der Sammlung Bezzi zwci Exemplare einer auffallend kleinen Atomosiart aus Kuba. Da mil die Bigotsche Artdiagnose, - sie ist in Sagmu, Hist. de isla de Cuba 18.51; erschienen - nicht zugäinglich war, will ich hier eine Beschreibung der mir vorliegenden Tiere geben. Sollten sich diese mit del Bigotschen Species similis nicht identificieren lassen, so wiirden sie als Vertreter einer nenen Species aufgefal'st werden miissen, da wie mit keinel der mir bekannt gewordenen Atomosianten wähere verwanitsehaftliche Beziehungen besitzen.

Kopf. Gesicht und Stirne glejchmaifsig mit gelblichweifser Bostïubung bedeckt. Die Behaarung des Gesidlits ist ebenso wie der Knebelbart, der aber die biischelfürmige Anordnumg der kiil'zeren Haare rermissen läfst, weifslich. Die Stirne träğt seitlich zwei schwarze borstenhaare, leer gelbgrau bestänbte sucheitel besitzt teils schwarze, teils fallgellhe Hiirchen. Die beilen Borsten des ziemlieh flachen Orellenhückers schwarz. Die Borsten des grau bestäubten Hinterhauptes sind fahlgelh und

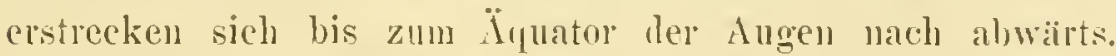
I ie kuirzere Behaarung des llinterhanptes, der wenig dichte backenbart sowie die Haare ler Kinngegend, der schwarzen T'aster und des Riussels sind weifslich. Die Fiihler ('lextfig. 56) sind schwar\% und elenso beborstet, mur die cinzelne längere Borste ist gelb. Das basalglied ist wenig länger als das zweite segment. das fein pubescente Endglied ist proximal efwas verbreitert, distal aluer zapfenfuirmig. verjiingt. 
'Thorax. Mesonotum schwar\%, glïnzend, fein punktiert und mit der gawwihnlichen anliegenten kurzen. licht messinggelben Beharmg versehen, der sich jederseits aine lieihe kurzer lorsocentraler l3orsten beimengt. bas schware Schilichen ist licht messinggelb behaart und an seinem freien liande mit nur zwei grelben Borsten bewehrt. Plenren und Hiiften mit Ausnahue der messinggelbe anliegende Behaarmg tragenden Ilesopleura gran bestäubt und zart weicslich behart. I he Beborstung des ganzen Thorax ist mit Ansuahme der schwarzen Priisuturalborste gelb. Der vor den gelben Schwimgern stchende Metapleuralschim fahlgelb. Das Collare cutbehrt gröberer Beborstung; das Mctanotum träigt nur einige wenire kurze Borsten von brïunlicher Farbe.

Abdomen schwar, glianzend, grob punktiert, mit der gewöhnlichen anliegenden, knrzen aber weng ilichten messinggelben Behaarung und schmalen weifsen Segumenteinschnitten. Die nu" wenig verlangerte Seitenbeharmong weislich, lie Discalborsten, die sich mu auf den vorieren drei Segementen finden. weifsgelb. Bauch graubraun bestiubt und zart hell behaart.

Beine schwarz, glïnzend, nur die ïulscrste Kniegegend, sowie das basale 1)rittel sïmtlicher Sehienen gelbbraun. Die sparsame kiirzere Beharung ist allenthalben weifslich, die Beborstung ist durchaus gelb; nur an den Tarsengliedern finden sich auch schwarze Borsten. Die wenig ausgebreitete bitrstenfïmige Beharung ist matt goldgelb, die Wimperbeharung der ILinterbeine, die namentlieh an den Schienen sehr dicht ist, weifs. Klanen sehwar\%, Pulvillen fahlgelb.

Fliggel sehwael briumlich tingiert, an der Wurzel etwas liehter. Die İderung ist bran, die erste Hinterrandzelle nur wenig verengert.

lomg. corpe. 4,5 mm, long. alar, 3,5) mm.

\section{Alomosia metullesecns n. sp).}

Vier Exemplare lieser leicht kemntlichen Art aus Mendoza (Westargentinien) in der Sammlung Hermann.

Kopf. Gesicht unten mit dichter weifser, anfwärts melır gelber l3estänlung bedeckt. Der Knebelbart, weleher die den meisten Atomosien 
e.gene Zusammensetzung besitzt, weis, ehenso die iibrige Behaumung des Gesichts. Stirne nul Selieitel ebenfalls mit weilser, hezw. gelblicher bestiubung bedeckt und zarter weifslicher Beluarmug. Das ockergelb bestiiubte Hinterhaupt triagt gleichfurbige, relativ schwach entwickelte Occipitalborstcu, die schon, iiber dem $̈$ İuntol der Augen verschwinden, und zarte weilse Behaarmug; auch del zarte Backenbart ist weifs. Riissel und 'T'aster sehwarz mit weifslicher Beharung. Fühler (Textfig. 57) schwarz, die Basalg'lieder der Hauptsache nach schwarz beborstet, $110{ }^{\circ}$ an der Unterseite des ersten Segmentes ist die Beborstmng gelblich. Das erste Segment ist ungefähr doplelt so lang als das kurze zweite. das schlanke, an seiner Spitzenhälfte deutlich pubescente Fudglied ist etwa $1^{1}{ }_{2}$ mal so lang als die beilen basalsegumente znsmmmengenommen.

Fig. 57.

Thorax. Mesonotmu mol Schildelıen dunkelergariun. stark glänzend und fein punktient. Die iibliche anliegende messinggelbe Beharmug ist wenig dicht, länger abstehende, ehenfalls gelbe dorsocentrale Hairchen tinden sich blofs anf der hinteren Hälfte des Thoraxuijckens. Die Seitenborsten, die Randborsten les Schildchens mu die kurzen Borstenstifte des dunkelgrau bestäubten Metanotmm sind gelbbram. I)as granweils bestänbte Collare trägt eine Reihe relatir schwacher, gelhbramer Borsten. Pleuren mit Ausnahme der messingrgelb beharten Mesopleura mit weilser Bestainbung bedeckt, die auch den 'Thoraxrand bis zn den Postalarhiiekelı siunut. Notopleuralborste und der vor den gelben sabingem stehende Mctaplemralschirm gelblieh. Hiften weifs hestäubt und ebenso wie die Plenren mit zarter und zerstrenter weifser Beharmug rersehen.

A bdomen ebenfalls dunkelerıgriin mit diahter und grober Punktienung und weifslichen, an den Seiten etwas verbreiterten Segmentaleinschnitten. I ie ibliche anliegende, messinggelbe Behaarmo nimmt mu auf dem sechsten Segmente einigermafsen erheblichere Länge an. An den Seiten ist die Beharmug gelblich, ebenso die Discalborsten. Bauch dunkelgran mit zartejo weifslicher Beharmng und zum T'eil gelbbraumen Segnenteinschnitten.

An den im wesentlichen roten Beinen sind die Hinterschenkel und -schienen dentich, wenn auch nicht erheblich, verdickt und an der Wu\%el 
durcheinend honggelb. Die Tonderschenkel tragen an ilner Oberseite einen dunkelbrannen Lïngswiseh, die 'Trochanteren der Hinterbeine, die Spitzen säntlicher Schienen mul Metatarsen, sowie die 'Tarsenglieder dunkelbrann. Dje lieharmug und Beborstung ist durchaus weifsliel bis gelblich, nur auf aler Oberseite der 'Tarsen finden sich einge sehwarze Borstenhance. Die dichte Wimperbehanung der Hinterschienen ist ebenfalls gelblich. Die biustenfümige Beharung der 'Tarsen und Vorderschienen ist rotgelb. Klanen schwar\% mit gelbbraned Wuzel, Pulvillen lichtgelb.

Fligel fast durehscheinend glashell, lebhaft irisierend mit dunklè Ailerung. Erste Hinterrandzelle wohl etwas rerengert, aber weit offen.

Long. colp. 7 mm, long. alar. 6 mm.

\section{Atomosia armata n. sp.}

Von dieser neuen Art, die sich sehon durch ihre betrichtlichere Gröfse sowie die ungemein dichte nul derbe Berlormmug des Collare von allen mir bekannt geworlenen Atomosiaspecies anszeichnet, befinden sich zwei $q$ aus Brasilien in ler Sammlung Bezzi.

Kopf. Gesicht relativ breiter als bei den benachbarten Arten, dioht mit grelber, fast goldgliuzender Bestäubung bedeckt. Der gleichfarbige Knebelbart besteht ans einem medial stehendem dichten Biischel kurzer, abwäls gedrickter Hare und ciner lieilue wenig lïngerer Borsten, die den scithdhen Munlınd eimehmen. Zwisehen ihnen stehen feinere Haare, die seitlich in die ziemlich diclite Behaarung des Gesichtes iibergehen. Die Stime ist seitlich gell, in der Mitte melı weilslioh bestänbt und mit ziemlieh dicht stuhenden gelblichen Haaren versehen. Die melı grangelb bestïnbte Seheitelgegend triigt seitlich einjge zarte Härchen von gelbhrauner

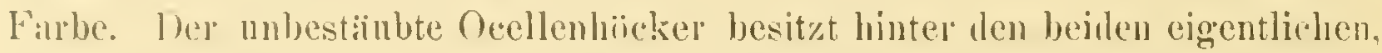
gelben ()cellaborsten zwei blasse, funere Borstenlaare. An lem granbraun bestỉibten Ilinterhanpte ist ler hintere (Orbitalrand dureh weilse Pestäubung breit gesäunut; die Reilı der kräftigen, gelbbraunen Orcipital-

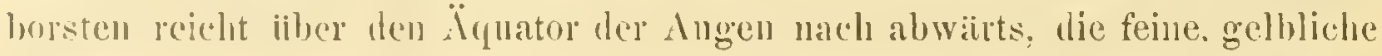
Ieharung geht nach abwiirts in den gleichfalls gelblichen Backenbart iiber. 
'Taster und Riissel schwarz mit bleichgelber Behaarung. Dio beiden Basal-

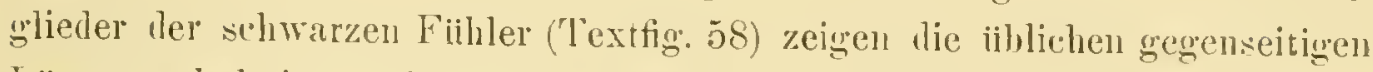
Lïngenverhältnisse und sind ansschlicfstich mit bleichrolber Beharung und Beborstung versehen, das leicht ockerfarben bestänbte, mur an der Spitze leicht pubescente Fndglied trïgt an seinem Oberranle anf stark vorspringender liante den weifslich durchschimmernden Zahngriffel.

Thorax. l)as grau bestiubte Collare ist mit einer Reihe iinfserst lerber, doruartiger üclbbraunel’ Borsten bewehrt, die pallisadenartig eng aneinander stehen. Das ebenso wie das Schlildchen glänzend schwarze, stark punktierte und mit der iblichen kurzen, anliegenden, messinggelben Beharrung versehene Mesonotum enthehrt der längeren, abstehenden, lorsocentralen behaamug vollstäulig. Schultersehwielen glänzend schwar, die l'ostalarböker diister rotbraun gefiilbt. Borsten des Mesonotmm, des Selildchens somie des ockergelb bestiubten Yetanotum fast rotbraun. Pleuren mit grauer, nacls aufwärts melr gelber Bestäubung. die wie iiblich die glïnzend

Fig. :38. schwarze, mit kurzer messingrelber Beharung versehene Mesoplenra freiläst, dafiir aber den seitlichen liand des Mesonotum bis zu den I'ostalalhiickern saimmt. Die selır zerstrente und zarte Belaarung del Plenuen gran, die kriiftige Notopleuralborste. ebenso wie der climne, ror den brannen solimingern stehende Metaplemalschirm gelbbraun.

Das gliuzend schwarze Abdomen mit seh" grober, gribchenartiger I'unktierung, die messingrgelben Haare ällserst kurz, so dafs sic ans den Gribchen garnicht herrorragen. Nur auf den sechsten Segmente, somie dem Seitemande des Ablomen ist die Beharmng etwas länger. lhe drei ersten Segmente tragen seitlich schmale silberweifse Hinterrandstlecken, an dem vierten und fünften Segmente findet sich die ïbliche weifse Sïmmmog. Die Discalborsten gelbbraun. Bauch diister gelbbraun mit änfiserst kurzer dnnkler Behatarung.

Die lieine goleichmaisig dumkelbraun, fast scluwar, nur dic inlserste

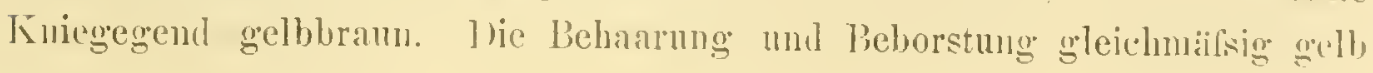
Nova Acta xerf. Nir. 1. 
bis welbbran. Die 11 imperbehammo an den Hintersehenkeln nnd llinterschienen ist gelblich mul an rlen letzteren selur licht. l)ie biirstenfirmige IBeharmong an der Interseite der 'T'arsen und Torderschienen fast fuchsrot.

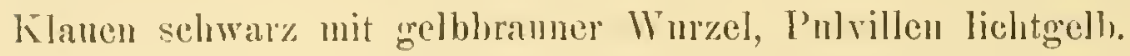

Fliigel mit leicliter bramer, an ler Wrrzel melu gelber 'Triibumar. An rler Wurzel sind säntlicho Adern gelbbram, dic Hiiltsader und die erste Lingsater belualten diese Farbe bis iiber die kleine Querader hinaus hei, im iibrigen aber ist die Älermg bram. Fiste Hintermandzelle geschlossen und resticlt oder selumal geiffinet.

Long. corj). $10 \mathrm{~mm}$. long. alar. $9 \mathrm{~mm}$.

\section{Atomosia glabratu Say.}

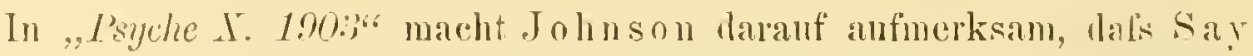
bei der liescheibumg seiner Laphriu glabrata offenbar zwei verschiedene Arten vor sich gehabt hat. Die eine derselben hat Jolıuson als A. Sayii abgetremnt und es sollen iiber diese an spaiterer Stelle einige Bemerkmngen angefiigt werden. I lie zweite Form wird dann die eigentlichen spe. glabratu darstellen. Um deren Artbegriff festzustellen. scheint es mir zweckmailsig zu sein. hier cine ansfihlurlichere Beschreibnng zu geben, deren Sicherheit datureh ermöglicht wird, dils sirb in ler coll. Winthem des k. k. IIofmusemus 17 ien ein als Type bezeichnetes Fxemplar befindet. Win zweites, semerzeit von Herrn Back in Amherst bezogenes Stuck findet sich in meiner eigenen Sammlung und endlich besitzt die Sammlung Bezzi zwei Stidcke. Sidmtliche Exemplare sfammen ans Noril-Amerika (Penmsylvania. Amherst, ITestfield) und stimmen unter sich und nit ler Type gat iiberein.

Kopf. Gesicht und Stirne gleichnälsig weifs bestiubt. Ler Kuebelbart besteht ans einen direkt iiber dem IInndrande gelegenen I3iischel

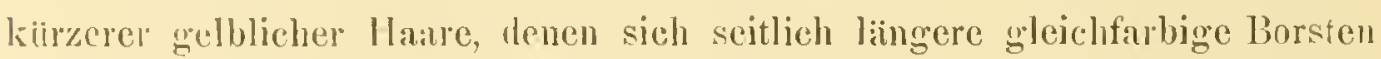
ameihen, die den seitlehen Mundrand in einer Jieihe eimmehmen und knrze. feine Hatue zwischen sich fassen. Dic Behanmorg des Gesichtes besteht ans reihenweilse angerdueten weishivhen, abwiits gebogenen llaaren, ron denen zwej umnittellar unter der Fiillerwurzel stehende dnreh hesondere linge aufallen. I)iese ganze Behaarung ist recht dicht, jedenfalls diehter 
als bei A. mellu. Die Stirne trägt iiber den Fühluln zarte Härrlen, am medialen Augenrande aber eine lieihe langer gröberer Borstentatare. Dic Fiirbung dieser Stirnbehatrung ist nirht bei allen mi: vorliegenden Śtiirken die nämliche; bei der 'J'ye ist sie durchaus weilslich, bei dem lixemplare meiner Sammlung ist die Seitenbeharung sthwarz, bei den beilen Stiicken ex tooll. Bezzi ist die Stirne durcluan schwar\% liehant. Anch die Farbe der zwei ()ellarborsten schwankt zwischen gelblich und sehwarz. Hic zart braun behante Scheitelgegend und das Hinterlanut sind gelbgrau bestiulut, die wenigen Oceipitalborsten sind gelbbraun, die feincre beharmng ales Hinterhautes ist melor weifslich mud geht allmällich in den dir.hten Packenbart iiber. Dic dunkelluaunen Taster und der liissel tragen lichte lisehasrung. An den Fiihlern ('Textfig. 59) ist das schwar\%lranne erste Segment nicht ganz doppelt so lang als das etwas verbreiterte, stets melir oder minder rotbraune zweite Glied. Das ebenfalls diister rotbranne Lindglien ist sehr dentlich pubescent. geradezu gefiedert, und hiohstens

Fig. 59. $1^{1}$, mal so lang. als die beilen Basalglieder zusanmengenommen. Der Zalngriffel befindet sich nahezu in der Mitte des Oberrandes. Die Belanrung der Basalglieder ist im wesentlichen sehwarz, nm an der Unterseite des ersten Segrmentes mischen sieh gelbliche Haare bei und anch die einzelne lingere Borste besitzt diese Farlue.

Thorax. Mesonotum und Schildedien sehwarz mit feiner l'unktienumg' und diehter, anliegender, äufserst kurzel Behandung ron goelblicher Farle? Die supraalaren und postalaren liorsten, die liandhorsten des sclibldchens und die Borstengruppe des Metanotum ockergelb; die P'risuturalborste aljer

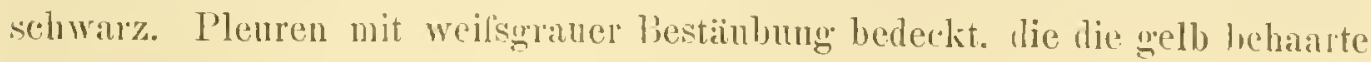
Mesopleura in ïblicher Weise freilitst. Die relatir feine Notoplemalborste. der Metapleuralschirm nul dic Schwinger lichtgelb. Die schwache lieborstung des Collare gelbhraun. Die Hiiften sind weil'sugran bestiubt und grangelb belaart.

Abdumen schwary mit recht grober I'unkticrung nul derselben gethen Behailung, wie sie das Mesonotmm einnimnt. I)as vierte und finte 
Senncut besitzen schmale, weils bestänhte llinterrandsiume, die an dem zweiten und dritten Segmente wohl aucli vorlunden aber so schmal sind. dafs sie bei der Betrarlitung von oben kaum deutlich walunehmbar werden. 1)agenen siud sie an den Seiten etwas rerbreitert und dalurch olne weiteres bemelkbar; auch das enste Segment tragt seitlich eine kleine, weilise bestaubte llinterrandsmakel. Jie Discalhorsten sind wcifslich. liauch lederInaun mit gleichfarbiger, zarter Behaarumg.

beine gliuzend golb- oder rotbram mit dunklerer Flccken- und Jimelenzeichnung, die so angeordnet ist, dafs die gelbbraune Färbung stets in ruberschender Weise sichtbar bleibt. An den Vorder- und Mittelschenkcln lälst dic Brimunng dic ganze Unterseite frei, an den Hinterschenkeln beschrïnkt sie sich als breiter Ring annähernd auf die apicale Hïlfte. Jic Schienen besitzen nur auf ihrer Aulsenseite einen mchr oder minder dunklen Längswisch. An den 'Tarsen sind die Endgolieder bram, die iibrigen aber nu an ihrer Oberseite mehr oder minder gebräunt. Die Wimperbehaarung der Hinterbeine ist weifslich, im iibrigen ist dic Beharrung. und Behorstung iler Hauptsache nach gelb oler briuulich, nur auf der Oberseite del Tarsen stehen vereinzelt auch schwarze Borsten. Klauen schwarz, Pulvillen fahlgell,.

Fliigel. An der äufsersten Flïgelwurzel sime die Alern gelb: nur die Hiilfsader hehält diese Färbung in ganzer Ausdehnungr bei, während in iibrigen die simutlichen Adern braun sind. Frste Hinterrandzelle vercugert, aber nicht geschlossen.

long. corp. $7 \mathrm{~mm}$, long. alar. $6 \mathrm{~mm}$.

1. mifipes Meq. als Synonym zu A.glabrata zu stellen (rgl. Kertrisc: Cutulogus) ist nicht angingig, wic durch Bemerkungen an spaiterer Stelle uachzuweisen ist.

Atomosia beckeri Jïnnicke.

1)ueh das licbenswiudige Hutgegenkommen der Direktion des zoologischen Museums in l)armstalt war es mir möglich, die beirlen aus Mexiko stammenden Typen zu untersucheu und dadurch der im allgemeinen ansreichenden Beschreibung J än ickes einige Ergänzungen beizufügen. 
Gesicht, Stine und Scheitel gleiehmälsig mit weilslieher Bestäubung* bedeekt. Knebelbart weifs, aus langen Borsten und feineren dichten Haaren bestehend, die sich aber in der Mitte des Mundrandes bischelfürmin gruppieren. Auch die weifse Behaarung des Gesichtes ist sehr lang und dicht und reicht bis zur Fihlerwurzel empor. Stime in der Mitte weil's behaart, am Angenande mit drei langen, schwarzen Borstenharen versehen. Scheitel und Hinterhaupt ebenfalls weifs behart, ebenso dic Kinngegend, die 'Taster und der Riissel. Anch der Backenbart ist weifs. Occipitalborsten und Behaarung des Collare bleichgelb. Der Ocellenhö̈ker triigt ein Biischel langer schwarzer Borsten. Dic Fiihler sind an den typischen Exemplanen defekt, so dals ich ibjer deren Beschaffenheit keine Aussagen machen kamn. Seitenhorsten des Mesonotum schwarz, Notoplenralborste und Metapleuralsehirm gelb. Metanotum schwary mit gelben Borsten. Das Schildehen besitzt die iblichen vier seitlichen liandborsten von gelber Farbe, keinen Borstenkranz (Jännicke?) Die vollstiindigg glashellen Fliigel besitzen durchaus gelbe Adern.

Die Art gehört in dic nïchste Terwandtschaft ron A. glabrata. wie bei dieser herrsclit an den Beinen die gelb bis rotbraune Färbung ror.

Long. colp. $7 \mathrm{~mm}$, long. alar. $6 \mathrm{~mm}$.

$$
\text { Atomosia rufipes Mcu. }
$$

II acquart, Diptires exotiques, suppl. 2. 39.

Aus der coll. Winthem des k. k. Hofmuseums in Wien liegen mir fiinf Exemplare dieser Species vor, die sämtlich mit der Macqualtschen Beschreibung ibereinstimmen. Ich betone dabei. dal's Maculualt auf die Verliingermng der Fiihler, sowie die Schwirrung der letzten Y'arsenglieder aufmerksam macht. Zul der Macupartschen Beschreibung passen anch drei Exemplare meiner eigenen Sammlung, aufserdem aber auteh A. Suyi Johnson. die ich selbst in einigen Cotypen der Liebenswiirigheit des Autors verdanke nud die auch in der coll. Bezzi vorbanden ist. Da Johnson darauf aufmerksam macht, dafs Sa y bei seiner Beschreibung ron A.glabrutu zwei verschiedene Arten von sich gehabt lıat, deren eine Johnson eben als A. Sayi abgetrennt hat, so muls auch die eine Form (Var. a) der 


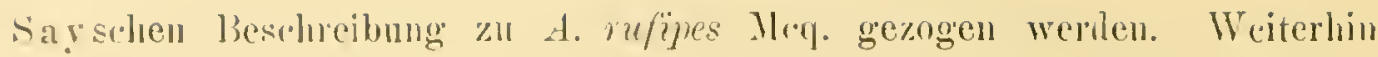
wall es mil durch das licbenswibdige Entgegenkommen des Herm Verral mighlich, anch linsicht in die Biggotschen 'l'yen von A. soror und cupoda zu nehmen, und es hat sich dabei ergeben, liafs diese beilen Arten unter

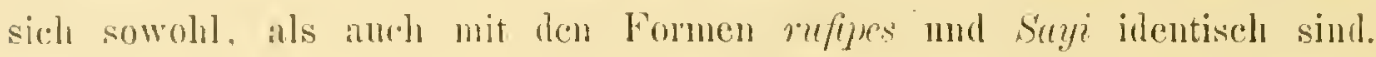
Auch die Sp. mucida O.-S., vielleicht anch $A$. anomyma Will. lassen sieh mit Fug mol liecht nicht vom d. vefipes tremen. lals dies der Fall ist, latist

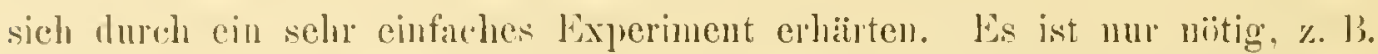
die 'l'ypen der .1. soror Big. mit lessen Beschreilumg von A. cuporla oder vice versa zu vergleichen, so wird man die weitestgehende Kunkordanz \%wichen diesen verschiedenen Beschreibungen und den 'Tierun selbst zu konstatieren vermigen. Jasselbe gilt auch bei einem Vergleich dor beiden Bigotschen Arttypen nit der Macpuartschen Bescheibung ron A. mfipes. lie ITnterselniede hestehen eben lediglich in mwesentlichen Kleinghkeiten, in einer mehr oder minder ausgedehnten particllen Briuunng oder Schwäirung dex arifstenteils rotgelben Beine und einel sohr geringen Verschiedenheit

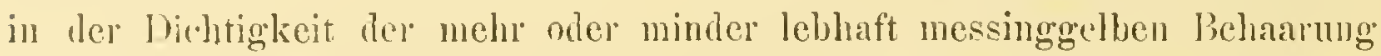
des 'l'horax. Wie wenig auf diese leichten Differen\%"n zu geben ist, liifst sich auch dadureh erkennen, dafs dic dunkleren \%ejelunugen an den Beincu bei len 'Typen ein und derselben Species gewisse Varianten in Ausdelmung' und Intensitait zeigon. Fäbungsdifferenzen sollen bei all den verschiedenen in Betracht kommenden Formen, die ich zu untersuchen Gelegenheit hatte, nicht geleuguet werten, alleiu diese scheinen mir so geringfiigrig za sein, dal's man aus ilunen, will man nicht cinfach der Willkiil Thiir und "Tor" iffinen, keine Artrechte abstrahieren kanu. Anch geographiseh gechiren alle diese Formen znsammen, inken sie auf Nordanerika und Mexiko beschrainkt sinu; wenigstens funde ich in meinem reichen siidanerikanischen Material keine einzige Form, lie mit A. rufipes irgendwic in Beziehung gruratelt werlen künute.

II ill man die in Frage kommenden Formen voneinander trenuen. so

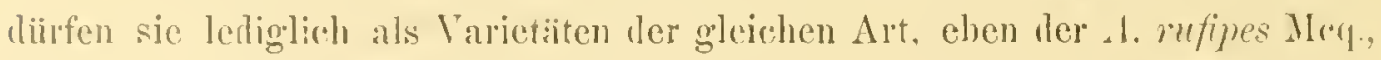
aufgefalst werilen; ioh werle daher zunäclst in Ergoiuzung der Macyuart-

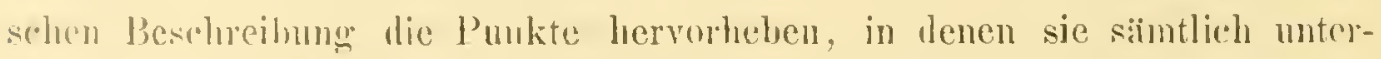
cintuler iibereinstimmen, und werde damn die I)ifterenzen angeben, lum die sich die cinzelnen Varictäten cinigemalsen voneinandel unterscheilen lassen 
Kopf. Gesicht mit gileichmälsiger neifser Bestiulnung und weifser bis fahlgelber Beharung versehen. Auch der Knebelburt ist weifslich, el besteht aus lälugeren Borsten und dazwischen genengten kiirzeren Hål’en. die jedoch die den meisten Atomosien eigene bischelfömmige Anordmm in der Mitte des Mundrandes vermissen lassen. Stime ebenfalls weifs bestiubt mo mit weilser, am Augenrande griberer Behaarung versehen, die sich anch auf den weil's bestiubten Scheitel fortsctzt. I)er Ocellenhöcker tright zwej lange Borsten von lichtgelber Farbe. Auch die nicht ljs zum Augenäquator herabreichenle borstenreilie des weilislich bis gelhyran bestänten Hinterhauptes ist gelb. Dessen feinere, aber immerhin ziemhich krüftige Beharmug ist ebenso wie der Backenbart und die Hate der Kinngegend, des Riissels mud der ziemliuh langen 'Taster weilslich. Die Fiihler ('Texttig. 60) sind relativ linger als bei len meisten iibrigen Atmusien und zWar ist diese Verlaingerung zunächst daranf zuriekzufiihren, dal's das erste Segment melu wie iloprelt so lang ist als das zweite, aber auch das sch deutlich pubescente dritte Segment zeichnet sich durch relativ gröfsere Liange ans. An seinel Medialthiche fällt eine ovale, ler Pubescenz entbehrente Stelle sehr anf. Die Farbe der Fibhles ist dunkelbrann, loch zeichnet sich das zweite Segment, häufig auch die Spitze les ersten. und die ITurzel des Aritten dureh lichtere Firbmug aus. Hic Beharumg der beilen Basalglieder ist vorwiegend sehwarz, doeh mischen sich ihr an del Unterseite des ersten Segmentes anch golbe Haare bei und the reremzelte lange Borste ist stets recht lebhiff gelb.

'Thorax. Mesomotmu s.hwarz glämend mit leichtem Erzschimmel' und feiner, sehr zerstrut stehender T'unkticrung; ilie Schulter- und Postalarhïckes in geringerer oder griilserer Ausdehnung gebbrim. Die mehr ofler

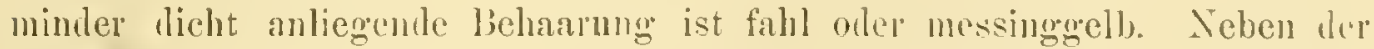
Mittellinie. auf der dic Ilärchen uach hinten gerichtet sind, liegrt eine streifenförmige Zone, inmerhalb leren die leharmng expusist scitwirts gekämmt ist, wihrend lateral lavon die Haare marlo hinten gerichtet ersoheinen; es entstcht dalurch eine Auleutumg ciner stremenförmigen \%eichumg. Nach 
hiuten wroten die Hare zicmlich lang und mischen sich mit gleichfalls grelben, dorsocentralen, abstebenden 13orstenharen. Anch das schwarze Schildehen trijgnt anliegende galbe Behaarungr und an seinem Seitenramde eine Anzahl lingerer, gleichfarhiger Borsten. Die Seitenborsten des Mesonotmm sind lebhatt gelb. Plenren mit Winschlnls der Mesoplenra, sowie der Hüften glochmalsig weil's his gelbgran bestäbt und mit gleinfarbiger feiner Behaarnng versehen, die mamentlich auf eler Mesopleura recht dicht ist. Notouleuralborste mul der vor Acu gelben Schwingern stehenke Metapleuralschirm gelb. Die Beborstung des gran bestäubten Collare und Metanotum ist gelbbrautu.

Ablomen schwarz gainzemal mit leichtem Erzschimmer. derber l'unkticrung und weil's bestainbten Segmenteinschnitten. Die anliegrende beharmmo ist weilslich bis fahlgelb und gewinnt gegen nie Spitze zu ziemlich beträiehtliche Länge. Die seitliche, abstehende Behaarnng ist lang: ebenfalls falılgell und gegren die Spitze zu länger. Weifsliche Discalborsten fincles sioh nur an ken drei vorieren Segmenten. Banch dunkelbraun mit iufserst zarter, zerstrenter lichter Behaarung.

Beine lebhaft rotgell, die Endtarsen an ilırer Oberseite stets schmarz, loch elstreckt sich diese Schwäñung bei den verschiedenen Tarietäten anch auf weiter proximal gelegene Abschnitte der Mittel-orler Hinterbeine, vor allem letzterel. Klanen schwarz mit heller Wurzel, Pulvillen gelh. Fhenso ist lie gesante Behaarmo und beborstmmg der beine gelb.

Die lyglinen Flïgel sind nur wenig brämlich tingiert. An der Fliigelwurzel sinl die Aleru in grölserer oder geringerer Ausdehnung gelb, im ibrigen aber dunkelbram. Frste Hinterrandzelle verengert, greschlossen oder k!ll' gestielt. Die lie Discoidal- md die vierte Hinterrandzelle distal absrhliefsenten Queratern sind nicht immer in der gleichen linie gelegen.

Inh gebe um eine Zusanmenstellnng ler verschiedenen Varianten:

a) Var. rufipes Meu. strictu sensu.

Die Enttasen selıwarz, lie Mittelschienen an ihrer Spitze efwas gebrïint. 
b) Tar. Stayii Iolunson.

Die Endtarsen mit Ausnahme ihrer Basis sehwarz. Die Hintersehenkel besitzen auf ihrer Unterseite nahe der Finlenkung in den 'Trochanter einen schwarzen punktförmigen Flecken. Auch an den Torder- und Vittelschenkeln sehe ich bei saimtlichen Exemplaren solche Flecken, die nur viel kleiner sind.

c) Tar. mucielı O.-S. Mexico.

Beharung des 'Thorax selır dicht, so dals die Grumlfarbe fast verdeekt wird. Postalarhöcker rotgelb. Nur die Eudtarsen mit Ausnalıue ihrer Basis schwarz.

d) Tar. soror ligig. Mexico.

Die Tarsen, an den Hinterbeinen auch die Schienen und Schenkel in ihren distalen Abschnitten in grö̈serer oder geringerer Ausclehnung gebriunt. Die Schenkel sämtlicher Beine besitzen an ihrer Einlenkung in die 'Trochanteren die gleiche, nur etwas ausgedehntere Punktierung wie bei Var. Sayii. J'ostalarlı̈̈cker diister rotgyelb.

e) Tar. punctifera Herm. Mexico.

Behaarung fles Mesonotum besonders laug. Fudtarsen schwarz, Ka laneu rot mit selwwarzer Spitze. Spitze der Hintersehienen schwarz. Postalırhïcker in grolser Ansdelumug lebliaft rotgelb.

Long. corp. $9 \mathrm{~mm}$, loug. alar. $8 \mathrm{~mm}$.

f) Varr. eupoda big. Hexico.

Die $2-3$ distalen 'larsenglieder nul das Spitzendrittel der Hinterschienen mehr oder minder g־ebriunt, Klaten schwarz mit roter Wurzel. Postalarhiicker teilweise rotgelb.

Long. corp. 9 mm, Jong. alar. 8 mm. 


\section{Ltomosia venustula Amibalzaga.}

Asililes argentinos. Anal. Soc. ('ient. Argent. IX. 1. 17. 1880.

Fin $q$ ans der Sammlung des k. k. Hofmnseums Wien, ein $o^{7}$ cx (onll. Hermann, heile ans Argentinien (Buenos Aires. Mendoza).

Die beiden Fixemplare stimmen mit der vollstindig ausreichenden lieschroibung von Arribalyaga völlig iberein, so dafs ieh iiber die Hentifizicung nicht den geringsten Zweifel habe. Die Art zeichnet sich schon durch ihren anffallend breiten, gedrungenen Habitus gegeniiher allen Arten des Gen. Homosin ans. I) anch sonstige l)ifferenzen (drei postalare Borsten, vollstinuliger Borstenkranz am freien Rande les Schildchens usw.) vorliegren. wirl sich wohl spiiterlun eine gencriselse Ahgrenznng gegeniber den iibrigen Atomosien als notwendig erweisen. lch muls aber darauf verzichten. da die beiden Exemplare kider an den Fiihlern defekt sind. Auch aus der Jieschreibung ron Arribalzaga lïrst sich uber die Beschaffenheit der Fulıler nichts entnehmen, alher der Antor macht selbst auf die Sonderstellungr der Sirer: remstulu unter den iibrigen Atomosien aufmerksan.

Long. cor'y. $5,5 \mathrm{~mm}$, long. alar. $5 \mathrm{~mm}$.

\section{Atomosia tibialis Mey.}

Ein $\supset^{-1} f$ ans Lucatan ex coll. Hezzi stimmt gnt zu der Beschreibung

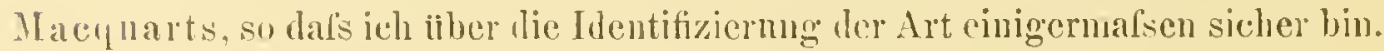

bie Art grelört zwall in allgemeinen iu die Verwandschaft ron 1. puella Wried., noch mehr aber nähert sie sich der gheivh näher zu besprechenden śrbinerschen Spec. uryyrophora insoferm, als das of an der Anlsenscite des apicalen Jnittcls der Hintersohienen, an dem Mutatarsus nul den folgenden 'Tasengliedern lange und livhte, weilse, fast silberschimmernde Behatrung hositzt, die anch den $q$, wem auch in wesentlich reduzierten Mafse, eigen ist. Wie Beine sind hei dem o dunkler, so dafs die rotbraune liarbung der Schiencn weniger deuthich wird. hic beiden Oechlarborsten sind bei dem or grelblich, hei dem of schwar\%. Die Fliigel besitzen auf der Mitte eine wenig in die Augen fallende dunklere Truibung, die auf cine verwaschene Siummog der Adern zuriukzufiilıren ist. Fisste Iliuterlandzelle verengert, aber nicht greschlossen. 


\section{Ltomosia Marquarti Bellardi}

dürfte wohl als Synonym zu i. tibiulis Mrop. zu setzen sein; dafïr spricht. den Hinweis von Williston (Biologia Centrali-Americana, p. :316) auf lie silberschimmernde Beharmng an den Hinterbeinen des of, mul die Angahe, dal's verschiedene der ihun forliegenden Exemplare gnt (pretty well) mit iler Beschreibung von 4. tibialis Mcy. übureinstimmen. Ich glaubte, diesen Nancn als den älteren vorzichen zu miissen; ein sicherer lintscheid iiber die Identitiit diirfte natiirlich mur durch die Terghleichung der 'Tyen sich ermighlichen lassen.

\section{Atomosia argyrophora Schin.}

Es liegen mir zelın Excmplare aus Nordbrasilien (Pincheiro) ex coll. Bezzi vor, die mit den Typen Schiners im k. k. Hofmusenm Wien rollständig iibereinstimmen. Zu ihr gehören anch nen in ter gleichen Sammlung befindliche Stiicke aus Siidbrasilien (Iguapé), die von Herm Biscluof fitschlich als A. genimlata determiniert waren.

Der Beschreibung Schiners mirchte ich folgente nälrere Angaben heifiigen:

Kopf. Gesicht am Mundrande silberweis, unter der Fiillerwurzel goldgelb bestiubt, die Stime ist mit silberweilser, die Scheitelgegrend mit grelber bestiuluung bederkt; lie gesamte zwischen den Augen freiliegrnde Fliiche des Kopfes bekommt dadurch eine expuisite regelmälsige Qnerbiinderung. durch die die Species in beilen Geschlechtern, wie mir scheint, leicht von ien benachbarten Arten zu unterscheilen ist. Die Farbe de's Knebelbartes und der lamgen borstenfümigen Behaarung des Gesichtes sihwankt von gell bis schwarz, doch sind wcnigstens die Gesichtshaare der Haujitsache mach meistens dunkel. Auch die Farbe der Stirnhehaarung ist nicht komstant. Die $t-6$ Ocellarhorsten dagegen sind stets schwarz. An den dunkelhraunen bis sehwayzen Fiiblern (Textfig. 61) ist das Basalglicd etwa 1'. mal so lang als das zweite segment, das spindelfürminge,

lig. 61. 
allenthalben deutliche jubescente Endglied $1^{1}$.2 mal so lang als die beiden basalen Segrnente zusammengenommen. Deren Belabung nul lieborstung ist durehaus schwarz, nur bei zwei Fxemplaren finlen sich an der Luterseite des ersten segmentes teilweise weilsliche lIare.

'l'horax. Die Scbulterbeulen des selıwaren Mesonotum zeigen bei allen untersuchten kxemplaren eine punktfüruige, wenn auch manehmal lecht muansehuliche Makel rou mohr ouler minder lebhaft rotbrauner Farbe. Jer iiblichen nessingogelben Beharung sind reichlich dorsocentrale schmarze Borstenhare beigemengt.

An dem schwarzen. derb punktierten Abdomen sind die weifs bestiuhten Segunenteinschnitte ainfserst sehmal nnd machen sich deutlich nur hei betrachtung von riekwïrts bemerkbar; die anliegende, messing gelbe behalrumg ist selır kurz und zart. Daher kommt es, dalis der Hinterleibsriicken bej Betrachtmg von oben glinzend sehwarz und fast nackt erscheint. I lie Zahl der weilslichen Disealborsten ist keineswegs konstant, meist finden sic sich nur auf den $3-4$ vorderen Segmenten. Der scharf abgrekantete Ilinterrand les sechsten senmentes ist bei allen untersuchten Exemplaren mehr odes minder deuthich gelbbran.

Anch die dunkleren Zeichnungen der gelb- bis rotbramen Beine sind keineswegrs konstant. Gehen wir rou der 'Tye Sehiners aus, so zeigen hier die suhenkel iler beilen vorileren Beinpare cinen dunkelbrannen, breiten ling, der die gelbbrame Farbe nur an MTural und Spitze sichtbar werten lälst; an den llintersehenkeln ist der braune Ring etwas weniger :usgedehnt. liei den lellsten Exemplaren aber tragen die gelbbraunen Schenkel lediglich an ihrer oberen kläche cinen dunkelbrannen Liungswisch.

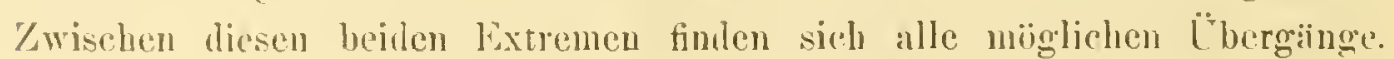
Jie spitzo der Suhienen sowic die 'larsen sind stets, wenn anch ebenfalls in rariabler Intensitait mul Ausulehumg gebrännt. Die von Selniner erwiihnte anffallende, diehte, silberglïnzende Behasung an den Hinterbeinen des $\jmath^{-1}$ findet sich bei allen mutersuehten Wxemplaren an der Anlsenseite der schienen und anf llen 'Tarsen, erstreckt sich aber hei einzeluen auch nehr oder minder weit iber die distale IIälfte der oberen Sehenkeltlärhe.

ber Aderverlauf anf den Fliigeln zeight kamm irgendwelche Tarianten. lie crste nud zweite Hinterandszelle ist hei allen Exemplaren nu wenig. 
verengert und stets offen; bei einem Wxemplar findet sich an der Gabelung der Cubitalader ein kurzer Aderanhang. Hie Farbe der Adern ist dunkelbrann, gregen die Fliigelwurzel etwas lichter.

Jas o merscheidet sich in ler Hauptsache kaum rom ơ. Die silberschimmernde Behaarnng an den Hinterbeinen fehlt zwar uicht vollständig, ist aber unter allen Umstinden bei weitem kiurzer. wenigrer dicht und unansehnlicher.

Hierher gehört sicher auch A. milipes 'Thomson ans Argentinien; ob aber die beiden Arten voneinander verschieden oder identisch sind, vermag ich aus der Beschreibung allein nicht mit Sicherheit zu entscheilen.

\section{stromborodire n. 2.}

Kopf ('Taf. Fig. 51 u. 52) nur wenig verbreitert mit grofsem Tiefendurchmesser, so dafs er im Profil halbkugelig erscheint. Das relatir schmale Gesicht ist an der Fihlerwnrzel sowie am Mmirande wenig rorgewöbt, in iibrigen plan. I ler Knebelbart besteht nur aus wenig zahlreichen Borsten, unter der Jihlelwurzel stehen einige änserst zarte Härchen, in ibrigen entbehrt das Gesirht der Behaarung vollständig. Die Stirue ist durch Ausrandung ler Orbitalräuler mälsig rerbreitert, in ller Mitte und am Rande mit einigen Haaren besetzt, der scheitel besitzt dic gleiche Breite wie das Gesicht und ist zicmlich dicht behart. Der verhältnismälsig wenig vorsuringende Ocellenhïcker trägt zwei lauge Borsten. Das Hinterhaupt besitzt zarte, zerstrente Behaarnng. die nach abwiilts in den diinnen Backenbart iibergeht; die Occipitalborsten erstrecken sich, diinner werdend. bis iber llen Äyuator ler Angen nach abwäits. Tler Riissel ist lang und derb, an seiner Unterseite mit einigen langen

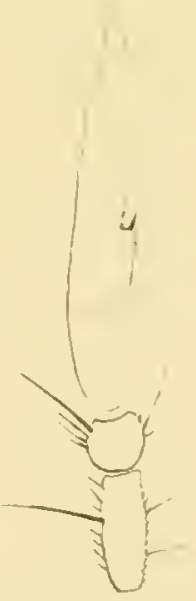

His. 6 ? Borsten rerselen, auch the an der Spitze beborsteten 'Taster sind relatis ansehnlicher als bei ten meisten Atomosinen. An den nicht auftallend rerlängerten, ziemlich tief stehenden Fiihlern ist das erste Glied etwa loppelt 
so lang als das kure zweite, kur\% hehaart und an seiner Unterscite mit einer einzelnen langen liorste bewelurt. Inas zweite Segment ist mu apical mit einigen Borstenlaaren relschen, das spindelfümige Eudglied (Textfig. 62) ist ungefailu doppelt so lang als die heiden Basalglieler zusammengenommen, olne Fudgriffel und mamentlich gegen die Spitze exquisit pubescent, fast getienlert. Kitwis hinter der Mitte des Oberrandes steht auf ler Kante einer ticfeu linkerbung der sehr kriftige Zahmgriftel.

'Thorax. Das mu selr wenig gewölbte Mesonotum und das an seinem Ranic mur mit knrzer, abstehender Behanrmng verseliene Schildehen sehr zart junktiert und goleirhmail'sign mit diehten, anliegenden, nach hinten länger werdenden Hamen von lichtel larbe bedeckt, zwischen denen sich reihenweise angeordnete, abstehende aber kurze dnsocentrale Haare hemerklich machen. Beborstungo" präisutural 1, supraalar 1, postalar 3-4, notopleural 2-3, Metapleuralschirm sehr diinn. Die l'lenren sind mit Ausnahme der Mesopleura gleichmaifsig bestaibt nnd zerstreut behart. l)as Collare ist beborstet, das Metanotum aber entbchrt der kurzen, stiftfïrmigen Borsten und triggt statt ihrer ein Biisehel feinerer Haare.

Das mailsig lange, nach hinten etwas rerbreiterte Alodomen besteht ans scehs von oben sichtbaren Segmenten, ist gleichmaifsig grob punktiert und unit sehr zarter abstehender Behaarnug versehen. An den Segmentaleinsehnitten hefinhen sich aus iulserst zarter Beharung bestehende, lateralwïrts verbreiterte Halbbinulen, lie an dem vicrten und fünften Segmente dureh feine Säume in der Jitte zusammenhängen. An dem Seitenrande des Abrlomen stehen nur wenig längere Haare, eigentliche Discalborsten fehlen.

Die lichten, fast durelischeinenden Beine siul zart: die simtlichen Schienen, sowie die Hintersuhenkel gegen die Spitze leicht verlickt. l)ie Belatrung ist abstehend und zart, die ehenfalls schwathen Borsten sind namentlich an den vorderen Beinpanren zahlreich vorhanden. Die bỉrsten-

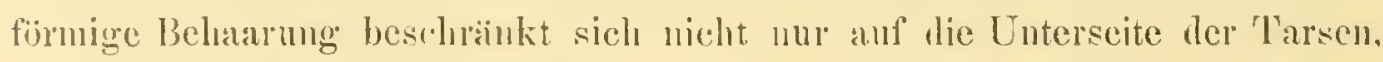
sondern bildet anch an le Spitze rler llinterschienen ein vorspringendes Kissen mit exquisit reihenweiser Auordunng der einzelnen Härelien. Die recht dichte Wimperbeharung nimmt sowohl die Hinterschienen, als anrh die Hinterschenkel an ilıren cinander zusehenden Flaichen ein. 
I ie relativ breiten Fliigel bieten in ihrem Aderverlauf wenig. charakteristisches. Die kleine Queradel steht an der Grenze des basalen Viertels ller Discoidalzelle.

Als typische Art betrachte ich:

$$
\text { strombocodia elegans of } 11 . \text { sp. }
$$

Ein einzehes Exemplar ex coll. Sehnuse ans L'eru, Ĺmahuankiali, Urubambaflufs, $500 \mathrm{~m}$ ii. d. .II.

Kopf. Gesicht und Stirne mit nckergelber Bestäubung beleckt. Knebelbart und Behaarung des Gesichtes fahlgelh, fast weifslich, die Stirne jedoch schwar\% behaart. Scheitel und Ocellenhiicker gliinzend schwarz, dieser mit zwei kräftigen schwarzen Borsten bewehrt, jener gelb behaart. Die gleiche Farbe besitzen auch die Haare und Borsten des in seinen oberen Partien ockergelh bestänbten Hinterhanptes; nach abwärts aber ist es mit fast weifser liestiubung bedeckt und mit weifslicher Beharmng versehen. Backenbart weils, Kinngegend, Taster und liiissel weifs behaart, letzterer auferdem an seiner Untertliiehe mit zwei kräftigen schwarzen Borsten bewehrt. Die beiden Basalglieder der schwarzen Fiihler sind brïunlich bestäubt und mit schwarzer, aber teilweise licht schimmernder Behaarung und Beborstung rersehen, das Endglied besitzt ockergelbe P'ubescenz.

'Thorax. Mesonotum unl Schildehen schwarz mit messinggelber Behaarung: die dazwische'n stehenden längeren dorsocentralen Härchen bräunlich. ehenso die Seitenborsten des Mesonotum und die Raudbehaarung. des Schildchens. Die Schulterbeulen sind in sehr geringer Ausdehnung, die Postalarbïcker vollstiindig diister rotbrann. Plenren unit weislicher. der Prothorax mit fast goldgeller Bestäubung und mit iulserst zarter, zerstrenter, lichter Beharung rersehen. Notopleuralborsten, der vor den fahlgellyen Schwingem stehende Metaplenratschirm, die Borsten des Collare und die Haare des weifslich bestainbten Metanotum brimulichgelb.

Abdomen glänzend schwarz mit leichtem riolettem schinmer und bleichgelber, nach hinten fast weifsheher Behaarung. Die Halbbinden an den Segmentaleinschnitten sind schneereil's. 
Jie buino sind einschliefslich der weils bestäubten Iliiften hellgelb, un die Bndtarsen und die Klanen sind schwarz. An den Hinterheinen ist die gelhe Fabbe etwas dunlier, mul die Hintersehienen sind an ihrer lidickseite ganz wenigg grehräunt. Die Beharumg und Beborstung ist ansschliefslich fahlgelb, die biilstentörmige Beharmmg goldgelb.

Die selıwach brimulich tingrierten Flïgel sind hỹaliu, lebhaft irisierend. Die Arlern bram. nur an ler Wurzel teilweise heller.

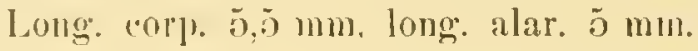

\section{Atrerefire Hacewurt.}

Dic Gattung wurle von Il acquart fiir den Wiedenannschen Asilus psilogaster errichtet. Priff man die Genusbeschreibung, so lïfst sich nicht das mindeste finden, was sieh fiir die Fixierung des Gattungsbegriftes nnd die systematische Einorhmmg verwenden liefse. Offenbar hat Ma cunart das 'Tier selbst gal nicht gekannt, llenn seine Beschreibung ist weiter niehts als rine französische Übersetzmng von $\mathbb{H}^{+}$iedeman $1 \mathrm{~s}$ dentschen T'ext, und so mnfste er matmigemiifs demselben Fehler verfallen, dem seinerzeit Wiedemann ans Hangel an geniigenten optisehen Hiilfsmitteln nnterlegen war. l)er I'nstand naimlich, dafs bei der Spec. psilogaster das dritte Fiihlerglicu, wie wil sehen werlen, nur scheinbar, in eine Borste endet, hat Wiedemann reranlalst. seine Species als Asilus zu beschreiben, und Maceyart hat clemgemails auch sein neu errichtetes Genus Atractia den Asiliuen zugewiesen. Lud diesen Irtum haben alle folgenden Autoren bis in dic neueste Zeit mitgremarht. Schiner, der Wiedemannsche Exemplare ler Sprec. psilogaster vol sich hatte, bemerkt zwar die Wienteman nselien Asiliden, 1866. pag. (i6t), dal's das Geums Atructia alleruächst verwandt mit den Atomosien sei unt gibt eine lieihe spezieller Hinweise fiir diese Terwandschaft, allein das Turhandensein der Fïhlerborste zwang ihn trotzdem zu einer Giureihnng des Genns hei den Asilinen. Williston (Psyehe V. 1905) der ebenfalls Atractien unter den Angen hatte, tritt mun goleichfalls vollständig fiir deven Zugehïrigkeit zu den Atomosinen cin, trotzdem aber tindet sich auch in Her nenesten Auflage (1908) seines treftlichen 
Mannal of North American Liptera Atractin wieder bei den Asilinen aufgeziihit. Das crscheint umso auffallender, als wir gerade Williston ein, wie ich sehe, recht wertvolles und verniinftiges nenes Einteilungsprinzip der Asiliden in solche mit eingliederigen und zweigliederigen Tastern verianken. Zu den ersteren gehoiren die Asilinen und Leptogastrinen, zu ter zweiten Gruppe die Laplurinen und Das!pogoniuen. Atractic aber besitzt zweigliederige 'Taster und schon dieser Lmstand hätte Williston auf den schon beschrittenen richtigen Weg zuriickweisen sollen. Auch in dem Catalogue of North American Diptera ron Aldrich (1905) figuriert Atractia bei den Asilinen, uur in dem Kertisezsehen Katalog wird der Gattung, offenbar in Finklang mit der ersten Notiz ron Williston, die riehtige systematische Stellung zngewiesen. Wie verhält es sich num aher mit der ominösen Endborste des Atractiatiihlers? Nimmt man den Fiiller ('Textfig. 63) eines bchiebigen genuinen Asilinen und untersucht ilhn bei stärkerer Tergrölserung an einem durchsichtigen Kahipräparat, so wird man sich unschwer, davon ïberzengen kömen, lals die Fiihlerborste aus einem kurzen hasalen und einem langen apicalen Gliede besteht und dafs diese zweigliederige Fïhlerborste diskontinuierlich, bewegrlich

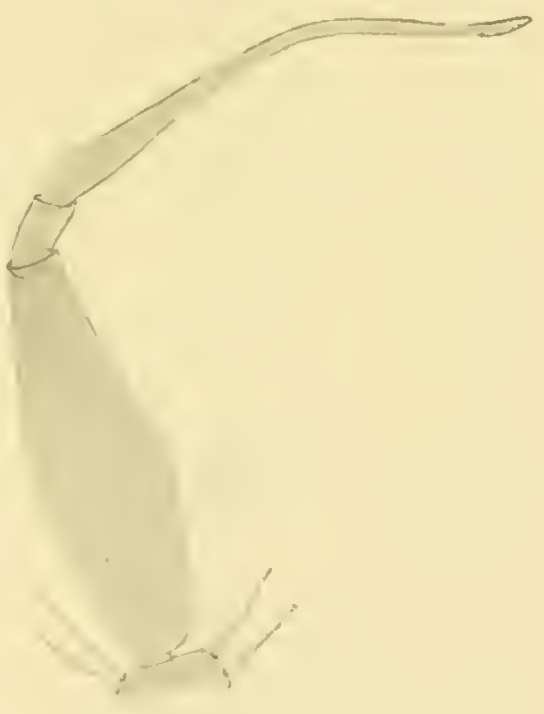

Fig. 63. der Spitze des dritten Fiillergliedes eingelenkt ist. Der Asilinenfuiller ist dementsprechend fiinfgliederig. Die Untersuchmg des Atractiafiihlers (Textfig. 64) aber ergibt total rerschiedene Terlibitnisse. Weder ist die "Lndborste” in sich gegliedert, moch ist sic als Gauzes diskontimuierlich dem dritten Fiihlergliede eingelenkt. Tiehnehr stellt sie lediglich ein Stiick dieses letzteren selbst. lediglich eine jene ..Endborste" vortïnschende Verlïngerung des dritten Fuillerglieiles dar. Nicht eimmal als Entgriftel ist sie zn deuten, lenn auch ein soleher ist stets beweglich der spitze des Fühlergliedes aufgesetzt. Leicht liifst sich fernerhin, worauf iibrigens: atch Williston (1905) aufmerksam machte, der typische Zahnstift, den 
wil bei allen Atomosinen fanlen, nachweisen und berioksichtigt man schliefslich, dafs auch bei Atractiu das typiseh gleiche Flügelgeider sich

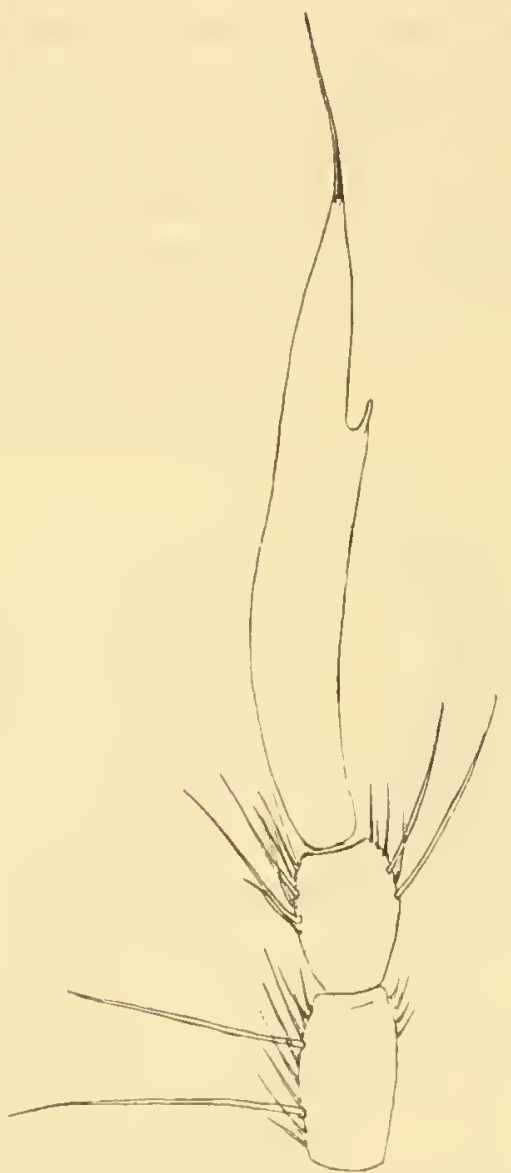

Fig. 64 fundet und dafs das Metanotum die gleiche Beha:unng an den Seiten trägt, wie wir sie bei allen Atomosinen angetroffen haben, so wird sich iiber die systematische Stellung des Genus Atractia irgendein begrindeter Zweifel nicht mehr erhehen kömnen, vielmehr kann es sich nur mehr darum handelı, die Merkmale festzustellen, dureh welche sirch das Genus, abgeschen ron dem eigentiimlichen Fiihlerbau, von benachbarten Atomosinengattmogen tremen liifst. Diesem Zwecke soll die nun folgende menanere Genusbeschreibung dienen.

Kopf (Taf. Fig. 53 u. 54) breit; der Breitendurchmesser bis iloppelt so grols als die Entfernung voun Mundrande bis zur Scheitelhiihe, Augen aber nicht brillenartig vorgequollen. Das ziemlich breite Gesicht ist gleichmårig sanft gewölbt und gegen die Fiililerwurzel etwas verengert. Der Knebelbart besteht ans reihenweise greordueten derben Borsten, denen feinere Beluar'ung beigemengt ist, erstreckt sich am ganzen Mumlranle nach abwirts und beschränlit sich im allgemenen auf die untere Gesichtshailfte. Daliiber trägt das Gesicht jederseits eine Dopjelreihe abwiirts gebogence Borstenhase, leren inmere Reihe bei einigen Arten zu derben Borsten ungewandelt ist, so dals dam die Grenze gegen die Borsten des Knebelhartes verwisclit erscheint. Wie Stirne ist durch Ausburlitumg des medialen Orbitalrandes maifsig bogrenfömmigg erweitert und mit ciner narbenartigen von dem Ocellenhöcker sich zur fïhlerwurel erstrcekenden Medianfurche versehen; dic behaarung ler Stirne und der

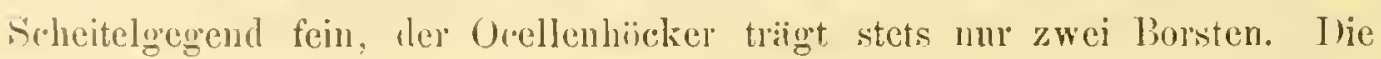


Borstenreihe des gleichmälsig bestäubten Hinterhauptes liifst sich, wenig schw:icher werdend, fast bis zur nuteren Angenecke nach abwiirts verfolgen. Die gut entwickelten Taster sind an ihrer Spitze beborstet, der mäfsig lange Ruissel trïgt an seiner Spitze biischelfürmige Behaarmug. 1)as erste Glied der Fïhler ist so lang oder hüchstens $1 \frac{1}{2} \mathrm{mal}$ so lang, als das zweite, an seiner Unterseite mit einer oder zwei derben Borsten besetzt und im übrigen unten und oben melır oder minder behaart. Das zweite Glied trägt ungeführ in der Yitte seiner Liainge kranzartig gestellte liingere Behaarnug. Das seitlich kompresse, manchmal sehr dentlich pubescente Fudglied ist bei einzelnen Arten, z. B. bei der Spec. psilogaster basal verbreitert, bei anderen mehr lineär. Apical ist das dritte Fiihlerglied stets seharf zugespitzt und läuft in eine mehr oder minder lange Borste aus, die sich nur bei Spec. conjungens durch auffallende Kiirze auszeichnet. Was die Lïnge des Fïhlergliedes betrifft, so ist sic ohne - Beriicksichtignng der Borste je nach den Arten zwei- bis fünfmal so grofs als diejenige der beiden Basalglieder zusammengenommen. Besonters möchte ich aber anf eine Tatsache aufmerksam macheu, der wir meines Wissens bei keiner anderen der zahlreichen Asilidenformen und iiberhanpt bei dem Dipteren nur ausnahmsweise begegnen. Das dritte Fühlerglied liilst nämlich bei einigen Atractiaarten einen gewissen, nicht zn verkennenden sexnellen Dimorphismus erkennen, der sich auf die Stellung des stets sehr dentlichen Zahngriffels, die Beschaffenheit des vor diesen gelegenen Fülıleral)schnittes sowie anf die Länge der Endborste bezieht. Diese Unterschiede werlen sich besser als ans einer Besehreibung, aus einem Vergleich der betreffenten Figuren erkennen lassen.

'Thorax. Das gleichmiafsig gewiillte, mpmuktierte Mesonotum ist mit lichter, mehr oder minder anliegender, eventuell schimmernder Behaarung bedeckt, der längere dorsocentrale Borstenhaare beigemengt sein kümnen. Schulterbeulen mit längerer biischelfïrmiger abstehender liehaarmng. Bei einigen Arten ist das Mesonotum teilweise bestaiubt nnd es machen sich dain Anleutmugen einer Striemen- und Fleckenzeichnung bemerkbar, namentlich sind dam die Anfünge einer breitgeteilten Mittelstrieme, wenigstens ror der Quernaht, zu sehen. Behorstung: pröisutural 3, supraalar 1. postalar 3, anlserdem befindet sich noch medial vor den Postalarhückern bei 
den meisten Arten eine Reihe gröberer Borsten, notoplenual 3-4, Metaplenralschirm gyt entwickelt. Das bestaubte und fein hehaarte Schildehen besitzt sechs Kandborsten, las Metanotum trïgt scitlich ein Büischel im allgemeinen feinerer Haare.

Das ahgeplattete, bei dem o etwas verbreiterte Abdomen besteht gewihnlich aus sechs von oben sichtbaren Segmenten, doch schiebt sich häufig genug auch ras siebente Segment in gröbserer oder geringerer Ausdehnung unter den freien, abgeglaitteteil Rande des sechsten hervor. Die Riickenflaiche zeight stets feinere oder gröbere I'unktielung und kurze anliegrende Behaarung. Die Farbe ist entweler schwarz, dann sind die cinzelnen Segunente mit durch weilse Bestaubung gebildeten HinterrandsHecken und feinen Segmentalsäumen ausgestattet, oder es macht sich auf ziemlich lebhaft rotbrauner Grundfarbe dunklere Flecken- und Bindenzeichunng bemerkl)ar. Die längere Seitenbehantung ist stets licht, Jiscalborsten finden sich nur auf den $2-3$ crsten Segmenten, aufserdem ist das sechste und siebente Segment mit längeren Borstenhaaren bewehrt.

Die Beine bieten kaun Charakteristisches. Die Schenkel sind relativ kahl, jedenfalls nur wenig dicht mit zarter, an der Unterseite längerer Beharmug rersehen, stälkere Borsten in selı beschränkter Anzahl findèn sich lediglich in der Umgebung der Knie. Die biirstenförmige Beharmug der Tarsen zieht sich an den Vordersehienen mehr oder minder weit empor und nimmt anch die sichienenspitze der iibrigen Beine cin. Wimperbehaarung fiudet sich an den Hinterbeinen fast aussohliefshich im Bereiche der Schienen. Bei dem or der typuschen Spec. psilogaster sind die Schienen der beiden volderen lieinuare von dichter, silberschimmeruler, fiederartig angeordneter Behaarung eingenommen.

Flïgel. llas Geider ist vollständig nach dem Typ der Atomosinen orientiert. Der Stiel der vorne relativ stumpfen Subcostalzelle ist ziemlich lang, erste Hinterandzelle stets meho oler minder verengert, aber nie geschlossen, vierte Hinterrandzelle und Analzelle grestielt, die kleine Querader steht stets iilore dem proximalen Drittel der I)iscoidalzelle.

Jie mir bekanut gewordenen Atractianten lassen sich durch folgende analytische 'Tabelle hestimmen: 
1. Grundfarbe des Abdomen leblaft hlau metallisclı glänzend.

lucide n. sp.

- Grundfarbe des Abdomen gelbbraum nit oder ohne dunkler Fleckenoder Bindenzeichnnng.

- Grumifarbe des Abilomen schwarz.

2. Unter der Fiihlerwurzel finden sich kurze, abwiirts gehogene Haare; 'Thorax lebhaft rotbraun mit schwarzer Fleekenzeichnnng; Abdomen fast einfarbig gelbbraun.

mbida n. sp.

- Unter der Fiihlerwurzel stehen lange, derbe Borsten; Thorax schwarz oder diister rotbraun; Abdomen mit ansgebreiteter dunkler Fleckenund Bindenzeichnnng.

3. Drittes Fiilılerglied lineär, auffallend lang, Endborste sehr kurz; die anliegende Thoraxbehaarung hinter der Quernaht nach der Seite gekäiumt. longicomis $11 . \mathrm{sp}$.

- Drittes Fühlerglied an der Basis stark verbreitert, Endborste lang: die anliegende 'Thoraxbelıarung hinter der Quernaht nicht nach der Seite gekämmt.

vivex $11 . \mathrm{sp}$.

4. Der Behaarung des Metanotum sind einige sehwarze, kurze und grobe Stachelbrrsten beigemengt. Bei dem $\sigma^{7}$ sind die Schienen der beiden vorderen Beinpare an ihrer Vorderseite durch silhersehimmernde Beharming gefiedert. psilogaster Wiedemann.

- Behaarung des Metanotum olne Beimengung auffallender Stachelborsten.

5. Mitte des Mesonotum mit ockerbranner Bestäubung bedeckt, welche eventucll die dunkle Grom lfarbe in Form einer mehr oder minter deutlichen Striemen- nnd Fleckenzeichnung freilialst. 6.

- Mitte des Mesonotum stets ohne Bestäubung.

8.

6. Drittes Fihlerghied hei stärkerer Vergröfserung sehr deutlich pubescent. Gesicht mit weifslicher Bestänbung bedeckt: Beine stets teilweise ge. schwärzt.

- Drittes Fiihlerglied nicht pubescent; Bestainbung des Gesiclites goldbraun; Beine durchaus lebhaft gellobram. fulripes n. sp.

7. Tor der Quernaht findet sich eine sehr deutliche, breit geteilte Mittelstrieme; Postalarhöcker in grö̈serer oder geringerer Ausdehnnng gelb- 
brann; liehatrung des Metanotum fahlgelb; Oberschenkel wenigstens an den Vorderbeinen stets in grölserer Ansilehnung rotbraun; Occipitalborsten fillugells.

picte $11 . \mathrm{sp}$.

- Mittelstrieme nur selı wenig angerlentet; P'ostalarhiicker schwarz; Behıarung des Metanotum schwarz; Oberschenliel auch an den Vorderbeinen schwarz; Occipitalborsten schwarz.

dispar $11 . \mathrm{sp}$.

8. Die anliegende Behaarung des Mesonotum ist ror dem Schildehen in anffallender Weise nach den Seiten gekämmt; Postalargegend in grolser Ausilehnung lebhaft gelb; unter der Fiihlerwurzel stehen derbe, abwiirtsgebogene Borsten.

comata n. spr.

- Die anliegende Behaarung des Metanotum ist mirgends nach den Seiten gekïmmt; Postalargegend schwarz; unter ler Fiihlerwurzel findet sich ausschliefslich kiirzere und feinere Behaarung.

9. Untergesicht auffallend verbreitert und dicht behaart; Körperbehaarnng sehr dicht, so dafs die schwarze Grundfarbe verderkt wird und Mesonotum $11 n d$ Abdomen mattgran erscheinen; Hinterbeine in ganzer Ausdehmung lebhaft rotbraun; Endborste des dritten Fiihlergliedes von gewöhnlicher Liinge.

pulceruleutu Schiner.

- Untergesicht nicht verbreitert; Körperbchanung sehr fein und zart, so dafs die Grundfarbe nicht ver:indert wird und Mesonotum mod Abdomen gliuzend scluwarz erseheinen; Oberschenkel der Hinterbeine schwarz; Endborste des dritten Fiillergliedes auffillend verkiirzt.

conjungens n. sil.

Als typische Art gilt

\section{Atractia psiloyaster Wied. \\ syll. + 4. coronata Srlin.}

Die Art stammt ans Brasilien und liegt in sicben bxemplaren aus der coll. Winthem les k. k. Hofmuseums in Wien vor.

$\sigma^{7}$ Kopf. Untergesicht mit branner, an Mundrande lichterer liestäubung. Ler Knebelbart und die Beharung des Gesichtes sehwarz und fahlgelb gemischt, die längeren Borsten dunkel. Die schwarze Stirne besitzt grangellse liestäubung und lichte Behaarung; der Ocellenhörker träigt zwei scliwarze Borsten. Scheitelgegend unl Hinterhaupt gleichfalls gellogran 
bis weifslich bestänht mit lichter Beharung, anch der Borstenkranz ist fahlgelh. Backenhart, die Behaarming der Kinngegend, des Riiissels und der Taster weilslich. Fiihler gelb ('T'extfig. 65), das dritte Segment an seinem Oberrande und seiner Spitze geschwärt, auch die borstenförmige Verlängermug und der Zahngriffel schwarz. Erstes Segment mit fahlgelber Behaarung, an der Lnterseite mit einer dieken schwarzen Borste. Zweites Segment schwarz beborstet.

Thorax. Das sehwarze Mesonotum ist an seinem ganzen hande in ausgedehntem Mafse mit graugelber Bestäuhung bedeckt. Der dichten, anliegenden, in wesentlichen fast weifsschimmernden, un seitlieh dunkleren Behaarung sind schwarze dorsocentrale Borsten in mäisiger Anzahl beigemengt. Die gröberen Seitenhorsten ansschliefslich schwarz. Pleuren und Hiiften allenthalben weifsgrau bestainbt und behaart. Notoplenralborsten und Metapleuralschirm weifslich. Sehwinger gelbbraun.

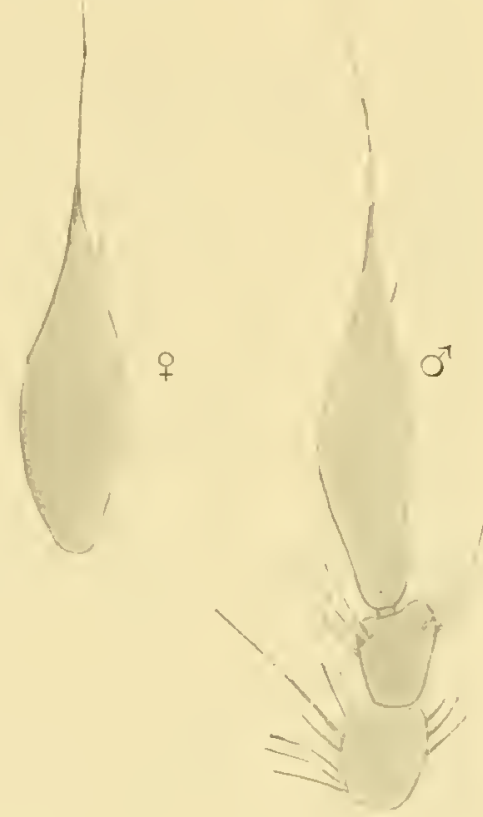

Fig. 65.

Schildchen mit Ausnahme des freien, mit sechs fahlgelhen Borsten versehenen Randes gelhgrau behaart. Collare gelhgran bestänbt mud gelb beborstet. Das ebenfalls gellogran bestäuhte Metanotum trägt aufser feiner fahlgelber Behaarung einige krättige teils schwarze, teils gelbe Stachellorsten.

Ahdomen schwarz mit feiner, aber deutlicher P'unktiermig und im wesentlichen dunkler, kurzer, anliegender Beharmug. Der Hinterrand des sechsten Segmentes gelbbraun. Die einzehnen Segmente besitzen am seitlichen Raude kleine, weifs bestäulte Hinterrandsflecken, die sich gegen die Nediane in anfserst feine Segmenteinschnitte fortsetzen. Der ziemlich langen, fahlgelben seitenbeharung sind an den ersten beiden Segmenten je $3-t$. an den iibrigen je eine Ihiscalhorste ron gleicher Farhe heigemengt. Las sechste Segment besitzt seitlich eine Gruppe längerer Borstenhaare. Bauch gell bestäubt. 
Beine. Obersehenkel mit Ausnahne der gelb gefairbten Wurzel und der Kniegegend, sowie die T'arsen braun bis schwarz. Die Schienen sind gelburaun, an der Spitze leicht gesehwäirt, an der Wrurzel jedoch lichter, an den beiden vorderen Beimparen fast weifslich gefärbt. Wie Behaarung nul Beborstung der Beine ist in allgemeinen weifslich bis gelb, nur die 'Tarsen tragen volwiegend schwarze Borsten. Die Sehienen der beiden vorderen Beinparre tragen lange, anliegrende, fast ferlerartige, weifsschimmernde Beharung, die Wimperbeharnug der Hinterbeine ist nur wenig dicht. Klanen schwarzbraun mit lichter Basis, Pulvillen liehtgelb.

Auf den schwach grau tingierten Flügeln sind die Aderus braun, nur an der Basis gुelbbraun gefübt. Die erste und zweite Hinterrandzelle ist gegen den Flïgelrand schwach verengt.

Das $q$ ist ron Sehiner als At. coronata beschrieben worden; die Untersuchmng iler mir vorliegenden Typen ergab aber. dals sich die Species nicht festhalten lïfst. Wie Unterschiede gegeniber dem ơ sind nur geringe. In der Beharung les Gesichtes, der Stirne und del ersten Fülılersegnuente und im Knebelbarte herrseht im allgemeinen die dunklene Farbe vor. Auf łem 'Thoraxriicken ist dic anliegende Behaarnng' ausschliefslich messingrolb. An den Beinen, die bei einzelnen Exemplaren etwas hellere Fiibung zeigen, felılt den Schienen der Vorder- mul Mittelbeine die lange gefiederte Behaarung. doch ist auch bei dem o die Beharmug der Schienen schneeweifs, nur bedentenl kiirzer und zarter.

\section{Atractia pulverulenta Schin.}

Die 'Type stammt aus Brasilien und befindet sich in rer Sammlung des k. k. Hofmusemms Wien.

Der kurzen liesehreibung dieser sicher selbständigen Art füge ich folgende nïheren Angaben bei.

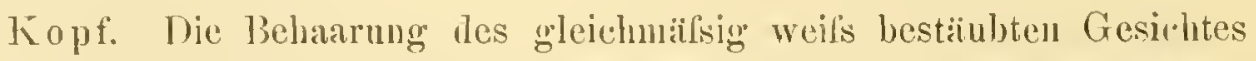
und der Stirne, sowie der Knebelbart weil'slich, auch das granweils bestïubte Hinterhanpt, die Kimmgegend, der Riissel und die "Taster sind weifslich behart. Die Borsten des Ocellarhöckers und des Hinterhauptes fahlgelb. 
Ebenso tragen die Basalglieler der Fiihler (Textfig. 66) ansschliefslich lichte Beharung:

Thorax. Die dichte, die schwarze Grundfarbe grölstenteils verdeckende, anliegende Behaarung des Mesonotum und les Schildchens weifslich, oder ganz licht messinggelb, anch die lingere abstehende Behaarung ist ausschliefslich hell. Die Beborstung des Thoraxrandes und des Schildchens fahlgelb, ebenso die Behaarung und Beborstung an den Seiten les grangelb bestäubten Metanotnu. Pleuren nnd Hiiften weilslich bestiabt und behart.

Abdomen schwarz, fein punktiert mit durch liclitere Bestiiubung gebildeten, aber wenig in lie Angen fallenden Hinterrandsflecken an der Seite der einzchnen Segmente. Die sehr lichte anliegende Behaarung des Hinterleibsriekens ist ebenso wie die Seitenbehaarung und die Discalborsten fahlgelb. Banch mit Ausualime Fig. 66. ler glänzend schwarzen Segmenteinschnitte grau bestiiuht umd licht behaart.

Die schwach gelblich tingierten Fliigel besitzen in ihrer Spitzenliälfte stiirkere, mikroskopische Behaarung, so dals eine leichte Triibung entsteht. I ie Hilfsader und díe erste Lïngsaler sind in grö̈lserer Ausdehnung gelh, die ïbrigen Adern lnaun gefärbt. Die beiden ersten Hinterrantzellen sind gegen den Fliigelrand nu sehr wenig verengt, dlie kleine Querader steht an der Grenze des proximalen Drittels der Discoidalzelle.

$$
\text { Atractia virax 11. sp. OT? }
$$

Zwei Exemplare ex coll. Schunse ans Peru (Urubambatufs, Umahuankiali, $500 \mathrm{~m}$ ii. ı. . I.) und fiunf kxemplare in meiner eigenen Sammlung ebenfalls aus Peru.

Kopf. Gesicht und stirne gleichmailsig mit diehter, weifser bestïnbung bedeckt. Der Knehelbart. die teilweise recht grobe Behaarung iles Gesichtes. und die feineren Hïrdhen der stirne und scheitelgegend ebenfalls wrifs. 1)as Hinterlanpt ist in den oberen Partien geblich, im ibbrigen weifsgran Nusa Acta XCVI. Nir. 1. 
hestïult, die Behaarung ist ebenso wie der Backenhart weils, die kräftigen Occipitalborsten gelblich, ebenso die beiden Ocellarborsten. Riissel und Taster schwarz mit gelblichweifser Behaarung. Fiihler (Textfig. 67) liell gelbbrann, das dritte Segment ist am Olerrande gegen die Spitze zu in gröfserer oder geringerer Ausdehmmg gebrïunt, die Endborste ist schwarzbraun. Die beiden ersten Segmente tragen gelblichweifse Behaarung, nur

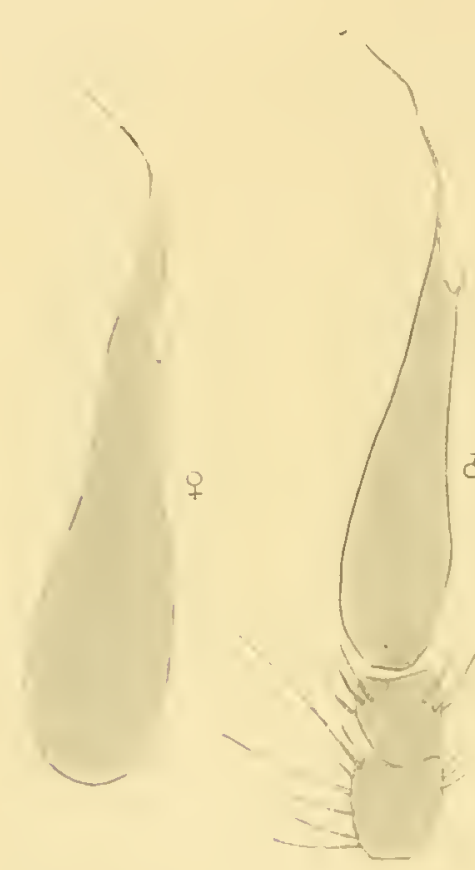

Fig. 67. an der Oberseite des zweiten Segmentes machen sich auch schwarze knrze Haare bemerklich.

Thorax. Mesonotum sehwarz, am Seitenund Torderrande in grofser Ausdehung mit weilsgrauer Bestäubung bedeckt und fein behaart; vorne machen sich die Anfünge einer breit geteilten Mittelstrieme bemerkbar. Der Hanptsache nach ist aber der Thoraxuicken mit ziemlich grober, anliegender, nach hinten zu länger werdenter Behaarung von fast golitgellser Farbe bedeckt. Postalarlï̈cker in grolser Ausdehnung rotgelb. Das gleiclifalls schwarze Schildchen ist mit Ansuahme seines freien Randes lehmgelb bestialut und licht behaart. Pleuren und Hiiften mit gelblicher lis graner Bestïubung unl feiner lichter Beharung. Die beiden Pr:ïsuturalborsten sind gewölmlieh schwarz, die ïbrigen Borsten, anch die Randborsten des Schildchens jeiloch stets gelbbram. Metapleuralschirm weislich. Das weifslich bestiubte Collare mit ciner lieihe fahlgelber Borsten. Das teilweise gelb bestäubte Metanotum trägt seitlich einige gelbliche Borsten und feinere Hïrchen. Schwinger hellgelb.

A bdomen undentlich punktiert, ziemlich lehluaft rot oder gelbbram mit schwarzer Flecken- und Binlenzeichnung; die jedoch die Segmentrïnder nuter allen Unstauden freilälst. Frstes Segment schwal\%, zweites segment mit kleimen Seitenflecken, die sich damm anf dem dritten Segmente beträichtlich verhreitern. jeloch die Grundfarbe noch in einep hreiten Mittelstrieme freilassen. Auf dem vierten Segmente ist diese schon seln verschmälert, auf 
dem fuinften wud sechsten Segmente finden sich breite, aber den Vorder- und Hinterrand nicht eimehmende sclwwarze Queloünder. Die Segmenteinsclunitte sind durch weilsliche Bestaubung fein gesiiumt. Die anliegende kurze Belaarung ist auf dem Hintelleihsriicken grölstenteils schwarz, an den Seiten, an den Segmentrintern, sowie auf dem ganzen sechsten Segmente jedocls gelblich. Discalborsten fahlgell). Banch gelbbraun mit grangelbliclier Bestiubung.

Beine im ganzen gelbbrann; an den Oberschenkeln gelit die Farbe mehr in Rotbraun über, während lie Schicnen, namentlich an den beiden vorderen Beiupaaren fiast liehtgele], grefarbt sind. Die Trochanteren sämtlicher Beine Aunkelbrann, ebenso sind die distale Hälfte der Hinterschenliel. die Riickseite der Mittelschenkel, die Schienenspitzen der Hintel- und Mittelbeine, sowie die simtlichen Tarsenglieder mehr oder minder gebrïunt. Die Belıarung und Behorstung ist an den Schenkeln und Schienen ansschliefslich gell, die 'Tarsen sind, wenigstens an den Mittel- und Hinterbeinen schwarz behaart und beborstet. Die biirstenförmigge Behaarıng an der Unterfiache ler Tarsen, namentlich der Metatarsen ist fuchsrot. Klauen schwarz, Pulvillen gुelb.

Fliigel ganz schwaeh brïunlich tingiert, lyyalin und ziemlich stark irisierend. Die Adern sehwarzbrann, die erste Hintermandzelle betridchtlich verengt.

Lollg. corp. $10 \mathrm{~mm}$, long. alar. $10 \mathrm{~mm}$.

Atractia rubida n. sp. or.

Ein einzelnes Exemplar aus Rio Grande do Sul (Brasilien) findet sich in ler Sammlung des k. k. Hofmusenms ITien.

Kopf. Untergesicht und Stirne gleithmälsig mit bräunlicher Bestaiubung bedeckt; Belaarung und Ḱnebelbart fahlgelb. Das braungrane Hinterhaupt ist am Iugenrande durch weifsgranc Bestaiubung gesiumt und ebenfalls fahlgelb behaart nud beborstet; auch die beilen Ocellarborsten besitzen diese Farbe. Taster unl Riissel duister braun, jene nit weilslibler. dieser mit gelber Behaarung. Die beiden Basalgheder der Fihler. - das 
Iritte felilt - lehhaft rot, an der Lnterseite fahlgelb, an del Oberseite schwar' behant.

'Thorax. Nesonotum rothram, am vorderen und seitlichen Rande mit diinner weilslicher Bestïubung beleckt. Torne findet sich eine ziemlich breite, mngeteilte sehwarze Mittelstrieme, die sich aber nur bis zur Quernaht erstreckt; die Seitenstrieme wind dureh eine hinter der Nalit gelegene schwarze Makel angedentet. Hinter der Sehultergegend findet sich ein Querband kurzer, anliegender goldgelber Behaarung, weiter nach riickwiirts ist diese sehr kur\% und im wesentlichen schwarz, vor dem Sehildchen einige kurze goldgelbe Haare. Die landborsten sind ausselıliefslieh schwarz. Das rote Schildehen ist gelblich bestäubt und mit fahlgelben Randborsten versehen. Die ebenfalls rotbramen Pleuren weifslich bestaiubt und liehaart, der Metajlenralsehirm gelb, die Notopleuralborsten sehwarz. Das weifslich bestiubte Collare ist fahlgelb beborstet, das diister rotbraune Metamotum trägt seitlich ein Biischel gelber Hiirchen.

Das relativ schmale, fast streifenförmige Abdomen ist lelohaft rot, wenig punktiert und nur auf dem fünften Segmente mit schwarzen Seitenflecken von dreicckiger Gestalt ausgestattet. Die sehr kurze Behaarung ist anf del" Riiekenfläche sehwarz, an seitliehen Rande und auf dem ganzen sechsten Segmente lïnger und gelb, Disealborsten vou gleicher Farbe finden sieh, wenigstens bei dem einzigen vorliegenten Fxemplare, nur auf dem ersten Segmente. Banch gelb, dureh Bestinbung matt mil sehr zallet behaart.

Beine lebhaft gelbbram und ziemlich grïnzend. Die Oberschenkel sind an den Torderbeinen in griil'serer Ansdehnumg, an den Mittelbeinen nur an ihrer oberen Fläche etwas gebräunt, die Hintersehenkel besitzen nale de kiniespitze einen breiteren sehwarzen Iing, anch die Spitze der Hinterschienen, sowie die Endtarsen sämtlicher Beine sind schwar\%. 1)ie lieharmug und beborstung ist fist ausnalmslos gelb, die biilstenförmige liehar'ung der 'larsen goldsehinmernd. Klanen schwarz, Pnlvilleu gell.

Fliigel loraliu, mit bramner, an der Wurel mit teilweise gelh-

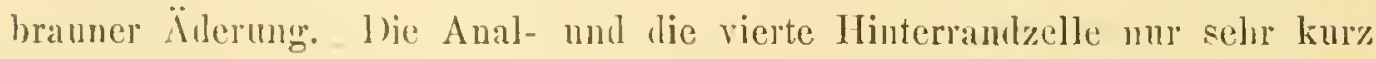
gestielt, ilic crste llintermandzelle ist gegen den Fliigelrand deutlich verengt. Long. corje. 9 mun, long. alar. $S \mathrm{~mm}$. 
Atractia picta n. sp. ?

syn. Atomosia picta Sehiner in litteris.

Das typisehe Exemplar stammt aus Tenezuela und befindet sich in der Sammlung des k. k. Hofmuseums Wieu.

Kopf. Gesicht mit dichter weifsgraner Bestiubung und weilslicher Behaarung. Dem ebenfalls weifslichen Knebelbarte sind am Mnndrande zwei schwarze Borsten beigemengt. Stirne mud Scheitel weifsgrau bestainht und weifslich behart. Ocellarborsten sehwarz. An dem mattschwarzen Hinterhaupte sind die linteren Orbitalrïnder durch weifsliche Bestänbnng breit gesäumt; die Occipitalborsten gelblich, die Behaturug mod der Backenbart weifs. Kinngegend mil Riissel weifs, die schwarzen 'Taster schwarz behaart. Die beiden Basalglieder ler Fiihler ('Textfig. 68) hellbraun, die Behaarnng anf iler Unterseite des ersten Gliedes weils, im iibrigen schwarz.

Thorax. Mesonotum durch ockerbraune, an den seitlichen und hinteren Randpartien liclstere Bestäubung matt. Torne treten lie Anfänge einer breitgeteilten scluwarzen Mittelstrieme, namentlich bei gewisser belenchtung, sehr bestimmt hervor, anch zwischen den graugelb bestäubten Scluiterbenlen und der Quernaht liegt eine scharfe schwarze Makel; die Postalarhöeker in grifiserer Ausdehnung gelbbraun. Ganz vorne findet sich teine abstehende Behaarmog von bräunlicher Färbung, ller Hanptsache nach aber

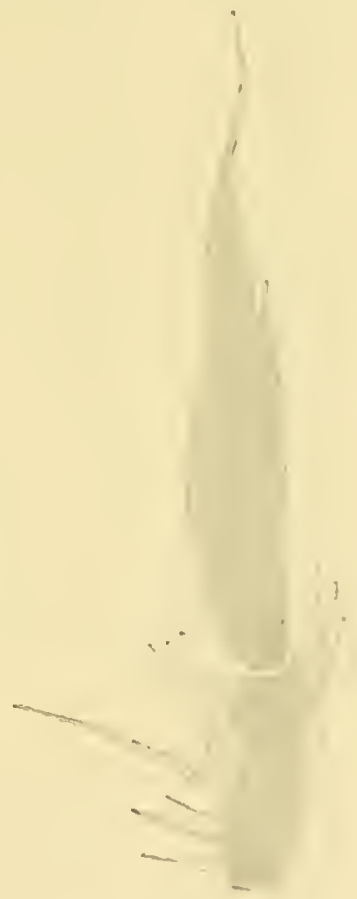

Fig. 68. wird las Mesonotum von anliegender teils goldgelber, teils fast fuehsroter Behaarung bedeckt, der vor dem Schildchen lïngere, schwarze dorsorentrale Borstenliare beigemengt sind. Die goldgelben Härehen erzengen bei gewisser Belenchtung ein die Schulterbenlen verhindendes schimmerndes Querband und mehmen anch den hinteren kand des Mesonotum rin. Has mattbraune Schildchen ist mit gelber Bestäubmug gesiiumt und mit goldgelber kurzer Beharung versehen. Die weifse Bestäubung der Pleuren liifst die 
schwarye Grundfarbe iiber den Torderliiften nud nnter der Fliigelwurzel fleckenartig frei. Die gesante Beborstung des 'Thorax mol des Schildchens ist schwarz, der Metapleuralschirm gelbbraun. Das grangelb bestiulte Collare fallgelb heborstet, las gell, bestiubte Metanotum trägt seitlich ein Biischel gleichfarbiger Härchen. Schwinger hellgelb.

Abdomen verhältnismälsig breit, sehwarz mit schmalen. aber sehr dentlichen weifs bestäubten Hinterrandssaiumen an saimtlichen Segumenten mul sehr grober Punktierung. Die anliegende Beharung der Riickenfliche ist messing gelb, die lïngere Seitenbehaarnng weilslich, die Discalborsten der beiden ersten Segmente falılgelb. Banch mattgelb mit grofsen schwarzen Mittelflecken auf den einzelnen Segmenten.

Beine melı oder minder lebluaft rotbraun, die Schenkel der Mittelund Hinterbeine, sowie dic Schienenspitzen etwas vertunkelt, lagegen ist die Kniegegend und die Wurzel der Sehienen an saintlichen Beinen ziemlich lebhaft gelbbraun. Die Behaarung und Beborstumg ist an den Schenkeln und Schienen sïmtlicher Beine fast ausnahmslos weifslich bis gelb, an den 'Tarsen brannrot. Die stark entwickelte biirstenförmige Belıarung der 'T'arsen erstreckt sich an der Innenfläche der Torderschienen weit empor und ist leblaft dunkelgoldgelb. Die lichte weifsliche Wimperbelaranng nimmt sowohl die Torderseite der Hinterschienen als anch die Unterfiache der Hinterschenkel ein. Klanen schwarz mit golbbranne IT'urzel. I'nlvillen liclitgell).

Die hyalinen Fligel sind schwach rauchgran, gegen die Spitze zu etwas intensiver tingiert, die C̈derung mit Ausnalme der änlsersten Fliggelwurzel schwarzhraun. Fiste Hinterlandzelle sejur deutlich verengt.

Hicher rechne ich anch zwei ans Costa Rica stammende Stiicke meiner eigenen Sammlung, die sich wohl durch etwas dunklere Gesamtf:irbung unterscheiden, im iibrigen aber mit der 'Type so sehr iibereinstimmen. lafs ich iiber ilıre Ilentitit keinen / weifel lıege.

Isong. corp. $9 \mathrm{~mm}$, long. alar. $8 \mathrm{~mm}$. 


\section{Atractia comata n. sp. q.}

Die Art liegt mir in zwei $q$, ans Costa Rica stammenden Exemplaren meiner Sammlung ror.

Kopf. Gesicht. Stirne und Scheitelgegend gleichmilsig weilsograu bestäubt und weifs behart. Auch die sehr groben Borsten des Gesichtes und des Kinebelbartes sind reifslich. Der unbestäubte Ocellenhöcker träigt zwei schwarze oder fahlgelbe Borsten. Das gelbgran bestäubte Hinterhaupt ist weil's behart und mit einer Reihe gleichfarbiger Borsten besetzt. Backenbart, die Behaarung" der schwarzen 'Taster, der' Ruisselwurzel und der Kinngegend weils, die Spitze des Riissels gelbbraun behart. 1)as dritte Glied der dunkelbraunen Fïhler (Textfig. 69) ist namentlich an seiner Innenfläehe gelblich bestäulst und läuft in eine relativ kurze Endborste aus; der Zahngriffel an seiner Spitze weils. Die Behaarung und Beborstung ist an der Unterseite des ersten Gliedes weilslich, im übrigen schwarz.

'Thorax. Mesonotum schwarz, ohne jede Striemen- und Fleckenzeichnung: die Postalarg'eg*end in grolser Ausilehnung grlänzend gelbbraun. Ton den Schulterbeulen erstreckt sich bis zu den l'ostalarhökern ein ziemlich breiter Saum fast silberweilser Bestäubung und zwar so, dal's auch medial vou diesem noch ein strichfürmiger Bestäubungsflecken sichtbar ist, im iibrigen entbehrt jedoch das Mesonotum der Bestäubung vollstiundig. Die dichte anliegende Beharung ist vor der Quernaht licht

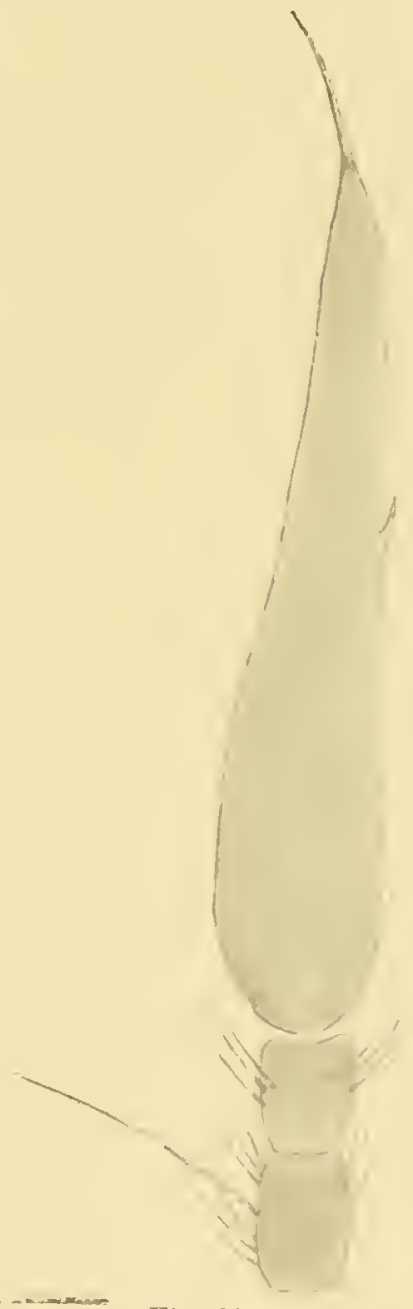

Fig. 69. messinggelb, hinter ihr in resentlichen sehwarz und etwas länger, doch findet sich auch hier jederseits ein Streifen inessingogelber, eigentümlich nach answärts gekiumuter Haare, der sich bis zum hinteren Rande des Thoraxriickens erstreckt. Ibie groben Borsten des Mesonotmm sind ausschliefslich schwarz. 
Das schildehen ist mit Ausmahme seines gäbzend schwarzen freien Randes hell messingrgelb bestäubt und behaart, Randborsten fahlgelb. An den schwarzen Pleuren ist die weilsgrane bestïulung nicht iiberall grleich dicht, so dals eine allerding undeutliche Bindenzeichmung entsteht; die zerstreute liehaarung ist weilslicl. Notoplemalborsten mul Metapleuralschirm schwarz. Collare weifsgrau hestiabt mit relativ sehwather weidslicher Bchaarung; das ebenfalls gratu bestiunbte Metanotum triagt seitlich ein Biischel gelblicher Hare. Schwingel gelb. Hüften grau bestiiubt mit hauptsächlich lichter Behaarmg. Abdomen schwarz mit relativ feiner Punktierung mul schmalen gelbbrannen Hinterrandbinden, an denen sich bei Betrachtung ron riekwairts anch eine feine, durch weifse Bestäubung gebildete Saimmung erkenmen

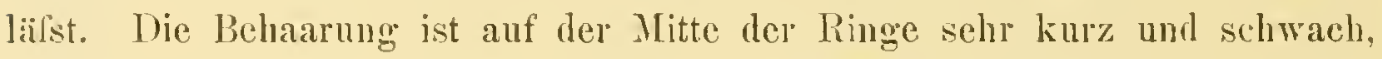
am Toriler- und Hinterrande jeiloch lïnger und hell messinggelb, so dafs das Abdomen eine ziemlich dentliche Bindenzcichnumg zeigt. Die Discalborsten sind an den beilen ersten Segmenten falılgelb, an den iibrigen schwarz. Das ventral verlagerte siebente Segment trigt an seinem gamzen Rande steife, abstehende Borstenhare von gelblicher Farbe, anch die Genitalien sind gelblich behart. Der Bauch ist vorne gelb, nach riickwiits sclwäirzlich, der Rand des Abdomen gelb gesäinnt nud mit ziemlich feiner, livliter Behaarung versehen.

Beine. Schenkel der beiden rorderen beimpare Jurehscheinend golbbraun: an der Aufsenseite in grörserer oder geringerer Auslehnung gebrïunt; an den Hintersehenkchn lıt sich diese Brïunung su selı ansgedehut, dals die urspringliche gelblorame Grundfarbe nur mehr an der Basis Heckenartig sichthal ist. Die beinweifsen Vorkelschienen sind nu an der Hinterscite und gegen die Spitze zu schwach gebriinut, an then Mittel- nul Hinterschienen jeloch beschränkt sich die beinweifse Färbung lediglich auf die hasale Hailfte, während die Spitzenhälfte dunkelbraun ist. D)ie Behaarnug ist an den Sohenkelı vurwegend licht, an den Sehienen richtet sielı die Farbe der Haare und Borsten ziemlich genau nach der Grundfarbe: die dunkelblannen 'T'arsen sind schwarz beborstet. Die grelbe bïrstenfiirunige Behasung an ihrer Unterseite macht sirelı an den Innenflächen der Tordersehienen nur wenig bencrkbar; die Wimperbehatrung ist weifslich. Klanen schwarz mit gelbroter Wrurel, P'ulvillen gelblich. 
Die hyalinen Flïgel sind an der spitze und an hinteren lande dureh mikroskopiscle Behaarung. sehwach rauchgrau getriibt, die dilem an der ällsersten Fliigelwurzel leblaft gelb, im iibrigen dunkelbraun. INic erste Hinterrandzelle deutlich verenut.

Long. corp. $10 \mathrm{~mm}$, long. alar. $9 \mathrm{~mm}$.

$$
\text { Aractia fulvipes 11. sp. ot. }
$$

Das typische Kxemplar stammt aus Brasilien (Blumenau) mud befindet sich in der Sammlnug iles k. k. Hofmusemms in Wien.

Kopf. Das relativ schmale Gesicht ist mit braungoldener Bestiulung dieht bedeekt, die Borsten des Knebelbartes und die iiber ihm stehenden verhältnismäfsig feinen, abwärtsgobogenen Ilare dunkel rotbraum. Stirne und Scheitelgegend weifs bestäubt mul nur sehr fein behart. Ocellarborsten schwarz. l)as Hinterlampt ist gelb, an ilem hinteren Angenrande und den unteren Partien weil's bestiubt, Beharung und Backenbart weifs, lie Occipitalborsten gelhlich bis weifs. Riissel und Taster dister rotbraun mit gelblicher Beharmng. Die beilen Basalglieder ter Fiihler (Textfig. 70) hellgelb mit vorwiegend sclwwarzer Behaarung mod Beborstung. das Endglied mit Ansualume seiner infsersten Wurzel dunkelbraun; der Kahustift mit weilser Spitze.

Thorax. Mesonotum dunkelbram, allenthalben mit ockerbrauner, an den Seiten lichterer Bestäubung bedeckt, so dafs eine Flecken- mul Strienenzeichmung sich mu seh"

Fig. 70. undentlich, und zwar nur bei gewisser Belenchtung, greltend maclit. l)ie kurze, abstehende Behiarung ist volwiegend schwarz, schimmerude anliegente behaarumg fehlt rollkommen. I) Schulterbenlen sind gebbraum. doch wird lie Grundfarbe fast vollstäudig von der ockerbrannen Bestiulnumg bedeckt; die Postalarlioker aher sim in grolser Austelumug lebluaft

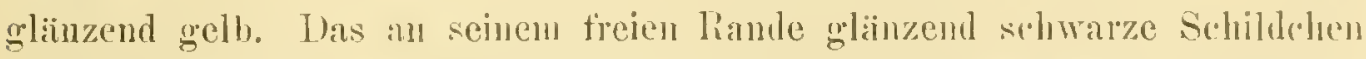
ist gelb bestainbt, seine Randborsten simd ebenso wie die gesante Beborstung" des Thoraxidickens schwarz. I'leuren mit sehı dichter, weilser. in len 
oberen Partien gelblicher Bestaubung bedeckt und mit sehr zerstrenter weifser Behaurung versehen; im bereich der Metapleura schimmert die jotbraune Grumlfarbe durch. Metapleuralschirm und Notopleuralbolsten gelb. Collare gelblich bestiubt und behaart, das schwarzbranne, gelblich bestiubte Metanotum träßş scitlich ein Biischel gelbbramner Härchen. Hüften weifs bestiinbt und behaart, Srhwinger weifsgelb.

Das schmule Abdomen ist glinzend schwarz und mu mit feiner. wenig dichter P’unktierung versehen. Die Segmenteinschnitte sind durch weilse Bestiulbung iulserst fein gesäumt. Die kurze Behaarung der Riickenfliche ist golilgelb, die längeren Seitenhare weifslich, die Discalborsten der ersten Segmente fahlgelb. Bauch gelb mit gramer Bestäubung.

beine durchans lebhaft gelbbraun, nur dic Tarsen, namentlich der Hinterbeine etwas verdnnkelt. Die wenig dielite Behaarung ist auf der Oberscite deر Schenke], an der Aufsenseite der Schienen nud an den Tarsen gröifstenteils sehwarz, in iibrigen gelb. Anch die Borsten sind zum Teil schwar\%. Die grollgelbe biirstenfurmige Beharung ler Tarsen setzt sich sowohl auf die Innenseite der Vortersebienen, als auch auf die Spitze der Hinterschienen fort. Die Wimperbeharung der Hinterschenkel und -schienen weilsliclugelb. Kilanen dunkelbrann, Pulvillen gelb.

Flïgel manentlich gegen die Spitze zu mit deutlicher durch mikjoskopische Belaarmog gebildeter Trübung. Die Adern sind hellbraun, an der Flïgelwurzel grelb. Die die vierte Hinterrandzelle distal al)schliefsende Queraner ist gegeniber der Abschlufsader der Discoidalzelle etwas proximal verscloben. daher die vierte Hinterantzelle relativ lang gestielt. Die kleine (Querader ist der Mitte der Discoilalzelle genïhert. Erste Hinterrandzelle nicht verengt.

Long. corp. $7 \mathrm{~mm}$, long. alar. $6 \mathrm{~mm}$.

\section{Atractia dispar n. sp. or $f$.}

Diese nene Art, deren beile Gesohlechter sich ziemlich bedentend von cinander unterseheilen, findet sich in 40 kxemplaren ans rerschiedenen 'Teilen P'erus in der Sammlung Schnuse. 
OT Koplf. Gesicht mit dichter gelhlichweiser bestainhmog heilcekt, der weilse Knebelbart reicht nur bis zur Hälfte der Höhe des Cresivlits empor, das in iibrigen mit kiirzeren, abwiirtsgebogenen ansualnuslos weifsen Haaren bedeckt ist. Strme mul sulieitelgegend gelh bestainbt und schwarz behatrt. Das gelbgran bestiunbe, an len Augen weids geranlete Hinterhanpt trigt in seinen oberen Particn schwarze, nach abwairts schwiichere weifsliche Borsten, die Beharmo ist ebenso wie der Backenbart rein weifs. Taster schwarz und ebenso beborstet. Kinngegend und die Mrurzel des pechbraunen Riissels weifs, ressen Spitze gelb behart. Fiihler schwar\%, anch die Behaarmug und Beborstung der beiden Basalglieder. Über die Gestalt des namentlich an seiner Spritze deutlich pubescenten Endgliedes rgl. Textfig. 71 .

Thorax. Die schwarze Grumdfarbe des Mesonotum wirl rollstaindig von braungraucr, an den Seiten lichterer Bestiubung verdeckt, so dafs nur bei gewisser Belenclitung Spuren einer breitgeteilten Mittelstrieme sichtbar werden. Die feine, aber recht dichte Behaarnng ist iiber den Fig. 71. Schnlterbeulen gelblich, im iibrigen aber schwarz und nach hinten zn länger. Schimmernte anliegende Härchen von messinggelber Farbe finden sich in individuell verschiedener Menge wohl beiderseits hinter den Schnlterbenlen, sie sind jedoch nie zu einer Qnerbinde vereinigt. Das schwarze Schildrhen ist nit Ausuahme seines freien Randes von okerlurauner Bestiubung bedeckt und ebenfalls schwarz behart. Ramiborsten des Schildiliens nud des Mesonotmm ilurchaus schwarz. Metapleuralschim weilshich, Notoplentaborsten schwarz. Das graubestäubte Collare trïgt cinen Kranz ziemlich grober, gelblicher Borstenhare, das gelbbestäubte Metanotum besitzt seitlich ein Biisclie] gröberer Borstenhare unl feinerer Härchen ron schwarzer Farbe.

Abdonen sehwarz mit leichtem schlackenblanem Sohimmer, zicmlich glänzend, die dentliche P'nnktierung unr wenig dicht. An den Seiten finden 
sich durch silberweilse liestaiubung gebildete, oblonge Hinterrandflecken, die wenigstens an den mittleren Segmenten durch iufserst feine IInterrandsäume untereimander zusanmenhängen. Die kurze anliegende liehaarung ist anf der liiickenfliche schwarz, die lingrere, abstehende Seitenbehaarung ist weils und zieht sich im Bereiche der Hinterrandflecken mehr orler minder anf die liickentliche empol: Discalborsten von weifslicher Farbe finden sich anf den ersten drei Segmenten. Das sechste Segment ist seitlich mit lïngeren teils weifslichen, teils schwarzen Borstenhaaren besetzt, ebenso trijgt der freie Rand des grörstenteils rentral verlagerten siebenten Segments lange, abstehende hleichgelbe Borsten. Genitalien weifslich behaart. Bauch schwarz mit zarter weifslicher Behaarung.

13eine. Die Schenkel der beiden vorderen Beinpare sind mit Ansnahme der gelb gefiiloten Kniegegend dunkelbram oder selswarz, die Schienen und Metatarsen elfenbeinfarbig, die folgenden Tarsenglienler bram bis schwarz. l)ie llinterbeine aber sind durchans schwarz gefälbt. Die Behaarmug und Beborstung sämtlicher Beine ist allenthalben weil's oder blals gelblich, nur die 'T'arsenglieder schwarz beborstet. Die hiirstenfürmige goldgelbe Behaarung derselben nimmt auch die lnneuseite der Torderselienen und die Spitze der Hinterschienen ein und ist hicr rein weils; ebenso dic Wimperbehaarmo der Hinterbeine. Klanen schwarz, Pulvillen gelb.

Die Fliigel simd an der Spitzenhältte und am hinteren Ramle zicunlich intensiv ranchgran tingient mol dureh mikjoskopische Beharumg getribt. Adern dunkelbram, erste Hinterrandzalle nur wenig verenğt.

Das $q$ unterscheidet sich in melnfacher lichtung von dem or. Indem ich nich begnige, lediglich die Untersehiede anzugeben, mache ich besonders anf die Differenzen im Ban des dritten riihleroliedes anfmerksam, die vor allem in der stellung des Zahnstifts und der Beschaffenheit des vor diesem stehenden Fiihlerabschnittes gegeben sind und die sich durch den Tergleich ler beiden Fig. 71 ohne weiteres werden erkemnen lassen. Metapleuralschirm in der oberen llälfte schwarz. An dem breiteren mol phumperen Abdomen sind die die weis bestäubten ITinterrandflecken verlindenden Segmentsäume deutlicher entwirkelt. Die weniger dichte Seitenbeharung ist an dun hintersten Segmenten schwarz, ebenso die 1)iscalhorsten des ersten Segmentes. Das sechste und siebente Segment ist branngelb gesiumt. An den Beinen 
sind die Färbungsdifferenzen recht beträchtliche; sämtliche Beine sind naimlich schwarz, und die helle Fäblumg macht sich nur an der Wrurzel der Torderschienen Heckenartig bemerkbar, Anch die Beharung und Beborstung ist zum Teil schwar\%.

Long. corp. $8,5 \mathrm{~mm}$, long. alar. $8 \mathrm{~mm}$.

\section{Atractiu conjungens n. sl. F \\ syn. Atractiu conjungens Schin. in litteris.}

Die Type luefindet sich im k. k. Hofmuseun Wien und stammt aus Brasilien.

Kopf. Das Gesicht ist weifs bestänbt, der gelblichweifse dichte Kmebelbart bodeckt nur das untere Drittel des Cresichtes, dariiber findet sich fenere, abwairtsgelrogene weifse Beharmug. Stime grau bestainbt und weilslich behaart. Der unbestiunlte Ocellenhöcker trïgt zwei schwarze Borsten, das weifslich bestäubte Hinterhanpt weifsliche Behorstung. Backenbart und Behaarung der Kinngegend, der Riisselwurzel und der Taster weilslich, Spitze des Riissels mit einem Biischel gelher Haare. Fiihler (T'extfig. 72) schwar\%, das erste Glied mit weilshieher, das zweite mit schwarzer Behaarung und Beborstung. Uas Endglied mur hörhstens doppelt so lang als die beiden Basalglieder zusammengenommen, anch verhältnismäfsig schmal, die Endborste auffallend kurz.

Thorax. Mesonotum schwarz, olne Bestiiubung,

Fig. 72 grlänzend, nur zwischen den Sichnlterbenlen und der Flibgelwurzel findet sich ein Sanm weifser Bestäubung; anch das schildchen ist mbestiulth. Die wenig dichte, aber ziemlich lange, nit sehwarzen dorsocentralen Borsten gemengte Behaarung ist allenthalben gelb. Präsutural- unl Supraalarborsten schwarz, Borsten der P'ostalargegend und des Schildchenrandes fahligelb. Plenren und Hiiften mit dichter weilser Bestäubung unl gleichfarbiger, relativ langer Beharmug. Notopleuralborsten und Metapleuralschirn weifsich. Collare und Metanotum weifs bestïubt und gelb behaart. Schwinger lichtgelb. 
Das relativ schmale $A$ bulomen glänzend schwarz mit feiner P'unktierung. der hintere liaml rles serbsten und das ventral verlagerte siebente Segment gelbbraun. Die äulserst zarte anliegende Behaarumg gelb, anch die weikliehe Seitenbehanrung ist nur knr\% uml zart. Die Discalborsten der beiden ersten Segmente weilslich, ebenso die Borstenlaare des sechsten Segmentes. Banch lehmgran, nach riickwiirts schwiarylich.

beine lıellbram, die Schenkel mit Ansnahme ihrer Wrmel und Spit\%e gebriunt, ebenso die Sehienenspitzen nnd die Endtarsen der Vorderbeine. Die Behaalung und Beborstmmg ist ansschliceslich weifslich bis geelb, nur an den 'Tarsen ler Hinterbeine finden sich einge dunklere Borsten. Die goldgelbe biirstenförmige Behanrung zicht sich an der Imnenseite der Tordepsolienen hoch empor, Wimperbeharmeg der Hinterschienen weils. Kilanen dunkolbram, Pulvillen geih.

Fliigol lyalin, furblos, mit lebhatter Irisierung. Adern an der Wurzel grelb, im iibrigen braun. Die kleine Queraler steht an der Grenze des proximalen I)rittels der Discoidalzelle, erste Hinterrandzelle dentlich verengrt. vierte Hinterrandzelle und Analzelle kurz gestielt.

Long. corp. $9 \mathrm{~mm}$, long. alar. $8 \mathrm{~mm}$.

Atractia longicornis n. sp. + .

Die aus Bahia (Brasilien) stammende Type befindet sicll in k. $\mathbf{k}$. Hofmuseum in Wien.

Kopf. Gesicht gran bestaibbt, Knebelbart und die iiber diesem stehende grobe Beharmug des Gesichtes fahlgelb. Stirne und Soheitelgegreml hell messingogelb bestainbt umb gelb behart. Anch die beiden Borsten des unbestänbten Ocellarhörokers, sowie der Borstenkranz des gyrangelblich bestiubten Hinterhauptes sind gell, Kinngegend, Wurzel des

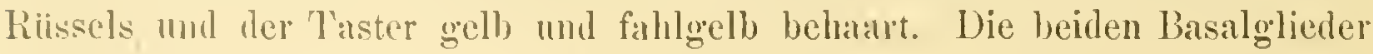
ler Fiihler ('Textfig. 73) rotbram mit grö́stenteils schwarzer Beharmug und Beborstung. Das schwarze Endglied ist fast füuf mal so lang als

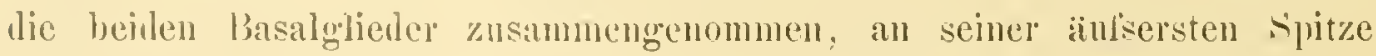
pubescent und mit einer anffallend kurzen kulborste versehen. 
Thorax. Mesonotum rotbraun mit leisen Spuren einer dunkleren Mittelstrieme. Schulterbeulen und Seitenrand gelb bestäubt. Die goldgelbe. dichte anliegende beharung ist vor dem Schildehen nach answïrts gekïmmt. Präsuturale und supraalare Borsten schwar\%, die Borsten der Postalargegend gelb. I'leuren rotbraun mit weis slichlgelber Bestäubung und Belaarung, Notopleuralborsten und Metapleuralschirm gelb. Schildchen goldgelb bestaiubt und behaart, mit gelhen liandborsten. Torderhïften gelb mit weifser Bestäubung und lehaarumg. das goldgelb bestäubte Metanotum trägt seitlich ein Biischel gelber ziemlich langer Borstenhaare.

Abdomen lebhaft gelbbrann, zart punktiert mit dunkelbraunen Seitenflecken, die sich nach riickwärts bindenartig verbreitern; fünftes mu sechstes Segment schwarzbraun, siebentes und Hinterrand des sechsten Segmentes gelbbrann. Die anliegende kurze Behaarung ist ansnahmslos goldgeli, die Hinter ränder s:imtlicher Segmente sind durch weifsgelbe liestiinbung fein gesiinmt und länger behart. Die lïngere Seitenbehaarung fellt fast vollkommen. die Discalborsten der ersten drei Segmente und die laugen Borstenhare des sechsten und siebenten goldgelb. Bauch gelbbrau mit goldgelber Bestäubung und gleichfarbiger zarter lichaarung.

Beine lebhaft geelb, nur die Endtarsen simtlicher Beine, die Oberschenkel und die Schienenspitze der Hinterbeine geeschwärzt. Die gesamte Behararung und Beborstung mehr oter minder lehhaft goldgelb. Klanen schwar\% mit gelblicher Wurzel, l'ulvillen weilslich.

Fig. 73.

Fli gel leicht gelbhrïinlich tingiert, gegen die Spitze durch mikroskopische Behaarung ctwas getriiht. Adern gelbbraun, erste Hinterrandzelle etwas verengert.

Long. corp. $10 \mathrm{~mm}$. long. alar. $8 \mathrm{~mm}$. 
Atractia lucina n. sp. or

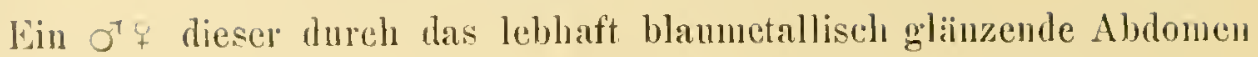
leicht kenntlichen Art aus Brasilien (Mare d'Espanha, Lspirito santo) ex coll. Hermanil.

Kollf. Ins schwarze Gesicht ist mit weifslicher bis gelblicher

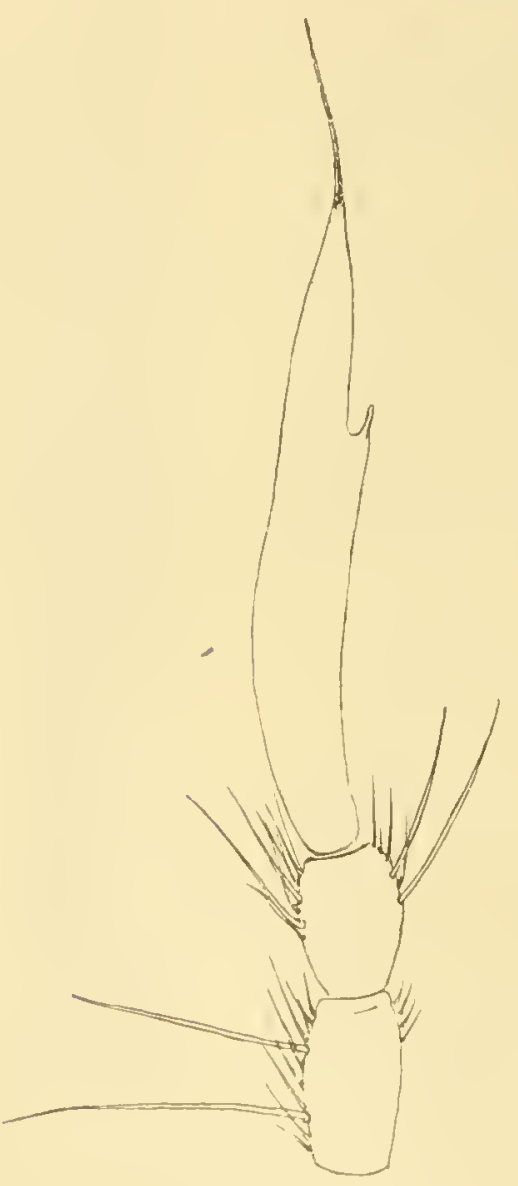

Fig. 7.t. Bestäubung beleckt; der Knebelbart besteht vorwiegend ans schwarzen Haaren, nur bei dem $q$ sind ilum am Mundrante weifse Haare in gröfserer Anzahl beigemengt. Stirne goldbrann bestiubt und ebenso wie die grau bestïubte Scheitelgegend schwarz behaart. Das Hinterhanpt ist am Augenrande mit didhter weifser Bestiubung versehen, auch seine Behaarmy sowie ter Backenbart weifs, llagegen sind lie oceipitalen mid lie beilen ocellaren Borsten schwarz. Die schwarzen Taster besitzen gleichfarbige beborstumg, der schwarze Ruissel ist an seiner Wurzel weifslich, ander Spitze gell, behaart. Fiilıler (Textfig. 74 ) schwarz und schwarz hehaart; das rephailtnismilsig schmale dritte Glied ist ohne Einschlul's les borstenförmigen Endstickes ungefiilu doppelt so laug als dic beiden Basalglieder zusanmengenommen.

Thorax. Insonotmu schwarz mit leicht blauen Netallylanz; die Schulterbenlen und die gesamte I'mrandung des T'loraxriickens ist mit weirslicher Bestäulung florkenartig beleckt, namentlich fitlt unmittellar ror dem Schildchen eine fast silberschimmernde Querbinde auf. Die breitgeteilte Mittelstrieme macht sich lediglich dureh ein etwas matteres Aussehen bemerklich, die Seitenstriemen sind nicht sichthar. Postalarhö̈ker diister rothraun, Schildelien glïnzend schwarz. Die kurze 
anliegende Behaarung ist vorwiegend, die Randheborstmug des Mesonotum und des Schildchens dnrehans schwarz. Die weifs bestiiubten Pleuren sind ebcnso wie die Hüften weils behart; die Notoplenralborsten nnd der grörste Teil des Metapleuralschirmes schwarz. Collare nnd Metanotum weifslich bestiiubt und behaart; Schwinger lichtgell.

Abdomen lehbaft blau metalliseh gliuzend mit zerstreuter, selu feiner Punktierung und silherweifsen Bestänhungsflecken an den Hinterecken des zweiten bis fiuften Segments. Die kurze anliegende Behaarnng der Riickenfläehc ist schwarz, die längere Seitenbehaarmng ist weifs und nimmt anf dem seehsten Segmente anch die Riickenfläche zum 'Teil ein; das erste Segment trägt seitlich einige selıwarze Discalhorsten. Der schwarze Bauch ist teilweise lelımgelb bestainbt ebenso wie die brannen Genitalien und weilslich behart.

An deı glänzend schwarzbranen Beinen ist die Kniegegend der Vorderbeine, bej dem $\sigma^{\top}$ aufserdem der grö́ste Teil der Hintersehienen gell). Die Behaarumg ist im allgeneinen weifslich, nur bei dem or sind die Obersehenkel vorwiegend sehwarz behart; die Beborstung ist im wesentlichen schwarz. Die bürstenförmige Behaarung saimtlieher. Tarsen nud der Innenflaiehe der Vordersehienen fuchsrot, anfserdem tragen die Unterseite der Metatarsen und die Schienenspitze grobe, lebhaft rotbraune Borsten. Klanen schwarz, Pulvillen gelb.

Die Flïgel siud dmreh mikroskopische Behaarmug leicht braun getriibt, die beiten Basalzellen gröistenteils hyalin. Die Adern dunkelbramn; dic erste Hinterrandzelle ist kurz gesticlt.

Long. corp. $13 \mathrm{~mm}$, long. alar. $11 \mathrm{~mm}$.

\section{Lopleocerreat n. $\mathrm{g}$.}

Das nene Genus steht zwar mit Atractia in allerniehstem verwanltschaftliehen Konnex, trotzdem aber scheint mir eine Reihe von plastischen Differenzen eine generische Abtrennung zn reehtfertigen.

Kopf ('Taf. Fig. ว̌ u. 56) wenn anch deutlich, so doch entschieden wenjger verbreitert als bei Atractic; die Höhe verhält sich zum Breitendurchmesser mngefüh wic llei zu fünf. Das zienlich gleichbreite Gesicht 
ist unten zu einem allerdings flachen, die ganze Gesichtshreite cinnehmenden Mundhöeker erhoben. Der Knehelbart, der sich auf das untere Drittel des Gesichtes beschränkt, besteht ans einer Doppelreihe weniger langer Borsten und einigen dazwischen stehenden sehr feinen kiirzeren Haaren, iiber ihm findet sich reihenweise geordnete abwiirtsgebogene Behaarung. Stirne dureh Ausrumdung der medialen Orbitahrïuder nur sehr wenig verbreitert unil wie der Scheitel mit zarter Behtarung rersehen. Ocellarhï̈ker mit zwei Borsten. Der Borstenkranz des Hinterhauptes erreicht den $\ddot{A} q u a t o r$ der Angen nicht und macht hier weicherer Behaarung Platz, die in den relatir diinnen Baekenbart iihergelıt. Riissel und 'Taster ohne besondere Merkmale. Die langen Fühler stehen anf einer schwachen Erhebung der Stirne; das erste Glied ist etwa $1 \frac{1}{2}$ mal so lang $o^{7}$ als das zweite und wie dieses in iiblicher Weise behaart und beborstet. Das seitlieh kompresse, schlanke dritte Fiihlerglied ist etwa dreimal so lang als die beiden Basalglieder zusammengenommen und läuft unter allmählicher Verjiing'mng in cine lange, nicht gerate horstenartige Spitze aus. Diese ist federhuschartig lang betiedert und anch der hinter den dentlichen Zalbustift stehende Fiihlerabschnitt ist an seinem oberen und unteren liande teilweise lang be-

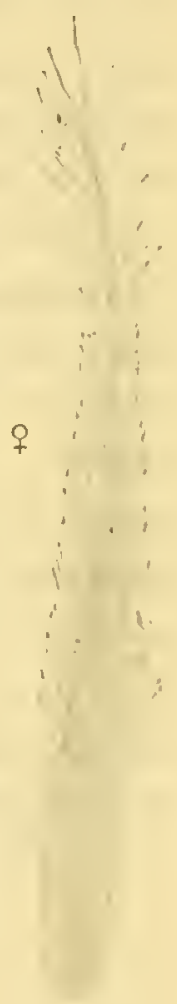

Fig. 75 b.

Fig. 75 a.

haart. Wie bei gewissen Atraetiaarten liist sich anch hier ein freilich nicht ganz so deutlieher sexueller Dimorphismus konstatiereu, ïber den am besten der Vergleich der beiden Fig. 75 a und $b$ orientieren wirl.

Tholax. Das flach gewiilhte Mesonotum ist ebenso wie das Sehildehen ron dichter Bestiiubung grleichmialsig bedeckt und mit dielhter, anliegender, 
nach riickwä̈rts länger werdender Behaarung versehen. Behorstung: präsutural 1, supraalar 1, postalar 2, notopleural 2. die hei den Atractiaarten iiber dem Supraalarlïeker stehende Borstenreihe fehlt; ler Schiildchenrand trägt vier Borsten. Metapleuralschirm gat entwickelt, das Metanotum trägt seitlieh ein Biischel feiner Härchen.

Das fein punktierte Abdomen besteht bei Betrachtung von oben aus sechs Segmenten und ist mit sehr feiner, anliegender. an den Segmenträindern etwas lïngerer Beharung versehen. Sämtliche Segmente besitzen seitlich dnrch weifse Bestänbung grebildete dreicckige Hinterrandflecken, die an den linteren Segmenten durch feine Sänme bindenartig vereint sind. Die längere Seitenbehaarung ist nur sehr wenig dicht, Discalborsten lassen sich nur an den drei vorlersten Segmenten beobachten. Das sechste und das rentral verlagerte siebente Segment tragen seitlieh lange Borstenhaare. Genitalien sehr klein und wegen dichter kurzer Behaarung in ihren intimeren Strukturverhältnissen nicht definierbar.

Beine schlank, zum Teil durchseheinend. Dic Oberschenkel namentlich der beiden vorderen Beinpare sind an ihrer Oberseite mit äufserst feinen, zerstrenten, ganz anliegenden Härchen, an der Unterseite mit einer Reihe lang abstehender Borstenlaare besetzt, an der Oberseite der Knie stehen einige etwas grübere Borsten. Die zart, aher ziemlich dicht behaarten Schienen und Tarsen sind namentlich an ihrer Innen- und Aufsenseite mit in Reihen gesetzten Borsten von erheblicher Länge bewehrt. Die goldgelbe bürstenförmige Behaarung zieht sich an den Vorderschienen hoch empor, die Wimperbehaarung ist an den zugewandten Fliiehen der Sehenkel und Schienen der Hinterbeine lang und dicht.

Fliigel durch mikroskopische Behaarung schwach getrübt. Der ziemlich lange Stiel der Subcostalzellelle fast gerade, die kleine Querader steht iiber dem proximalen Irittel ler Discoidalzelle, die diese und die vierte Hinterrandzelle distal abschlielsenden Queratern verlanfen in gleicher Richtung, meist auch in der gleichen Linie, erste Hinterrandzelle kaum verengert, vierte Hinterrantzelle relativ lang gestielt. der Stiel der Analzelle erreicht den Fliigelrand nieht ganz. 
Als typische Art besehreibe ich

$$
\text { Lophoceracu pennate } 11 . \mathrm{sp} \text {. oT } \mathrm{T} \text {, }
$$

die sich in elf Exemplaren aus P'eru (Pachiteamindung $150 \mathrm{~m}$ i. d. M.) und Bolivia-Mapiri (Sarampioni 700 m ii.d. M.) in der Sammlnng Schnuse befindet.

Kopf. Gesicht weifs bestäibt, Knebelbart und die iiber ihm stelıende Behaarung weifslich. Stion und Scheitel gelbgrau und meist dunkel behart. Ocellarborsten schwarz. Jie Borsten des graugelb bestäubten Hinterlauptes bräunlichgelb, lie feincre Behaarung und der Backenbart weifs. Die Behaarung der Kinngegend und les braunen kiissels gelblich, die bramen Taster meist schwarz belonstet. Fiihlel dunkelbraun, die beiden Basalglicder ausschliefslich schwarz hehart und beborstet.

'Thorax. Mesonotmm grleichmäfsig' ockergelb bestäubt und mit feinel, anliegender, teils gelber, teils dunkler Behaarung bekleidet. Postalarhöeker meist teilweise gelbhraun. Die Färbung der gröberen Seitenborsten und Aer Randborsten des gleichfalls oekergelb bestäubten Schildehens schwankt zwischen gelbbrann und schwarz. Pleuren, Collare und Huiften mit teils ockergelber, teils weifsgraner liestiubung und schr zerstrenter weifslicher beharumg versehen. Anch die läbung der Notopleuralborsten variabel. Metapleuralschirm gelblich, das ockergelb bestiiubte Metanotum trïgt seitlich cin Biischel relativ feiner gelhlicher Haare. Schwinger lichtgelb.

Aldomen sclıwarz, mälsiģ glänzend, deutlich punktiert und mit anliegender; feiner Behaarung von gelher Farbe verschen. Saimtliche Segmente besitzen seitlich ziemlich ausgedehnte, von silberweifser bestäubung gebildete, dreieckige Hinterrandstecken, die rom dritten segmente an durch feine liandsäume untereinander in Verbindung stehen; auch die Behasung ist hier lïnger und weifs. Die diime, lïngere Scitenhehaarung weifslich, die 1)iscallhorsten der drei ersten Segmente fahlgelh bis weifslich, ebenso die liingeren borstenhane des sechsten mol siebenten Segmentes. Der braune Banch ist an den Seiten nnd an deu Segmenträindern durch lehmgelbe Bestaubung breit gesiiumt nud zart behaart.

lieine durchseheinend licht gelbbraun, die Endtarsen gesehwärzt, die Sehenkel und Sehienen der Hinterbeine in variabler Ansdehmug gebraimnt. 
Die Sehenkel der beiden vorderen Beinjaare besitzen an ilırer oberen Seite äufserst feine, anliegende, zerstreute schwarze Härchen, im uibrigen ist die Behaarnng der Beine fast ansuahmslos gelb. Die Borsten sind an der Oberseite der Knie sehwarz, im iibrigen aber vorwiegend gelb, doch kommen da und dort auch vereinzelte dunkle Borsten vor. Die biirstenförmige Behaarnng der Tarsen und Vorderselienen blafs goldgelb, die lange Wimperbehaarung der Hinterbeine weifslich. Klanen dnnkelbram mit heller Wurzel, Pnlvillen gelb.

Die Flügel sind sehr wenig gebrïnnt und durch mikroskopische Behaarnng getriibt. Die Adern sind nur an der änfsersten Flïgelwurzel gelb, im übrigen dnnkelbramn.

Das of unterscheidet sich von dem of anfser durch den etwas anderen Bau des dritten Fühlergliedes durch das Prïvalieren hellerer Fïrbung an den Borsten des Thorax.

Long. corp. $\check{5}-6 \mathrm{~mm}$, long. alar. $4,5-5,5 \mathrm{~mm}$.

\section{Ifybo:elortes $11 . \mathrm{g}$.}

Unter diesem Namen fasse ich einige Arten von durchaus glinzend sehwarzer Farbe genersich znsammen, die in ilrem Habitus lebhaft an gewisse kleine Empididen erinnern. Sie stellen mit ihrer Körperlänge von nur wenigen Millimetern zusammen mit den Species des Dasypogoninengenus Tounsendia die kleinsten aller bislang beobachteten Asilidenformen dar.

Kouf nur mälsig verbreitert (Taf. Fig. 57 n. 58); sein Hïhendurchmesser verhailt sich zur Breite ungefähr wie $3: 4$. Das wenig vorspringende, plane, mit erentuell schillernder, jedenfalls diinner lichter Bestäubung bedeckte Gesicht ist von muten nach oben nahezn gleich breit, der Knebelbart, der sich ungefiihr auf die untere Gesichtshälfte beschränkt, besteht ans einer Doppelreihe langer Borsten und dazwischen stehenden kiirzeren Haaren; iiber ilum stehen reihenweise angeordnete abwärts gebogene Härchen. Die ebenfalls licht betäubte Stirne ist durch Ausrandung der medialen Orbitalränder mälsig verbreitert und mur an den Seiten fein beborstet. 
Daregen ist die Seheitelgegend mit dicht stehenden Borstenhaaren besetzt; der Ocellarhïcker trïgt zwei lange Borsten. Der Borstenkranz des nur schr diunn bestäubten Hinterhauptes beschränkt sich auf dessen obere Hälfte, der Backenbart ist mäfsig entwickelt. Riissel und 'Taster relativ kurz, diese an ihrer Spitze beborstet. Fiihler verhailtnismälsig kurz, lie beiden behaarten Basalglieder beinahe gleieh lang, las seitlich kompresse, seh" dentlich jubescente Endylied 11/2 bis 2 mal so lang als die beilen Basalglieder zusammengenonmen, entweler pfriemenförmig oder in eine ovale, in eine belaarte Endborste ('lextfig. 77) auslaufenle Platte ungewandelt. Der Zahnstift ist stets relativ grol's. Ob an den Fiihlern in greicher Weise wie bei den Atractariarten ein gewisser sexueller Dimorplismus vorkommt, kann bei dem nur sehr geringen Lmfang des mir zu Gebote stehenden Untersuchungsmaterials nicht entschieden werlen.

'Thorax. Das mäsig gewölbte, glïinzend schwarze und unpunktierte Mesonotum zeigt meist nur in geringer Ausdehmug diinne Bestäubung und ist mit relativ langer, aber feiner, abstehender Behaarung bekleiket. Pleuren und Hiiften gleichmäisig bestäubt mit schr zarter, an letzteren etwas längerer Behaarung versehen. Beborstung: jrïsutural 1 2, supralar 1, postalar 2, notopleural 1-2, der Schildchemand ist mit lingeren, anfwiirtsgebogenen Haaren besetzt, von denen zwei oder vier zu langen kräftigen Borsten u!ngebildet sind. Das Metanotum trïgt seitlich ein dichtes Bisehel relatir langer Borstenhaare.

Das streifenfürmigre schmale, auch hei dem o nu sehr wenig verbreiterte, bei Betrachtung von oben aus sieben Segmenten bestehente Abrlomen ist im allogemeinen fein punktiert, ebenfalls glinzend schwarz und mit sehr feiner. anliegender Behaarung bedeckt. läingere abstehende Seitenbehaarung findet sich nu' an den drei ersten Segnuenten; eigentliche Discalborsten lassen sicl uu bei eincr Art beobachten, im iibrigen sind sic durch einige lange Borstenhare ersetzt, lie sich wie jene auf lie beilen ersten Segmente beschräinen. Auch der Hinterrand les sechsten und siebenten Segnent tragen längere Borstenlıare. Dic sehr kleinen Genitalien sind ventral versteckt und lassen wegen dichter, feiner Belıarmug ihren intimcren Bau nur mangelhaft erkennen; es liefs sich mur soviel feststellen, dalis das or Genital in seitliche Zangrenarme endet. 
Beine im allgeneinen zart und wenig dicht behart; die Hintelbeine mälsig, aber deutlich verlängert. Die Schenkel sind wenigstens an den beiden vorderen Beinparen mit langen und feinen abstehenden Haaren besetzt, aufserdem tragen die Knie sämtlicher Beinc an ihrer Oberseite einige gröbere Borsten. Die reihenweise die Vorder- und Anfsenseite der Schienen einnehmenden Borsten besitzen betriachtliche Länge. Die 'Tarsen sind bei dem $o^{\top}$ entweder an den Hinterbeinen oder aber deu rorlereu Beimparen mit anffallender, dichtanliegender, scheeweifser Behaarung beleckt. I’ulvillen relativ grols.

Die lebhaft irisierenden Flïgel simd duch mikroskopische Behaarung in grölserer oder geringerer Ausdehnung zart getribt. Der ziemlich lange Stiel der Subcostalzelle läuft der derb beborsteten Randader fast rollkommen parallel, so dafs die Randzelle anfallend verschmailert ersclıcint. Erste Hinterrandzelle breit offen, oder nur ganz wenig verengert, die kleine Qnerader stelıt noch iiber dem proximalen Drittel der Discoidalzelle, die diese und die vierte Hinterrandzelle distal abschliefsenden Queradern verlaufen nicht immer in der gleichen Richtnng, niemals in der gleichen Linie, Anal- nnd vierte Hinterrandzelle gestielt.

Ton den drei mir bislang bekannt gewordenen Arten beschreibe ich als typische Species

$$
\text { Hybozelodes nigellus n. sp. or }+ \text {. }
$$

Zwei or, ein $q$ aus Peru-Meshagua (Urubambaflus, 700 m u. d. M.) ex. coll. Schnuse.

Kopf. Gesicht mnd Stirne mit schillernder gelblicher, gegen deı Mundrand weifser Bestäubung bedeckt, Knebelbart, Behaarung des Gesichts. der Stime und der Scheitelgegend schwarz, ebenso die beiden Borsten des Ocellenhöckers. Auch das Hinterhaupt besitzt dünne, teils gelbbranne, teils weifse Bestäubung; die Occipitalbeborstung schwarz. Backenbart, die Beharang der Kimngegend, ter schwarzen 'Taster und des Ruissels weilslich. Fiihler ('lextfig. 76) schwarz, mit ausschliefslich sehwarzer Behaarung und Beborstung. Das erste Glied ist nur wenig lainger als das zweite, das pfriemenfömige Endglied fast doppelt so lang als die beiden Basalglieder zusanmengenommen, allentlalben deutlich jubescent. 
'Thorax. Mesonotum glïnzend schwar\%, nur an den Seiten mit einem feinen Sam ockergelber Bestiubung beleckt. Die sehr zarte abstehende Behaarung hräunlich, die Seitenborsten sehwar\%. Das Schildchen ebenfalls glinzend schwar\%, nur seli zart heliant, am Rande mit zwei langen schwarzen Borsten und einer heihe lïngerer Hale besetzt. P'leuren grau bestïubt und mit sehr sparsamer weifslicher Belaarung versehen.

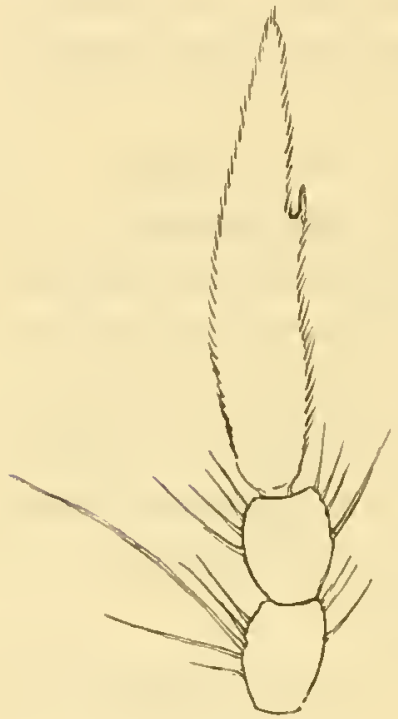

Fig. 76 . Notopleuralborsten scliwal", Metapleuralschim gelblich, Schwinger gelb. Collare grau bestiiubt und weilslich behaart, das schwarze Metanotum traigt seitlich ein Biischel ziemlich langer, schwarzer Borstenhaare.

Abdomen glinzend schwarz, zart junktiert und mit zarter, anliegender gelber Belaarung bedeekt. Die weil'sliche Seitenbehaarmng ist nur an den drei ersten Segnenten länger; die Tiscalborsten der beiden ersten Segmente sehr zart und wenig auffallend. Die Borstenhare des siebenten Segmentes schwarz. Bauch schwarz mit selır sparsamer weifslicher Belıarıng:

Die wenig beharten Beine goliinzend schwarz. Die langen Haare an den Schenkeln sind grelb, die Borsten auf der Oberseite Rer Knie schwarz. Die zarte Behaarung der Sehienen und 'T'arsen sïmtlicher Beine im wesentlichen gelb. An ilen Vorrler- und Hinterbeinen ist die Beborstung vorwiegend schwarz, an den Mittelbeinen jedoch lıaptsäichlich gelb. Die biirstenförmige Behaarung der Tirsen, die sich an den Vorderschienen hoeh emporzicht, ist goldgelb, dic lange und diclite Wimperbeharmo der Hinterbeine reifslich. Hie 'T'arsen der Hinterbeine erscheinen durch lange, anliegende schnceweifs schinmernde Behaarung verdickt. Klauen schwarz, Pulvillen weils.

Fliigel brïulich, durch mikroskopische Behaarung gleichmaisig* getribt und sehı lebhaft irisicrend. Ader'n dunkelbrauı.

Das f unterscheidet sich von dem or lediglich durch den Mangel der schneeweifsen Bchaamug an den Tarsen der Hinterbeine.

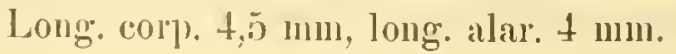




$$
\text { Hybozelodes albipes n. sp. o'. }
$$

Die Art, die sich in emem einzelnen Exemplare aus Peru-Meshagua (Urubambatluls) in der Sclunuseschen Sammlung luetiulet, ähnelt der vorigen im grolsen und ganzen sehr, so dafs es genight, die Cutersuhiede anzugeben.

Knebelbart und Behaarmng des Gesichtes weifs, die Taster schwarz beborstet. Die Basalg̣lieder dep braunen Fiihler schwarz behart, das Endglied fehlt. Mesonotum durrhans mit diinner. brauner Bestäubung beleckt und schwarz behaart. Das ebenfalls hestäubte Schildehen triggt an seinem Rande längere Behanrung und vier Borsten von sehwarzer Farlue. Collare schwarz behaart, das grangelb bestiubte Metanotmu seitlich mit gelbbramen Borstenharen. Metapleuralschirm in dev oberen Hälfte schwarz. Das schwarzhraune Aldomen ist sehr zart punktiert nnd mit feiner anliegender bräunlicher Behanrung versehen. An den mittleren segmenten sind die Hinterainter seitlich tureh weifse Bestänbung äul'serst fein gresänmt; die wenigstens an den vorderen Segmenten recht lange Seitenhehaarung ist weifslich, auf dem ersten Segmente finden sich zwei schwarze Discalborsten. Jas sechste und siebente Segment besitzt der IIanptsache nach meifse Borstenbeharung, auch die Genitalien sind weilslich behart. Banch dunkelbraun mit verhältnismälsig läingerer liehter Bchaarung. Sichenkel ter Vorilerbeine gelb, die Schienen und Tarsen durchscheinend beinweils, der Fudtarsus schwarzhraun. Auf der Oberseite der Knie, an der Vorhirseite ler Schienen und Tarsen steht cine Reihe sehwarzer Borsten, in iibrigen ist die gesamte Behaarung mol Beborstung weilslich. Dic Mittelbeine fehlen. Sehenkel der Hinterbeme mit Ansnahme der gelbbraunen äufersten Murel und Kniegegend dunkelbraun, ebenso die T'arsenglieder, Schienen und Iletatalsus gelb. I)ie Borsten sind zum gröberen Teil schwarz. die gesauten Haare jedoch weifslixh, anfserdem findet sich an der Lnterseite der Tarsen

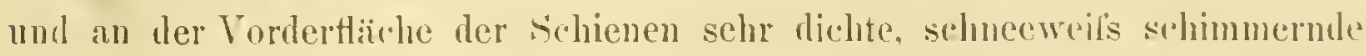
Behaarmug. Klanen dunkelbram, Pulvillen weils. Die Flighel sind cbenfalls bräunlich tingiert und an der spitzenhälfte lureh mikroskopische behaarung getribt. I)ie die Discoilalzelle und die vierte Hinterrandzelle distal rova Acta xevi. Nir. 1. 
alogrenzenten Queradern stehen nahezu in der greichen Linie, die erste Ilinterlandzelle ist schwach verengert.

Long. corp. $5 \mathrm{~mm}$, long. alar, $4,5 \mathrm{~mm}$.

$$
\text { Hybozelodes platycerus n. sp. oT. }
$$

Zwei Exemplare ans l'eru-Meshagna (Urubambaflus) betinden sich in der Schnusesehen Sammlung.

Kopf ('laf. Fig. 59 u. 60). Gesicht, Stirne und Scheitelgegend mit goldgelber Bestainbung bedeckt, anch das Hinterhaupt ist sehr diimn gelblich bestäubt. Der Riussel ist an seiner Wrurel weisslich

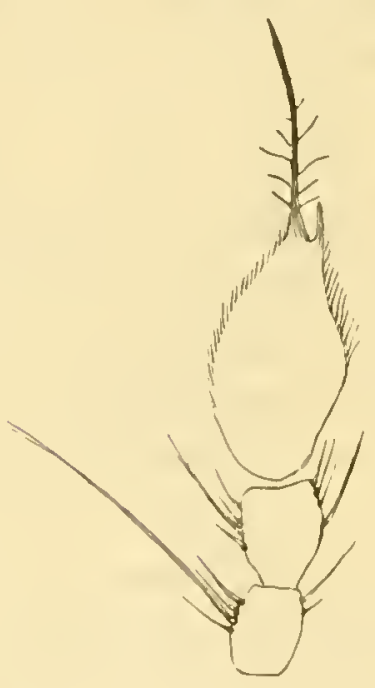

Fig. 77 . behaart, im iilurigen aber ist die gesamte Behaarung und Beborstung des Kopfes ansuahmslos schwarz. I) beislen ebenfalls schwarz behaarten Basalglieler der schwarzen Fiuhler (Textfig. 77) sind ron nahezu gleicher Lainge, das Endglied ist wenig lïnger als die beiden Grundglieder zusammengenommen und stellt eine ovale, sehr teutlich pubescente Platte dar, lie sich in eine basal beharte Endborste fortsetzt, an deren W'urzel sich ein sehr dentlicher Zahnstift findet.

Thorax. Das glänzemil schwarze Mesonotum träg't umr vorne und an dem iufsersten Seitenrande Spuren brännlicher Bestänbung und ist mit relativ langer, abstehender Beharming von brämnlicher bis schwarzer Farhe bedeckt. Ias ebenfalls glänzend schwarze Schildchen trïgt an seinem Rante aufser ciner lieilıe lingerer Hare zwci lange Borsten, die ebenso wie die Seitenhorsten des Mesonotum schwarz sind. Pleuren, Hiiften und Collare gran bestäubt und licht hehaart. Notopleuralborsten schwarz, anch dem gelblichen Metapleuralschirm siud oben einige schwarze Haare heigemengt. Das bräinulich bestäubte Metanotum ist seitlich gelb behart, die Schwinger sind hellbratun.

A hdomen glänzend schwarz, leicht punktiert und mit zarter, gelblicher anliegender licharung rersehen. Die an den drei ersten Segmenten lïngere 
Seitenbehaarung ist weifslich, ebenso die schwaehen Discalborsten des ersten Seg'mentes. 1)er dunkelbraume Bauch ist an den Seiten und den Segmentalräudern lehmgelb bestäubt und weifslich behaart. Behar'ung der Genitalien weifs, die Borstenhare fler heiden Endsegmente vorwiegend schwar\%.

Beine glinzend schwarz; an den beiden vorderen Beinparen ist die Kniegegend und die Wurzel sämtlicher 'Tarsen schmal gelbbraun gefärbt. Die wenig dichte Behaarung ist vorwiegend weifslich, die längeren Borsten teils schwarz, teils weifslichgelib. Die biirstenfürmige Behaarung ist an den Hinterbeinen goldbrann, an den beiden vorderen Beinparen weifslich, anch sind hier die 'Tarsen an ihrer Vorderflache mit dichter, anliegender schnecweifser Behaarung belleckt. Klanen schwar\%, Pulvillen weifs.

Die sehr lehhaft irisierenden Flïgel sind schwach rauclırran tingiert rnd dureh mikroskopisehe Beharung wenig getriibt. Adern schwarzbraun. Die die Discoidalzelle und die vierte Hinterrandzelle distal abschliefsenden Queradern verlaufen nicht in ler gleichen Richtung, die erste Hinterrandzelle ist nicht verengert.

Long. corp. $5 \mathrm{~mm}$, long. alar. $4 \mathrm{~mm}$.

\section{Über die geographische Verbreitung der Atomosinen.}

Betrachten wir zunäelst die Horde der Atomosinen in ihrer Gesamtheit, so liifst sich mach unseren gegenwärtigen Kenutnissen feststelleu, dals ilır Torkommen dureh den 40. Brejtengrad seine nördliche bzw. sülliclue Begrenzmug erhält. Nmr relatir wenige Species sind bis zum $40^{\circ}$ nördlich hin verbreitet mud es lailst sich bei dem weitgehenden Interesse, das die Dipterologie in Europa sowohl wie Nordamerika gefunden hat und noth findet, kamm erwarten, dals sich diesen wenigen so weit nördlich verbreiteten Arten noch sonderlich viel neue zugesellen werlen. Anders diirfte es sich mit der siidlichen Grenze rerhalten; einerseits sind ja die J.andesgrebiete, die sich siidwirts des 40. Grades befinden, dipterologisch noch recht wenig, fast kaum erforscht, andererseits finden sich gerale in Argentinien und aurh in Chile noch relativ viele Arten verbreitet, so dafs sich möglicherweise fiir Siidamerika lie siidliche Grenze fiir das Vorkommen der Atomosinen etwas 
iiber den 40. Breitengrad verschieben diiste. Auch der rertikalen Ausbreitung scheinen lelativ ziemlich enge Grenzen gesteckt zu sein; es lälst sich wenigstens ans den sehr genanen Fundortsangaben des Schu useschen Materials, in denen auch die Meereshöhen gebuhrende Beriicksichtignng şefunden haben, entnelnuen, dals iiber 800 Meter iiber dem Meere Atomosinen nicht mehr beobachtet wurden. 1)ie kleinen Riuber scheinen also im grofsen und ganzen warue Klimate zu bevorzugen, und nur einige wenige Arten halben sich, wie gesagt in Nordamerika, gewissermalsen verint in relativ kiiltere Zonen.

ITas mun die geographisehe Terbreitung der einzelnen Atomosinengattungen betrifft, so mufs der vorstehenden monographischen Darstellung entnommen werden, dafs entgegen unseren bisherigen Anschanmugen dem Vorkommen der cinzelnen Gattungen in den Eroteilen sellst ilure sehr bestimmten Grenzen gezogen sind, die nur ganz ausnahnsweise durchbrochen werden. I)abei können die Gattmugen iiber die einzelnen Erdteile eine weitgrehende nordsiidliehe Ausdehmung besitzen. Dies des näheren zu zeigen, ist der Zweck nachfolgender Tabelle, in der die einzelnen Atomosinengenera in der lieihenfolge ihrer verwandtschaftlichen Beziehungen anf ihre geogra])hische Verbreitung untersucht werden sollen.

Amalhomyia.

Cerotailia.

Cyplotomyin.

Protichisma.

Buthiopis.

Enmeeosoma.
Beludschistan.

$$
\text { l'aläartische t'auna. }
$$
Nordamerika. Mexiko. Siidamerika. Nearktische und neotropische F a 1111 a.

Brasilien. Peru. Nentropische Fauna.

perit.

Neotropische Fauna.

l'eru.

Neotropische Falla.

Brasilien. l'eru. Bolivien.

Neotropische Fauma. 
Beitrïge zur Kenntnis der südamerikanisehen Dipterenfauna.

Dissmeryngoles.

Oidardis.

Atomia.

Lamprozona.

Automolina.

Lörinella.

Goneccalypsis.

Clariola.

Cenochromyia.

Epapleroditus.

Othoniomyia.

Adelodus.

Aphestia.

Cyanonedys.

Atomosia.
Surinan. Peru. Brasilien.

Neotropische Fauma.

Peru. Bolivien.

Neotropische Fauna.

Mexiko. Brasilien. Peru. Bolivien.

Neotropische Fauna.

Chile.

Neotropische Fauma.

Chile.

Neotropische Fanna.

Siid-Rufsland.

Palaiarkisclue Fall a.

Transvaal. Formosi.

Äthiopische und orientalische F'a uน ก.

Ňeu-Guinea.

Australisclue Fauna.

Nen-Guinea. Celebes.

Australische Fallua.

Nen-Gninea.

Australisebe Fanua.

Brasilien.

Neotropische Fauna.

Queensland. Neu-Suid-WTales.

Australische Fanua.

Brasilien. Mexiko.

Neotropiscolıe Falua.

Qneensland.

Australische Fanna.

Nordamerika. Mexiko. Siidamerika.

Nearktische und Neotropiscle F' a ll 10 a. 
Strombocollia.

Atractia.

Lophoceraea.

Hybozelodes. l'eru.

Neotropische Fauna. Brasilien. Venezuela. Peru.

Costa Rica.

Neotlopisehe Fauna.

l'eru.

Neotropisclie Fauna.

Peru.

Neotropisehe Fauna.

Dals sich aus dieser geographisehen Skizze noch keineswegs bindende Schlisse über lie Ausbreitung der Atomosinen ziehen lassen, liegt auf der Hand. Dies gilt ja nieht minder auch fiir die rein systematische Erkenntuis dieser Gruppe der Asiliden, so grofs auch schliefslich der Formenkreis ist, der fiir die vorstehende Bearbeitung beniitzt werden konnte. Wenig Material, das wir aus fernen Ländern erhalten, ist nit soviel Fachkenntnis, mit soviel Licbe und Sorgfalt zusammengetragen, wie dies in nicht genug anzuerkennender Weise von Seite des + Herm Seluuse geschehen ist. Sammler und Händler, denen wir unser iibersecisches Untersnchungsmaterial fiir gewöhnlich vertanken, pflegen ja bekanntermassen Dipteren nur mehr oder minder nebenbei einzntragen, sie werden achtlos gerade an so kleinen und sehmneklosen Formen voriibergehen, wie sie die Atomosinen gröl'stenteils darstellen. Erst einer ferneren Zukunft wird es vorbehalten sein, in rällig befriedigender Weise unsere Kenntuisse iiber die Systematik und die geographische Verbreitung ler Atomosinen zu vertiefen und zu erweitern, die vorliegente Monographie sollte nur versuehen, ein etwas ausgedehnteres und abgerundeteres Bilıl unserer momentanen Kenntuisse zu geben. 


\section{LAPHRINAE (strietu sensu).}

\section{Analytische Genustabelle der südamerikanischen Laphrinae (strictu sensu).}

1. Die auf einem Stiruhöcker sitzenden Fiibler auffallend verlängert, erstes Glied etwa finfmal so lang als das kurze zweite, Entglied etwa dreimal so lang als die beiden Basalglierter zusanmengenommen; Arten von dioctriaartigem Habitns.

Rhopalogaster Macquart. 209

- Fuihler nicht verlängert, Stirnfortsatz fehlend: meist grösere Arten von mehr gedrungenem Habitus.

2. Riissel gerade, seitlich komprefs, an scinem oberen Rande scharf gekielt.

- Riissel gerade oder säbelförmig nach oben gekriimmt, von rundlichem Qnerschnitt oder deutlich von oben komprefs, jedenfalls oben nie gekielt.

3. Beharrung des Gesichts aus silberschimmernden Schïpuchen bestehend, Knebelbart anf relativ wenige lange Borsten reduziert; Ocellarborsten fehlend; Unterklapue der or Genitalien nicht sackartig nacl unten erweitert, mit scharfen Chitindornen bewehrt.

Pholidotus n. g. 229

- Behaarung iles Gesichts nicht schüppohenförmig, Knchelbart aus zahlreicheren Borsten bestehend oder direkt buschig; Ocellarborsten rorhauden; Unterklajue des or Genitals nach unten sackutig vorgetrieben aber ohne auffallende Anhaugsgebilde.

4. Mittelgrofse, relativ kahle Arten, deren kolbig verdickte Hintersehenkel an jhrer Unterseite reihenweise angeordnete, in stare Borsten anslanfenle Warzen tragen. 
- Hiuufig grofse, teils hummelartig, teils schwaicher behaarte Arten, deren nur milsig verdickte Hinterschenkel nie mit reihenweise angeordneten. in stalle Borsten anslanfende Warzen versehen sind.

\section{Laphria Mcigen. 218}

5. Frste Hinterandzelle stets weit vor dem Flïgelrande geschlossen, die nach ılem Hinterrande laufenden Adern verlieren sich vor diesem entweder ganz, oder werden doch anffallend feiner; Arten von unansehnlicher. glanzloser Färbung von exquisit asilusartigem Habitus.

Dasythrix Löw. 21)

- Erste Hinterrandzelle geschlossen oder offen, die nach den Hinterranile der Fliggel laufenten Adern miinden in diesen in gleichbleibenter Stiolke cin; Arten ron meist lebhafter Fïbung und echtem Laphrientypus.

6. 'Taster zylindrisch; das relativ kahle Hinterhaupt trägt in der Scheitelgegend eine Gruppe anffallend langer und derber Borsten; Grundfarbe des Kiirpers stets lebhaft gelb mit mehr oder minder entwickelten sehwarzen zeichnumgen. Smeryngotaphria n. 8226

- 'Taster exquisit abgeplattet, von aufsen löfelartig' gehïhlt; Hinterlaupt mehr oder minter dicht gleichmälsig behart oder beborstet.

7. Grulse pelzartig behaarte Arten von exquisit hummelartigem Aussehen; der sehr dentlich zweispitzige Riissel gerade. von oben betrachtet, auffallend breit gedriickt.

Dasyllis $100 \mathrm{w} .235$

- Meist nur mäsig grofse, schwächer, jedenfalls nie pelzartig behaarte Arten von schlankeren, nie lummelartigem Aussehen; der meist sibelartig nach ohen gekriumute Riissel, von oben betrachtet. nicht anffallend breit gedriickt.

8. The erste Submaroinalzelle duroh eine Querader geteilt, il. h. drei Submaroginalzellen vorhanilen.

Pogonosoma Rondani. 267

- Die erste Subnarginalzelle nicht geteilt, 1. J. nur zwei Submarginalzellen vorhanden.

9. Ther Riissel triigt ohen ein sehr anffallendes Biisohel starker Borsten.

-_- ber liiissel oben nicht heborstet.

Neophoneus Macintart. Tusa IIalker. 2039 


\section{Rhoprelogrested Macquat.}

Das Genus Rhopalogaster wurde ron Macquart (Suites ì Buffon I) auf die Wiedemansehen Laphria longiconnis mit folgender Gattungsdiagnose anfgestellt: Antennes de la longueur du thorax; troisième article sans style distinct. Abdomen tris-grible. terminé en massue. ()rgane copulateur sphérique au-ilessous, muni de deux pointes en-dessus. Jambes posterieures terminces par me forte pointe. Ailes ì la premicre et la 4. cellule postérieure fermíes.

Da ich einige nene Arten vor mir habe, so möehte ich zunäichst deren Beschreibung einige die Macquartsehe Gattmingsdiagnose erginzende und erweiternde Bemerkungen iiloer das Genus Rhopalogaster vorausschicken.

Der Kopf ('Taf. Fig. 61 u. 62) ist stark in die Quere ausgezogen, fast dreimal so breit wie hoel, die Augen sind brillenartig vorgerpullen, so dafs die ganze Kopfform lebhaft an Holcocephula oller Cerotainia erimert. Gesichtshöeker kaun angedeutet, der aus langen gekrimmten Borsten bestelıende Knebelbart beschrïnkt sich auf die untere Gesichtshïlfte. An dem Mundrande stehen kiirzere Borstenhaare, in! iibrigen ist das Gesicht namentlich bei dem ơ mit niedergedriickter, meist goldgelb oder schneeweils schimmernder, schuppenartiger Behaarung dicht bedeckt. Die Stirne verbreitert sich gregen den Scheitel sehr betrichtlich und ist wie dieser mit rauhel Behaarung versehen. Die langen Fiihler (Textfig. 78) stehen auf einem stark

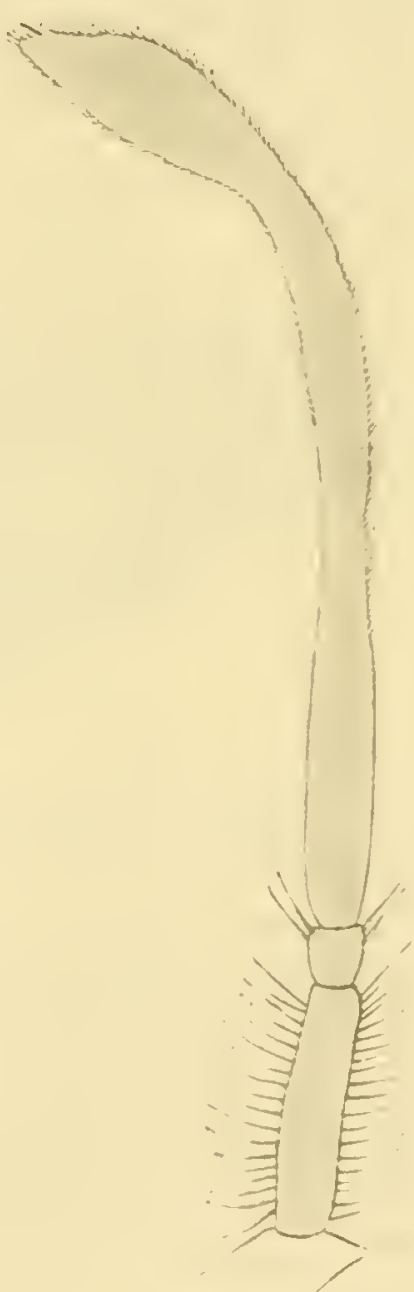

Fig. 78. vorspringenden Stirnhücker, wie wir ihn bei gewissen Dioctrien antretten, mit denen iiberhampt die lihopalogasterarten in ihrem Habitus eine gewisse nicht zu verkemende $̈$ hnlichkeit besitzen. Das verlängerte, beharte erste Fiihlerglied ist fast fünfmal so lang als das sehr kurze, fast kugrelfoirmige 
zweite Segment. Das baudartig abgetlachte thitte Fiillerglied ist gut dreimal so lang als dic beiden Basalglieder zusammengenommen; knze liehaarung lialst mamentlich scine Spitze pubescent erseheinen, so dafs ein feiner, nagelartiger Endgriftel, der sich am oberen Rande, etwas hinter ler Fiihlerspitze findet, nicht immer gleirh dentlich zu nuterscheiden ist. Das lfinterhaupt springt namentlich unten ziemlich beträichtlich hinter den Angen vor, entbehrt eines Borstenkranzes rnllständig, ist dayegen mit dichter borstenfürmiger Bcharmug verselıen, die in den stark entwickelten buschigen Backenbart iibergeht. Ocellauhïcker mit einigen relativ knrzen Borsten besetzt. Der

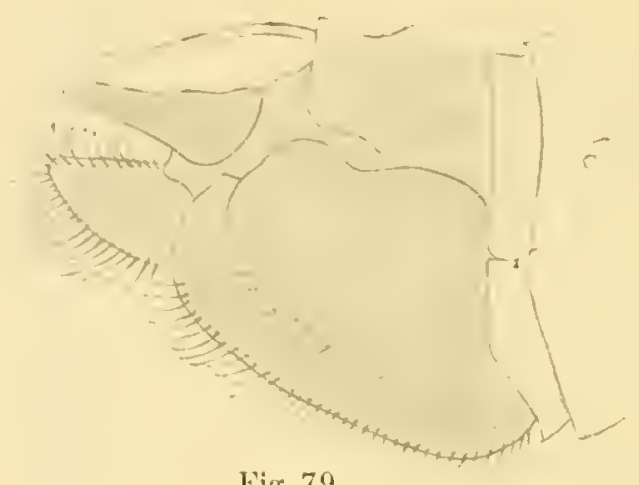

Fig. 79. seitlich kompresse Riissel ist ziemlich lang. die schlanken Taster sind an der Spitze beborstet.

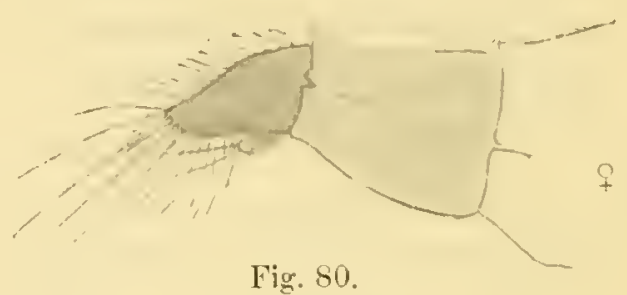

Thorax. Ihas kahle Mesonotum besitzt mur sehwache Beborstung. (praisutural 1. suplaalar 2), dagegen ist die Mesopleura mit zahlreichen Borsteuhaaren besetzt und auch der Metapleuralschirm ist stark entwickelt. S.'hilulchen ohne Randborsten, Metanotmm kahl.

Thas Abdoucn, an seiner Basis verengt, ist bei der einen Art (fascipennis) kur\%, bei den iibrigen Arten jedoch verliingert und lurch Verschmäehtigung des zweiten Segmentes exyuisit keulförnig. Die behaarung ist sehr kur\% und zerstreut, das erste Segment ist scitlich mit Borstenhaaren dielut besetzt, Jincalborsten fehlen vollständig. Jie Genitalien sind gut entwickelt, an den mäunlichen Organ (Textfig. 79) fallen oben zwej lange Chitindornen besonders anf, die Legeröhre (Textfig. 80 ) ist lang beborstet. An den langen Beinen sind die Hinterschenkel und -schienen meist mehr oder minder verdickt; den fiir die spec. longicomis ron W'iedemann und von Macy urt besehiebenen starken Dorn an den Spitzen derHinterschienen besitzen die mir bckannt gुewordenen Arten nicht. Jagegen zeigt sich luei diesen 
an den Schienen mehr oder minder stark entwickelte fahnenartige Behararung, lie eventuell anch die 'T'arsen eimummt und angenscheinlich einen sckunlären Geschlechtscharakter darstellt.

An den Flïgreln ist die stmmpf endigende Subcostalzelle mit einem ziemlich langeu Sticl rersehen und die erste Hinterrandzelle greschllossen und wie die vierte Hinterrantzelle und die Analzelle lang gestielt. Die kleine Queraler steht iiber dem proximalen Drittel der Iisenidalzelle.

Als typusche Art gilt

$$
\text { Rhopulogaster longicarnis Wied., }
$$

wobei iclı noclumals anf les Vorhantensein eines starken Dorns an der Spitze der Hinterschienen aufmerksam mache. Ich kenne die Art nicht, denn das mter diesem Namen in der Winthemschen Sammlung des k. k. Hofmuseums Wien steckende einzige Fxemplar besitzt jenen Dorn nicht und stimmt auch in anderen Punkten mit der Beschreihnng. Wiedeman n nicht iiberein, so dars ich es vorziche, dasselbe als

zn beschreiben.

$$
\text { Rhopalogaster aurifer n. sp. or }
$$

Kopf. Gesiclit mit lebhaft goldgelben schuppenartigen Haren bedeckt, im iibrigen aber ist der Knebelbart und die gesamte Behaarung des Kopfes ausnahmslos schwarz. Fiilıler schwarz. Der seithiche Orbitalraud zeigt unten eineu breiten Saum weifser Bestiuhnug.

Thorax. Das mattschwarze Mesonntun kahl mit Spuren briuulieher Bestaiubung an den Seiten und sehr zerstrenter schwarzer, abstehender Behaarung und gleichfarbiger Beborstung. Schildchen ebenfalls schwar\%. Pleuren und Hüften ockergelb his grauweil's bestiubt und durchans. auf der Mesoplema sehr dicht behasat; auch der Metapleuralschirm ist ansschliefslich schwar\%. Metanotnm graugelb bestiubt, Sclıwinger braun.

Abdomen. Das mattsehwarze erste Segment triigt anf seiner Oberseite stellenweise kurze, an den Seiten lange weifsliche Beharung, der sich einige schwarze, relativ schwache Borsten beincugen. Das stielartig versehmälerte zweite segment ist schwarz, besitzt jedoch eine schmale gelbbranne Vorderrandsbinde, ron ier sich eine Mittelstrieme eine Strecke weit abzweigt. und ist seitlich mit einigen längeren weisslichen Haaren hesetrt. 
Eine ähnliche Zeichmmg findet sich auch auf dem sich allmählig verhreitemulen dritten Segmente, welulıs wie die beiden folgenden dieht mit nessinggelbel Bestaiubung bedeekt und mit zalter, sehr zerstreuter, gelber, anliegender Behaarung versehen ist. Auch auf dem Torderrande des vierten Segmentes selimmert die gelbbramne Grumlfarbe etwas durch. J)as sechste und sicbente Segment, cbenso wie die Genitalien, schwarz und schwarz behaart. Die heiden Chitindornen sind rotbraun, die Spitzen des nuteren Zangenapluarates gelb beborstet. Bauch gleichmärsig pechbraun.

Die glänzenden Beine sind sehr dunkel kastanienbraun, die Sehienen del beiden vorderen Beinpaare ewwas heller und durchaus schwarz behaart und beborstet. Die stark verdickten Sehienen der Hinterbeine tragen hinten einen Streifen sehr dichter, abstehender Haare, die biirstenförmige, gelbbraune Behaarung der 'Tarsen erstreekt sich anch auf dic Innenseite der Vorlerselienen. Klanen seluwarz, die gelben Pulvillen erseheinen von unten betrachtet weifs.

Fliigel g’eiehmäsig intensiv rulsselıwarz getriiht. Die hintere basalzelle ist mit ockergelber, dic Analzelle und der Flïgellappen mit weifser Bestäubung bedeekt, so dafs hier bei anffallender Beleuchtung die Fliigel weifslieh elseheinen. Adern durcliaus sehwarz.

Long. corp. $14 \mathrm{~mm}$, long. alar. $10 \mathrm{~mm}$.

$$
\text { Rhopalogaster lineata 11. sp. ․․ }
$$

Ein einzelnes Stiick aus Rio Grande do Sul befindet siel in k. k. Hofmusem Wien, ein zweites (Brasilien, Mare llispanha) ex coll. Hermann, cin trittes (Bolivicn, Iungas von Coroico, 1800 m ii. d. II) ex coll. Schnusc.

Kopf. Das schware, gegen den Mundrand grau bestäubte Gesicht träigt mu am medialen Augenrand einen Samn falılgelber sehuplenartiger Behaarung. aluf der Mitte ist es schwarz behart. Der Knebelbart, dic Haare am Mundrande und der Kinngegend, an Riissel und an den Tastern weilslieh; Stirne, Scheitel, Hinterlaupt gelb behart, der Backenbart jeloch schwarz. Das erste Glied der picehbraunen Fiihler ist gelb, das zweite schwarz behart.

Thol'ax. Das schwal"ze, kahle Mesonotum ist seitlich und vor dem Schildchen sehwach graugelb bestänht und laist auch Spuren einer breiten, vorne geteilten Mittel- und Heckenartiger Scitenstriemen erkenuen. Die sehr zarte, 
zerstreute Behaarung ist ebenso wie die Seitenbeborstung gell. I)as an der Basis ebenfalls bestäubte Sehildchen ist zart behaart unl aufserdem an seinem Rande mit einigen langen, fahlgelben Borstenhaaren beweht. Die gran bestäubten Pleuren und Hïften sind mit gelblicher bis weifslicher Beharung versehen, aueh dem schwarzen Metapleuralschirm sind in seincr unteren Hälfte einige gelbliche Borsten beigemengt. Das schwarze Metanotum ist teilweise gelbgrau bestiubt. Scliwinger braun.

Abdomen. Erstes Segment mattschwarz, in ller Mitte mit knrzer, an den Seiten mit langer falılgelber Belaarung. Das stielartig verjuingte zweite Segment ist durchseheinend gelbbraun, mit ciner ziemlich breiten, durch gelbliche Bestiubung gebildeten Hinterrandsbinde und aufserdem mit einer sehwarzen U-förmigen Zeichnung versehen, welche dic Grundfarbe jedoch an den Seiten frei lälst. Wie folgenden Segmente sind mattsehwar\% und mit relativ diehter, kurz anliegender, feiner Behaarung von gelber Farhe bedeckt. Der Hinterrand des rlritten und vierten Segmentes ist durch gelbliche Bestäubung gesäumt. Legeröhre mit rorwiegend gelber Beborstung:

Beine tief dunkelbraun, die Schienen der beiden rorderen Beinpaare kastanienbraun, die Knie saimtlieher Beine schmal gelbbraun. Die Behaarung und Beborstung ist fast ansschliefslich gelb. Die bürstenfürmige gollbraune Beharung beschräıkt sich auf die Unterseite der Tarsen. Klanen schwarz, Pulvillen gelb.

Die Flïgel besitzen dem vorderen Rande entsprechend eine ausgedehnte und scharf abgegrenzte ziemlich intensive rauthbraune Truibung, welche die erste Hinterrandzelle ganz ansfiillt, die ïufsere Submarginalzelle jedoch gröbstenteils freiläst. Die Gabelstelle der Cubitalader, die distale Begrenzung der Discoidalzelle und der hinteren Basalzelle, sowie dic Analader intensiver gesïmmt.

Long. corp. $11 \mathrm{~mm}$, long. alar. $9 \mathrm{~mm}$.

$$
\text { Rhopalogaster niphardis n. sp. or } q \text {. }
$$

Ein or, sechs $q$ cx coll. Sehnuse ans Bolivia-Mapiri (Sarampioni 700 un und S. Carlos $800 \mathrm{~m}$ ii. 1. M.).

Die Art scheint nichst verwandt mit Rh. longicomis Wied. zu sein, von der sie sich jedoch durch gewisse Fäbungslifterenzen sicher unterscheidet. 
ơ. Kopf. Litergesicht sclıwarz, durch ockergelhe Bestiubung matt, his an den Fiihlerfortsat\% mit dichter und ziemlich langer, anliegender rostroter liehaırung bedeckt. liehaarmug des Mundrandes goldgelb, der Knebelbart besteht ans vier langen schwarzen Borsten. Stirne mul Scheitel schwarz, mit zerstrenter goldgelber, an Augenrande mit schwarzer Behanrung. Ocellarborsten goldgelb, Fiihler schwar\%, die heiden Basalglieder glänzend, mit kurzer, schwarzer Belaarung, das dritte Glied matt. die Spitze schneeweifs, fast silherschimmend behaart. Hinterhanpt schwarz, oben schwarz, nach abwirts goldgelb behart, der dichte lackenbart ehenfalls goldgelb. Riissel und 'Taster schwarz, ersterer gelb. letztere schwar\% behaart.

'T'horax schwarz, durch zarte hraune Bestäubung matt, ohne Zeichmnng, mit zerstreuter, anfrechtstehenler kurzel Behaarmg ron schwarzer Farbe. Anch nie sehr vereinzelten griberen Borsten sind schwarz. Schildchen schwarz. Pleuren schwarz, in den vorderen Partien mit oekergelber, in den hinteren mit graner Bestainbung; gleichfarbige Bestiiubung bedeckt anch das Metanotum. Fin Biischel üher den Torderhüften besteht aus gelben, jenes der Mesopleura teils ans gelben, teils aus schwarzen Haarcn. Schwinger bram mit liehtgelben Endknopf, der vor ihnen stehende Metaplemalschirm ausschliefslich schwarz. Vorderhiften mit sclokoladefarbener, Mittel- mol Hinterhiften mit ockergelber liestäubung, Behaarung schwarz.

Abdomen. Frstes Segment schwarz mit granem Bestäubungsanflug und namentlich an ten Seiten mit langer, alstehender, weilslicher Beharung. Seitenborsten schwarz. Z/weites Segment sehr schmal, stielförmig, schwar\% nit ledergelber Tordermulbinde, die in der Vitte eine striemenförnige Fortsetzung man linten besitzt. Mer llinterrand des Sogmentes ist in der Mitte wrlstartig verdickt. Die Beharung ist auf der Riickenfliche äulserst fein, zerstrent mul schwar\%, am Seitenrande lang mol weifs. Das dreieckige dritte Segment ist schwar\% mit breiter, in der Mitte zackenfürmig ansgezogener Vorderrandbinde von ledergelber Farbe. Behantung äulserst fein, an seitenraule felılend. 1 )as breite, bandförmige vierte Segment ist sammetschwarz, seitlich mit ockergelber Bestiiubung, das füfte segment ebenfalls breit bandförmig*, leblaft rostgelb, dureh feine schneeweifse Bestäubung in gewisser líchtung silberschimmernd. Beide Segmente besitzen nur äufserst zarte, in wesentlichen dunkle Behaarung. Uas sechste und sichente Segment 
schmal, schwarz, mässig gläinzend, seitlich mit längerer schwarzer lieharmug. Hypopygium glänzend schwarz mit teils lichter, teils schwarzer Beharang. Dic gesehwungenen Dornen des Oberstiickes sind durchscheinent gelb.

Beine im allgemeinen glinzend grauhram bis schwarz. Die Vorderund Mittelschienen, sowie die basale Hälfte der Hintersehienen gelbbrann. Die wenig dichte lehaarmng und Reborstung ist im allgemeinen schwarz. I lie Vorderschienen sind an ilner Innenseite mit langen, franzenartigen, silberschimmernden Haaren besetzt, die sich anch anf die Innen- nud Oberseite simtlicher Tarsen fortsetzen. Auch die Tarsen der Mittel- unl Hinterbeine besitzen. wenigsten an ihrer Oberseite, solche silberschimmernde Behaarung. endlich nimmt diese anch die Hinterseite der Hinterschienen an ihrer apicalen Hälfte ein. An der Unterseite sind simtliche T'arsen mit kurzer, biirstenartiger Behaarnng von rostgelber l'arbe besetzt; Klanen glïnzend sehwarz, Pulvillen lichtgelb.

Fliigel rauchbrann getriibt, am Wurzelvorderrand dunkler. Älerung. schwarz.

Das $q$ unterseheidet sich ziemlich betrïchtlich vom of, trotzdem kann iiber die Znsammengehörigkeit der Gesehlechter irgendwelcher Zweifel nicht bestehen; ich gebe die Beschreibung des $q$, indem ich nur die 1)ifferenzpunkte hervorhebe.

Untergesiclıt, Scheitel mind Hinterhaupt mit ockergelber bezw. graner Bestänbung versehen; die gesante Behaarmig des Kopfes ist ausmahmslos schwarz. Auch auf hem Thoraxriicken und den Pleuren ist die zarte Bestäubung grau und anch hier findet sich nur schwarze Behaarung. Auf dem Abdomen zeigt das ebenfalls stielförmig verjüngte zweite Segment lie gleiche Zcichnung wie bein oT, das dritte Segment besitzt eine nur ganz schnale Vorderrandbinde von ledergelber Farbe, die iibrigen Segmente aber sind einfarbig schwarz. Die Behaarung ist anf dem ersten Segmente ebenfalls schwarz, das zweite Segment trägt seitwiilts bräunliche Härchen, die iudserst kurze und zerstrente Behan'mug auf dem dritten und vierten. sowie auf den Endsegmenten ist chenfalls schwarz, dagegen anf dem tïnften unl sechsten Segmente weifs. Die Legerihre ist ebenfalls schwarz hehatart und beborstet, nur anf der äulsersten Spitze findet sich ein Biischel lichter Hitare. 1)ic Beine sind mit Ansuahme der lichtgelben Wurzeln der Hinter- 
schicnen gleichmilsig kastanienbraun, glainzend, auch hier ist die Behaarung und Beborstung schwarz, mu die Schienenspitzen und die Metatarsen der beiden vorderen Beinpaare sind mit kurzer, biirstenartiger Behaarmng von rostroter larbe versehen und endlich sind die Hinterschienen an ihrer Hinterseite dicht weifs behaart. I)ie franzenartige, silberschimmernde Behaarung aber fehlt rollkommen. Die Fligel sind im allgemeinen wohl etwas lichter als beim $\Im^{7}$, besitzen jelloch eine tief dunkle Vorderrandhinde. Long. corpl. $12 \mathrm{~mm}$, long. alar. $9 \mathrm{~mm}$.

$$
\text { Rhopalogaster fascipennis 11. sp. 우. }
$$

Die Art besitzt bei fliichtiger Betrachtung dureh den gedrungenen Hinterleib nur wenig Ähnhlichkeit nit den vorigen Species, eine genanere Untersuchmng wird aber alle das Genus Rhopalogaster charakterisierenden Merkmale finden lassen, so dafs an iler Znsanmmengehörigkeit der Arten trotz der Verschiedenheit des Habitusbildes nicht zu zweifelı ist.

2 z ex coll. Schuuse aus Peru-Meshagua (Urabambaflus, $350 \mathrm{~m}$ ii. d. M.)

Kopf. Untergesicht und Stime schwarz, teils glïnzend, teils mit ockerbranner Bestäubung bedeckt. An den Seiten des Untergesichts findet sich weifse Bchaarmng, die, nach ahwiirts sich fortsetzend, sich dem schwarzen, ziemlich dichten Knebelbart beimischt. Behaarung der Stirne schwarz. Scheitelgegend schwarz und kahl, das Hinterhaupt jedoch mit ockerbramer Bestaiubng bedeckt und dicht schwarz behaart. Der diinne Backenbart ist weifslich. Riissel und 'laster schwarz mit gleichfarbiger Beharung. An den Fïhlern sind die beiden Basalglieder gliinzend schwarz und schwarz behaart, das dritte Glied ist durch ockerbranne Bestäubung matt und zeigt an einer Spitze in geringer Ausdehung weifse Pubescenz.

Thorax dunkel pechbraun, mïlsig gliinzend, an den seiten, der Qnernaht, den Postalarhöckeru, der Gegend medial von den Schulterbeulen und am Prothorax mit ockerbranner Bestäubung bedeckt. Die kurze Behaarmng des Thoraxriickens ist schwarz. Das Schildehen trägt teilweise ockerbraune Bestiubung. Anch die P'lenren sind teils mit schokolatebrauner, teils mit graner Bestäubung bedeckt; dic dichte Behaarung der Mesoplenra, 
sowie der Metapleuralschirm sind schwarz. Hiiften braun bestiubt nnd schwarz behaart.

Das A bdomen ist an seiner Basis nur wenig verengt, relativ kurz, höchstens doppelt so lang als der Thorax, und golechmiifsig gliinzend pechbram gefairbt. Die lange Seitenbehaarnng und -beborstung les ersten Segmentes ist schwarz, die gleiche Farbe tragen auch die feinen und kurzen Härchen auf dem zweiten und an den Seiten des dritten Segmentes, im iibrigen ist aber die kurze und zerstrente Behaarung weilslich; ebenso auf dem Genitalsegment, das an seiner Spitze ein Biischel liingerer, lichtbrauner Borstenlaare trägt.

Die kraiftigen Beine sind im allgemeinen glänzend rotbrann, die Oberschenkel mit Ausnahme der Kniegegenu, die Schienen an der Aufsenund Hinterseite pechbraun. Die Behaarung und Beborstung ist schwarz. Die Hintersehenkel sind in der apicalen Hälfte kolbig verdickt und an der Aufsenseite mit diehter schwarzer Beharung versehen. Die Hinterschienen sind in ganzer Ausdehmung stark verdickt und an iler Vorder- und namentlich der Hinterseite mit kammartig gestellter, dichter Behaarung versehen. Auch der Metatarsus der Hinterbeine, der wie die Schienenspitze an der Unterseite kurze rostgelbe Biirstenbehaarmng triggt, ist merklich verdickt. Klauen schwarz, Pulvillen liclitgelb.

Die Fliigel sind an der Wurzelhiilfte nnd an ter Spitze bram getriibt, so dafs dazwischen eine lichtere, leicht grelbliche Binde liegt. Mikroskopische Behaarung lälst am vorderen Fliigelrande einen nur im reflektierten Licht sichtbaren milchweifsen Fleck entstehen. Die Äderung ist pechbram.

Long: corp. $8 \mathrm{~mm}$, long. alar. $8 \mathrm{~mm}$.

In der Sammlung Schn use findet sich ein drittes, leider sehr schlecht konserviertes Exemplar _ es fehlen die Fiihler sowie las Abdomen welches aus Bolivia-JIapiri (S. Ernesto $800 \mathrm{~m}$ ii. d. M.) stammt. Bei diesem Exemplar ist die Behaarmng der Stirne, des Untergesiehtes, sowie der untere T'eil des Knebelbartes goldgelb. Ob wir in liesem Exemplare in Analogie zu den sexuellen Färbungrerhältnissen bei Rh. miphardis das Männchen von Rh. fascipennis vor uns haben, liást sich leider mit Sicherheit nicht 
fesstellen. ich miiehte nur bemerken, dafs die Beine die eigentumlich franzenartige Behaarmug, die wir bei dem or von Rh. niphardis kennen gelernt haben, vermissen lassen.

\section{Lupluire Heigen.}

Dals die alte If eigensche Gattung Laphria einen einheitlichen 'Typus darstellt, wird heutzutage kein Dipterologe mehr ernstlich glauben; uberaus zallheiche. zum 'leil recht heterogene Formen sind unter ihm wie unter einem Sammelbegriff zusammengefafst worden. Die früher oder später notwendig werdende Aufteilung des Genus Laphia gerade auf der Grundlage siilamerikanischen Materials in Angriff zu nehmen, halte ich fïr vollkommen zweck- und aussichtslos, weil das Genus gerale in der neotropischen Fauna, sehr zum Lntersehied gegen die paläarktische und namentlich die asiatische und indomalavische Region gar nicht besonders artenreich vertreten ist und die einzelnen Individuen, wie es scheint, relativ weit seltener vorkommen, wie dort. Ich möehte hier nur betonen, dafs ich aus, wie ich glaube, recht durchsichtigen Griuden, die ich an spaiterer Stelle auffiilıren werde, jene nordamerikanischen hummelartigen Formen, die bislang stets unter dem Namen Dasyllis gefuihrt werlen. wieler dem alten Genus Laphiria zuführen und jenen Namen fiir einge ausschliefslich siidamerikanische Species reservieren werde.

\section{Lar)l) rirl.}

Las Genus Lampria wurde bekanntlich von M a cqu urt (Dipt. exot. I, 2) aufgestellt. Allein Macquart hatte seinem Gattungshegriff eine weitere Ausdehnung gegeben, als dies unserer modernen Ansehaumg entspricht; denn er hatte seinem Genus Lampria zum 'Teil Laphrienformen eingeorhet, lie wir hentzutage dem von Schiner aufgestellten Genus Maira zu subsummieren pflegen. Der Linterschied zwischen den beiden Genera spricht sich iibrigens schon in deren geographischer Verbreitung deutlich genug. aus. Alle Lampriaspecies (in moderner Auftassung) sind Bewohner des amerikanischen Kontinents, wïhrend die Mairarten ausschliefslich der indo- 
malayischen Fauna angehören. Mich auf die Angaben des Kertésezschen Kataloges stiitzend, finde ich nur einige wenige, wie ich glanbe, nur scheinbare Ausnahmen. Lampria clavipennis Guill. (Revne zool. 1843) stammit von der malạischen 'Tritonbay; es wire aber wohl zu untersuchen, ob diese Species wirklich zll Lampria gehïrt, was mir jedoch, da mir die betr. Literaturstelle nicht zuginglich ist, zurzeit unmigglich ist. Auf der anderen Seite wirl die Macquartsche Laphria splendens (Suites ì Buffon I) aus Surinam von Kertéscz lem Genus Maira zugerechnet. Prift man aber die Beschreibung Macyuarts, so geht ohne Zweifel hervor, dafs hier ein Tersehen Keltésczs vorliegt und dals die Beschreibung unweigerlich anf eine Lampriaart zn beziehen ist. Ja, es ist anzunehmen, dals die MI a cquartsche Species splendens mit der gewöhnlichen Lampria clavipes vollständig zusarnmenfüllt. So diirfte lenı die nbige Angabe iiber die geographische Verbreitung der beiden Genera Lampria und Maira olne Ausnahme zu Recht bestehen.

Eine systematische Untersuchung der beiden Gattungen wird selbstverstiindlich eine gewisse Verwandtschaft ergeben, deren Gral aber nicht iiberschätzt werden darf. Denn zunïchst lassen sich schon im Habitus Unterschiedle leicht feststellen, die sich freilich mit Worten nicht prizise beschreiben lassen, aber doch so in die Augen springende sind, dafs schon bei fliichtiger Betrachtung eine Velwechselung ron Maira- und Lampriaarten ansceschlossen erscheint. Aber auch vollkommen sichere plastische Enterschiede lassen sich zwischen den beilen Genera ohne besondere Miihe konstatieren. In der Bildung des Kopfes sind sie freilich nur geringe. Wohl ist bei den Mairarten der Kopf stairker abgeplattet. melır scheibenfürmig, die Scheitelgegend ist bei Haira glatt, wähırend sie bei den Iamprien eine leichte, kielförmige Mittelleiste besitzt, die von dem Ocellenhïcker nach lem Collare herabliiuft. Allein diese Unterschiede fallen, wie gesagt, weuig in lie Augren. Dagegen ergeben sich im Ball des dritten Fiillergliedes schon etwas deuthchere Differenzen. Bei den Lamprien erscheint dieses an seinem Ende doppelspitzig; zunächst ist die Spitze des Fiihlergliedes selbst in einen scharfen Dorn ausgezogen, ausserlem macht sich seitlich der in einer grubigen Tertiefung liegende, riemlich lange Hudgriffel deutlich bemerkbar. Dagegen ist bei Mainu die Spitze des dritten Fiihlergliedes abgerundet 
1und der kur\%e Endgriffel ist fast vollkommen in seiner Delle verborgen und daher nur schwer wahnehmbar. Beziiglich der Chätotaxie vermochte ich am Thorax irgendwelehe durehgreifende Untersehiede nicht festzustellen, dagegen sei darauf besonders anfuerksam gemacht, dafs alle Mairaspecies an den mittleren Abdominalsegmenten seitlich je eine kräftige Discalborste besitzen, die den Lamprien völlig fehlt. Auch Unterschiede im Bane des Hypopygs sind charakteristisch. Bei Maira ist das Hypopygs relativ klein, dagegen springt es bei den Lamprien durch eine fast sackartige Ausladung der Unterklappe stark kolbig naelı unten vor. Das bequemste differenzielldiagnostische Merkmal wird aber immer in der Bedornung der Hinterschenkel bei den Lamprien zu suelıen sein und zwar handelt es sich 1 m kegelförmige Chitinvorspriinge, dereu Spitze eine derbe, meist hellgefürbte Borste eingelenkt ist.

\section{Lampria clavipes oT.}

Es liegen mir 25 Stuicke vor; ex coll. Sehnuse vier Exemplare, Bolivia-Mapiri (Sarampioni und S. Carlos, 700- $800 \mathrm{~m}$ i. d. M.), Peru (Puorto Yessup, $300 \mathrm{~m}$ ), ex coll. Lichtwardt sechs Exemplare aus Brasilien und Cajenne, ex coll. Hermann 15 Exemplare aus Brasilien und Surinam.

Die Art ist in ker Färbung der Hinterleibssegmente selır variabel. Halten wir uns dabei zmaichst an die Angaben der Literatur, so finden wir in der alten Fabriciussehen Beschreibung die Augabe: abdomen nune aureum, nune obseurum, segmento primo aureo. In Wiedemanns Beschreibung heirst es: Hinterleib erzarben, bald gold- bald rotgelb behaart, erster Abschnitt immer goldharig. Wndlich macht Schiner (Novarareise) darauf aufmerksam, dafs lie Farbe lies Bauches rotgelb ist, was sich z11weilen anch suf die Oberseite hinaufzieht. Fine Untersuchung des mir rorliegenden Materials lialst nun folgendes feststellen. Das erste Hinterleibssegment ist bei alleu untersuchten Exemplaren erzgriin gliuzend und mit anliegender yollener Behaarung verselien. An den folgenden Segmenten zeigt zich dagegen eine weitgehende V'ariabilität der Grundfarbe. Gehe ich ron den innkelsten Exemplaren (vier ex coll. Schnuse, eines ex coll. Lichtwarlt) aus, so ist bei diesen die Grundfarbe ein glanzloses Schwar\%, 
das nur auf der vorderen Hälfte des zweiten Segmentes eventuell erzgriinen Schimmer zeigt. Aber auch bei diesen dunklen Exemplaren besitzt das sechste und das kurze siebente Segment in wechselnder Ausdehnung rotbraune bis fuchsrote Grundfarbe. Diese breitet sich nun bei den helleren Exemplaren immer mehr auf Kosten der sehwarzen Grunifarbe auf den vorderen Segmenten aus, so dafs diese nur mehr in Form mehr oder minder ausgedehnter, schwarzer Mittelfleeke iibrig bleibt, und endlich ist bei den hellsten Exemplaren der ganze Hinterleib mit Ausnahme seines ersten Segmentes fuchsrot gefärbt. An dieser Variabilität partizipiert auch das Hypopygium, das bei den dunkelsten Exemplaren glänzend pechbraun, bei den hellsten licht rostgelb gefärbt ist. Die kurze, anliegende Behaarung des Abrlomen richtet sich in ihrer Färbung im allgemeinen wohl nach dem Untergrunde; bei allen, auch den dunkelsten Exemplaren, ist aber das sechste und siebente Segment mit schimmernder, rostroter Behaarung bedeckt, die seitlich in Form feiner Randsänme sich anch auf die weiter vorne liegenden Segmente festsetzt. Bei den helleren Varietäten breitet sich die rostrote lehaarung: auf Kosten der schwarzen von den Seiten her mehr und mehr aus, doch bleibt auch bei den hellsten Exemplaren, bei denen die Segmente durchans rostgelb gefïrbt sind, auf der Mitte des zweiten, dritteu und vierten Segmentes die schwarze Behaarung erhalten und nur bei einem einzigen Exemplare meiner Sammlung ist diese so reduziert, dafs nur mehr ein schwacher Riickenstrich des dritten und vierten Segmentes schwarz behaart erscheint. Beziiglich dieser Farbvarianten möge endlich noch betont werden, dafs von dem mir vorliegenden Untersuchungsmaterial nur finf Exemplare der dunklen, die iibrigen sämtlich der helleren Varietät angehören.

Gegeniiber diesem schwankenden Färbungscharakter des Ahdomen zeigt sich anf dem 'Thorax eine gewisse Konstanz. lis mag hierzu bemerkt werden, dafs bei keinem einzigen der untersuchten Exemplare die schimmernde goldene Behaarung des Thoraxriickens bis an dessen Vorderrand reicht, sondern in scharfer Grenze an rorderen Drittel des Thoraxriickens schwarzen Haaren Platz macht. Dagegen hesitze ich zwei Exemplare, bei denen sich diese schwarze Behaarung weiter nach hinten ausbreitet, so dafs nur mehr der hintere und die Seitenrainder des Thorax vou goldglïnzenden Haaren eingenommen werlen. Ganz besonders aber möchte 
ich anf die Konstan\% in der Zahl der Dornen der Hinterschenkel aufmerksam machen; die Beschreibung, die Macquart von der Bedornung vibt, ist völlig richtig, und ich kann ihr nur beifiigen, dals anch die Trochanteren in einem stumpfen Fortsat\% enden und dafs die Anlsenseite der Hinterschenkel malıe den Knicen eine cinzclne, gelbe fast dormartige Borste besitzt. Die Konstanz in der Bedornumg seheint mir nun um deswillen ron gewisser Bedeutung zu sein, da Wiedemann angibt, dal's die Zahl der Ziahne an den Hinterschenkeln nicht immer gleich sei. Dies und die oben zitierte Angabe ïber die Fiarbung des Abdomen machen es nimlich in hohem Grade wahrscheinlich, dals dic Wiedemannsche Beschreibung von Lampria clavipes gar keine einheitliche ist, sondern dafs hierfiir verschienlene, nicht näher zu eruierende Lampriaarten Verwenlung fanden. Anch die Bemcrkung Rondanis iiber die Inkonstanz der Bedornung darf vielleicht nach dieser Richtung gedentet werden.

\section{Lampria clavipes t.}

Eine Beschreibung des $q$ von Lampria claripes wurde von Sehincr (Novarareise) gegeben. Ich besitze in meiner Sammlung drei $q$, die vollstiindig mit den Schinersehen Angaben übercinstimmen und es scheint mir unzweifelluaft, dals dic Sehinersche Beschreibung völlig zu Recht besteht. Ich fiige ihr bei, dals die stahlblaue Färbung auch mehr in Schwarz iibergehen kann, und dafs die goldgelbe Behaarung des 'Thoraxriickens wenigstens in der Mitte bis fast an den vorderen Rand sich crstreckt, der medial von den Schulterbeulen mit graubrauner Bestainbung bedeckt ist. An den Hinterschenkeln zähle ich drei Dornen, deren an meisten basalstehender kleiner als die beiden anderen ist. Nun liegen mir aber neun Lampria $q$ o (vier ex coll. Schunse, drei ex coll. Lichtwardt, zwei ex coll. Hermann) vor, welche zu dem Schinerschen lypus nicht passen, wohl aber mit der Beschreibung, die seinerzeit II acy uart von dem $q$ der Lampria clacipes gegchen hat, übereinstimmen. Schiner glaubt, dal's die

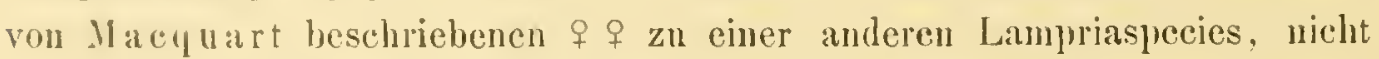
aber zur Spec. cluvipes gehören und wird in dieser Ansicht von OstenSacken unterstiitzt. Prift man vorurteilslos die sämtlichen vorliegenden 
Beschreibungen von Lamprien, so wird man mit bestem Willen kein or finden, zu dem die von Macquart beschriebenen $q q$ in Grïfse, plastischen Merkmalen usw. irgendwie zu passen vermöchten, und es liegt daher für mich die Vermutung nahe, dafs dic $q$ des 'lypus Macquart und Schiner doch susammengehören und dals die Spec. clavipes anch in weiblichen Geschlechte die gleiche Variabilität besitzt wie im männlichen. Eine gewisse Stiitze fïr diese Vermutung möchte ich schon darin erblicken, dafs die vier in der Sanmlung Schnuse befindlichen, sämtlich dem 'Typus Macyuart zugehörigen + o in bezug auf Fundort und Flugzeit recht gut mit den $\sigma^{7} \sigma^{7}$ iibereinstimmen. Aber auch die direkte Untersuchung liefert fül diese Vermutung einigermafsen beweisende Daten. Die $q$ f des 'Typus Macquart zeigen wenigstens, nur in zerstrenterer Weise an den Seiten des Abdomen und des Thorax die gleiche goldgelhe Behaarung, wie sie bei den $q q$ des Typus Schiner grö̊sere Areale des Körpers bedeckt, und diese wiederum besitzen an dem Vorderrande des Thorax den gleichen branngranen oder weifsgrauen Bestäubungsfleck, den Ma equart in seiner Besehreibung des $q$ rom Lampria clavipes erwiihnt. Nachtrighlich hatte ich Gelegenheit, das Material des k. k. Hofmuseums zu untersuchen, welches aus 37 or und 13 o besteht. Iel konnte bei den ơ die gleichen Variabilitaiten in der Fiärbung des Abdomen konstatieren und auch dabei feststellen, dafs die dunklere Form die relativ seltenere ist. Ton den 13 q gehören vier dem Typus Sehiner, die iibrigen dem Tylus Macquart an.

\section{Lampria fulgida Schin.}

Aufser den drei typisehen Exemplaren Schiners tein $0^{7}$. zwei +1 aus dem k. k. Hofmuseum Wien finden sich an ggleicher Stelle noch sieben Exemplare (drei $o^{\top}$, vier $q$ ) und endlich besitze ich noch sieben Exemplare (drei $\sigma^{\top}$, vier $q$ ) in memer eigenen Sammlung. Alle diese kxemplare stimmen unter sich und mit der wohlberechtigten Schinerschen Besehreibung vollstäindig iiberein.

Sehiner gibt die Anzall der Dornen des Hinterschenkels beim $\sigma^{\top}$ mit zwei an; ich bemerke dazu, dafs diese Zahl nicht immer konstant ist, ich zälle bis zu vier Dornen. Das Sehinersche Originalexemplau besitzt 
iibrigens auch noch einen allerdings kleinen und schwachen dritten Dorn. Schiner lat aber ïbersehen, dalis an der Basis der IIntersehenkel sich konstant ein lerber nach cinwiirts gewendeter borstenloser Chitinzapfen befindet. Das $q$ ist durch die rote Fiarbung des Banches leicht von dem $q$ von L. clacipes zn unterscheiden, dagegen stimmt die Bemerkung, dafs sich das ot durch den ,auf der Oberseite vorherrschend rotgelben Hinterleib“ ron dem $O^{\top}$ von $L$. clavipes unterseheide, nach dem, was oben ïber dieses gesagt wurde, absolut nicht. Der Unterschied liegt viehmehr in tler Ausdelnumg des rotgelben Filzes auf dem Iesonotum.

\section{Lampria dives Wied.}

Fs liegen mir vier von Schiner determinierte, aus Brasilien stammende q $q$. ans dem k. k. Hofmusenm Wien, sowie ein o $o^{-1}$ zwei $q$ aus Bolivia, Sarampioni $700 \mathrm{~m}$ ii. d. M. ex coll. Schunse vor.

Ich bemerke, dafs Wiedemann die Grölse mit nur 4 mu angibt; es nurs ihm also ein anffallend kleines Exemplar vorgelegen haben. Da seine Beschreibung sich nur anf das $q$ bezieht, so gebe ich in folgendem die Besehreibung des $\mathrm{O}^{7}$, die zugleich zu einer etwas genaueren Kenntlichmachung der Art selbst dienen soll.

Kopf. Untergesiclit mattselıwarz, teilweise mit fast goldgelber Bestäubung. Auch die seitliche Behaarung des Gesichtes, sowie der Kuebelbart gelb, letzterem sind oben lange sehwarze Borsten in geriuger Zahl beigemengt. Stirne schwarz mit schwarzer Beharung, Seheitelgegend blangrin, metallisch glïuzend; Hinterlaupt schwarz mit graugelber Bestäubung. Behaarung des ganzen Hinterhauptes schwar\%. Fühler schwarz mit gleichfarbiger Behaarung der beiden Basalglieder; anch direkt unter der Fihlerwurzel finden sich einige lïngere schwarze Haare. Der wenig dichte Backenbart fahlgelb. Riussel schwarz mit liehter Behaarming an Spitze und Wurzel. Taster schwarz und schwarz beborstet.

Thorax. Collare schwarz mit schwarzer Beborstung. 'Thoraxrücken schwar\%, teilweise mit erzgrincu Reflexen, in ganzer Ansdelnung mit rostroter, goldschimmernder, aber ku\%er und anliegender Behaarung bedeckt, welche nur in der Gegend der Schulterbeulen, sowie an dem seitlichen 
Thoraxrande die schwarze Grmudfarbe freiläst und hier lingerer sehwarzer Belaarung Platz macht. Anch die relativ schwachen Seitenborsten sind schwarz. Schildchen sehwarz mit dichter rostroter anliegender Behaarnng, aher ohme Randborsten. Metanotum und Pleuren schwarz, letztere mit diuner, gelbgrauer Bestäubung. Auf der Ylesopleura steht ein Biischel lingerer, goldgelber Haare, ein gleiches, nur weniger ansgedehntes finlet sich anch iiber den Vorderhiiften. Notoplenralborsten schwarz, auch der ror den schwefelgehben Schwingeru stehende Metaplenralsehirm ist grörstenteils schwarz.

Abdomen. Erstes Segment lebhaft erzgriin mit ziemlich zerstrenter gohdglinzender Behaarung. Die iibrigen Segmente sind seitlich rostrot, welche Farbe aber auf dem Hinterleibsricken durch die anliegende, kntre schwarze Behaarnng diister erscheint. An den Seiten- und Hinter'ändern simtlicher Segmente breitet sich gohlgelbe Behaarung binlenartig aus. Das glänzend pechbranne Hypopyg trïgt schwarze Behaarung nnd Beborstung. Bauch gleichmälsig rostrot mit zerstreuter, in wesentlichen rostgclber Behaarung:

Beine. Iluiften schwarz mit leichter, graugelber Bestäubung und fahlgelber Behaarung. Schenkel und Schienen sämtlicher Beine erzgrïn nit lebhaftem Glanze. Die Beharrung und Beborstung ist ansnahumslos rostgeib, aber wenig dicht und z. B. verglichen mit Lampria clavipes ziemlich kurz. Die rerdickten Hinterschenkel besitzen an ihrer Oberseite einen Streifen dichter, anliegender Beharung ron rostgelber Farbe, sind aber im übrigen relatir kahl. An ilırer apicalen Hälfte sind sie unten mit einer gröfseren Anzahl (7-8) starker, in rotgelbe Stachelborsten endigender Chitinziilne bewehrt, ebenso befinlet sich an ihrer Wurzel ein borstenloser Zahu und endlich ist auch der pechbraune, glïnzenle Troehanter mit zwei Zühnen versehen. Die stark gekrümmten Hinterschienen besitzen an ihrer Spitze nicht nur den allen Lamprinen eigenen, mit kurzen Borsten besetzten Ḧ̈̈ker, sondern sind noch mit einem relativ langen Zahnfortsatz versehen. Die pechbraunen Tarsen sind an ihrer Oberseite in wesentlichen schwarz. an ihrer Unterseite rostgelb, teilweise bïrstenartig belaart und beborster. Ḱlauen sehwarz, Pulvillen licht rostgelh.

Fliigel mit ranchschwarzer 'Triibung. Stïrkere nikroskopische Behaarung biklet in einzehnen Zellen eine gan\% verwaschene, sich nur 
wenig abhebende Fleckenzeichnumg. An der Fliigelwurel ist die 'Triihung etwas weniger intensiv. Adern schwar\%.

J.ong. corje. etwa $13 \mathrm{~mm}$, longr. alar. etwa $10 \mathrm{~mm}$.

\section{Smerymgolaphria $11 . \mathrm{g}$.}

Ton dem nıspringlichen Genus Laphria sind im Laufe der Zeiten verschicdene kleinere Genera abgespalten worken; trotzdem birgt es anch in seiner jetzigen Fassung noch recht lieterogene Formen in sich, die, wie ieh glaube, immer mehr zu einer weiteren /erfïllung des urspringliehen Genus zwingen werden. Unter dem Namen Smeryngolaplava will ich eine Gruppe vou Formen zusammengefarst laben, die eiunder durch eine Reibe von auffallenden plastischen Merkmalen recht nahe stehen mul auch durch den allgemeinen Habitus sowie charakteristische Färbung zueinander gehioren. Als typische Art betrachte ich die alte IViedemannsche Species melamura. Hhr schliefsen sich, soweit ich nach dem mir vorliegenden Material schliefsen kann, noch Laphria mumitor O.-S. aus Zentralameriki, sowie die indomalayischen Formen signatipes und soror v. d. Wulp, phalaris O.-S., notabitis Men. und eine wahrscheinlich nene nordanstralische Art an. Jie ,lastischen Merkmale, die allen diesen Formen eigen sind und damit das nene Genus smeryngolaphria charakterisieren, lassen sich in folgenden feststellen. Ein eigenthicher Gesichtshöcker fehlt vollstïudig, das Untergesicht ist vielmehr in seiner ganzen Fläche gleichmälsig nach unten vorgewölbt. Der relativ kurze Rüssel besitzt rundlichen Querschnitt und ist nach oben nicht gekielt, die Spitze der ,Unterlippe" läuft in zwei rundliehe, fein behante Knöpfehen aus. An den Fülllerı ist das erste Segment mngefälul $1^{1}$ ? mal so lang als las zweite, das dritte, seitlich kompresse Segment ist doppelt so lang als die beiden ersten zusammengenommen und an seiner abgrestumpften Spitze mit einem sehr deutlichen, dornartigen lindstiftchen bewehrt. An dem Hinterhaupt fallen die Scheitelborsten (3-4) durch ilıre ungewiinhliche lainge und Dicke anf, weiter nach abwirlts findet sich oft eine isolierte Gruple kuirzerer Borsten (2-4). Thorax und Abdomen relativ kahl, nur mit kurzer steifer Behaarung, nie pelzartig behaart, dagegen mit 
sehr starker Beborstung. Prïsutural 4-5, supraalar 4-5, postalar 3, notopletural 3-4, sentellar 8-10. Alle diese Borsten zeichnen sich durch ihre Derbheit und Lïnge ans. Auch die prisentellaren Borsten, sowie die Beborstung des Metapleuralhöekers seh" lang. An dem Abdomen besitzen die +—5 ersten Segmente seitwärts 2-3 lange und derbe Disealborsten. Das Hypopygim ist relativ klein und zeigt in seinem Ban Älnnlichkeit mit den Verhältnissen bei Nusu, namentlich fällt im Gegensatz zu Laphria und deren näheren Verwandten die untere Klappe durch ihre Kleinheit anf. Die relativ langen Beine sind ziemlich kahl, mit zerstrenter abstehender, selır langer Behaarmg und derben Borsten. Alle Smeryngolaphrien besitzen eine lebhaft gelbrote Grundfarbe des Körpers, die mit mehr oder minder entwickelten schwarzen Zeichnungen versehen ist.

\section{Smeryngolaphria pictipennis n. sp.}

Zwei $q$ aus Bolivia-Mapiri (S. Ernesto, $300 \mathrm{~m}$ i. d. M.) ex coll. Sehnuse. Kopf. Untcrgesicht gelb mit gleichfarbiger dichter Bestäubung. Auch der dichte Knebelbart, sowie die ziemlich lange bis fast zur Fiihlerwurzel emporreichende Behan'ung des Untergesichtes ist gelb. Die g]eiche Farbe besitzen anch dic mit lichter Behaarung versehenen Taster und die W'nrzel des Riissels, dagegen ist die gelb beharte Spitze des letzteren gebrïunt. Das Hinterhaupt ist in seinen oberen beiden Dritteln schwarz, nach abwiirts jedoch gelb, beide Partien besitzen weifse Bestiubnng und Behaartung. von der die starken Seheitelborsten sowie die kleine Borstengruppe nach abwïrts sich durch ihre fuchsrote Färbung abheben. Backenbart weifs. Fiihler gelb. das dritte Segment mehr rotgelb mnd leicht bestïnbt: die Behaarmig und Beborstung der beiden Basalsegmente ist gelb, nur anf der Oberseite des zwciten Segmentes finlen sich einige kure, sehwarze Haare.

Der Thoraxriicken ist gleichmäl'sig rotgelb, ohne jede Striemenzeichnnng, nur auf der Quernaht und den Sehulterbeulen gelb hestäubt. Auf dem Collare und dem Prothorax findet sich eine grofse, glinzend schwarze Makel. Die knrze Behaarming ist nur auf den Schulterheulen und deren Umgebung gelb, in übrigen aber schwarz; dagegen sind die starken Borsten am Seitenrande und vor dem Schildchen lehhaft fuchsrot. Auch das rotgelbe 
Schildehen trägt schwarze kurze beharung und fuchsrote liandlyorsten. bie gelben Pleuren und die Hiiften sind dieht weifslich bestäubt und licht behastr, lagegen ist die zerstreute Beharung in den oberen l'artien der Pleuren, ebenso wie die Beborstung der Notopleuralnalit und des Metaplenralhiickers grelb. Das Collare ist seitlich und unten mit weifslichen Haaren besetzt.

l)as gleichalls gelbrote $\Lambda$ bdomen zeigt nur vorne mäfsigen Glanz, nach hinten zu erseheint es durch dichte gelbe Bestiulung matt. Das zweite, dritte und rierte Segment mit unscharf konturierten, basal gelegenen schwarzen Mittelmakeln, auf denen anch die anliegende Behaarung schwarz ist. Anf dem ersten. fiinften und sechsten Segment er\%engt diese anliegende Behaarung wenigstens Andentungen von Mittelmakeln. Im ïbrigen ist die Behaarung des Abdomen durchaus fuchsrot; sie ist im allgemeinen kurzanliegend und erhält nur an dem Seitenrande, namentlich der hinteren Segmente, gröfsere Länge und mehr borstenfürmigen Charakter. Die starken Discalborsten der ersten fiuf Segmente sind fuchsrot. Hypopygimm rotgelb mit gleichfarbiger Behaarung und Beborstung. Bauch gelb mit zarter lichter Behaarung.

Beine durchans grelb mit gleichfarbiger Behaarung mul Beborstung. Gebramut sint nur die iulsurste Spitze der Iinterschenkel, die distale Hälfte säntlieher 'Tarsenglienter, sowie die Krallen.

1)ie fast durchsichtigen Fli goel sind gelb mit zwei grolsen schwarzen Flecken. Ver grösere derselben nimmt die Fliigelspitze völlig ein und begrenzt sich proximalwaits an der Gabelstelle der Cubitalader sowie der lie Discoidalzelle distal abschliefsenten Aster. Der kleinere Fleck zieht ron dem distalen Ende der hinteren Basalzelle rol der Analzelle gregen den Fligholianl. Hier stehen beide Flecken durel einen bräunlichen 'l'riubungssaum nit cinander in Verbindung, der sich wischartig anch in die Analund Axillaryelle fortsetzt. Die Fliigeladern sind in allgeneinen rotgelb, im Bereiclie ler beiden lilecke jedoch sehwarz.

Das $q$ unterseheidet sich kaum rom $0^{7}$, mur sind auf dem vierten, fiinften und sechsten Abdominalsegmente die sehwarzbraunen Mittelmakeln alusgedelunter, so dals die Segmente fast in ganzer Ausdehnung gebräunt erscheinen. Hand in Hand danit hat auch die schwarze anliegende Beharung eine griofsere Ansdehnung angenommen.

l.oug. corp. $17 \mathrm{~mm}$, long. alar. $15 \mathrm{~mm}$. 


\section{Ploolirlotels 11. s.}

Formen rom Gesamthabitus der Nusaarten, ron diesen, sowie ron den gemninen Laphlrien jedoch durch eine Reihe plastischer Merkmale leicht zu unterseheiden. Untergesicht statt der Haare mit glïnzenden Schiippehen dieht beileckt, Gesichtshöeker klein, Knebelbart aus einigen wenigen Borsten bestehend, die reihenweise geordnet seitwïrts an dem Gesichtshöeker stehen. Mundrand mit einer Reihe von Borsten. T'aster mit zylindrischem, ziemlich langem Furdglied, dessen Spitze mit einigen sehr groben Borsten besetzt ist. Der oben gekielte Riiissel lang, gerade, wagerecht stehend. Ocellenhücker olme Borsten. An den Fiillern sind die beiden Basalglieder fast gleich lang, das dritte Glied ist spindelfürmig, fast doppelt so lang als die beiden Basalglieder zusammengenommen, an der Spitze mit

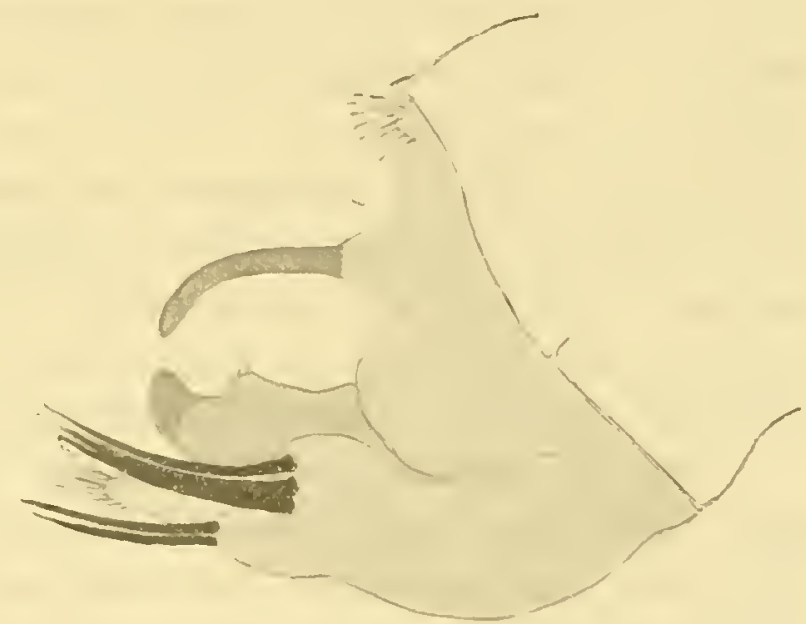

Fig. 81: einem spitzen, mach anfsen gewandten Enilgriffel bewehrt. Sichildchen ohne gröbere Randhorsten. Genitalien thes or ron sehr eigentiimlichem Ban ('T'extfig. 81). Beine nur wenig behaart, Klanen relativ kurz, die P'ulrillen fast kreisrund. Bei dem $\mathrm{O}^{\mathrm{T}}$ sind die Trochanteren der Vorder- und Hinterbeine mit eigentiimlicher, kammartig angeordneter Berlormung rersehen. Das Verhalten der Fliigelïdermg bietet nichts (harakteristisches, die erste Hinterrandzelle ist nur ganz wenig vereugt, die Querader steht anf dem basalen Drittel der langen Discoidalzelle.

\section{Pholitotus rubriventris ot o n. sp.}

Ein or ans Peru ex coll. Hermann, ein ans Surinam in ther Sammlung des k. k. Hofmuseums in Wien. 
Kopf. Gesicht und Stime schwarz, zum grösten Teil mit bleichgelher his nckergelber Bestiinbung beleckt. Das Lntergesicht tright gleichmälsig anliegende, gliinzende Schuppenbeharung von weilslicher Farbe, unter den Fiihlern jedoch auch abstehende, bleichgelbe Härchen. Der Kinebellart besteht aus einigen langen schwarzen Borsten, anfserdem wird der Mundrand von einer Reihe steifer Borsten und feinerer Haare von weifsheher Farbe eingenommen. Stime nnd Ocellarhöeker mit zarter, gelber Beharrung, ebenso ist an hem gelblich bestiubten Hinterhaupte der Borstenkran\% gelb. Nach alowärts wird die Behaarung des Hinterhanptes liehter und geht in den weifslichen Backenbart iiber. Riissel und Taster pechbraun, glänzend, das erste Glied der letzteren mit feiner, gelber Behaarung, das zweite 'Tasterglied an seiner Spitze mit einigen grohen, sperrigen Borsten yon sohwarzer Farlue besetzt. Fiihler dunkelbraun, dic zwei Basalgheder glänzend. das dritte Glied durch helle Bestäubung matt und lichter erscheinend. Die Behaarung der Basalglieder ist im wesentlichen bleichgelb, doeh tright das zweite Glied auch einige kurze selıwarze Borsten.

Thorax mit goldgelber Bestiubung, von der sich die braune mngeteilte Mittelstriene und die an der Quernaht in Flecken aufgelïste Seitenstrieme sehr deutlich abheben. Die zerstrente, anliegende Behaarung des 'Thoraxriickens ist in wesentlichen schwarz, die lingeren prisentellaren Borstenhare sind jeiloelı goldgelb. Die derben Borsten an Ranle des Thorax braun. Schildchen ebenfalls dicht goldgelh bestïubt, der gilinzend pechbramne Hinterrand trägt eine Reilıe dïnner, anfgebegener, gelber Haare. Pleuren grangelblich hestäubt mit zarter gelber Behaarnug. Tor der Notopleurahnalit cine schwarze, derbe Borste. Haarschirm vor den rostgelben scluwingern bleichgelb.

Abromen glinzend rostrot, das erste Segment seitlich geschwairzt, aber mit gelblicher Bestainbung. Gleiche Bestiubung billet auch auf dem zweiten, dritten und vierten Segment wenig in die Augen fallende, dreieckige Hinterrandflecken. Dic kurze, zerstrente, anliegente Behaarung ist auf dem ersten, zweiten und dritten segment goldgelb, an den folgenden seluwar\%. liscalborsten sind nicht vorhanden. Die lichtere Behaarung an den Seiten des ersten Segmentes bleichgelb, die beiden letzten Segmente tragen goldgelbe, derbe Randborsten. Genital grainzend rot, die eigen- 
tiumlichen Zaihne und Borsten desselben pechbraun. Die Behaarung des Genitals ist schwarz, uur die Unterklappe triigt an ihrer Spitze ein Biische! heller Haare, Banch rostrot mit weilsheher Bestäubung und ziemlich langer. feiner abstehender Behaarung von weilslicher Farbe.

Beine. Hiiften grau mit weifslicher Behaarung. Beine dunkelbraun bis schwarz, glainzend mit volwiegend weifslicher Belıarung. Die Trochanteren der Torder- und Nittelbeine mit eigentiimlichen kanmartigen, kurzen Dornen versehen. Torderschenkel ohne gröbere Borsten, jedoch an der Unterseite nit langen, abstehenden, nicht hesonders dichtstehenden, weilslichen Haaren versehen. Die Vorlerschienen besitzen an inrer Unterseite rostgelbe, gläuzende biirstenförmige Behaarumg und tragen anfsen und medial einige fahlgelbe, an der Spitze jedoch schwarze Borsten. An den Mittelbeinen sind die Schenkel nur gegen die Spitze zu nit einigen gelblichen Borsten besetzt. Die Mittelschienen entbehren der biüstenförmigen Behaarung vollstindig, aufsen und medial tragen sie einzelue schwarze, an ihrer Vorderseite jedoch eine Reihe gelblicluer Borsten von auffallender Läıge. Hinterschenkel mit weifslichen Borsten an der Oberseite, die Schienen besitzen die gleiche biirstenförmige Behaarnng wie an den Vorlerbeinen, sind aber im iibrigen borstenlos, mur gegen die Spitze zu findet sich eine einzige lange Borste von weifslicher Farbe. Jie Tarsen sind an saimtlichen Beinen schwarz behaart und beborstet, an den Vorder- und Hinterbeinen aufserdem an ihrer Unterseite mit biirstenfürmiger rostgelber Behaarmng versehen. Die relativ kurzen Ḱlanen dunkel jechbraun, die lebhaft gelben Pulvillen breit, rundlich.

Flïgel an ihrer Wrurzelhälfte durchscheinend, an der Spitzenhälfte mit satt rotbramer, durch sehr grobe mikroskopische beharung gebildeter 'Truibung. Die Tribung bildet in der fünften Iinterandzelle einen keilfirmigen Wisch und fiilt anch die vierte Hinterrandzelle nicht vollstindig ans.

Long. corp. $16 \mathrm{~mm}$, long. alar. 12) n111.

Das $q$ nuterscheidet sich nur wenig voul or. so dafs es aus der gegebenen Beschreibung ohne weiteres erkannt werden kann. Es sei nur elwähnt, dal's die ockergelbe Bestäubung weniger lebhaft ist, vielnehr einen mehr granen 'Ton besitzt und dafs an einzelnen Stellen z. B. an Hinterkopt' die Beborstung schwarze Farbe annimmt. 


\section{I'holidotus ruficaudis o n. sp.}

Ein cinzelnes of ans l'eru (Pachiteamiindung $150 \mathrm{~m}$ ii. 1. II.) befindet sich in der Sammlnng Selıuse.

Kopf. Untergesicht schwarz mit leichter gellygraner Bestiubung, die nur an den medialen Augeuriindern etwas lichter ist. Im iibrigen ist die ganze Gesiehtstiache bis fast nnmittelbar an die Fïhlerwurzel von silberglänzenlen Schup]en besetzt, denen unter den Fiihlern auch einige weifse Haare beigemengt sind. Die spärlichen Borsten des Knebelbartes schwarz, dagegen ist die weichere Behaarung am Mundrande weifslich. Der relativ lange Riissel dunkel pechbraun, an der Wurzel weifslich, an der Spitze gelb]ich hehaart. Die Taster schwarz, brïmulich fein behaart, an der Spitze mit einigen änlserst derben schwarzen Borsten. Stirne ziemlich dicht geelbgrau bestäubt, seitlich mit feiner weilslicher Behaarung, Ocellarlı̈̈ker mit kurzen gelblichen Haaren. Hinterhanjt schwarz mit graucr bis silberweifser Bestäubung, Borstenkranz schwarz, die feine Behaarung in der oberen Hälfte ebenfalls schwarz, nach abwiirts weifslich. Backenbart weils. Fiihler schwarz, das erste Glied an der Unterseite mit weilser, an der Oberscite mit schwarzer Beharming, las zweite Glicd beilerseits schwarz behaart; drittes Glied mit zarter branner l3ereifung.

Thorax schwarz durch Bestiiubung matt. Mittelstrieme ziemlich breit, the fehlende Mittellinie wirl Inrch eine Reihe kurzer, anliegender Borsten ron schwarzer Farbe angedentet. Die Seitenstrieme wird dureh die Quernaht in zwei Flecken aufgelist, deren hinterer vor lem Schildehen mit der Mittelstrieme zusammenhängt. Schulterbenlen tief braunrot. Die ganze Umrandnug des Thoraxrïckens, sowie die Zwischenriume zwischen den Striemen siml mit weifslicher bis nekergelber Bestänbung versehen. Der cbenfalls graugelb hestänbte Prothorax mit längerer weifslicher Behaarung und eince lieihe grüberer schwarzer Borsten. Dur Thoraxuicken triggt zerstrente anliegende, aussululiefslich schwarze beborstung, anch die supraalaren und postalaren Borsten schwarz. Das mattschwarze Schildchen ist gregen seine Spitze zu mit ockergelber Bestäubung beleckt und am Rande mit einer Reilie schwacher Haare von schwarzer Farbe hesetzt. Metanotum mattschwar\% mit zwei weilslichen Bestänbungsflecken. Pleuren allenthalben 
weifsgrau bestäubt, nur unter der Schulterbeule mit querliegender, oblonger, unbestänbter Makel. Die zerstrente kurze Behaarung weifs, einige Borsten unter der Fliigelwurzel schwarz, ebenso besitzt der vor den braunroten Schwingern stehende, weilsliche Metapleuralschirm in semem oberen T'eile einige längere Borsten von schwarzer Farbe. Hiiften weilsgrau liestäubt und weifs behaart.

Die Grundfarbe des Abdomen ist auf den fiinf ersten Segmenten schwarz, mit mälsigem Glanze, an den folgrenden Segmenten jedoch rot. Frstes Segment mit weifser Bestïubung bedeckt, so dafs die schwarze Grundfarbe nur in Form ron Flecken sichtbar wird, deren Form und Ansdehnung aber sehr von der Richtung der einfallenden Belenebtung abhängig ist. Auch die Beharung ist gröstenteils weifs und zwar seitlich ziemlich lang und abstehend, wïlırend sie ant der Riickenfläche selır zart und anliegend ist. Seitlich findet sich anfserdem eine Reihe stiirkerer weilslicher Borsten. Das zweite, dritte und vierte Segment triigt seitlich grofse, durch weilse Bestäubung gebiłdete Hinterrandsmakeln vou dreieckiger Gestalt. Dic feine, anliegende Behaarmug ist an dem ganzen Seitenrande der Segmente weifs, auf der Riickentiache schwarz. Das fiunfte Segment ganz schwarz, seitlich aber ebenfalls weifs behaart. Seehstes und siebentes Segment rot, seitlich ebenfalls mit zarter weilser Behaarung. Die gleiche Beharung findet sich auch an den Seiten des Genitalsegmentes, das aber im iibrigen mit langen schwarzen Borsten bewehrt ist, denen sich oben ein Biischel feiner, fast goldgelber Haare beimengt. Dic Grundfarbe des Banches entspricht vollkommen der Riickenfläche, ist aber allenthalben mit dichter, weifser Bestiubung versehen, die auch das fünfte Segment zum grössten Teile eimnimmt. Die zarte Behaarung auf den vier ersten Segmenten weils, auf ilen folgenden jedoch gröfstenteils schwarz.

Beine schwarz, stark glinzend mit relativ geringer, rorwiegend weifslicher Behaarung. Vorderschenkel an der Unterseite mit längeren weifslichen Borstenhaaren, die Torderschicnen an der Anfsenseite und gegen die Spitze zu mit schwarzer Behorstung, an der Innenseite mit dichter. bürstenförmiger jostgelber Behaarung. Die Mittelschenkel an ler Oberseite der Kniegegend mit einigen weifslichen Borsten, die Mittelschienen sind an ihrer Aufsenseite mit einer Reihe sehr anffallender, lauger weilsheher Borsten 
versehen, an der Spitze aber schwar\% beborstet. Hinterschenkel an der Oberseite mit einigen weifslichen Borsten. die fast borstenlosen Hinterschienen tragen an der Innenseite ihres Spitzendrittels hiirstenfürmige, rostgelbe Beharung. Die Tarsen samtlicher Beine schwarz hehart und beborstet. An den Vorder- und Hinterbeinen sind die Metatarsen und dic drei folgenden "l'arsenglieder ebenfalls mit biirstenfürniger rostgelber Behaarung verschen. bie Klauen sind relativ kurz und stumpf, die gelben l'ulvillen rundlich und hreit.

F'liigel an dev Spitzenhälfte schwarz, an der Wurzelhälfte durchscheinend. Die Grenze der schwarzen 'l'riibung ist seharf, sie folgt der Analader, lä́st die änlserste Spitze der fünften und vierten Hinterandzelle frei, geht daun der die Discoidalzelle basal abschłiefsenden Ader, sowie der kleinen Querader entlang und läuft von hier riemlich senkrecht in den vorderen F'lügchand aus.

Long. corp. $18 \mathrm{~mm}$, long. alar. $16 \mathrm{~mm}$.

\section{Pholidotus anceps $q$ II. sp.}

Peru (Pachiteaniundung), ex coll. Schnuse.

In Färbung, Behaarung und Beborstung des Kopfes, des Thorax und der Beine dem Photidotus ruficuudis fast vïllig gleich. Anf dem Thoraxrïcken sint nur die Interstitien zwischen den Striemen, sowie der seitlichc Rand mit ziemlich lehlaft goldgelber Bestiiulung beleckt, die auch das schildehen bis anf seinen freien schwarzen liand völlig einnimmt. Anffallend jedoch ist die völlig andere Färbung des Abdomen. Dasselbe ist ıämlich in ganzer Ansdehnung hellrostrot mit fahlgelben Einschnitten, mäisig glänzenl. Die Segnente $1-5$ sind seitlich dnnkelbrann gesäumt mud aufserdem teikweifse mit weifser Bereifung versehen und zwar in der Art, dafs das erste Segment in scincr ganzen lainge weifs bestäubt erscheint, wiilırend die drei folgenden Segmente dreicckige weilse Hinterrandsflecken besitzen. lie kurze anliegente liehalaung ist schwar\%, auf lem ersten Segmente jedoch, sowie auf den Hinterrandstlecken weifslich. Banch ebenfalls gelbrot mit leichter grancr Bestiubung und feiner weifser licharung. An den Fliigeln faillt die graue 'Triibung der Spitzenhailfte nur wenig auf, ilıre Begrenzung 
gegen die hyaline Wurzelhälfte hat jedoch die gleiche Verlaufsrichtung wie bei $P$ \%. ruficandis.

Da mir num ein einzelnes $q$ vorliegt, muls ich die Frage, ob es sich doch nicht vielleicht um eine hellere Varietiit von Ph. ruficaulis handeln möehte, offen lassen. Ich habe es vorgezogen, das Tier hier als nene Species zu beschreiben, da ihm die total verschiedene Färbung tes Abdomen ein ganz anderes Anssehen verleiht, das bei fluehtiger Betrachtung kaum an eine Artzusammengehörigkeit mit Ph. ruficundis denken lifst.

Long. corp. $14 \mathrm{~mm}$, long. alar. $11 \mathrm{~mm}$.

\section{Dresyllis Liow.}

Ohne weitere Charakterisiermug wurde das Genus Dasyllis von Löw (Bemerkungen über die Familie der Asiliden 1851) auf die siidamerikanischen Laphria hämorrhoa und croceiventris Wied. und die afrikanische Laphria. nigripennis Wied. errichtet und von ihm mit Reeht hervorgehoben, dafs die afrikanische Species mit den beilen genannten südamerikanischen Arten nicht in allen Punkten iibereinstimme. Löw dentete damit selbst sehon die Notwendigkeit einer generischen Abtremming an und so hat Sehiner (Verh. d. zool. bot. Vereins, Wien 1866) auf die beiden Spec. nigripennis Wied. und xylocopiformis Walk. das Genus Hyperechiu errichtet. Ton S'eite verschiedener Autoren sind diesen im Laufe der Zeit eine Reihe von Arten subsummiert worden. so dass wir zurzeit - ich folge dabei den Angaben Griinbergs (Deutsch. ent. Zeitschr. 1907) - ungefähr ein Dutzend sichere Hỵerechiaarten, saimtlich der alten Welt angehörent, kennen. Nun ist aber andererseits Liow insofern ein erheblicher Irrtum unterlanfen, als er aufser den beiden genannten suidamerikanischen Species für das zu errichtende Gemus Dasyllis auch ,viele andiere amerikanisehe Arten" reklamierte, wornuter er die bekannten nearktischen polzartig beharten Laphrien vom 'Typ der Laphria giossa. fulithorax, saffirana usw. verstand. Vergleicht man jedoch liese mit den Formen hëmorrhoa und croceiventris, so wird man unschwer erkennen, dafs die letzteren mit jenen auch nicht das mindeste zn tun haben und da Löw das Genus Dasyllis primär auf Spec. hämorhoa und croecirentrie 
errichtet hat, so wird sich eine Definition des Genus cben aussehliefslich auf diese heiden Species zu heziehen haben. J)as Genus Dasyllis ist demuach folgendermalsen zu begrenzen.

Plmmpe Arten mit starker, aber nie eigentlich pelzartiger Behaarmng. Las weit ïher die Augen vorspringende Gesieht verläuft völlig plan, geneigt nach abwärts, so dafs ein Gesichtshö̈ker vollständig fehlt; in der Mitte entbehrt es der Behaarung, dagegen finden sich seitwïrts lange niedergedriickte Haare, die in den kriftigen, geneigt stehenden Knebelbart iibergehen. Auch die Stime ist in der Nitte kahl, dagegen sind Scheitel und Hinterhanpt mit langer vorwäits gebogener Behaarung rersehen, die sich abwaists in den relativ schwachen, jedenfalls nicht buschigen Backenbart fortsetzt; eigentliche Occipitalborsten fehlen. Der an seiner Wurzel lang behaarte Riissel ist seh" kurz und. was besonders betont sei, von oben her exquisit breit gedriickt, zweizipfelig: das zweite 'Tarsenglied ist seitlich komprefs. abgeplattet und löttelartig gehijhlt. An den Fühlern ist das erste Glied etwas linger als las zweite, beide namentlich an der Unterseite nur wenig behart, das Endglied ist ungefäh. 11/2 mal so lang als die beiden Basalglieder zusammengenommen, seitlich komprefs, fast bandförmig, und an seiner spitze mit einer grubigen Jelle versehen, ein Endgriffel ist nicht vorhanden. Mesonotum relativ kahl, nur mit wenig dichter abstehender, unter keinen Umständen pelzartiger Behaarung versehen, dagegen am Rande mit äufserst zahlreichen und derben prisuturalen. smpraalaren und postalaren Borsten bewehrt. Schildehen glatt mit langen Randharen. Pleuren mit buischelförmiger Behaarung, die namentlich anf der Mesopleura sehr dicht und lang ist, Notoplenralborsten vorhanden. Abdomen relativ länger als bei deu Hyperechiarten, namentlich goilt dies fiir die Siec. croceiventris. Ain den vorderen Segmenten fehlt pelzartige Beharung vollstaindig, nur die Segmentalränder sind dichter behart, lagegen sind die hinteren Segmente mit langer und dichter Behaarung versehen; Discalborsten fehlen. I Jie or Genitalien sind verhältnismässig kleini, dicht beborstet und im wesentlichen von gleichem laa wie bei Hyperechia. The ranh beharten beine sind entschieden relativ länger als bei den Hyperechiaarten, hieten aber in iibrigen nichts charakteristisches. An den Fliigehn ist die schmale erste Hinterrandzelle stets offen, die kleine Querader steht noch iiber dem proximalen Drittel der Discoidalzelle, Analzelle gestielt. 
Begrenzt man das Geuus Dasyllis in dieser WTeise, so kommt es in die unmittelbare Verwandtschaft der Hyperechiaarten der afrikanischen und orientalischen Fanna, die jelloch vou ilum durch den melı gredrungrenen Habitus, durch die kenlenförmige Gestalt des meist relativ kïrzeren driten Fïhlergliedes, lurch die liüzeren Beine und die geschlossene erste Hinterrandzelle leicht zu trennen sind. Mit ien Sjec. grossa Fabr. mul Konsorten aber haben die Dasyllisarten nnter keinen ITmständen nähere verwandtschaftliche Beziehungen; es geniigt schon der Hinweis, dals bei diesen rein nordamerikanischen Arten der relativ lange Riissel in exquisitem Mafse seitlieh komprefs ist und dafs die Taster zylindrisch sind. Damit schliefsen sie sich unmittelbar an lie genumen Laphrien. speziell an unsere Laphria flava und ilure zahbreichen Terwandten an und ich gebe Terrall (British Flies, vol. V, p. 695) volkommen Recht, wenu er diese in konsequenter Wreise dem Genus Dasyllis in seiner bisherigen Fassung beiziihlt. Jedenfalls kann dieses Genus in der Ausdehunng, wie dies bis jetzt in der Literatur iiblich war, nicht festgehalten werden, da es so nur eine ganz willkiirliche Aneinanderreilıung von Formen darstellt, die weder in wichtigen plastischen Merkmalen, noch auch in allgemeinen Habitus zusammengehïren.

Als typische Art des Genus Dasyllis ist zu betrachten:

$$
\text { Dasyllis hämorrhoa Wied., }
$$

die mir in drei bolivianischen Exemplaren (zwei $o^{\top}$, ein $q$ ) ans meiner Sammlung sowie zehn Stiicken (Bolivia. Mapiri) ex coll. Sehu use vorliegt. Durch die Liebenswiirdigkeit des Herrn Dr. Griinberg war es mir möglich. die aus Brasilien stammende Type aus dem Berliner Musem zu untersuchen und es hat sieh dabei ergeben, dafs die beiden ron II a cquart bescliriebenen Arten fascipennis und maepotens vollstaindig mit der Wiedemannschen Species iibereinstimmen, so dafs die Macquartschen Namen als Synonyme hierher zu setzen sind.

Als zweite Art ist aufzufithren:

\section{Dasyllis croceiventris Wied.,}

die ieb in zwei Exemplaren aus Brasilien kenne; ïber die Identifizierung besteht kein Zweifel. 
Als dritte Art beschreibe ich

$$
\text { Dasyllis erythruru n. sp. or }+ \text {. }
$$

Lin or $f$ aus Paraguay befindet sich in meiner Sammlung.

Kopf schwarz, der hintere Orbitalrand mit breiter, durch graugelbliche Bestäubung gebildeter Säumung, Knebelbart und die gesante Bchaarung des Kopfes durehaus selıwar\%.

Thorax schwarz, matt, mit allenthalben schwarzer Beharung und Beborstung. Schildehen schwarz mit lebluaftem blanen Metallglanz und schwarzer Randbeharung.

A bdomen gröfstenteils mattschwarz mit schmalen gelben Hinterrandssämmen an den ersten fïnf $\left(\sigma^{\top}\right)$ oder sechs $(q)$ Segmenten. Die folgenden Abschnitte, sowie die Genitalien rotbraun. Die Behaarung ist bei dem $\sigma^{\top}$ durchans schwarz und naeh hinten ziemlich lang, ebenso die grobe Beborstung des Hypopygs, das nur an seiner Unterklappe gelb behaart ist. Bei dem $f$ sind die gelben Hinterrandssänme teilweise, das seehste und siebente Segment und die Legeröhre durehaus gelb lang behaart; anch das fünfte Segment triagt seitlich ein Biisehel gelber Haare.

Beine schwarz und durchweg schwarz behart, nur an der Unterseite der 'Parsen macht sich rotbramne Biirstenbehaarung wenig bemerkhich. Klauen schwarz, Pulvillen gelb.

Fliigel an der Wurzel tiefselıwarz, im ïbrigen sind sämtliche Adern mit brauner Trübung breit gesäumt, die jedoch am Flïgelrande die Zentren der Zellen freiläist. An dem hinteren Aste der Cubitalader ist diese sammartige 'Tribung besonders intensiv, so dafs ein von der Gabelstelle zum Fligelrande ziehender Wisch entsteht.

Long. corp. $29 \mathrm{~mm}$, long. alar. $21 \mathrm{~mm}$.

Als vierte hierher gehörige Art ist nach einer briefliehen Mitteilnng des Herrn Verrall, in dessen Besitz sich die Bigotsche 'Tye befindet, auch

$$
\text { Dasyllis albicollis Big. }
$$

zu betrachten; ich kemme die Art nicht. 


\section{Dresylechire Williston.}

Dieses Genus sei hier, da es nur in einer einzigen nordamerikanischen Speeies, D. atrox Williston bekannt geworden ist, nur nebenbei erwähnt. Offenbar handelt es sich bei dem wohlberechtigten Genus um eine Zwischenform zwischen Dasyllis-Hyperechia einerseits, den genuinen pelzartig beharten Laphrien andererseits. Ich fiihre folgende plastischen Merkmale an, die eine Differenzierung leicht gestatten werden. Untergesicht und Stime mit gleichmäfsig dichter Behaarung, der auffallend kurze hiissel besitzt rundlichen Querschnitt, das zweite Tarsenglied ist fast kugelig aufgeblïht und alleuthalben dicht behaart. Die verschmälerte erste Hinterrandzelle ist wie bei Hyperechic an Fliigelrande geschlossen, die kleine Querader steht fast iber der Wrurzel der Discoidalzelle. Da das einzige Fxemplar ron Dasylechia atrox, das ich in meiner Sammlung besitze, des dritten Fiihlerglieles entbehrt, mufs ich mich auf die Angabe Willistons. dafs dasselbe mit einem Endgriffel versehen sei, verlassen.

\section{Nusu Walker.}

Andrenosoma Rondani.

Auf \%wei ostindische Formen hat Walker $18 \partial 26$ das Genus Nusa mit folgender Gattungsuliagnose anfgestellt: Antennis articulus secundus primo brevior, tertius subclavatus, primo paullo longior et multo latior; femora gracilia, tibiac posticae subcurvae; alis areola prima postica ab margine remota, secunda et tertia aperta, quarta prope marginem elausa. Dicse in den Insecta Saundersiana p. 105 gegebene Diagnose wird durch eine recht gute Abbildung (1)l. IV Fig. 4) trefflich illustriert. Im gleichen Jahre errichtete Rond an i anf die bekannte paläarktische Laphria atra L. das Genus Andrenosoma lediglich unter dem kurzen Hinweis, dafs die finfte und sechste Längsader vor dem Fliigelrande mit einander verbunden seien und stellte mit der ebenso kurzen Gattungsdiagnose: Venae longitudinales 3 et 4 renula transversaria conjunctae fuir die Fabriciussche Laphiu marocenu das Geuns Pogonosoma auf. Anf dieses werde ich an späterer Stelle nochmals 
zurilckzukommen haben, vorilerhand soll es sich nur darum handeln, aus der literatur die Angaben zu sammelı, die ron versehichenen Antoren für eine nihere Charakterisierung des Genus Nusa gemacht worden sind. Zunaichst maclite Schiner in seiner Fauna austriaca darauf aufmerksam, dafs bei den Nusaaten das Untergesicht weit unter die Augen herabreicht und dafs die mittleren $\mathbf{A b d o m i n a l s e g m e n t e ~ s e h r ~ b r e i t ~ s i n d , ~ a u e h ~ b e t o n t e ~ e r , ~ d a f s ~}$ die erste Hinterrandzelle nicht immer geschlossen und gestielt, sondern (Spec. albibarbis MIg.) nur verengt oder fast gesehlossen sei. Durch Löw werden wir weiterhin anf den aufwärts gekrimmten liissel sowie anf die Kileinheit und eigentimliehe Beschaffenlieit des Hypopygium aufmerksam genacht und endlich finde ich bei Terrall noch die Angaben, dafs dic Borsten des Hinterhauptes nur schwach entwickelt sind und dafs die Schenkel mud Sohienen iiberhaupt nur wenige Borsten besitzen.

Versuchen wir mun auf Grund dieser Literaturangaben und unter Beriicksichtigung eines ausgedehnteren, den verschiedenen Fannengebieten entstammenden Untersuehungsmaterials uns cin Bild der Merkmale zu entwerfen und deren Wertıng fiil die Charakterisielung des Genus Nusa zu luifen, so läst sielı dariber vielleicht folgendes feststellen. Zunächst sei betont, dal's gerade das Merkmal, das Rondani einzig mud allein fiir die Fixierung des Nusabegriffes verwendete, das Verhalten ler ersten Hinterrandzolle, fiir die Gattungsdiagnose ijberlanut nicht verwertbar ersoheint: es gribt Nusaarten mit gestielter, am Rande geschlossener, rerengter und breit offener erster Hinterrandzelle. Auch individuelle Varianten nach dieser lichtung kommen zur Beobachtung, ieh brauche dafiir uur auf die Notiz Schiners iber die Spec. albibarbis, sowie auf die Wiedemannsehe Beschreihung von Spec. pymropyga hinzuweisen und kann solche Angaben auch auf Grund des mir vorliegenden Untersuchungsmaterials bestaitigen. Im übrigen Terhalten der Flïgeläderung fincle ich erst recht nichts, was für das Genus ITusa einigermalsen charakteristisch wäre.

Besser verwerthar fiir die Gattungsdiagnose erscheint das Verhalten der Fiihler, speziell ihres dritten Segmentes insofern, als sich wirklich fiir alle Nnsaarten eine gewisse Kïrze der Fiihler als charakteristisch feststellen läfst, die vor allem eben das dritte Fiihlerglied betrifft. Hailt man sich dabei zunäichst an unsere rersehiedenen paliarktischen Formen, so ist 
das Endglied der Fühler, seitlich komprefs, exruisit keulfürmig, d. h. an der Basis enge, daun plützlich blattartig erweitert (Schiner). Tach dieser Richtung stimmen auch die südamerikanischen Species grörstenteils mit den Paliiarkten ïberein, doch ist mir ein und die andere Art bekannt geworden, bei der die keulenförmige Gestalt vielleicht etwas weniger deutlich in die Frscheinmng tritt. Beziiglich der intimeren Struktur bietet freilich das dritte Fühlerglied ziemliche V'erschiedenheiten. Gehen wir auch hierbei auf die bekannte Species atra L. zuriek, so zeigt die Spitze des dritten Fühlersegmentes an ihrer Aufsenseite eine kreisrunde, kraterförmige Delle, in deren Tiefe ein kurzer Endgriffel nicht immer leicht erkemnbar ist. Dadurch nun, dafs diese Delle sich bei den rerschiedenen Arten mehr und mehr verflacht, wird der Endgriffel dentlicher sichthar, bis er endlich bei ler siidamerikanischen Spec. erythrogaster Wried. neben der eigentlichen Spitze des Fühlerghliedes frei zutage liegt. Was nun die beiden Basalglieder betrifft, so darf betont werden, dafs bei allen mir bekannten Nusaarten das erste Segment ungefähr $1^{1 / 2}-2$ mal so lang als das kurze, becherfürmige Glied ist; dieses ist an Unter- und Oberseite nit starren, borstenförmigen Haaren besetzt, während das Basalglied an der Unterfläche vorwiegend weichere Behaarung besitzt. der sich eine lange und derbe, abwärts gerichtete Borste beimengt.

Der Schluissel für das richtige Verständnis der Gattungscharaktere scheint mir aber in der intimeren Reliefierung der unteren Partien des Kopfes zu liegen. Schon Schiner macht darauf aufmerksam, dal's bei den Nusaarten das Untergesicht weit unter lie Augen herabreicht. Genauer, namentlich unter Zuhilfenahme durchsichtiger Kalipräparate, untersucht. stellen sich die Verbältnisse folgendermafsen dar. Das Hinterhault reicht weit nach abwiirts und bildet einen von der unteren Augenecke gegen den seitlichen Mundrand sich abflachenden, kissenartigen Wulst, der völlig von der dichten Behaarung des Backenbartes eingenommen wird. Zwischen ihm und der seitlichen Abuachung des grrofsen, dicht beharten und beborsteten Gesichtshöckers findet sich eine dreieckige, unbehaarte Stelle. die wir als Backenregion bezeichnen können. Aber anch nach riickwiirts von dem Backenbartwulste trifft man auf ein dreieckiges Feld, welches der Behaarung völlig entbehrt und als derb chitinisierte, dreikantige Protuberanz seitlich weit vorragt. Nach abwärts nnd medial ron ihr treffen wir auf das 
Kinn sowie die Wurzel des Riesels, die beile wienter mit Hatren versehen simt. Man wird diesen dreikantigen Hörker, nlag er anch bei manchen Nusanten durelı die langen Haare des Backenbartes mehr oder minder verdeckt werden, bei Betrachtung des Kupfes ron rorne her nie vermissen und mufs ilnu fiir das Terstandnis der systematischen Stellung des Geuns N'use eine besondere llichtigkeit zumessen. Ich verde anf diese an späterer Stelle nochmals zuriickznkommen haben, möchte aber schon jetzt darauf hinweisen, dals der Hïeker \%. B. Hen Formen des Genns Laplrvia strictu sensu vällig fehlt mul dals schon daraus hervorgehen mag, dafs das Genus Suse systematisch mit den Laphriaarten keinc nähere Terwanitschaft hesitzt. Auch die Untersuchmog von Taster mol liissel wirl mı das bestaitigen kömmen. Bei Nusa nämlich stellt das Fudgolied rler 'l'aster ein seitlich kompresses, ganz flaches, oblonges oder fast sclanfelfömiges, an der Anfsenfläche lötf̈elartig gehiililtes Gebilde dar, las an seiner Spitze mit derben Borsten versehen ist und dem libssel von der Seite her platt anliegt. Was letztereu betrifft, so ist er hei allen Nusaarten relativ kmra, kegelfömig; mehr oder minder nach oben gebogen und von oben her komprefs. Dafs rie "Unterlipper ans parigen Stiicken besteht, wirl man an den zwei derb chitinisierten, zart behaarten Endknöjfehen erkennen kïnnen, welche die Spritze der "Unterliplew gewissermafsen gegabelt erscheinen lassen. Zwischen ihnen ragt dann der Hypopharynx, die "Znnge", als dolchartige, an der Oberseite biirstenfirmig beharte Spitze hervor. Auch hier mirrhte jeh grleich die Unterschiede gegeniber den genuinen Laphrien angeben. Bei diesen ist das Endglied les Tasters stets zylindrisch, walzenföming, in seiner ganzen Ansilehnung beborstet, der längere liissel ist seitlich

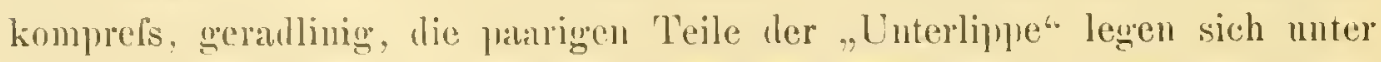
Bildung einer mah oben gekielten Schneide aneinander.

In Ban des 'Thol'ax vermisse ivh ebenso wie in der Anorinung und Anzahl der thorakalen Borsten jede irgendwie charakterisierenden Ziige. lch mörlite nul dal'anf aufuerksam malvhen, dals das Metanotum bei gुeWissen Nusiluten seitlich cine biischelformige, meist selwarze beharmung triagt, Während es bei anderen vollständig kahl ist. Es liilst sich daranf eine recht bequence finteilung nicht mu der siidanerikanischen, sondern ibberhaupt aller Nusaarten aufbanen und es sei hier nur noch bemerkt, dafs 
mnsere paliarktischen Species saimtlich der Beharmng des Mctanotum entbehren.

Auch das Abdomen hesitzt nichts charakteristisches mal es sei hicr blofs daranf hingevicsen. dafs die hiscalborsten nur auf dem ersten Segmente in Nehrzahl, auf den folgenden in Gegensatz zu den genuinen Laphriaarten nur in Einzahl rorhanten sind und zwar stehen sie annähernd in der Mitte ler seitlichen Segmentalränder. Auf die relative Kleinheit des $o^{\top}$ Genitales wurde bereits von Lïw anfmerksam gemacht und ich kam diese Angabe dahin ergiinzen, dals dascelbe ans einer unparen Unterklappe und parrigen zangenartigen Uberklappen besteht, welehe oben eine oblonge Nische zwischen sich frei lassen mul mit teilweise rcht charakteristischen Anhängen versehen sind, die, wie wir spuiter schen werden, häufig genug als Kriterium fiir dic Differenziernng der Arten benutzt wurden. Die Legeröhre ist lang und sticlfürmig vorgestreckt, jedenfalls auffallend linger als wir sie bei den genuinen Laphriaspecies zu funden gow obht sind.

An den Beinen finde ich nichts charakteristisches, weler in der Form, noch in der Anordnung der im allgemeinen reichliehen Behaarung und Beborstmng, und beziighlich des Fliigelgeäiler diirfte schon oben das Nötige Erwälummg gefunden haben.

Löw (beschreibungen europ. I)ipteren III, pag. 139.) hält eine eventuelle generische Abgrenzung der sidamerikanischen Nusaarten von den iibrigen für notwendig. Nach Untersuchung eines ctwas ausgedehnteren Artenmaterials, als es Löw wohl zu Gebote stand, wïste ich nichts anzugeben, was einen solchen Schritt zu rechtfertigen vermöchte; demn die griifsere Sohlankheit des Habitus, welche wenigstens grewissen siilamerikanern eignet, allein kïmte bei der Übereinstimmnng saimtlicher anderer charakteristischer Merkmale kanm Terwendung finden. I)amit soll aber keineswegs geleugnet werden, dafs gerade unsere allbekannte paliiarktische Jusa atra L. nicht nur Jurch ihren relativ breiten Habitus, sondern noch viehmehr durch ihre diehtere biehaarung unter ihren Genusgenossen cine gewisse Sonderstellung einnimmt.

Als typisehe Art ist zu betrachten:

Nosu aequalis Wth. aus Ostindien. 
Ich wende mich nunmehr einer Auscinandersetzung der Nusaarten zu. die mir aus Siidamerika bekannt geworden sind. Durch das liebenswirdige Entgegenkommen des Senckenbergschen Museums in Frankfurt a. M., fuir welches zu danken ich auch an dieser Stelle nicht versäumen müchte, war es mir möglich, die dort aufbewahrten Wiedemannschen Typen zu untersnchen, so dafs sich die Identifiziernng des mir vorliegenden Speciesmaterials wenigstens grörstenteils in gesicherten Bahnen bewegren duirfte. Aber trotz dieses giunstigen Umstandes war mil eine restlose Interpretation ter von Wiedemann aufgestellten Spezies nicht möglich, und ich habe mir mehr und mehr die Ansicht gebildet, dafs der Autor selbst vielleicht nicht ganz iiber die Begrenzung der von ihm creierten Species im Klaren war, eine Veruutung, die schon durch den Text, welcher die Wiedemannsehe Beschreibung von Laphria myrhacra (Aufsereurop. zweifl. Insekten, I p. 518.) begleitet, mehr wie Wahrscheinlichkeit gewinnt.

\section{Analytische Tabelle zum Bestimmen der mir bekannt gewordenen südamerikanischen Nusaarten.}

1. Das Metanotum trägt seitlich biischelförmige Behaarung.

- Metanotum vollständig kahl.

2. Abdomen und Beine zum gröfsten Teil lebhaft griin bis blau metalliceh glänzend. rubidapex n. sp).

- Abdomen und Beine nie metalliseh glänzend.

3. Beborstung des 'Thorax und des Schildchens leblaft gelb.

- Beborstmog des 'Thorax und des Schildeliens ausmahmslos sehwarz. 5 .

4. Abdomen schwarzbraun (nur zuweilen an den Seiten des ersten und zweiten Segmentes ziegelrot); Fliigel mit Ausuahme des geschwiirzten Spitzenviertels lebhaft gelb mit saffrangelben Adern. rufipemus Wied.

- Abdomen durchaus rot; Fliigel mit leichten braunen, wolkigeu Tribungen und durchaus schwarzbraunen Adern.

phönicogaster n. s].

5. Grundfarbe des Abdomen ganz oder doch stets in gröfserer Ausdehnungr rot.

6.

- Grundfarbe des Abdomen mit Ausnahme der gelbrot gefürbten Endsegmente scliwar\%. 
6. Abdomen gleichmälsig mit äufserst dichter, filzartiger Behaarung von roter Farbe bedeckt, dureh weifse Bestäubung gebildete Flecken- oder Bindenzeiehnung nicht vorhanden; die Oberklappe des or Genitales trïgt rote Chitindornen; distale Hälfte der Fliigel gleichmärsig tief gesehwärzt; grofse, plumpe Art. formirolosa Walker.

- Das Abdomen trägt jederseits kleine weirse Bestäubungstlecken, die je zwei zusammenstofsenden Segmenträndern gemeinschaftlich sind; die sehr feine, wenig dichte und nie filzartige Behaarung des Abdomen vorwiegend schwarz; Dornen an der Oberklappe des o' Genitales schwarz; Flügel hell mit lichten wolkigen Truibungen der Spitzenliälfte; kleinere Art von relativ schlankem Habitus.

crythrogaster Wied.

7. Die Oberklappe des ơ Genitals läuft in einen langen trommelschlïgelförmigen Fortsatz aus.

pyrrhopyga Wied.

- Die Oberklappe trägt an ihrer Spitze ein Büschel lebhaft goldgeller, reusenartig gestellter Haare.

cyrtophora n. s]).

- Die Oberklappe trïgt au ihrer Spitze eine Gruppe schwarzer; sehr derber Chitindornen.

erythrogaster Wied.

(Nota. Da die Spece erythrogaster Wied. in Varietäten vorkommt, bei denen das Abdomen mit Amsnahme des rotgellen Aftersegments sehr dunkel, oder sogar röllig schwarz ist, wurde sie zweimal, unter Nr. 6 und 7 aufgefiihrt.)

8. Abdomen und Beine lebhaft blaumetallisch glänzend. Fliigel gleichmailsig tiefsehwarz mit violetten Reflexen.

olbus Walker.

- Abdomen und Beine nie metallisch glïnzend; Fliigel hyaliu, oder mit wolkigen 'Truibungen, oder mit sehr bestimmter flecken- oder bindenartiger Zeichnung.

9. Flitgel ganz hyalin; Beine durehaus gelbrot. abdominalis Brown.

- Fliigel nie gleichmialsig hyalin, Beine ganz, oder wenigstens an den Selienkeln und Tarseu Ilunkel gefürbt.

10.

10. Hintersehenkel und die Spitze der Hinterschienen mit auffallender keulenförmiger Terlickung; Flïgel mit sehr zierlicher, scharf begrenzter Flecken- und Bindenzeichnung. pygothora sehiner. 
- Hinterschenkel und -schienen nie mit auffallender keulenfürmiger Verdiekung: Fliigel stets mu* mit wolkigen, dunkleren \%eichmumgen.

11. Abdomen stets in grofser Ausdelumng lehhaft lot.

Abdomen dunkelbraun mit gleichniissiger oder bindenartiger lehmgelber Bestïubung, oller sehwarz mit gelbrot gefiirbter Aftergegend.

12. Knebelbart zum grösten 'Teil aus auffallend kurzen, stachelartigen Borsten bestehend; Sehienen siintlicher Beine mit Ansnahme der Spitze rot: Fliggelspitze und eine die Basalzellen distal begarenzende binde seliwarz.

xanthomema Wied.

- Knebelbart aus langen Borstenharen bestehend: Schienen sämtlicher Beine oder wenigstens an den Hinterbeinen schwarz; Spitzenhälfte der Fliigel mit gleichmäisigen wolkigen 'T'viibungen.

13. Truzellälfte der Torder- und Mittelschienen rot; Stime und Scheitel mit sehr dichter Beharrung, auch der Ocellenhöuker behart.

rufiventris Blanchard.

- Schiencn sämtlicher Beine sehwarz; Stirne und Scheitel relativ kahl, am inneren Orbitalrande steht eine einzelne sehr derbe Borste, Ocellenhöcker nur mit den ïblichen beiden Borsten versehen.

calogastra Philippi.

14. Abdomen dunkelbraun mit gleiehnälsiger oder hindenartiger lehmgelber Bestiillbulng. sareophaga $11 . \mathrm{sp}$.

- Abromen schwar\% mit weifsen seitlichen Bestïubungstlecken, die hintersten Segmente in wechseluder Ausdehmung lebhaft rot gefïrbt.

15. Die Stirne tright am medialen Augenrmde eine Reilıe gleichlanger Borstenhare: Unterklappe des or Genitales zweizipfelig grespalten.

?? pymlacre 11 ied.

- Die Stime trïigt an medialen Augenrante aufser kürzerer Beharmug eine einzelne besonders derbe Borste; Unterklappe des or Genitales nieht zwoizipfelig gespalten. ?? erythropyga Iried. 


$$
\text { Tusa rubidapex n. sp. ot. }
$$

1 or ex coll. Hermann ans Tenezuela.

Kopf schwarz. Untergesicht seitlich mit graugelber Bestäubung unt gelblieher bis weilser Behaarung. Dem schwarzen Knebelbarte sind an Mundrande einige falllgelbe Borsten beigemengt. Riissel schwarz, an der IT urzel mit weifslicher, an der' Spitze mit dunkler' Behaarung. 'Taster schwarz nud schwarz beborstet. Stirne unbestiubt, seitlich mit sclıwarzer Behaarung; cbenso sind die Borsten des Ocellarhöckers sclıwarz. Scheitelgegend und Hinterhaupt schwarz, dieses weiter abwärts mit gelbgrauer Bestäubung bedeckt; Behaarung und Beborstung schwarz. Fiihler schwal'z, las zweite Segment an seinem Torderrande, das relativ lange und wenig keulförnige dritte Segment an semer Wurcl sehmal gelbbraun gesaiumt. Das dritte Segment trägt gelbbraune Bestäubrng. Mit Ausnahme ded weifslich behaarten Fiilılerwurzel besitzen dic Basalglieder schwarze Behaarmng und Beborstung.

T'horax dunkelbran mit der iiblichen Stricmenzeichnumg. Die durelı eine gellograu bestänbte Mittellinie geteilte Mittelstrieme häng’t mit dem hinteren Teile ıler Seitenstrieme zusammen. Die gesamte Umrandung iles Thoraxriickens, sowie die Interstitien zwischen den Striemen sind mit gelblichgraucr l,is ockergelber Bestäubung bedeckt. Die zerstreute Belaarung sowie die Beborstung des Toraxrickens ist schwarz, ebenso ist las braunbestiubte Schildehen sehwarz behaart mol beborstet. Metanotum durch branne Bestäubung matt. Pleuren gelblichweils bestiubt nut vorwiegend hell behart. Um die Notopleuralnaht steht ein Biischel schwarzer Haare, ebenso ist die Notoplemalborste schwarz. Der Haarschirm vor den lichthramen Schwingeru ist ehenfalls schwarz. Hiiften grau luestäubt und fahlgelb behaart.

Das relativ schmale Abdomen ist scluwa, mit leblaft blangrinem Metallglanze, das sechste Segment ist rotgelb gesiiumt, die folgenden Segmente sind ebenso wie das Hypopygimm leblaft rotgelb, gainzent. Die ersten drei Segmente zeigen kleine, wenig in die Augen fallende, durels weilse Bestiubung gebildete Hinterrandstlecken. Die zarte Behaarung der liickenHäche ist auf den ersten drei Seg*menten licht, gelıt aber aut den folgenden in schwarz iber. Ebenso verhält sich die ziemlich lange Beharung am Rande der Tergiten. Die [)iscalborsten sind schwarz. Die letzten Seguente 
sind ebenso wie das IIypopygium rotgelb behart und beborstet. Der Bauch cutspricht in seiner Fairbung der Rüickenfläche des Abilomen, die vorwiegend dunkle Beharung ist sehr zerstreut.

Beine mit Ausnahme der 'Tarsen blaugriin metallglainzend mit vorwiegend schwarzer Beharung. Die Torler- und Mittelschenkel tragen oben, namentlich aber unten lange gelbliche Behaarung, die sich stellenweise auch auf den Schienen findet. An den Hinterbeinen tritt die helle Behaarung mehr zurỉck. Gröbere Borsten von schwarzer Farbe finden sich auch an den Knien und den Spitzen der Schienen. Die 'Tarsen sind schwarz und ebenso behaart und beborstet. Klauen schwarz, Pulvillen lebhaft gelb.

Flïgel mit gleichmälsig bramner 'Tribung, nur in der Axillarzelle, der Analzelle, der hinteren Basalzelle und an der Wurzel der Subcostalzelle finden sich völlig durchscheinende Stellen. Erste Hinterrandzelle breit offen; die vorlere Zinke der Gabelader ist mit einem kurzen, rücklaufenden Aderrudiment versehen.

Long. corp. $18 \mathrm{~mm}$, long. alar. $15 \mathrm{~mm}$.

\section{Nusa rufipennis Wied.}

Ich habe die Art, von der ich je ein $\sigma^{7}+$ aus Surinam und aus Brasilien besitze, mit den Typen Wiedemanns aus dem Senckenbergsehen Museum in Frankfurt a. M. vergleichen kümen. Dadureh ist nicht nur die Identifizierung gesiehert, sondern es liefs sich auch ohne weiteres feststellen. dafs die Art im Gegensatze zu Schiner, dem Genus Nusa einzureihen ist.

Nusa phönicogaster n. sp.

Neur of, sechszehn + aus Bolivien (Mapiri, Sarampioni $700 \mathrm{~m}$, S. Ernesto, S. Carlos $800 \mathrm{~m}$ ii. d. M.) ex coll. Selınuse, ein $\sigma^{-1}$, zwei $q$ ans Bolivien ex coll. Hermann.

An dem ungestriemten, mit goldgelber Beborstung versehenen Thorax sowie dem cochenilleroten Abdomen leicht kenntlich.

Kopf glainzend schwarz, Untergesicht mit sehr zarter weifser Bestäubung bedeckt, die jedoch die schwarze Grundfarbe in der Mitte und in 
der Backengegent freilicst. Die Beharung des resiehts ist in den oberen und seitlichen Partien vorwiegend weirs, die Backengegend jedoch trïgt einige schwarze Borstenhaare. Der Knebelbart besteht aus langen schwarzen Borsten, denen jedoch beim ot anch einige von goldgelber Farbe beigemengt sind. Mundrand schwarz beborstet. Riissel und Taster glänzend schwar\%, die letzteren mit schwarzen Borsten. Der liiissel trïgt an seiner Wurzel teils schwarze, teils weifsliche, an iler Spitze vorwiegend gelbe Haare, die Zunge ist lebhaft goldgelb bürstenfürmig belaart. Die unbestäubte Stime trägt seitlich einige gelbe Haare, ler Ocellenhö̈ker zwei lebhaft goldgelbe Borsten. Das Hinterhanpt ist an den Augenränlern goldgelb bestiubt, seine Behaarmug mod Beborstung ist an dem Scheitel gelb, weiter nach abwärts schwarz, ter Backenbart jeloch besteht ans gelben Haaren. 1)ie Fiihler sehwarz. Das erste Gliel ist hehl behaart, das zweite schwarz heborstet. Die einzelne Borste an der Unterseite des ersten segmentes ist meistens schwarz, bei einzelnen Stiicken goldgelb gefürbt.

Thorax schwarz, ohne Zeichnung, durch diume ockergelbe Bestäubung matt. Die gewöhnliche Striemenzeichnung wird lediglich durch etwas dichtere und hellere Bestänbung angedeutet, die sich an dem scithehen Thoraxrande, auf ten Postalarhöckern, medial von den Sehulterbeulen, sowie auf der Qucrnaht ausbreitet. Die Behaarung des Thoraxriickens ist sehr zerstrent, ansschliefslich gelb, fast borstenfürmig. Die präsuturalen, supraalaren, postalaren und präscutellaren Borsten sind sïmtlich goldgelb. Prothorax schwarz und schwarz beborstet. Das Schildehen ist mit Ausnahme seines freien, nit goldgelben Borsten besetzten Randes oekergelb bestäubt und gelb behaart. Anch das Metanotum trägt lichte ockergelbe Bestäubung, die sich seitlich zn einer kleinen, fast goldgelb lenchtenden Makel rerdiehtet. Die sehwarzen Plenren sind mit drei ockergelb bestäubten Striemen versehen; die vorderste erstreckt sich von dem Prothorax zur Vorderliifte, lie mittlere geht, lie Notopleuralnaht siumend, von der Flügelwurzel zu den Mittelhiiften, die hinterste läuft über die Meta- und Hypopleura nach den Hinterhuiften hinab. Dic zerstreute, aber ziemlich lange Beharung ist nur ganz rone schwarz, im iibrigen aber gelb, anch der vor den rotgelben Schwingern stehende Metapleuralsehirm ist goldgelb. Hiiften mit gelblicher Bestïubung und goleichfarbiger Behaarung; an den Vorderhiiften ist diese linger uud fast weil's. 
A bdomen mit Ausmahme seiner äufsersten, brangefïbten Wurzel gleichmäisig cochenillerot, durch einen Hauch weifser Bestäubung, die seitlich etwas dichter liegrt, matt erscheinend. Die kurze, anliegende Bebaarumg ist allenthalben goldgell); die ersten fünf Segmente tragen jederseits eine em. zelne lote l)iscalborste. Auch an den Seiten des sechsten und siebenten Segmentes ist die mehr borstenförmige Behaarung goldgelb, welehe Farbe auch die Beborstung der glänzend rostroten Genitalien besitzt.

Beine dunkelpeelibraun mit durchweg goldgelber sparsaner Behaarung und Beborstung. An sämtlichen Beinen sind die Sehienenspitzen, sowie die 'Tarsen an ihrer Unterseite nit goldgelber bis roter bürstenfömiger Beharung versehen. Die Enttarsen sind sehwarz beborstet, die Ḱlauen schwarz, die Pulvillen gelb. An der Kinicgegend der Hintersehenkel, an der Aufsenseite und an der Vorderseite der Tarsen an den Hinter- und Mittelbeinen finden sich einzelne derbere Borsten von fuchsroter Farbe.

Fliigel an der Vorderanthälfte mit branner 'Triibung, gegen den Hinterrand hyaliu. Die Tribung schliefst sich im allgemeinen den dunkelbraunen Aderu an und führt zu einer verwaschenen Zeichung, die sich iiber einigen Adern - Gabel der Cubitalader, kleine Querader, apicale Begrenzung der hinteren Basalzelle — Heckenartig verdichtet. Die erste Hinterranizelle ist weit offen, die kleine Querader steht ungefïhr auf der Mitte der Discoidalzelle.

Long. corpe. $19 \mathrm{~mm}$, long. alar. $14 \mathrm{~mm}$.

Nusa formidolosa Wlk. ơ

Ein $\sigma^{7}$, zwei $q$ ans Clininui ex coll. Hermann, ein $q$ ebendaher ex coll. Czerny.

Dic leicht kenutliche Species lälst sich mit der Wralkerschen Beselıreibung und der von Bellardi gegelsenen Abbildung ohne Mïhe in Übereinstimmung bringen. Ich mache besonders auf die nugewölnulich dichte, filzartige rote Behaarung, die das ganze Abdomen gleichmälsig deckt, sowic darauf aufmerksam, dafs lie Obcrklappe des $\sigma^{-1}$ Genitales mit einer Reihe derber stachelartiger Borsten von roter Farbe bewehrt ist. Im übrigen darf ich auf die beiden Literaturstellen verweisen. 
Nusa erythrogaster Wied. oro

Von dieser anscheinend hïufigen Art liegen mir aufser den typischen Exemplaren (drei ot, ein $q$ aus Brasilien) Wiedemanns ans dem Senckenbergschen Mnseum in Frankfurt a. M., zehn ebenfalls brasilianische Stiicke des k. k. Hofmuseums in Wien, sowie ex coll. Schnuse zwölf lixemplare ans Peru (Urubambaflufs, Umahuankiali, $500 \mathrm{~m}$ ï. d. M.) vor. Ich bemerke, dass dic peruanischen Stiicke zum T'eil etwas gröfser und alle dunkler gefärbt sind, dafs sie aber im iibrigen völlig mit den anderen iibereinstimmen. Die Species ist vor allen anderen an der höchst eigentümlichen. auch von Schiner (Novarareise) er-

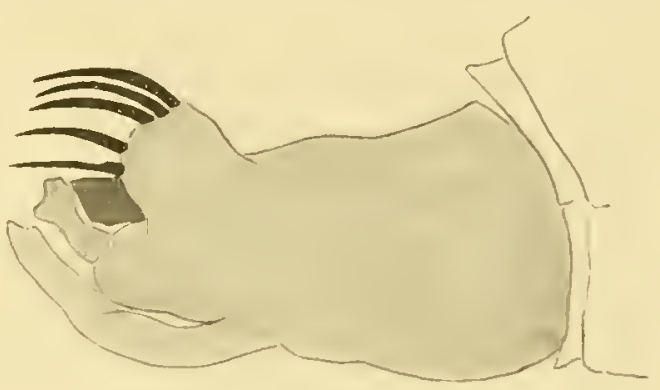

Fig. 82. wähnten Bedornung des mämnlichen Genitales (T'extfig. S2) leicht kemutlich und wird aneh naeh der Wiedemannsehen Beschreibung kanm verkannt werden können. Trotzdem füge ich ansfiihrliche Angaben hei, 1 m die Art auch in ihrer erheblichen Variationsbreite festzustellen.

Kopf. Gesicht mit bleieh messinggelber Bestiiubung beleckt und mit gelblicher, am Mundrande längerer Behaarung versehen. Der stark entwickelte Gesichtshöcker entbehrt in der Mitte der Bestänbung unıl träigt den ansschliefslich ans sehwarzen Borsten gebildeten Kinebelbart. Stirne nnd Scheitel ebenfalls messinggelb bestäubt, die lïngeren Haare am inneren Orbitalrande teils gelb, teils schwarz, auch die zarte Behaarung des Scheitels von wechselnder Farbe. Der unbestäubte Oeellarhüeker trägt zwei schwarze Borsten. Das grau bestaiubte Hinterhanpt ist oben der Hanptsache lach mit schwarzer Behaarung versehen; die Occipitalborsten sind nur schwich entwickelt, dagegen finden sich weiter nach abwïrts hinter dem dichten. bleichgelben Backenbarte einige kräftigere, schwarze Borsten. Beharung des Kinnes und der Wurzel des Rüssels ebenfills bleichgelb. Die Riisselspitze trägt biischelartig gelbe Haare, die schwarzen 'Taster sehwarze Beborstung. An den Fïhlern sind die beiden Basalglieder schwarz oder dunkelbraun, das dritte Segment ist in gröfserer oder geringerer Ausilehnung 
diister rotbraun. Die Behaarung ist anf dem zweiten Segunente uml der oberen rliiche des ersten konstant schwarz, an dessen Interseite, die mit cincr einzelnen gräberen schwarzen Borste bewehrt ist, vorwiegend bleich.

'Tholax. Mesonotum rotbraun bis schwarz; gelbe bis grauweifse Bestäubung lailst die iibliche Flecken- und Strienenzeichnung in scharfer Weise erkemnen, die Mittelstriene ist wenigstens vorne durch eine gelbbestäubte Mittellinie breit geteilt, die Seitenstrieme an der Quernalut in zwei grofse Makeln zerfallen. Die wenig dichte, ror dem Schillehen etwas lingere Beharung ist ebenso wie die Randhehorstung ansschliefslich schwarz. l)as perhbranne solhildrhen ist an seiner basis gelb bestäubt und ausschlielslich schwarz behart und beborstet. Plenren mit weisgramer bis gelber Bestiubung einigemafsen Heckenartig bedeckt und gelblich behaart. I nmittelbal vol der Notopleuralnaht findet sich cine Gruppe lïngerer und steiferer Haare, die ebenso wie die Notopleuralborste schwarz sind. Dem gelben Metaplenralschim ist ohen eine Flocke scluwarzer Borstenhane beigemengt, das schwarze, grau bestäubte Metanotum ist seitlich biischelartig selwary hehaart. Schwinger braun mit helleren Knolf, die schwarzen Hiiften sind weifslich belaant.

A b) lomen verhïltnismälsig schmal, sich nach hinten etwas verjuingend. Die ersten fünf Segmente cochenillerot, die folgenden rotgelb gefairbt. Anch bei den lellsten Stiicken ist aber ler Seitenrand des ersten und zweiten Segmentes geschwärzt. Diese Sehwärung kam sich num in griilserem oler geringerem Nalse iiber das Abdomen ausbreiten, so dat's schliefslich tixemplare beobachtet werilen, bei denen die ersten fiuf Segmente sowie die proximale Hälfte des scehsten Segmentes glänend schwarz sind. An den Seiten hesitzen die fünf ersten Segmente kleine weifslielie Bestïubungstlecke, die je zwei zusammenstehenden Segmentalrändem gemeinschaftlich sind und bei gout konservierten Wxemplaren durch schmale, den Segmenteinschnitten entsprechende Binlen untereinander verbunden werden. Ehenso erscheint dann dic Wurzel des ersten Seguentes weifslich bestiubt. Auch bei den dunkelsten Stiicken hleibt die gelbrote Fiirbung des sechsten und siebenten Segmentes sichtbar, dagegen ist das Genitalsegment in griblscrer oder goringerer Anstehnmng geschwäzt. Die eigentumliehen breiten Domen der Oberklappe des or Gienitales sind aber, ebenso wie dessen 
feinere Behaarung, anch bei den hellst gefiipten Exemplaren schwarz. Die kurze anliegende Behaarung ist anf den ersten fünf Segmenten untel allen Unstïnden schwarz, auf dem sechsten und siebenten Segmente nur bei den hellen Exemplaren gelb. Die lange, abstehende Seitenbehaarung ist weifs, die horizontal gerichteten Discalborsten, deren das erste Segment zwei, die iibrigen je eine besitzen, sind sehwarz. Die Fiirbung des licht behaarten Banches richtet sich nach der des Abdominalriickens.

Beine durchans schwarz. An den beiden vorderen Beinparen ist die Beharung der Oberschenkel weils und an der Unterfläche von betrïchtlicher Länge, die Knie sind schwarz behaart. An den Hintersehenkeln findet sieh in reieherem Malse schwarze Behaarung. Die Torder- und Mittelschienen trag'en an ihrer Vorderfläehe eine Reihe schwarzer Borsten, im iihrigen aber ist die namentlich aufsen lange Behaarung im allgemeinen gelblich, nur bei den dunkelsten Exemplaren iiberwiegend schwarz, doch finden sich aneh bei den hellsten Stiicken an der Basis der Schienen einige besonders lange, schwarz gefürbte Haare. An den Hintersehienen ist die Behaarmug und Beborstumg vorwiegend schwarz. Die 'Tarsen saimtlicher Beine sehwarz behaart und beborstet. An der Unterseite trag*en dic Tarsen der Torderund Hinterbeine gelbe biirstenfiirmige Behaarung, die an deu Vorderbeinen anch die apicale 11 ïlfte der Schienen, an den Hinterbeinen die Schienenspitze bedeckt. Klauen sehwarz, Pulvilken rostgell).

Flïgel. Wurzel glashell, die Spitzenlälfte ranclıgran mit einigen klaren Zellen (Viede mann) und zwar ist diese Auflellung bei den dunkelsten Exemplaren am meisten ansgedehnt. Die erste Hinterrandzelle ist stets geschlossen, meistens melı oder minder lang grestielt. Die vordere Gabelzinke der Cubitalader besitzt bei einigen Stïcken den Stumpf eines Aderrudimentes.

Das $q$ muterscheidet sich kaum von dem $o^{\top}$, anch bei ihm macht sich die gesehilderte Variabilität in der Färbung res Abdomen bemerkbar. Die Legeröhre ist an ihrer Spitze geschwärzt und mit langen gelben Borstenhaaren versehen.

Bemerken möchte ich, dals die Laphria contusa Wied, deren 'Type $\left(\sigma^{\top}\right)$ aus dem S'senckenberg'schen Museum in Frankfurt a. II. mir vollicgt, weiter nichts ist als ein mansgefärbtes Exemplar von Nusa erythrogaster; die Spec. 
contusa ist dementsprechend einzuziehen. Aufserdem diirften, soweit dies die betreftenden Beschrcibungen erkennen lassen, die Arten

$$
\begin{aligned}
& \text { Nusa clausicella Meq., } \\
& \text { Nusa laticornis Walk. und Nusa cincta Bell. }
\end{aligned}
$$

als Synonyme zu Spec. crythrogaster zu ziehen sein.

\section{Nusa pyrrhopyga Wied.}

Die Art liegt mir in den Typen ( $0^{\top}$ P ) Wiedemanns aus dem Senckenbergschen Mnseum in Frankfurt a. M. vor, aufserdem befindet sich unter den sechs Exemplaren des k. k. Hofmuseums Wien eines, das mit „ex Mus. Francofurt" bezettelt und daher wohl als Cotype Wiedemanns zu betrachten ist, endlich besitze ich zwei o elsenfalls aus Brasilien stammende Stiicke in meiner Sammlung.

Zu der Wiedemannschen Beschreibung möchte ich folgende nähere Angaben machen:

Kopf. Die Behaarung am Seitenrande der Stime, an den beiden ersten Fiullergliedern und den Tastern ebenso wie dic beiden Ocellarborsten schwarz. Die schwarze Behaarung des Hinterhauptes reicht bis zum mnteren Drittel der Angen lierab, der Backenbart aber ist weifs.

Thorax. Auf dem Mesonotum und dem Schildehen sind die Randborsten sowie die zerstreute, abstehende Behaarmig schwarz. Die Pleuren sind ziemlich gleichuälsig gelblichweifs bestainbt nnd behaart, mur in der Umgebung der Notoplenralnaht ist die Behaarung ebenso wie die Notopleuralhorste schwarz. Dem ebenfalls schwarzen Metapleuralschirm sind nnr muten einige helle Haare beigemengt, das Metanotum trïgt seitlich schwarze biischelartige Behaarung. Hiiften weilslich bestäult und behaart.

An dem schwarzen Abdomen sind das sechste und siebente Segment, sowie die Genitalien lelhaft gelbrot gefïrbt und ebenso behaart. Das zweite, dritte und vierte Segment besitzen seitlich leichte gelblichweifse Bestäubung, die sich an den Hinterecken Heckenartig verbreitert, nirgends aber auf die Riickenfliche iibergreift. Dic kurze anliegende Behaarung ist an den vier ersten Segmenten gelblichweifs und setzt sich auf den zweiten 
Segmente etwas auf die Riickenfläche fort. Discalborsten schwarz. Der eigentuimliche Ban des $\sigma^{7}$ Genitals wird am besten ans beistehender Fig. 83 ersichtlicl.

Beine durchans schwarz, ziemlich glänzend. An den Oberschenkeln der beiden vorderen Beinpaare ist die Beharung im wesentlichen gelblichweils und an der Unterseite von erheblicher Liinge, an den Hinterschenkeln jedoch vorwiegend schwarz. Die Schienen der beiden vorderen Beinpare schwarz behaart und beborstet, an der Hinterseite mit langen, fahnenartig angeordueter schwarzer Behaarmig besetzt, der kiirzere gelbliche Haare beigemengt sind, die Hinterschienen besitzen iiberwiegend schwarze lBehaarung und Beborstung, nur im basalen Drittel

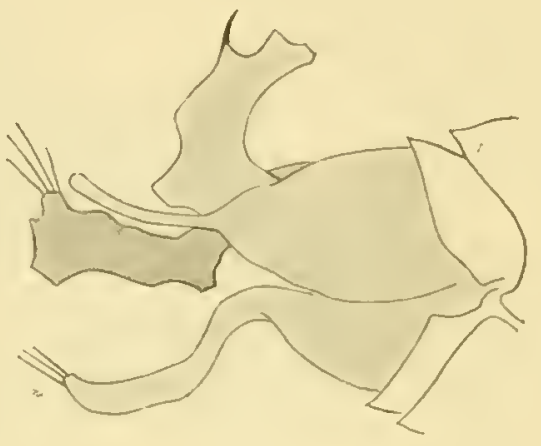

Fig. 83. finden sich auch kürzere weifshche Haare. 'Tarsen siintlicher' Beine schwarz behaart und beborstet. Bürstenfürmige Behaarumg von fuchsroter Farbe findet sich an der Hinterfläche der Vorlerschienen, an den Schienenspitzen der Hinterbeine und der Unterseite saimtlicher 'Tarsen. Klauen schwarz, Pulvillen gelb.

An den Flïgeln ist die erste Hinterrandzelle bei den mir rorliegenden Exemplaren wohl etwas verengt, aber breit offell.

$$
\text { Nusa cyrtophora } 11 . \text { sp. }
$$

Ein einzelnes or aus Minas Geraes (Brasilien) ex coll. Hermann. Aus der nächsten Verwandtschaft mit $N$. pyrrhacra Wied., aber von ihr nicht nur durch Färbungsdifferenzen, sondern vor allem dureh den Bau des $\sigma^{-T}$ Genitals verschieden.

Kopf. Untergesicht seitlich mit dichter weifslicher Bestäubung mul Beharung. In einer von der Fiihlerwurzel zum Mundrande reichenden Mittelstrieme liegt jedoch die schwarze Grundfarbe frei. Knebelbart schwarz. Stirue und Hinterhaupt hellgrau bestäubt, jene mit weifslicher, dieses in 
den oberen Partien mit schwarzer Behaarung. Borstenkranz und Ocellarborsten ebenfalls schwarz. Nach abwärts nimmt die Hinterhauptsbehaarnng alhuählich hellere Fäibung an und geht in den sehr dichten, buschigen, weilsen Backenbart iiber. Riissel und 'l'aster schwarz, gläuzend mit dichter weifslicher Behaarung. Die beiden Basalglieder der Fïhler schwarz, glänzend, las keulenförnigge dritte Glied an seiner W'nrzel rot, im übrigen dureh helle Bestiubung matt. Die Behaarmng des ersten Gliedes ist weifslich, die einzelne Borste an seiner Unterseite schwarz, das zweite Glied trägt ausschliefslich schwarze Beborstung.

'Thorax mit der gewöhnlichen braumen Striemenzeichnung und gelbgrau bestäubten Interstitien. Die Mittelstrieme ist durch eine breite, bestäubte Mittellinie geteilt und hängt vor dem Schildchen mit der aus zwei grofsen Flecken bestehenden Mittelstrieme zusammen. Auch die Schulterbeulen sind dunkelbraun. Die relativ recht lauge Behaarung dès 'Thoraxriickens besteht aus vorwiegend sclıwarzen Borstenharen, die jedoch ausschliefslich die gran bestïnbten Stellen des Thorax cinnehmen nnd daher eine exquisit reihenförmige Anordnung zeigen. Nansentlich die prïiscutellaren Borstenliaare fallen durcl besondere Länge auf. Die kräftig entwickelten präsuturalen, supraalaren und postalaren Borsten ausnahmslos schwarz, ebenso die Randborsten des an seiner Basis grau bestäubten, schwarz behaarten Schildchens. Pleuren weifslich bestäubt mit ebenfalls zienlich langer weifser Beluarung; die Notoplenralborste jedoch, sowic einige Borstenhare in deren Umgcbung schwarz. Der weicsliche Metaplenralschirm vor den braunen Schwingern besitzt oben auch einige Hare von schwarzer Farbe.

An dem ziemlich schmalen Abdomen sind die ersten fünf Segmente sehwarz, das sechste und sicbente rot, die Genitalsegmente wiederum schwarz. Das erste Sigment ist an seiuer vorderen Hälfte weifslich bestäubt, die vicl folgenden Segmente besitzen von weilser Bestänhung gebildete Vorderrandsbinlen, die ungefähr $1 / 3$ — $1 / 4$ der Segmentläinge einnehmen. Die sehr lichte, anliegende Behaarung auf der Riiekenfläche del beiden ersten Segmente ist teils weifs, tcils schwar\%, anf den folgenden alusschliefslich schwarz; die Seitenbehaarung selır lang nud dicht, an ten irei ersten Segmenten weifs, auf dem vierten und tînften Segment schwarz. Die gleiche Farbe besitzen aluch die Seitenborsten des ersten, sowic lie Discalborsten des zweiten und 
dritten Segmentes. Auch die Beborstung der an ihrer Riickenfliche mit anliegender roter Behaarung versehenen roten Segmente ist schwarz. 1)as siebente Segment zeigt an seinem Hinterrande eine unbehaarte Depression von dreieckiger Gestalt, deren Rïnder von langen, roten Borstenhaaren besetzt sind. Das glänzend schwarze Hypolygium trigt vorwiegend schwarze, lange Beborstung, in der Kluft zwisehen den Zangen jedoeh, sowic an deren oberen Ecken fallen Biischel eigentumlich reusenartig angeordneter Borstenhare von fast goldgelber Farbe sehr in die Augen (T'extfig. 84). Der Bauch träigt lange, abstehende weifsliche Behaarmig.

Beine. Huiften grau bereift mit dichter, weifslicher Behaarung. An den gliinzend

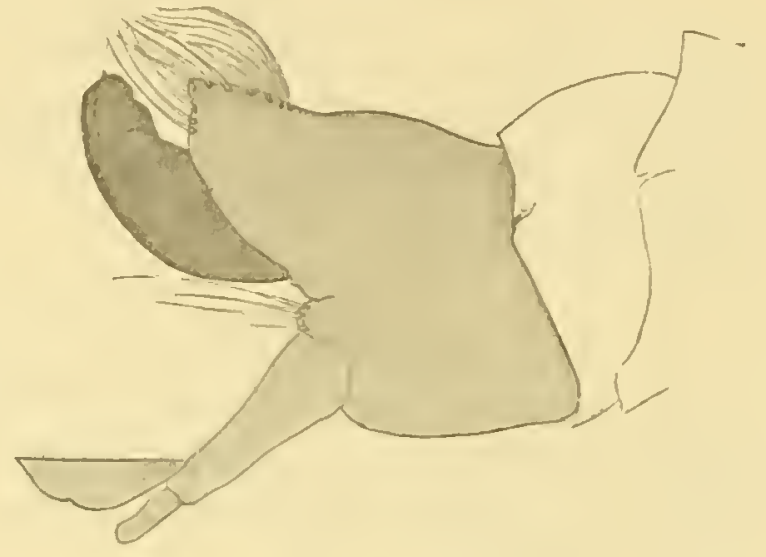

Fig. 84. schwarzen Beinen fällt die iiberans lange und dichte, vorwiegend weifsliche Beharmg, welche die vorderen Beinpare besitzen, sehr auf. An den Hinterbeinen sind die derben Borsten der Kniegegend, die lange Behaarung an der Unterseite der Obersehenkel und der Hinterseite der Schienen schwarz. Die Tarsen sind im allgemeinen sehwarz behaart und beborstet, an den Vorder- und Mittelbeinen jedoch an der Unterseite mit bïrstenartiger Behararung von kastanienbrauner Farbe besetzt. Klanen schwarz, Pulvillen bleichgelb.

An den Flügeln ist die Spitzenhälfte schwärzlich getriibt. An den distalen Rande der Discoidalzelle, in der geschlossenen und gestielten ersten Hinterrandzelle, sowie in der Submarginalzelle finden sich hyaline Streifen. Die Adern sind an der Spitzenhälfte sämtlich schmal braun gesiämnt.

Long. corp. $17 \mathrm{~mm}$, long. alar. $13 \mathrm{~mm}$. 


\section{Nusa olbus Wlk. \\ Laphria olbus Wlk.}

Dreifsig Exemplare ex eoll. Sehnuse aus Bolivia - Mapiri (Sarampioni $700 \mathrm{~m}$ und S. Ernesto $800 \mathrm{~m}$ ii. d. M.), ein or $q$ ex coll. Hermann aus Peru.

Auch diese Laphin mufs nach ilhren ganzen plastischen Merkmalen fiir das Genus Nusa reklamiert werden und stellt die grölste bisher aus Amerika bekannt gewordene Nusaspecies dar. Im ubbrigen geniigen die von Walker und von Macquart gegebenen lieschreibungen vollständig zur Erkennung der Art.

\section{Nusa abdominalis Brown.}

Von dieser auch in Mittelamerika (Cuba) vorkommenden Art, die sieh durch ihre vollstïndig glashellen Flitgel und durchaus gelbrot gefiiibten Beine olne weiteres erkennen läfst, besitze ich ein einzelnes $f$ aus Arizona in meiner Sammlung.

\section{Nusa pygophora Schiner or.}

Die Art, die mir in der aus Venezuela stammenden 'Type vorliegt, ist nach der Beschreibung Schiners nicht zu verkenmen; es geniigt vor allem der Hinweis anf die kenlförmige Verdiekung der Hinterschenkel und Hinterschienen, sowie die zierlich bunte Flitgelzeichnung ('T'ıf. Fig. 63), um die Species anf den ersten likick von den iibrigen Nusaarten zu trennen. Dagegen mufs die Bemerkung Schiners iiber den Ball des Genitals - ganz frei stehend, gestielt - mit einiger Reserve aufgefarst werlen; die Untersuchung der Tyle läfst meines Ermessens ohne weiteres erkennen, dafs das Genitalsegment lediglich durch eine zufällige Verletzung in seiner Verbindung mit dem letzten Tergiten gelockert ist.

\section{Nusa xunthocnema. Wied. or t.}

Die Type Wiedemanns in dem Senckenbergsehen Museum ist anselheinent verloren gegangen. Es liegen mir von dieser durch gewisse plastische Herkmale leieht kenntlichen Art vor: sechs Exemplare beiderlei 
Geschlechts im k. k. Hofmuseun Wien aus Brasilien, ein or (Brasilien), ein $q$ (Paraguay) ex coll. Hermann, ein $q$ (Peru) ex coll. Schunse. Simtliche Stiicke stimmen unter sieh mul mit der Besehreibung W iedemanns gut iiberein, sodafs, namentlich nnter Beriicksichtigung nachstehender Angaben die Artbegrenzung keine Schwierigkeit bietet.

Kopf. Das schwarze Gesicht ist breiter als bei den iilorigen Arten, entbehrt eines Gesichtshöckers vollkommen, sondern ist viehnehr in toto vorgewölbt. Seitlich und unter den Fiihlern ist das Gesicht grelblich bestïubt und weils behaart. Besonders eigentiumlich ist die 'Textur des Knebelbartes; derselbe besteht nämlich aus antfałlend kurzen, starren, sehwarzen Borsten, denen nur oben feinere weilsliche Haare beigemengt sind. Stime gelblich bestïubt mul hehaart, Ocellarborsten schwarz. Das grau bestiubte Hinterhaupt ist in seiner oberen Hiilfte schwarz hehan't und beborstet, Backenbart, Behaarung der Backen, der Kinmgerrend und der Wurzel des Riissels wcilslich. Die spitze des letzteren fuchsrot, die Taster schwarz behaurt. Die Basalglieder der Fiihler sind schwarz hehart, nur das erste Glied trïgt an seiner Unterseite anfser ciner starken schwarzen Borste weilsliche Haare.

Die Grundfarbe des Thorax ist im allgemeinen ein mehr oder minder diisteres Rotbraun; die Sehulterecken, sowie die in zwei grolse Makeln getrennte Seitenstrieme ist schwarz. Weifse bis gelbe Bestaubung, die sich an der ganzen Cireumferenz und auf ler Riickentläche des Thorax ausbreitet, erzeugt eine namentlich bei grut erhaltenen Stiicken sehr lebhafte Striemen- und Fleckenzeichnung und liifst anch die Mittelstrieme breit geteilt erscheinen. Die abstehende schwarze Behaarung des Mesonotum gewinnt vor dem Schildchen grölsere Länge und Dichtigheit. In der Mitte des Vorderrandes befindet sich eine Flocke längerer gelblichweifser Hare. Randborsten ausschlicfslich schwarz. Pleuren gleichmïlsig weilsgrau bestäubt und relativ dicht behaart. Notopleuralborste und eine Gruppe lingerer Haare in deren Umgebung sehwarz; Metaplenralschirm ausschliefslich weifs. Das dunkelbraune, schwarz behaarte und beborstete Schildchen zeigt zwei durch gelbe Bestäubung gebildete basale Makeln. l)as dunkelbraune, mit graugelber diinner Bestiiubung versehene Mesonotmm entbehrt der Behaarung vollständig. Hiiften gran bestaiubt und weifs behaart. 
Abdomen lebhaft rotbraun, das erste, vierte und fiinfte Segment seitlich in gröfserer oder geringerer Ausdehnung geschwärzt, das sechste und siebente Segment sowie die Genitalien rotgelb. Die kurze anliegende Behaarung ist auf dem sechsten und siebenten Segmente und auf den Genitalien ausschliefslich rotgelb, aufserden erstreckt sich diese rotgelbe Behaarung als mehr oder minder breite Mittelstrecke bis zum ersten Segmente nach vorwärts, wïhrend im übrigen die fiuf ersten Segmente schwarz behaart sind. Die längere Seitenbehaarumg ist im wesentlichen weifslich. die Discalborsten schwarz. Bauch gleichnäfsig rot mit lichter Behaarung.

Beine schwarz, die Schienen in grofser Ausdehnung rot. Die Behaarung der Oberschenkel ist an den vorderen beiden Beinpaaren vorwicgend weifslieh und an der Unterseite recht lang; an den Hinterschenkeln privaliert auch an der Unterseite schwarze Behaarung. Die Vorder- und Mittelsehienen tragen an ihrer Vorderseite und an iler Spitze schwarze Borstenhaare, sind aber im iibrigen mit langer, an der Aufsenseite fahnenartig angeordneter gelblichweifser Behaarung versehen; an den Hintersehienen sind die sehwarzen Haare rejehlieher, an der basalen Hälfte findet sich vor allem an der Innenseite sehr dichte, fast silberschimmernde Behaarung. 'T'arsen aussehliefslich schwarz behaart und beborstet, deren rotbraune biirstenförmige Behaarung fällt nur wenig anf und ist auch an den Torderschienen nur auf die äufserste Spitze beschränkt. Klauen schwarz. Pulvillen gelb.

Fliigel hyalin mit auffallender schwarzer, binden- und fleckenartiger Zcichnung. Die erste Hinterandzelle ist bei allen Fxemplaren geschlossen und gestielt. An dem vorderen Gabelaste rler Cubitalader findet sich konstant ein mehr oder minder entwickeltes Aderrudiment.

Die Zugehörigkeit des $\%$ unterliegt keinem Zweifel, da die Unterschiede gegeniiber dem or nur geringe sind. Die namentlich an den Schienen kürzere lichte Behaarung ist bei dem $q$ rein weifs. Bemerken möchte ich noch, dafs bei dem einen, tadellos konservierten Exemplare die rote Grundfarbe des Abdomen an den vorderen Segmenten untel leichter, gelblicher Bestäubung verschwindet. 
Nusa rufiventris Blanchard o?.

Die Beschreibung Blanchards geniigt wohl zur Erkennung der Art, die ich in einem or ans Chile vor mir habe; da jedoch eine nahe rerwandte Species konkurriert, sollen folgende ausführlichere Angaben gemacht werden.

Kopf. Das nur wenig bestäubte Gesicht trägt auffallend dichte Beharung, die in den oberen Partien schwarz, nach unten weislich ist. Dem ebenfalls dichten, schwarzen Knebelbart sind am Mundrande weifsliche Haare beigemengt. Auch die grauliche Bchaarung der Stirne und des Scheitels ist recht dicht und namentlich macht sich am medialen Angenrande ein Büschel stattlicher schwarzer Borstenhaare bemerklich. Der Ocellenhöcker trïgt aufser den beiden schwarzen Borsten büschelfürmige graue lehaarnng. Die dichte, im wesentlichen schwarze Behaarung des Hinterhauptes s:ïumt diinner werlend den ganzen hinteren Orbitalrand, aber auch hinter dem buschigen weifsen Backenbarte stehen neben dem Kinne noch einige schwarze Borsten. Die Behaarung des letzteren, des Fiissels und der Taster ist weils. Die schwarzbraunen Fühler sind an der Aulsenseite des ersten Segmentes weifslieh, im iibrigen schwarz behaart und beborstet.

Thorax. Auf dem schwarzen Mesonotum findet sich unr in geringer Ansdehnung weifsgrame Bestäubung, so dafs die iibliche Striemen- und Fleckenzeichnung nur andeutungsweise hervortritt. Die kurze, abstehende Behaarung sowie die Randbeborstung ist durchaus schwarz. Schildchen glänzend schwarz und ebenso lebaart und beborstet. Auch die schwarzen Pleuren tragen nur ganz diinne, grauweifse Bestïubung und stellenweise lichtere Behaarung. Vor der Notopleuralnaht findet sich ein Biischel langer, vorwiegend schwarzer Haare, anch die Notopleuralborste schwarz. Metapleuralschirm in der oberen Hälfte schwarz, in der unteren weils. Das schwarze Metanotum trä̀nt seitlich eine graubestïubte Makel, entbehrt aber der Behaarmug.

Das Abdomen ist mit Ausnahme des ersten schwarz gefirbten und behaarten Segmentes durchans lebhaft gelbrot und nit gleichfarbiger kurzer. anliegender Behaarung bedeckt. Auch die Discalborsten sind rot. Das 
verhältnismifsig kleine, einfach gebaute Hypoprgium ist mit langen grelben Borstenharen besetzt. Behaarung des Banchẹs weifslich.

An den schwarzen Beinen ist die basale Hälfte der Sehienen an den beiden vorderen Beinpaaren lebhaft rot gefïrbt und anch die Hinterschienen tragen an ihrer Wurzel eine kleine rotbraune Iakel. Die an der Unterseite sehr lange und dichte Behaarung ist an den Vorder- nnd Mittelschenkeln weifs, die Schienen sind an den Vorderbeinen vorwiegend schwar\%, an den Mittelbeinen weifs behaart und beborstet. Dic Hinterbeine tragen ansschliefslich schwarze Behaarung und Beborstung, und nur in der Umgebung der linie finden sich kürzere weilse Haare. Tarsen durchaus schwa\% behaart un] lang beborstet. Biirstenförmige Behaarung von gelbroter Farbe macht sich nur an den Tordertarsen bemerkbar und nimmt auch den urörsten Teil der Innenfliche der Vorderschienen ein. Klauen schwarz, l'ulvillen gelb.

An ten Flügeln ist das Wurzeldrittel glashell, die iibrige Fläche ziemlich intensiv rauchgrau gefärbt. Adern dunkelbraun, erste Hinterrandzelle breit offen.

\section{Nusa calogastra Philipui o.}

Die ebenfalls chilenische Philippische Speeies stelit offenbar der N. rufuentris Bl. ungemein nahe. Da ich von dieser nur ein einzelnes $\sigma^{7}$, von Spec. calogastra nur ein $q$ ror mir habe, wäre vielleicht die Vermutung nicht ganz von der Hand zu weisen, dafs die beiden Arten zusammengehören, allein ich möchte doch für die Selbständigkeit beider plaidieren, da sich Spec. calogastra nieht blofs durch Färbungsdifferenzen, sondern auch durch gewisse plastische Merkmale von 1 . ruficentris unterscheiden lïst. Ieh begniige mich. auf liese Unterschiede aufmerksam zu machen.

Das Gesicht ist mit diclter gelber Bestiubung bedeckt, dagegen ist die allenthalben gelbliche Beharung wenig dicht, namentlich fehlen unter der Fuihlerwurzel die langen Haare vollstïndig. Auch Stirne und Seheitel besitzen nur geringe Behaarung, der Ocellarhïeker ist nur mit den beiden gewöhnlichen Borsten bewehrt, und das graubestaubte Hinterhaupt ist oben nur mit relativ vereinzelten schwarzen Borstenhaaren, weiter abwärts mit 
kurzen gelblichen Härchen besetzt, die in den ebenfalls wenig dichten Backenbart iibergehen. Die schwarzen 'Taster sind schwarz beborstet, anch die Fubler tragen durchaus schwarze Behaarung. Iiscalborsten der $\mathrm{Ab}$ dominalsegmente schwarz. Beine einfarbig schwarz, die Behaarung sämtlicher Oberschenkel weifs, die Schienen sind gelblich behaart, an ilırer Aufsenseite mit sehwarzen Borsten besetzt. An den Vorderschienen befinden sich nur einige rostgelbe Borsten. Die scliwarz beborsteten 'l'arsen sind gelblich behaart. Biirstenförmige messingrgelbe Behaarung findet sich an der Unterseite sämtlicher Tarsen und aufserdem auf der Innenseite der Torderschienen und der Schienenspitze der Hinterbeine. Die F'ügel sind auf der Spitzenhälfte leicht braun tingiert, die rotbrannen Adern zum gröfsten Teile mit schwachen dunkleren Adersiumen versehen.

$$
\text { Nusa sarcophaga n. sp. \&. }
$$

Zwei $q$ ex coll. Schnuse aus Peru (Pachiteamiundung, 150 m ii. d. M.), ein $q$ ex coll. Hermann aus Peru (Villanota).

Die Art erinnert in der Firbung und ilurem etwas gedrungenen Bau lebhaft an eine unserer gröfseren Sarcophagaarten.

Die Grundfarbe des Kopfes ist schwarz. An dem Untergesicht läfst lehmgelbe Bestäubung die Grundfarbe in einer von der Fiihlerwurzel bis zum Munde reicheuden, breiten Mittelstrieme frei. Dic dichte Behaarung des Untergesichts ist weifslich, dem schwarzen Knebelbart sind gegen den Mundrand gelbe Borsten beigemengt. Stirne und Hinterhaupt mit fast messinggelber Bestäubung, die Ocellarborsten und die Borsten des Hinterhauptes rostgelb, die Behaalung gelb. Backenbart weilslich. Taster und liiissel dunkel pechbraun, beide mit schwarzer Behaarung. Fiihler braun, das erste Glied ist gelb behart und trägt anf seiner Unterseite eine derbe Borste von rostgelber Farbe, das zweite Glied ist schwarz behart und beborstet.

'Thorax und Schildchen mit bleich messinggelber Bestaubung bedeckt, von der sich die in einzelne Flecken zerlegte Seitenstrieme, sowie die breite, durch eine helle Bestäubungslinie median geteilte Mittelstrieme braun abheben. Schulterbenlen schwarz, die Gegend des Postalarhöckers 
diister rotbraun. Metanotum brann, durch Bestiubung matt und jederseits mit einem Bestiubungstleck ron bleiehmessingerelber Farbe verziert. Die kurze abstehende Behaarmo' des Thoraxrïckens ist im allgemeinen fahlgelb, jedoch lommen an dem Seitenrande, sowie auf den hinteren Partien auch schwarze Haare vor. Die liugere Behan'ung der Schulterbenlen ist ausschliefslich schwarz. Die präalaren, supraalaren und postalaren starken, sowie die feineren prisentellaren Borsten nud die Randborsten des Schildehens sind durehaus schwarz. Pleuren allenthalben fabl messinggelb bestäubt, die braune Grundfarbe tritt nur in einer unter der Sclulterbenle anf der Mesopleura gelegenen Makel zutage. Die Notopleuralborste schwarz; dagegen ist der Metapleuralschirm vor den lichtbramen Schwingern gelb.

Auf dem sehwarz gefürbten Abdomen breitet sich graugelbe bis hellmessingrgelbe Bestainbung bindenartig aus. Das erste Segment ist nur an den änfsersten Seiten leicht bestäubt, anf dem zweiten Segment bildet die Bestäubung eine in der Mitte hreit unterbrochene Hinterrandsbinde, anf dem dritten und vierten Segment bedeckt die Bestïubung den ganzen Hinterraud und breitet sich anch auf den Vorderrand der Ringe aus, so dafs die schwarze Grundfarbe nur mehr in Form oblonger Querflecken sichtbar bleibt, die folgenden Segmente fast vïllig von messinggelber Bestäubung bedeckt, so dals nur mehr kleine schwarze Hinterrandtlecken iibrig bleiben. Die anliegende, ziemlich dichte Behaarung ist durehans gelblich, nur an den Seiten des ersten Segmentes mischen sich anch einige längere schwarze Hitrchen bei. Hier finden sich auch zwei derbe Borsten, die ebenso wie die Discalborste des zweiten, dritten und vierten Segmentes rot sind. Achtes Segment und Legeriblire glïnzend rostrot mit einigen langen hellen Borsten. Banch schwarz, zicmlich gleichmilisig grau bestiubt und mit zerstrenter heller Behaarung versehen. Hiiften grau mit weifslicher Behaarumg.

Beine schwarz, ziemlich stark glïnzend, allenthalben mit fahlgelber Behatrung, die an den Torderbeinen besonders dicht ist. Die vereinzelten Borsten an der Spitze der Oberschenkel sind gelb, an den Hinterschenkeln lebhaft rot. Die Beborstung der Sehienen ist gelb. Die 'Tarsen sind an ihrer Unterseite mit leblaft goldgelber biirstenartiger Behasung versehen und mit schwarzen und gelben Borsten bewehrt. Klanen schwarz, Pulvillen hellgulb. 
Flïgel hyalin, an der Spitze mit leicht graner Trübung, die sich auch in das distale Ente der Discoidal-, der vierten Hinterrands- und der Analzelle erstreckt. Ein zweiter graner Wisch liegt in der proximalen Ecke der Discoidalzelle und siiumt die Begrenzmng der hinteren Basalzelle. Die Adern sind an der Fliigelwnrzel rotbrann, im iibrigen dunkel. Die subcostalader und die Hilfsader behalten die rotbraune Färbung anf eine lange Strecke ihres Verlaufes bei. Erste Hinterrandzelle breit offen.

Long. corp. $13 \mathrm{~mm}$, long. alar. $11 \mathrm{~mm}$.

Anm. Das zweite Exemplar ex coll. Schnuse ist etwas kleiner und dunkler, die gelbe Bestiubung des Abdomen ist weniger ausgedehnt und bildet an allen Segmenten gleichbreite Hinterranlbinden, die Borsten sind dunkler, die Oeellarborsten rein schwarz.

\section{Nusa pyrracra Wied.}

Von dieser Art liegt mir die freilich nicht mehr gut erhaltene Type ans dem Senekenbergschen Museum vor; trotzdem bin ich iiber die Artbegrenzung keineswegs sicher. Fine rergleichende Untersuchung mit Spee. erythropyga Wied. hat nur soviel ergeben, dafs bei spec. pyrthacre die Behaarung ler oberen Gesichtspartien, der Stirn und des Scheitels eine etwas diclitere ist und dals namentlich der innere Orbitalrand ron einer Reihe gleichlanger Borstenhare gesïnmt ist. Unter Bericksiclitig"ung dieses Umstandes habe ich fünf Exemplare (ein of vier $q$ ) alls dem k. k. Hofmusemm iu Wien und drei Stiicke (ein $\sigma^{\top}$ zwei $f$ ) meiner Sammlung - alle ans Brasilien - zu der Spec. mymucre gestellt; es hat sich Ilabei ergeben, dafs die beiden ot im Bau des Hypopyginm zusammenstimmen, dafs sie sich aber hierin von dem ơ der Spec. erythropyya unterscheiden.

\section{Nusa crythropyga Wied.}

Aurh hier habe ich die Type aus dem Senckenbergschen DLuseum untersuchen künnen. Ob sich die Angabe Wiedemanns, dafs die weilsbehaarten Seitentlecken auf dem zweiten Ablominalsegmente bindenartig zusammenlängen, festhalten lïlst, kann fiiglich bezweifelt werden. ebenso 
bedarf die weitere Angabe, dafs anf dem zweiten und dritten Segmente auch dic Grundfarbe cincn weifsen Querfleeken besitze, insofern eine Korrektur, als auch bei dieser wie bei allen konkurrierenden Species die Fleckenzeichnung lediglich auf weilse Bestäubung zuriickzufiihren ist. Dagegen möchte ich bemerken, dafs dic Stirne an Orbitalrande aufser kiirzerer Behaarung eine einzelne, sehr derbe schwarze Borste trägt. Über den Ban des or Genitales kamn ich keine Auskumft

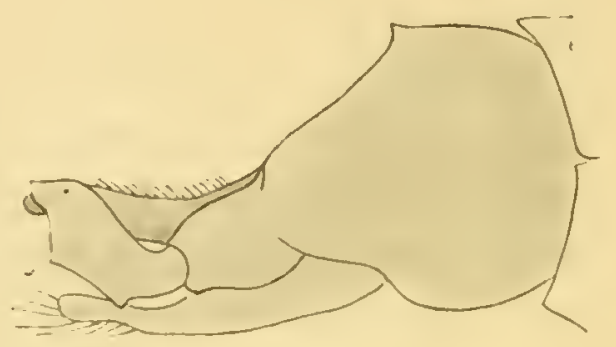

Fig. 85. geben, da dasselbe bei der Type zerstört ist. Mit einem grofsen Fragezeichen habe ich zwei of und ein $\sigma^{\top}$, dessen Hypopygium anf beistehender Fig. 85 abgebildet ist, aus dem k. k. Hofmuseum zu der Spec. crythropyga gestellt.

Jedenfalls bin ich zur Zeit aufser Stande, die beiden speeies, die sich, um das nochmals zu betonen, von den ihnen iiberaus ähnlichen Arten myrhopyga und cyrtophora durch das kahle lletanotum hestimmt genng unterscheiden, unit einigermafsen befriedigender Schärfe von einander zu trennen.

Zu der Gruppe mywhopyga - cyptophora einer-, erythopyga - pywhacra andererseits diiften noch zu zählen sein die Species:

fulciecula say., rinerea und circumdate Bellardi, pilipes Macquart, sexpunctata und marginalis Williston, die schon deswegen, weil ich die Tyjen nicht mutersuchen komnte, hier weitere Beriicksichtigung nieht finlen kömnen. Aber abgesehen davon wird nur eine Untersuchung gröfserer lieihen mit genanen Fundortsangaben im Stande sein, diejenigen versehiedenen Nusaarten, an deren sehwarzem Abdomen die Aftersegmente rot gefärbt sind, eventuell rou einander zu trennen.

Auch ïber die Sifece. mesoxantha IV ied. komte ich mir keine Ḱlarheit verschaffen, da lie Type des Senckenbergschen Musemus anscheinend verloren gegangen ist. Die Willistonschen Arten chablyeu aus S. Domingo und rubila aus Mexi॰o, welch letztere ich einem einzelnen Stiick des k. k. Hofunseums in I"ien vor mir zu haben glaube, scheinen mir herechtigt zu sein. 


\section{Pogonosomer, Rondani.}

Ieh habe schon oben angedeutet, dafs ich las Genus Pogonosoma keineswegs als eine besonters glückliche Schüpfung Rondanis ansehen kann. Untersucht man nümlich irgend eine einschlägige Art, z. B. unsere allbekannte Spec. maroccanum, etwas genauer, so wirl man anch nicht die greringste Verschiedenheit gegeniiber dem Geuns Nusa festzustellen vermïgen: im Bau des Kopfes, les Riissels, der Taster und der Fühler, in der Beschaffenheit des Kürpers und der Genitalien, in den Beborstungsverhältnissen, kurz nach jeder Richtung stossen wir auf die gleichen plastischen Herkmale, lie uns dureh die Lintersuchung der Nusarten genugsam bekannt geworden sind. Die einzige Differenz bietet das Fliigelgeitler insofern, als die erste Submarginalzelle dureh eine Querader zweigeteilt ist. Seit wir aber z. B. durch die Untersuchungen Th. Beckers iiber das Asilinengenus Apoclea wissen, dafs das Yorhandensein von zwei oder drei Sulumarginalzellen wenigstens bei den Asiliden - für die Feststellung der Gattung keine irgendwie massgebende Bellentung besitzt, werden wir anch der trennenden Querader allein fïr die Differenzierung von Nusa und Pugonosoma keinerlei diagnostischen Wert beimessen diirfen, umso weniger, als wir ja bei gewissen Nusaarten ein mehr oder minder entwickeltes Aderruliment an der vorderen Zinke ler Cubitalader antrafen. Nun soll ja nicht geleugnet werden, dafs die Spec. maroccunum durch ihre etwas aberranten Behaarungsverhältnisse im Habitus nielit so ganz einer echten und rechten Nusa entspricht; sie verbïlt sich in :ihnlicher Weise etwa wie Nusa atra L. zu ihren Gattungsgenossen. Betrachtet man dagegen etwa unsere paläarktische Species Pogonosoma unicolor. Lw, oder die nearktische Art dorsutum, oder eine beliebige indomalarische Species, so wird man neben den besouderen Merkmalen auch den Allgemeinlabitus der Nusaarten auf len ersten Blick zu erkennen rermügen. Wenn ich gleichwohl hier wenigstens den Xamen Pogonosoma noch festgehalten habe, so geschieht dies weit eher aus einer gewissen historischen Pietiit, als dafs ich von der Existenzberechtignng des Rondanischen Genus irgendwie iiberzeugt wïre.

Südamerikanische hierher gehörige Arten sind meines Wissens bislang nicht beschrieben, und auch in Norlamerika sind nur die beiden Species 
ararhnoides Big. und doratum Sar. bekannt geworden, Die in den verschiedenen Katalogen bei Pogonosoma untergebrachte Wiedemannsche Laphria melanoptera soll teste Bigot die die erste Submarginalzelle tremmende Querader iiberhaupt nicht besitzen.

\section{Noophomens Williston.}

Das Gems Phoneus (nomen praeoce.) wurde von Macquart auf folgende Merkmale begriindet: "trompe munie d'une grande touffe de soies vers le milien en-dessous; ahdomen q terminé par un long oviductus. pieds fen velus, cuisses postérienres non renftées, jambes droites, quatrième cellule postèrieure des ailes beauconp plus courte que la discoidale". Nach meinen Erfahrungen gehört nun das Genus Neophoneus offenbar in die alleruächste Verwandtschaft ven Tusa und ich kann mich eigentlich nur mit gewissen Bedenken zu einer generischen Abtrenmung entschliefsen. Die Angaben, die Macquart iiber den Bau der Beine macht, können schon von vorneherein als wertlos betrachtet werden, dasselbe gilt aber anch für die relative Kürze der vierten Hinterrandzelle gegenuiber der Discoidalzelle. Denn diese Kiirze treffen wir nicht nur bei allen Nusaarten, sondern auch bei verschiedenen, anch paläarktischen Species des Genus Laphria str. s. an: richtig ist ja wohl, dafs bei Neophoneus die Länge der vierten Hinterrandzelle nur ungefähr $3 / 5$ derjenigen der Discoidalzelle entspricht. Anch die Angaben Macquarts iiber die Legeröhre diirfen nur mit grol'ser Reserve anfgenommen werden. Denı abgesehen davon, dals anch bei gewissen schlankeren Nusaarten der siidamerikanischen Fama die Legeröhre eine gewisse Verlängerung erkennen läfst, cntspricht lie hetreffende Angahe Nacquarts nicht eimmal der Wahrheit. Wie die Zeichmmg auf der Mac qu u rtschen 'Tafel 7 Fig. 5 (Diptires exotịnes, vol. I, 2) und die Untersuchung des mir vorliegenden Materials erkennen lassen, handelt es sich nämlich nicht sowohl um eine Verliingerung der Legerïhre, als vichehr darmm, dals das ganze hintere Einde des Abdomen rom fïnften Segmente an eine gewisse Verjiingung erfülurt. lis bleibt also nur als cinziges Charakteristikum die eigentiimliche biischelförmige Behaarmng auf der 
Oberseite des Riissels iibrig; diese ist tatsïehlich vorhanden und auf Maequarts Fig. 5 a, so roh diese auch ausgefihrt ist, in richtiger Weise dargestellt. Im iibrigen aber finde ich im Bau des Kopfes, der Taster, der Fiihler, in der Behaarung und Beborstnng des Förpers und der Beine. im Verhalten des Fliigelgeïlers anch nieht den geringsten Unterschied zwischen Nusa und Neophoneus; denn auch das Torhandensein eines Aderanhanges an der Gabel der Cubitalader, das Schiner in seiner bekannten Bestimmungstabelle für die Charakterisierung des Genus verwendet, kann ernsterer líritik nicht Stand halten. Legt man der Büsschelbehaarung des Riissels besonderen Wert bei, so mag immerhin das Macquartsehe Genus Neophoneus als solehes bestehen bleiben.

Zu Neophoneus gehören anfser der typischen Art Serrillei aus Brasilien die Speeies favotibia Bigot. (Annal. Soc. Fint. de France, ser. V. VIII. p. 239) ans Haiti und Laphrie Amandus Walker (List. dipt. Brit. M[ns. II. 11. 27:3) ans Brasilien. Zwei weibliche, ans Surinam stammende Sticke meiner eigenen Sammlung sowie ein ơ (Kio Grande do Sul) aus dem k. k. Hofmusenm Wien hassen sich mit keiner der drei Besehreibungen restlos in Übereinstimmung bringen, so dafs ich sie als

\section{Neophoneus mustela n. sp. or $q$.}

besehreibe, wobei ich freilich die Frage, ob es sich nicht doch mur um eine Varietät der Macyuartschen Art handeln möchte. einstweilen offen lassen mufs, da mir die Untersuchung der Typen nicht möglich war.

Kopf schwarz, glänzend. An dem Gesicht lidlst die weifsliche Bestäubung die Grundfarbe nur in Form einer breiten Mittelstrieme frei, der Knebelbart ist schwarz mit untermischten weilsen Haaren. Auch am Mundrande, sowie an den Seitenteilen des Gesichts ist die Behaarung weils. Stime und Scheitel tragen graue Bestïubung und seitlich weifsliche Behaarung, die beiden Ocellarborsten sind jedoch schwarz. Das grau bestäubte Hinterhaupt besitzt im wesentlichen weirsliche, lange Behaarung. der nur einige wenige schwarze Borsten heigemengt sind; ein eigentlicher Borstenkranz felılt, der Backenbart ist weifs. Der schwarze Rüissel ist an seiner I'urzel mit teils schwarzen Borsten, teils weilslichen Haaren beset\%t und trïgot auserdem auf seiner Oberseite ein anffallendes Büschel sehwarzer Borsten. 
'T'aster schwar' und schwar' behart. Fiihler braun, das erste Segment ungefith $1 \frac{1}{2}$ mal so lang als das an seiner Spitze gelblich gesiumte zweite Segment. Das erste Segment weifslich behaart mit ein oder zwei schwarzen derben Borsten an seiner Unterseite, das zweite Segment ansschliceslich schwarz beborstet.

Thorax rothraun mit granweifser Bestäubung und schwarzer Striemenzeichmung. Die Mittelstrieme ist breit geteilt und erreicht das Schildchen nicht, ebenso hört die an der Quernaht geteilte Seitenstrieme schon vor diesem anf. Schulterbeulen ebenfalls dunkelbraun. Die zarte zerstreute Behaarung des Mesonotmm ist vorne weifslich, nach riickwärts durchans schwarz, ebenso die starken Borsten am seitlichen Rande. Metanotum und Schildchen dïster rotbraun, jenes mit einigen sehr zarten weifslichen Härchen, dieses mit schwarzen Randborsten. Pleuren rotbrann mit verwaschener, dunklerer Zeichnung, gran bestiubt und zart weifslich behaart. Notopleuralborste schwarz, schwach, der Haarschirm vor den hellbrannen Schwingern gelb mit vereinzelten schwarzen Borstenhaaren. Hüften dunkel rotbraun mit graner Bestïubung und lichter Beharung.

Abdomen lebhaft rot und mälsig gliinzend. Erstes Segment an den Seiten schwarzbrann, ebenso sind das zweite, dritte, vierte und fiinfte

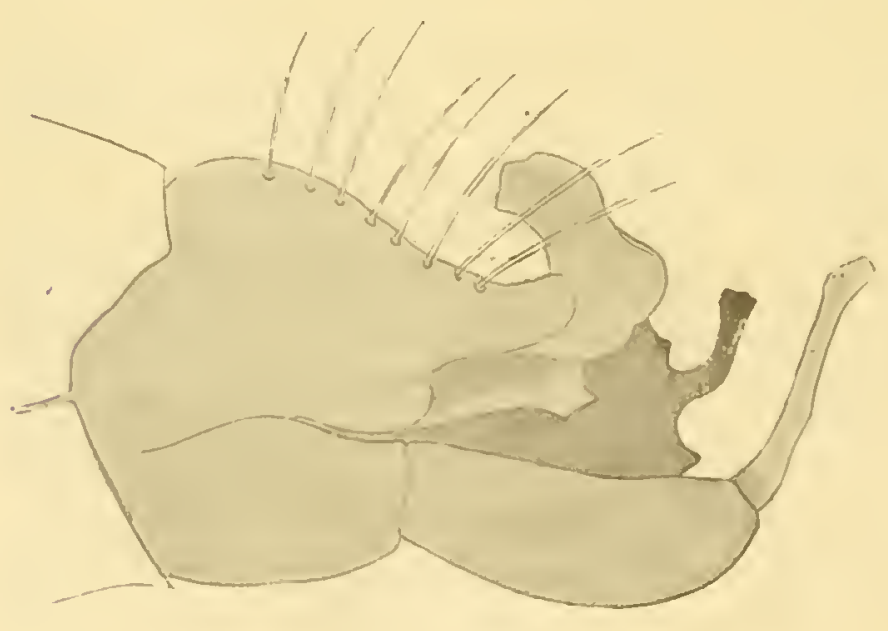

Fig. 86. Segment seitlich durch lreieckige schwarze Makehn, die die ganze Höhe der Segmente einnehmen, zackig gesïmmt. Die kmrze anliegende Behaarung ist rot, nur iiber den schwarz gezeichneten Flecken samt den Discalborsten schwarz. Das erste und der vordere Rand des zweiten Seginentes sind seitlich mit etwas lïngerer, rorwiegend weifslicher, die Genitalsegmente ('Textfig. 86) mit gelber Beborstung verselıen. Bauch lebhaft gelbrot, glïnzend, 
mit sehr zarter Behaarnug, die an den vorderen Segmenten weirs, auf dem fiinften und sechsten Segmente jedoch schwarz ist.

Beine dunkelpechbraun, ziemlich stark grinzend, die Schienen in ihrer Wurzelhälite rot. Die maifsig dichte Behaarung der Schenkel nnd Schienen'ist weifslich, an dem Wurzeldrittel der Hinterschienen rein weifs, die Bebolstung der Hauptsache nach selıwarz. 'Tarsen durchaus schwarz behaart und beborstet, Klauen schwarz, Pulvillen gelb.

Fliigel. Breite ranchgraue Adersïume erzeugen an der Šlitze und dem hinteren Rande der in übrigen durchscheinenden Flïgel eine dentliche wolkige Trubung. Die basale Grenze derselben begleitet die Cubitalader von ihrer Gabelstelle proximal bis zum vorderen Ende der hinteren Basalzelle, folgt deren distaler Begrenzung und schneidet iiber die Spitze der Analzelle in den Fliigelrand ein. Adern durchans schwarz; erste Hinterrandzelle am Fliigelrande geschlossen, die Analzelle und die vierte Hinterrandzelle, letztere seln lang, gestielt. Die distale Begrenzung der vierten Hinterrandzelle ist exquisit bogenförmig:

Long. corp. 17-24 mm, long. alar. 22-19 mm.

\section{Dasythrix löw.}

Das von Lïw errichtete Genus zeichnet sich neben anderen Merkmalen durch sein iiberaus charakteristisches Fluigelgeäder so bestimmt aus, dal's ich der Beschreilung des Autors nichts loizufiigen habe. Die Frage, ob die afrikanischen und palïarotischen Arten, namentlich gilt dies fiir die Spec. ruficornis v. d. Wulp, mit den siidamerikanischen Formen ohne weiteres generisch verbunden bleiben kïnnen, soll hier nicht weiter beriilnt werden. Mit der Angabe Lüws. dals Dasythrix als eine Übergangsform ron den Laphrinen zu den Asilinen zu betrachten sei, kann ich wohl iibereinstimmen.

Von den beiden bistang bekannt gewordenen südamerikanischen Species ist mir Dasythrix leucophïa Arribalzaga ans dem k. k. Hofmusenm in Wien in einem oro hekannt geworden, welches mit der Beschreibung vollständig übereinstimmt, so dafs ich iiber dic richtige Interpretation keinen Zweifel liabe. 


\section{Lycomyir Bigot.}

Uas von Bigot errichtete Genus ist bislang, auch noch in dem grofen Kertúsczschen Kataloge fälschlich zu den Laphrinen gestellt werden. leh gebe dem von Osten-Sacken gemachten Vorschlage, es bei den Asilinen unterzubringen, vollstiudig recht und werle daher erst an spiiteres Stelle nochmals daranf zuriickzukommen haben.

Am Fingange dieser den Laphrinen grewidmeten IJntersuchung fanden gewisse Genera Krwahumng, die offenbar nach ilurem Gesamthabitus sowohl als atuch nach gewissen Ziigen ihres Fliigelgeïders als Zwischenformen anfyefalst werden konnten, die die Laphrinen mit jener Horde der Dasypogoninen rerknüpfen. deren Torderschienen mit dem bekamnten nagelartigen Dor'u bewelırt sind. An dieser Stelle soll nun eine sehr eigentuimliche südamerikanische laubtliege beschricben werden, deren Flïgelgeäder sic wohl den Laphrinen zuweist, während sie im iibrigen dem 'Typus jener Dasypogoninen entspricht, deren Vorderschienen jenes Endlornes entbehren. Lediglich dem alten Löw schen Einteilungsprinzip znliebe luabe ich dieses anffallende Tier bei den Taphrinen untergebracht, bin mir aber wohl bewufst, dals es unter diesen schon durch den Umstand. dals die Legeröhre ron einem Kranze derber Chitindornen beschirmt ist, stets einen Fremdling darstellen wirt.

Ich beschreibe es unter dem Namen

\section{Enigmomorphess $11 . \mathrm{g}$.}

Art von mittlerer Grïse.

Kopf breiter als hoch (Taf. Fig. 64 u. 65). Das breite, nach der Fihlerwurzel nur sehr wenig verjuingte Gesicht ist an Mundrande anfgeworfen, darïber deutlich ausgehiihlt, dicht bestiiubt, aber harlos. Der einreihige, borstige Kuebelbart beschrinkt sich auf den Mundrand, erhält aber seitlich eine Ergiinzung durch ein Biischel niedergeitrickter, am Augenrande emporragender Borstenhare. Die Stirne ist durch schwache Ausrandung der Orbitalränter etwas erweitert und seitlich ebenso wie der 
Scheitel grob behaart. Der Ocellarhöeker träigt vier Borsteu. Das bestäubte Hinterhaupt ist in der Mitte dicht beborstet und mit einem Borstenkranze besetzt, der sich ungefähr bis zum $\ddot{A}$,uator der Augen herabverfolgen lälst. Der Backenbart ist kurz und wenig dieht, die Kinngegend mit langer, dichter Behaarung versehen. IJer märsig lange, gerale Rüssel ist seitlich komprefs, oben gekantet und wenig behaart. Das zweite T'astergliell ist wenig länger als das erste, an seiner Spitze mit einer kleinen Delle versehen, beide borstig behaart. Fiuhler (Texttig. 87) mälsig lang; die beiden kurz beharten zylindrischen Basalglieder von nur annähernd gleicher Länge, das seitlich kompresse, ganz schwach spindelförmige Endglied ist nicht ganz $1^{1 / 2}$ mal so lang als die beiden Basalglieder zusammengenommen und an seinem Oberrande, in geringem Mafse auch unten, mit anliegender steifer Beharung versehen. Einen Endgriffel besitzt es picht, dafur ist es an seiner Spitze kelchartig verbreitert, was namentlieh bei der Betrachtung ron oben deutlich wird.

Thorax. Das ziemlich flache, bestäubte Mesonotum lälst eine breitgeteilte Mittel- und eine in Flecken aufgelöste Seitenstrieme erkennen; die Behaarung ist nur sehr kurz und zerstreut, dafuir wird die Mittelstrieme jederseits ron einer Reihe langer Dorsoeentralhorsten flankiert. Die Schulterbeulen sind mit vier Borsten bewehrt und auch die

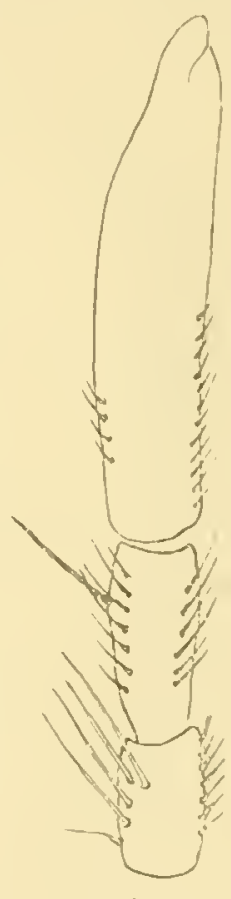

Fig. 87 . Borsten des Seitenrandes sind stark entwickelt: präsutural 3, supraalar 2 , postalar 3: das Schildchen triigt 2 Randborsten. Die bestïubten Pleuren besitzen nur iiber den Vorderhïften und auf der Mesopleura etwas dichtere Behaarung. die Notopleuralborste fehlt, der Metapleuralschirm ist relatir scliwach entwickelt. Metanotum nackt. Das Collare ist oben beborstet, seitlich dicht biischelförmig behart, der Seitenhöcker des Prothorax trëight aulser dichter Behaarung eine einzelne Borste. Hüften mälsig stark heborstet.

Das nach hinten verjingte, relativ schlanke $A$ bdomen ist mehr wie doppelt so lang als der 'Thorax, Jesteht aus acht Segmenten, deren sechs vordere dureh Bestäubung matt erscheinen, die kur\%e Legeröhre ist von einem Kranze aufallend langer Chitindornen umgeben. Die 
Beharmng des Abdomen ist im allgemeinen kurz und unansehnlich, mur das erste Segment besitzt seitlich aufser längerer beharmmg eine Reihe kreïftiger Discalhorsten.

Die relativ schlanken, diinn beharten Beine bieten kaum etwas Charakteristisches: erwiihnenswert erscheint mir, dafs die Oberschenkel der Borsten entbelıren, dagegen sind diese an den 'Tarsen sehr zahlreich und kräftig. Die Krallen und Pulvillen sind normal entwickelt. Ein Enddorn an den Vorderschienen ist nicht rorhanden.

Soweit nun entspricht das vorliegende Tier in allen seinen plastischen Merkmalen dem Charakter der Dasypogoninen, von denen es in seinem Habitus am meisten einer der kleineren Deromyiaarten ähnelt. Die ziemlich schmalen Fliigel aber zeigen in ihrem Aderverlauf ansgesprochenen Laphriencharakter, 1. h. die Subcostalzelle ist gesehlossen und ziemlich lang gestielt. Aufsertem zeigt die Fliigelmembran im Bereiche gewisser Zellen, vor allem in der hinteren Basalzelle eine gewisse Querfïltelung, wie wil sie bei den Asilinen, z. B. bei gewissen Eraxarten so häufig antreffen. Der vordere Ast der Cubitalgabel mündet noch vor der Fliigelspitze in den Vorderrand ein, die erste Hinterrandzelle ist breit offen, die dritte Hinterrandzelle ziemlich breit, die vierte Hinterrandzelle geschlossen und ziemlich lang gestielt, die Analzelle an Fliigelrande selbst geschlossen. Die kleine Querader steht ungefähr iiber der Mlitte der auffallend langen Discoidalzelle.

Als typische Art besclureibe ieh:

$$
\text { Enigmomorphus paradoxus 11. sp. + , }
$$

die nur in einem einzelnen, aus Paraguay (Asuncion) stammenden Exemplare des k. ung. Nationalmuseums in Budapest vorliegt.

Kopf. Gesicht und Stirne gleichmäsig goldgelb bestäubt, auch ler Knebelbart und die Beharming der Stime besitzen die gleiche Farbe. 1)agegen sind die Ocellarborsten sowie einige kräftigere Haare an Seitenrande der Stime schivarz. Hinterlaupt graugelb bestäubt und gelb beborstet. Batekenbart und die Beharung der Kinngegend und des Riissels weifslich. Dieser und die 'Taster lunkelbrann, letztere mit goldgelber Beharung. 
Fülller gelbrot, das Endglied gegen die Spitze zu gebräunt. Was erste Glied trägt an seiner Unterseite gelbe Haare, im iibrigen ist die Fühlerbehaarung durchans schwarz.

'Thorax. Mesonotum und Schildchen gelbbrann, die Schulterbenlen und der Seitemrand heller bestäubt; die breitgeteilte, nicht besonders sclarfe Mittelstrieme hört ziemlich weit vor dem Schildchen anf, die fleckenartige Seitenstrieme setzt sich, spitz zulaufend, bis fast zum Schildehen fort. Die kurze Beharung ist in der Nitte schwarz, an seitlichen und linteren Rande gelb. Die Borsten, aueh die des Suhildehens, sind durchaus schwarz, mur die Schulterbeulen, die Seitenhöcker des l'rothorax und das Collare gelb beborstet. Hiiften und I'leuren weifsgrau, nach oben mehr gelb bestaiubt und weifs. resp. gelblich behaart. Metapleuralschirm gelb, Schwinger rotgelb.

Abdomen. Die Grundfarbe ist ein mehr oder minder diisteres Rotbraun, das jedoch nur anf den beilen letzten Segmenten sowie am Hinterrande vorderer Abschnitte frei zutage liegt, im übrigen aljer unter dichter Bestiubung versehwindet. Diese ist in der Uitte schwarzbrann. am Seitenrande graugelb. Die kurze Behaarung ist fast ausnahmslos schwarz, nur an den Seiten des ersten Segmentes sind die längeren Haare und die Borsten gelb. Bauch gleichmäfsig grangelb bestaiubt und zart schwalrz behaart. Die rotbranne Legerïhre trägt kurze gelbe Behaamug, ler Dornenkranz ist dunkelbraun.

Die Beine sinl gelbrot, nur das spitzendrittel der Hinterschienen und die Enten der Tarsen gebräunt. Die zarte Behaarung ist fast ausnahmslos schwarz, die Imenflüehe der Torder- und die Spitze der Hinterschienen sowie die 'Tarsen sind, mit goldgelber, bürstenförmiger Behaarung versehen. Die Borsten sind schwarz, nur an den Schienen der beiden vwrleren lieinpare finden sich auch solche ron gelber Farbe. Krallen schwarzbram, Pulvillen gells.

Die schwach brïunlich tingierten Flitgel sind an der Spitze und einem Teil des Hinterandes ziemlich intensiv ranchbraun getribt. die Adern sind an der :üfsersten Wurzel gelb, im iibrigen dunkelbraun.

Long. corp. 16 mm, long. alar. $9 \mathrm{~mm}$. 


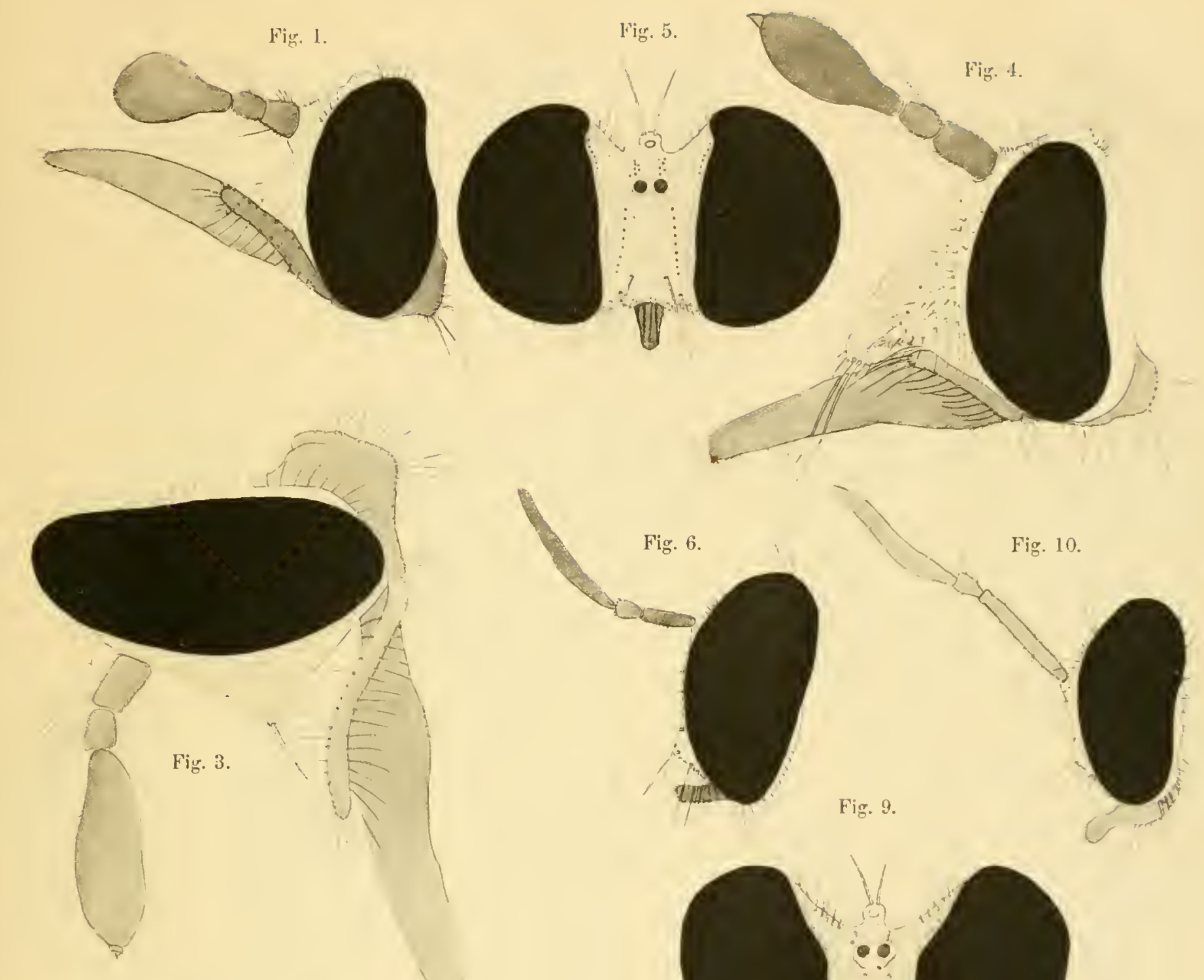

Fig. 9.

Fig. 10 .
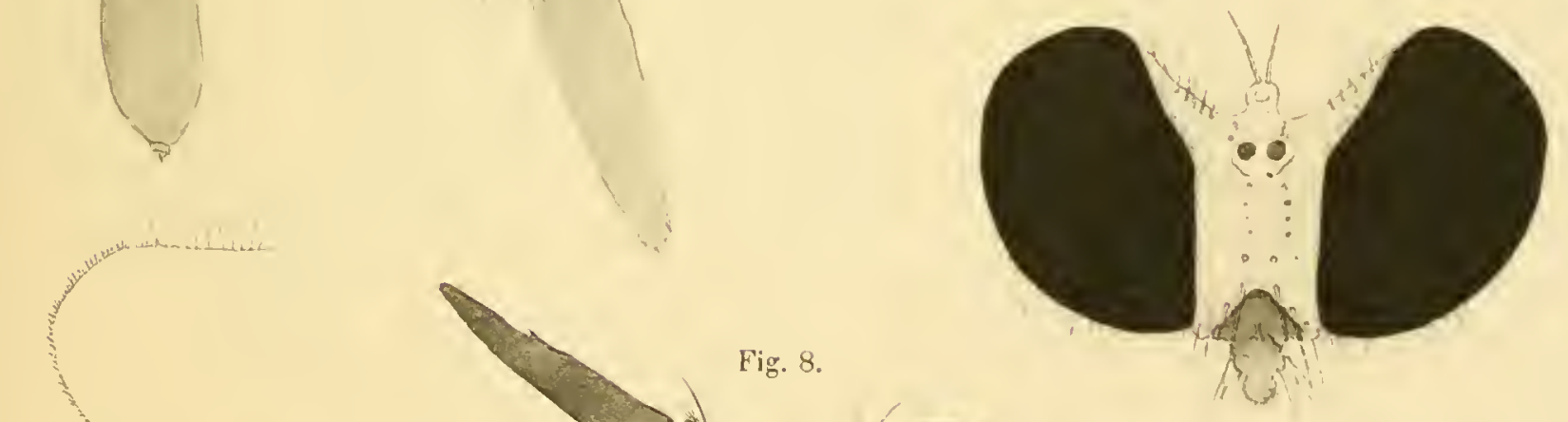

Fig. 7 .

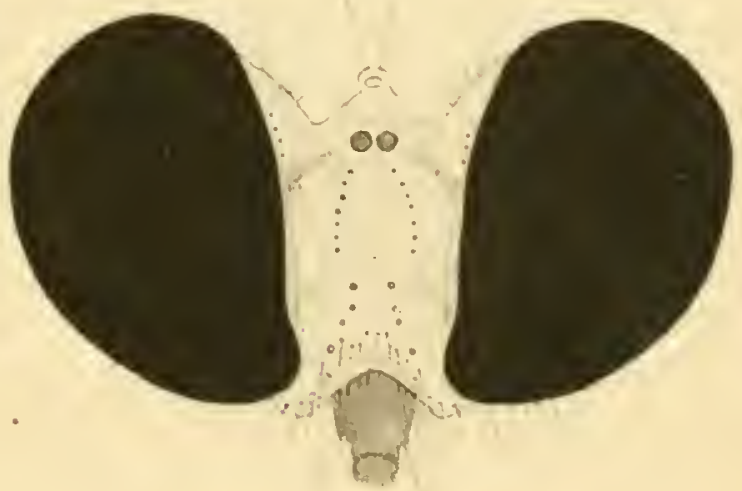

l'. Hermann: Siblamerikinnsche Dipterenfauna. 'Taf. 1. 

Fig. 11.

Fig. 13.

Fir. 11.

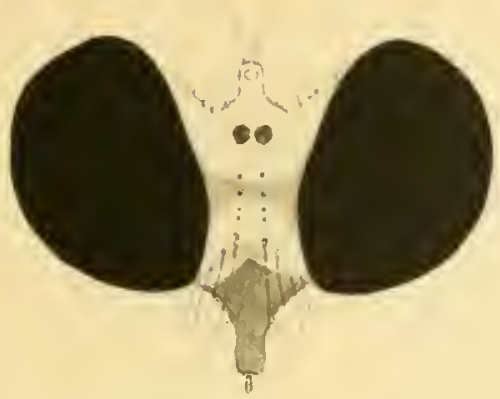

Fig. 12.

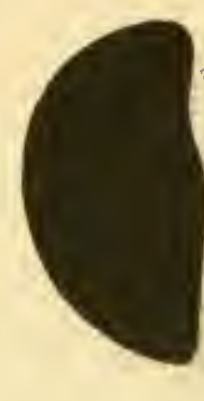

Figr. 15.

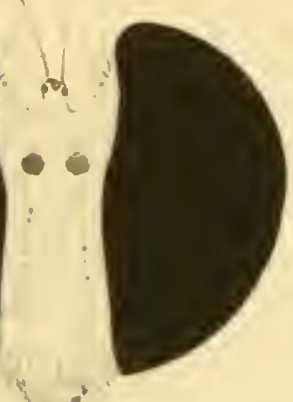

Fig. 16
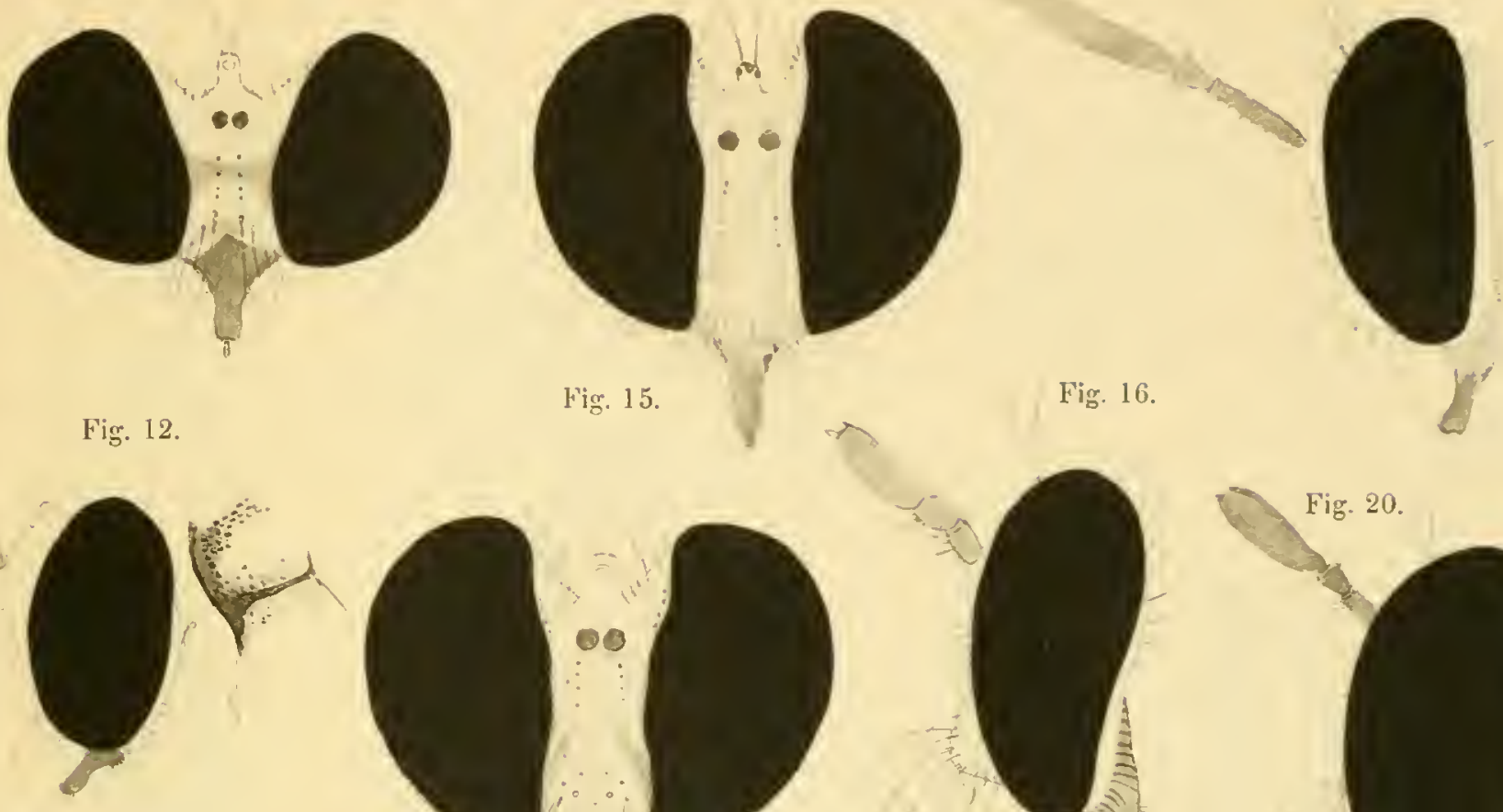

Fir. 17.

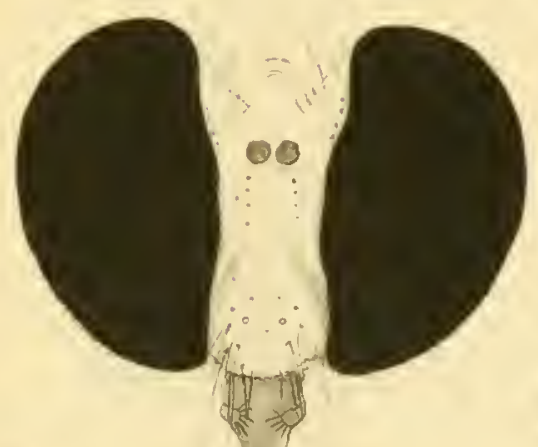

Fie. 21.
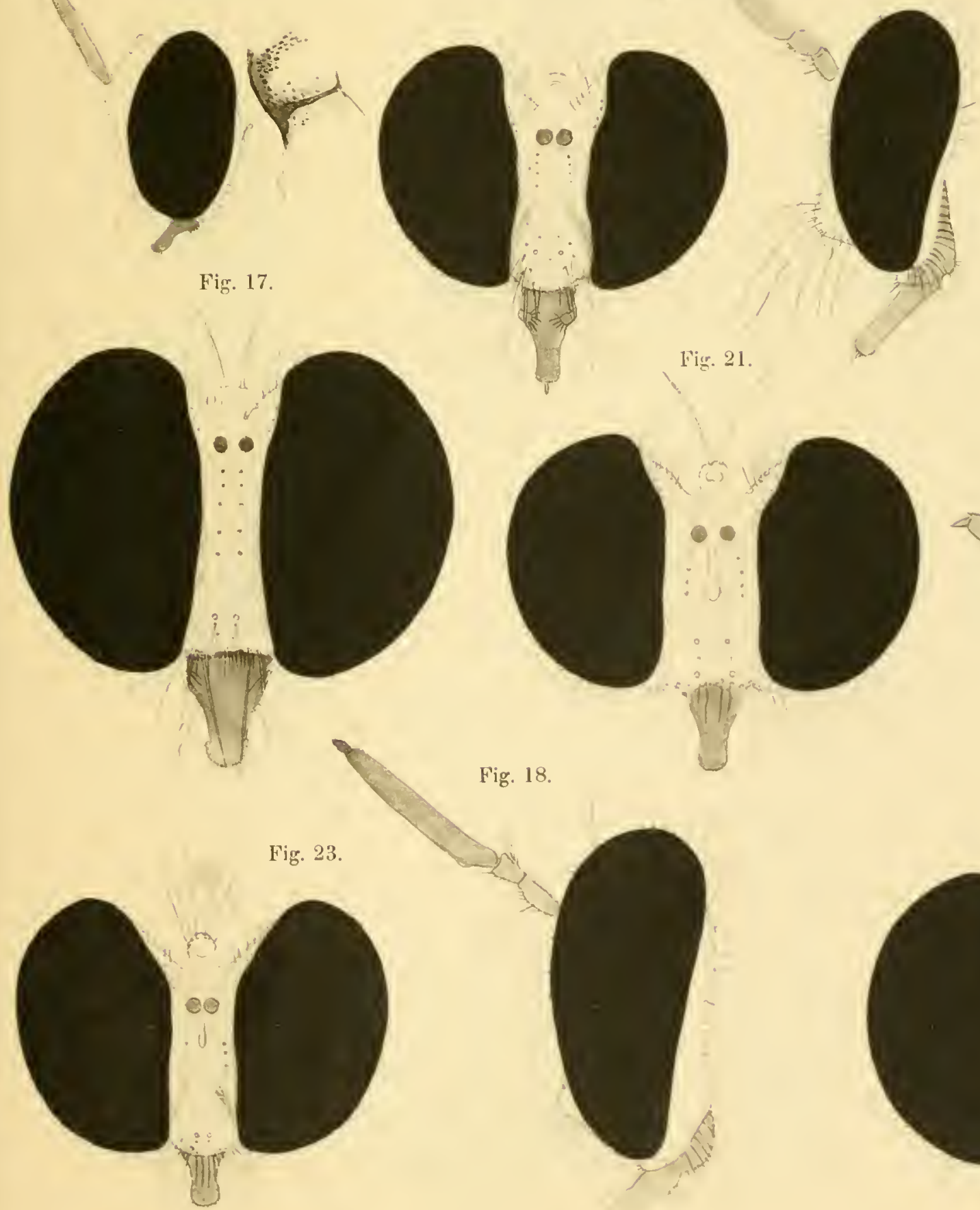

(

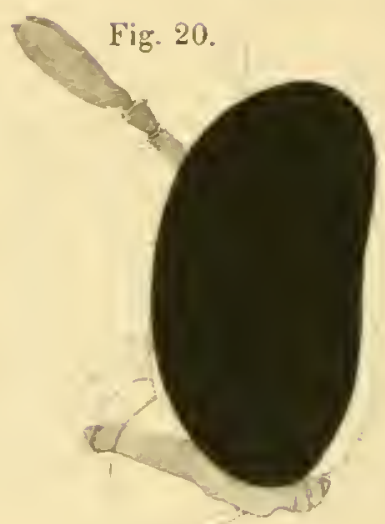

Fig. 18.
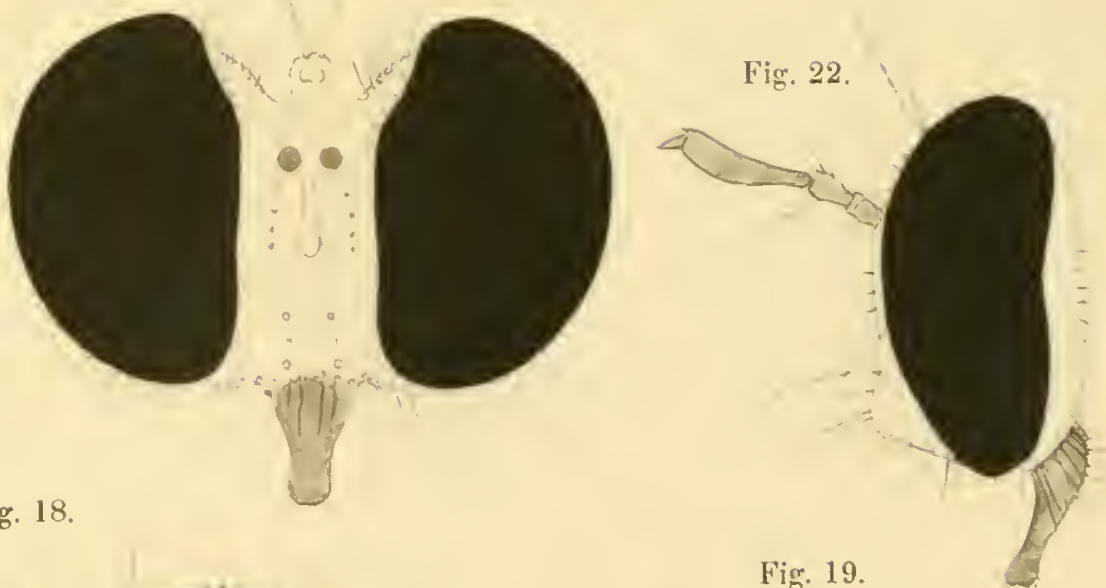

Fig. 19.

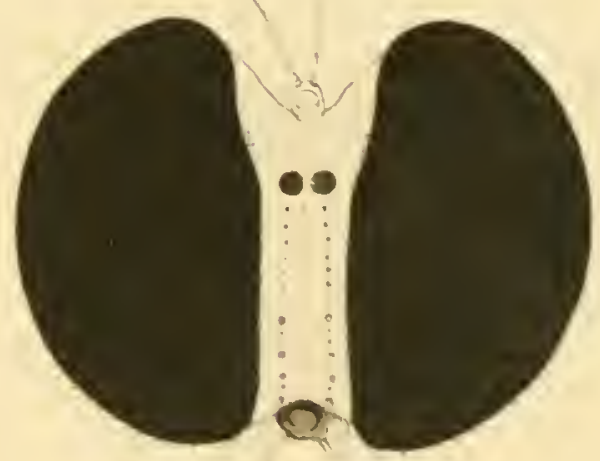

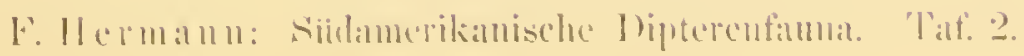



Fig. 24.

Hig. 25.

Fig. 33.
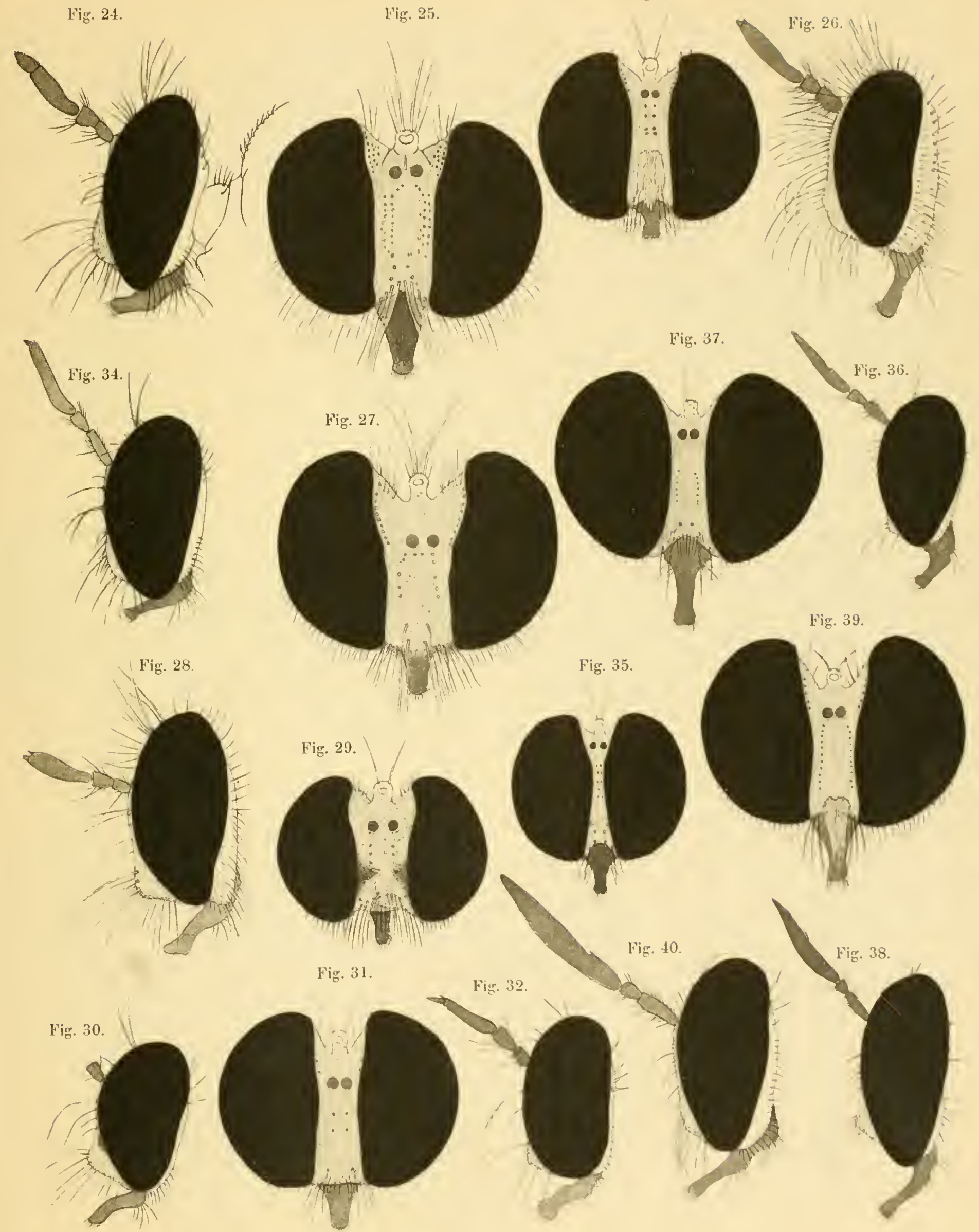

Fig. 41.
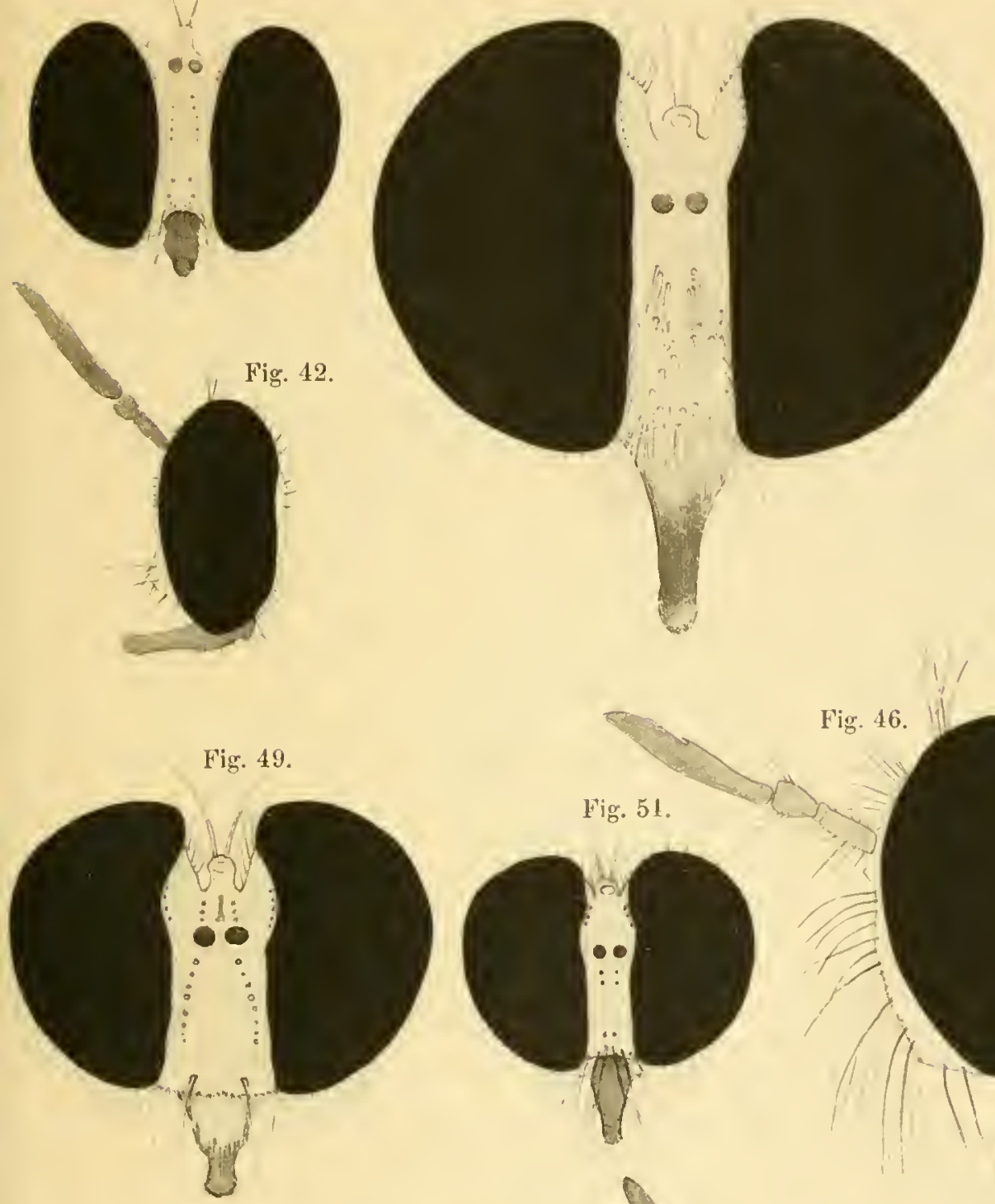

Fig. 49.

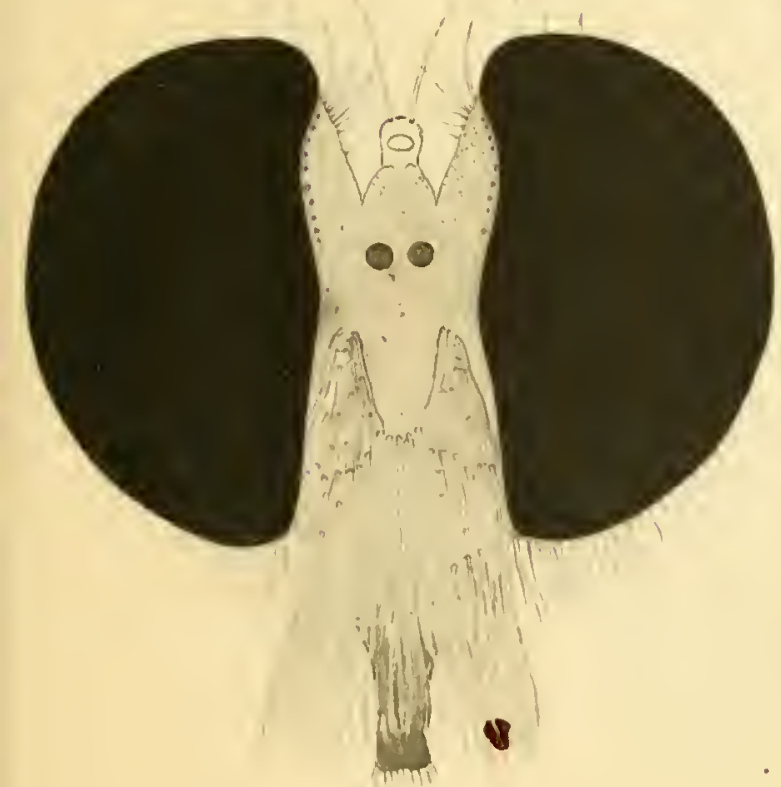

I’ig. 43.

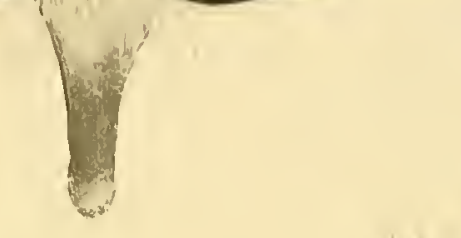

Fig. 46.
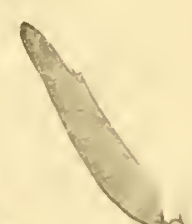
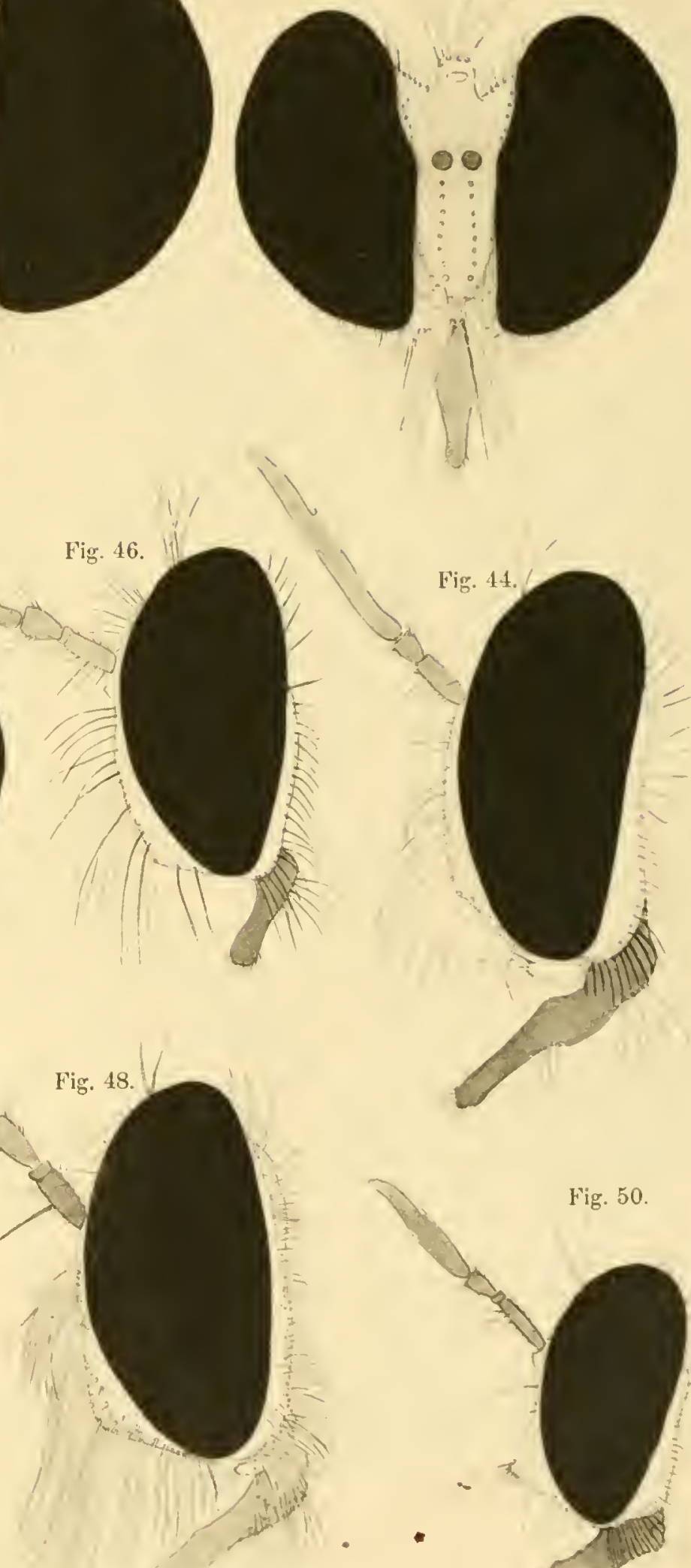

Fig. 50

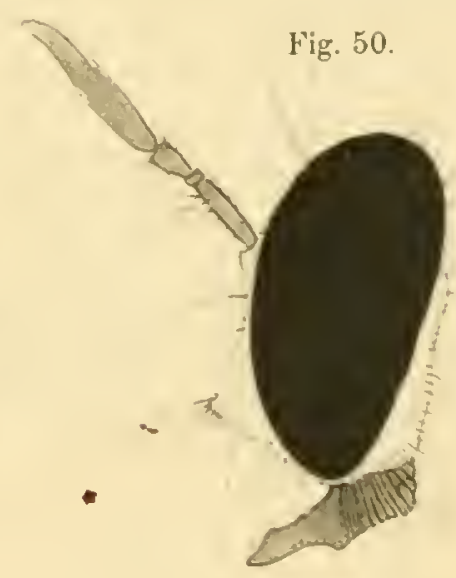

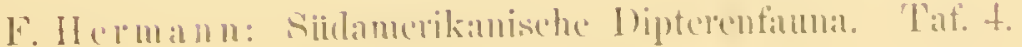



Fị. 53.
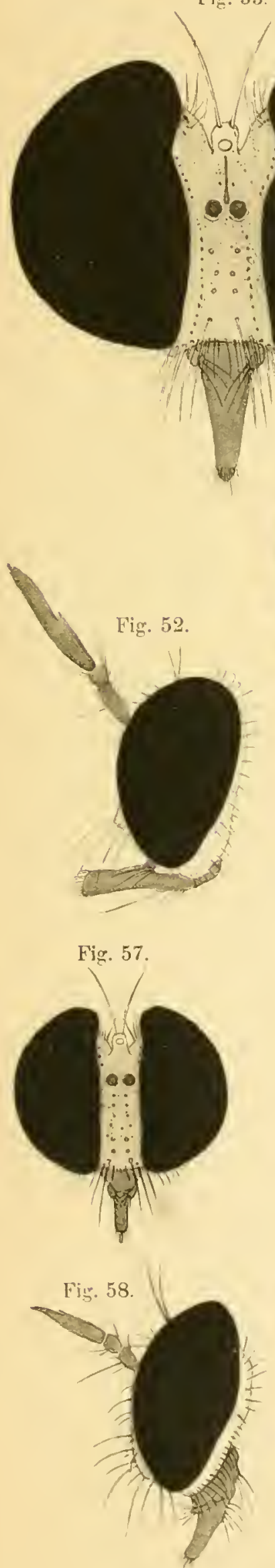

Fig. 55.
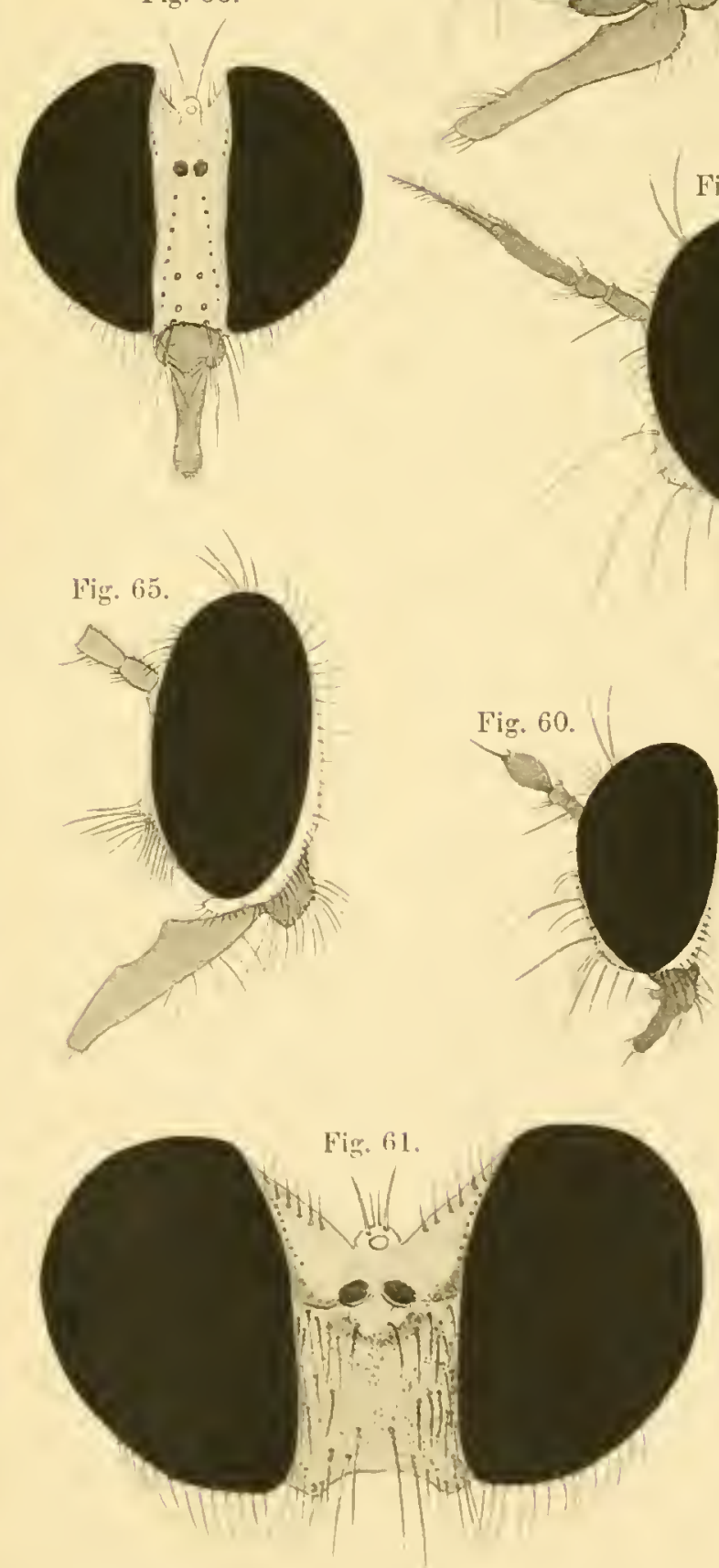

Fin. 61 .
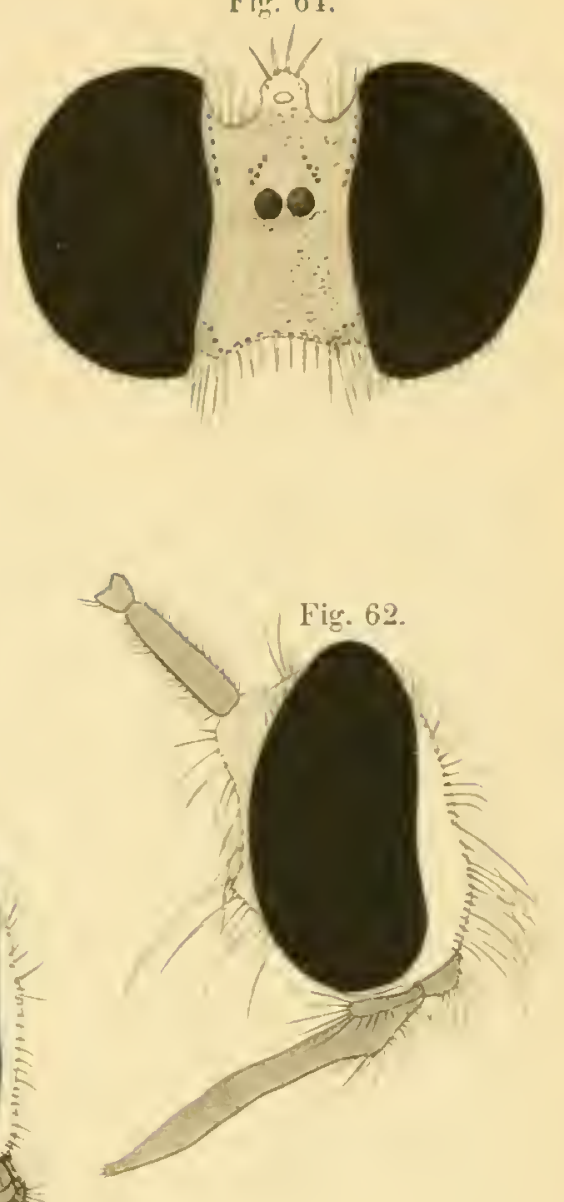

Fig. 59.
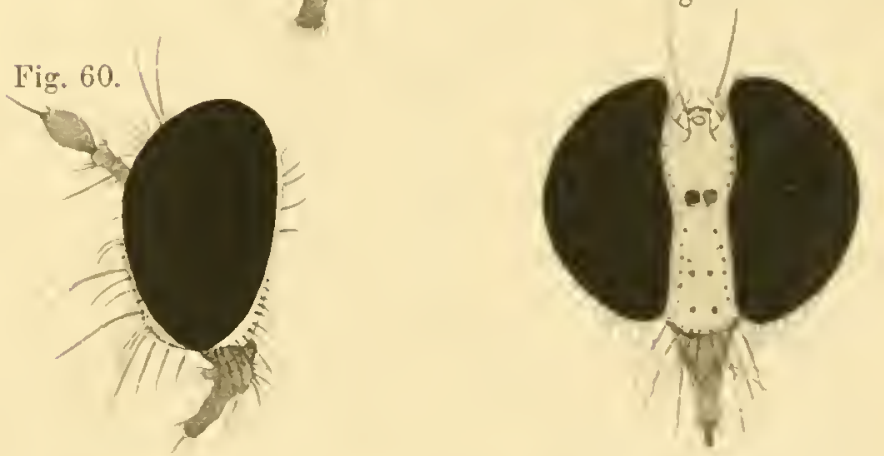

Yix. 63.

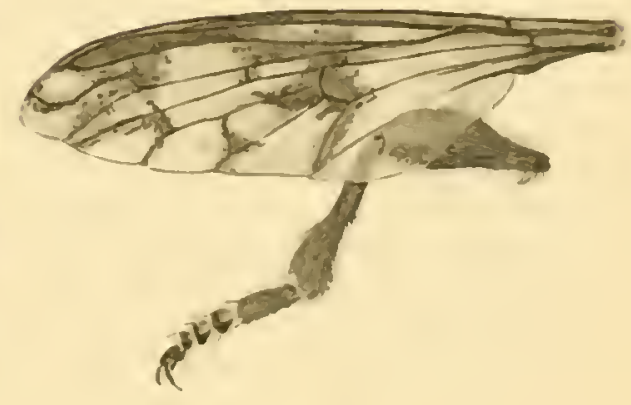





\section{$\checkmark$}

$$
\text { - }
$$


Folgende zuletat ron der Akademie leransgegebene Seluiften zoologisch-anatomisehen

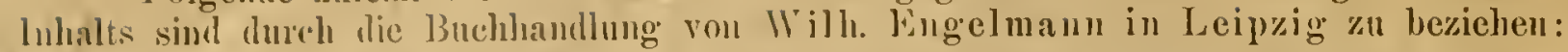

Burckliardt, lind. Das Zentral-Nervensystem der Selachier als Grundlage fur eine l'hylogenie des Vertebraten-

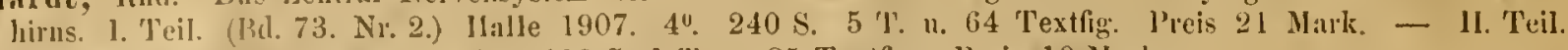
(13d. 94. Nr. 1.) llalle 1911. 40. 112 S. 1 'T'. H. 85 Textfig. Preis 10 Mark.

cramter, M. Beitrige zur Kenntnis der Polydaktylie und Syadaktyllie beim Menschen und einigen Haustieren. (Bd. 93. Nr. 1.) llalle $1910.4{ }^{0}$. 42 S. u. 6 'T. Preis 4 Mark 50 P'fg.

Verhoult, Kall WV. Uber Diplopoden. 11.-15. Aufsalz (31.-35.): Beitrüge zur Kenntnis der Glomeriden, Juliden, Aseospermorpha und lysiopetaliden, sowie zm Fauna. Siziliens. Untersuchngen über Art- und Gruppensystematik, Morphologie, nachembryonale Entwicklung, Biologie und Geographic. (Ba.92. Nr. 2.) Halle -1910. 4". 310 S. 11.9 T. l'reis 24 Mark.

IBe\%zi, M. Fam. Empididae. Beitrïge zur Kenntnis der suidamerikanisehen Dipterenfauna. (Bd.91. Nr. 3.) IIalle 1909. 40. 115 S. u. 1 T. Preis 7 Mark.

Ferhoeff, Karl W. Vergleiehend-morphologisehe Studie iiher die coxopleuralen Körperteile der Chilopoden, mit besonderer Berticksichtigung der Scolopendromorpha. (Bd. 86. Nr. 2.) 11:alle I906. 40. $152 \mathrm{~S}$. 1. 44 Textfig. l'reis 10 Mark.

Frielerichs, Karl. Untersuelungen ïber die Entstehung der Keimblatter und Bildung des Mitteldarms bei Käfern. (Bd. 85. Nr. 3.) Halle 1906. 40. 104 S. 11. 4 'T. l'reis 17 Mark 50 l'fennig.

Samelleek, Ernst. Fine Gehirnmissbildung bei Ilatteria punctata (Spenodon punctatus). Kritische Mlonographie als Beitrag za einer rationellen Teratologie des Gehirns. (Bd. 85. N1. 1.) 11alle 1905. 4". 120 S. u. 2 T. Preis $10 \mathrm{Nark}$.

llibluer, Firnst. Wetter'agen und Vogelzug. Die Rotkehlehen-Wanderungen an der dentschen Ostseeküste und ibler den europisischen liontinent. (Bd. 84. Nr. 4.) llalle 1905. 4\%. $102 \mathrm{~S}$. u. 4 'T. l'reis 8 Mark.

V(rhoeff, Karl, W. Über vergleichende Morphologie des Kopfes niederer Insekten mit besonderer Beriicksichtigung der. Dermapteren und Thysanuren, nebst biologiseh-physiologischen Beitrïgen. (Bd. 84. N1. 1.) Halle 1905. 4.. 144 S. II. 8 T. Preis 12 Mark 50 Pfg.

Itelling. A. Beitrige zm Anatomie nnd Systematik der Latemargiden. (Bd. 82. Nr. 4.) llalle 1904. $194 \mathrm{~S}$. 2 T. 42 'Textfig. Preis 12 Mark.

lBloch, B. Die geschichtlichen Grundlagen der Enbryologie bis anf Harvey. (Bd.82. Ni. 3.) 1lalle 1904. $4^{n}$. 20 S. Preis 6 Mark.

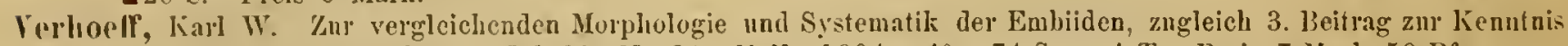
des Thorax der lnsekten. (Bd. 82. Ni. 2.) Ilalle 1904. 40. 74 S. 11. 4 T. Preis 7 Mark 50 Pf.

Forster, A. Das Muskelsystem eines männlichen 1'apua-Neugeborenen. (Bd. 82. Nr. 1.) Ilalle 1904. 4". 140 S. u. 3 T. Preis 15 Mark.

Verhoeff, Karl W. Über die Endsegmente des Körpers der Chilopoden, Dermapteren und Tapygiden und zur Syrstematik von Japix. (Bd. 81. Nr. 5.) Halle 1903, 4". $46 \mathrm{~S}$. u. $2 \mathrm{~T}^{\mathrm{T}}$. Preis 3 Marle 50 Pf.

Ïber" Tr:icheaten-Beine. Vierter" nnd fiunfter Anfsatz: Chilopoda nnd Hexapoda. (Bd. 81. Nr. 4.) Halle 1903. 40. 47 S. u. 4 T. Preis 5 Mark 50 Pf.

Beitrïge zur' vergleichenden Morphologie des 'l'horax der Insekten mit Berïcksiehtignng der Chilopoden. (Bad. 81. Ni. 2.) Halle 1903. 40.62 S. 11. 7 'T. Preis 8 Mark.

Kiedlingrer, R. Untersuchnngen über den Bau von Styelopsis grossularia der Ostsee. (Bd. 81. Nr. 1.) IIalle 1902. 4". 64 S. u. "i T. Preis 12 Mark.

('olın, Ludwig. Zur Anatomie und Systematik der Vogeleestoden (13d. 79. N1. 3). llalle 1901. 4". 188 S. 11. 8 'T. l'reis 18 Mark.

Burcklurrit, liud. Der Nestling von P'sophia erepitans und das Jugendkleid von Rhinoclietus jubatus. (Bd.79. Nr. 1.) l1alle 1901. 4". 11 S. 11. 2 T. Preis 6 Marrk.

Der Nestling von lihinuelıetus jubatus. Ein Beitrag zm Morphologie der Nestrügel nal zur systematik der lihimochetilên. (Bd. 77. Nr. 3.) Halle 1900. 40. 48 S. u. I T. l'reis 5 Mark.

Verhoefl, kinl W. Veber den Jiantungsvorgang der biplopoden. (Bd. 77. Ni. b). Halle 1901. 4". 18 S. II. I'l'. Preis 1 Mark' $50 \mathrm{Pf}$.

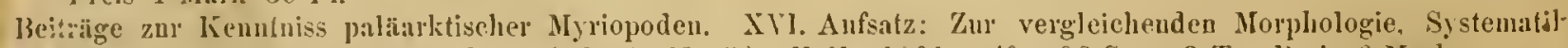
und Geographis der Chilopoden. (Bd. 77. Nr. 5.) lialle 1901. 4n. 96 S. u. 3 T. l'reis 6 Hark.

srherich, K. Ceber die Bildung der keimblitter bei den Musciden. (Bd. 77. Nr.4.) llalle 1901. 4n. $70 \mathrm{~s}$. 11. 3 T. Preis 9 Mark.

fimer, 'Th, und Vickert, C. Die Artbildung und Verwandtschaft bei den Schwimmvögeln nach deren Zeiehuung dargestellt. (Bd. 77. N1. 1). Halle 1899. 40. $110 \mathrm{~S}$. 13. 65 Textablildungen. l'reis 7 Mark.

lirat, A. Hirudineenstudien. (Bd. 72. Nr. 2). 11alle 1899. 40. 190 S.. 15 T. II. 27 Zinkographien. Preis 30 Mark.

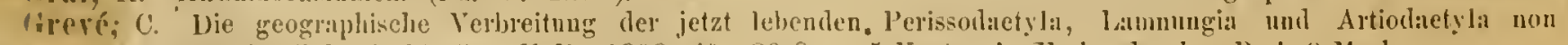

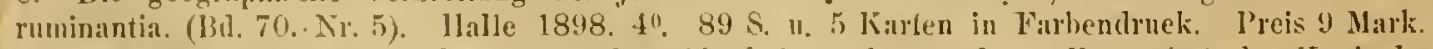

Jaseu, F. Muskelu und Nerven des proximalen Abschuittes der vorderen Bxtremitit des Kaninchens. (Bu, 199. Ni. 3). Jalle 1897. 4". 27 S. u. 4 'T'. l'reis 5 Mark.

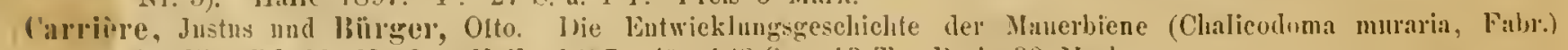

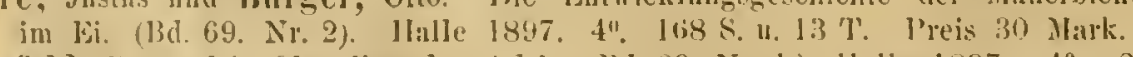

landenleld, h. v. Die Clavulina der Adria. (Bil. 69. Ni. 1.) Ilalle 1897. 4". 251 S. 11. 12 T. l'reis 27 Mark.

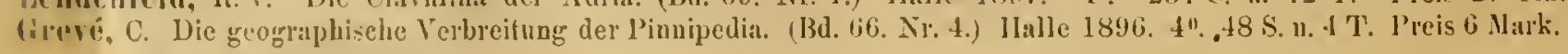





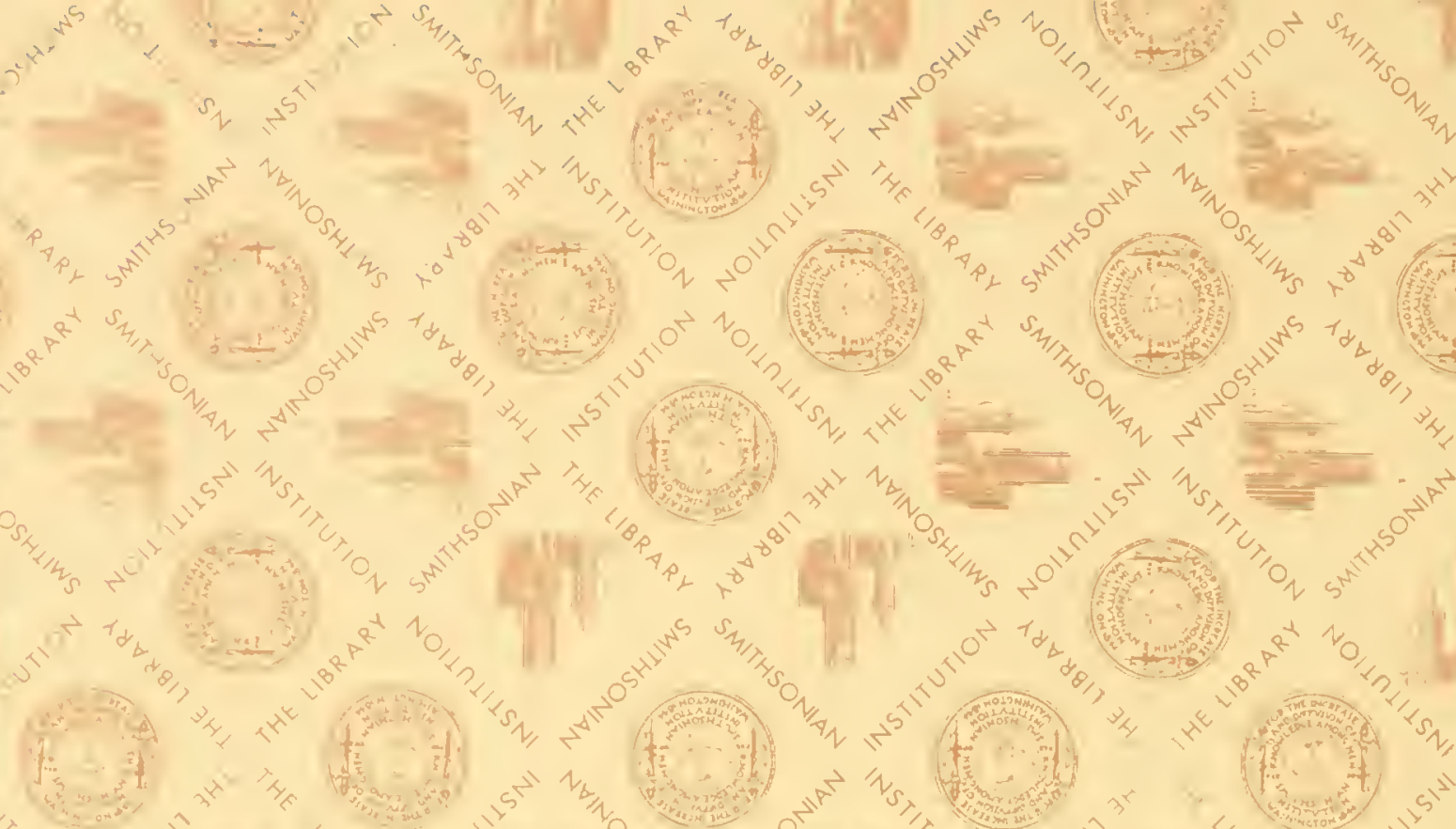

(40)

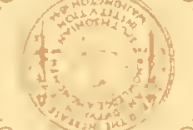

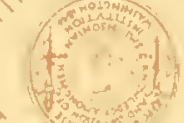

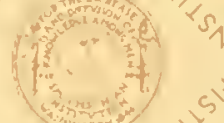
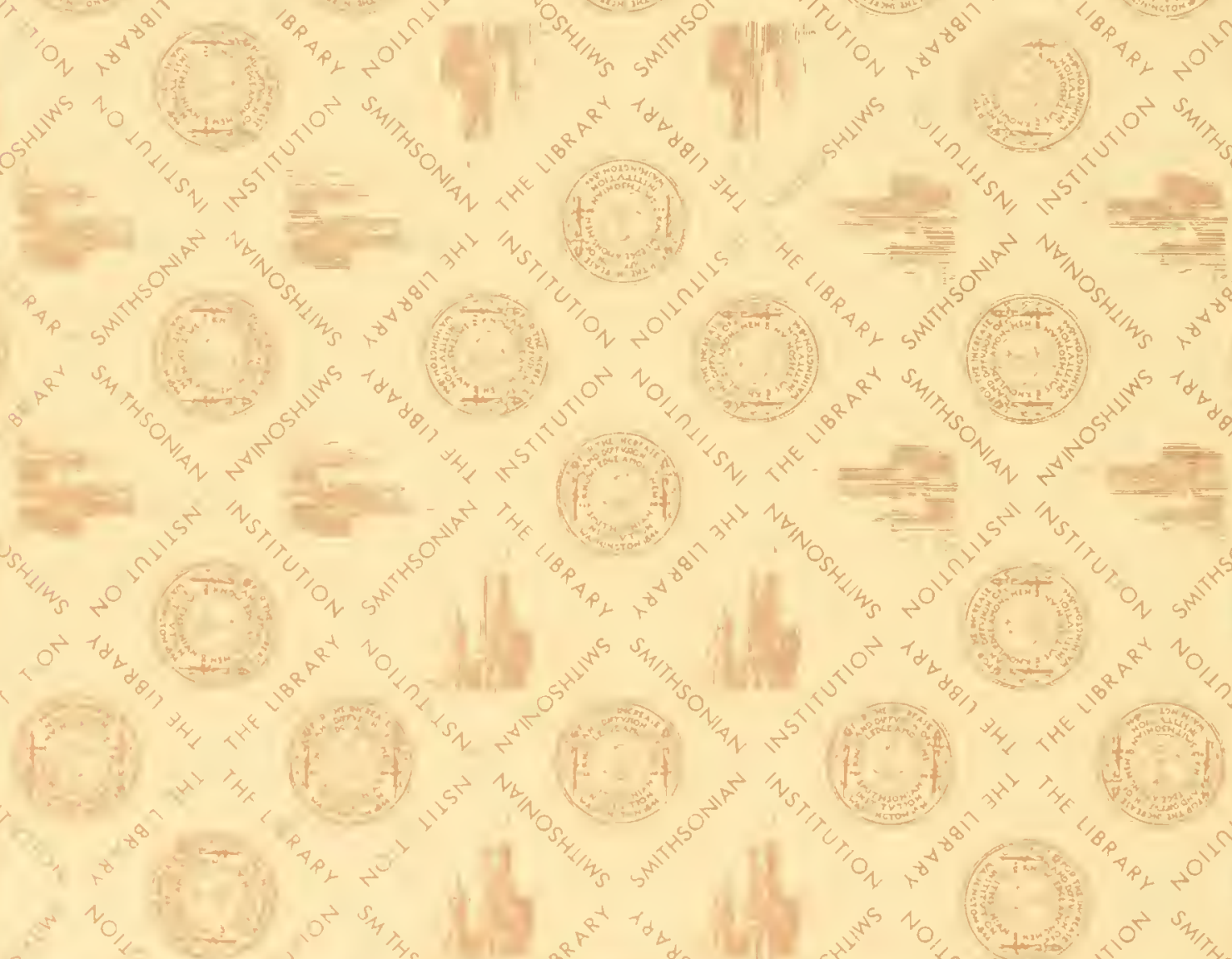

i
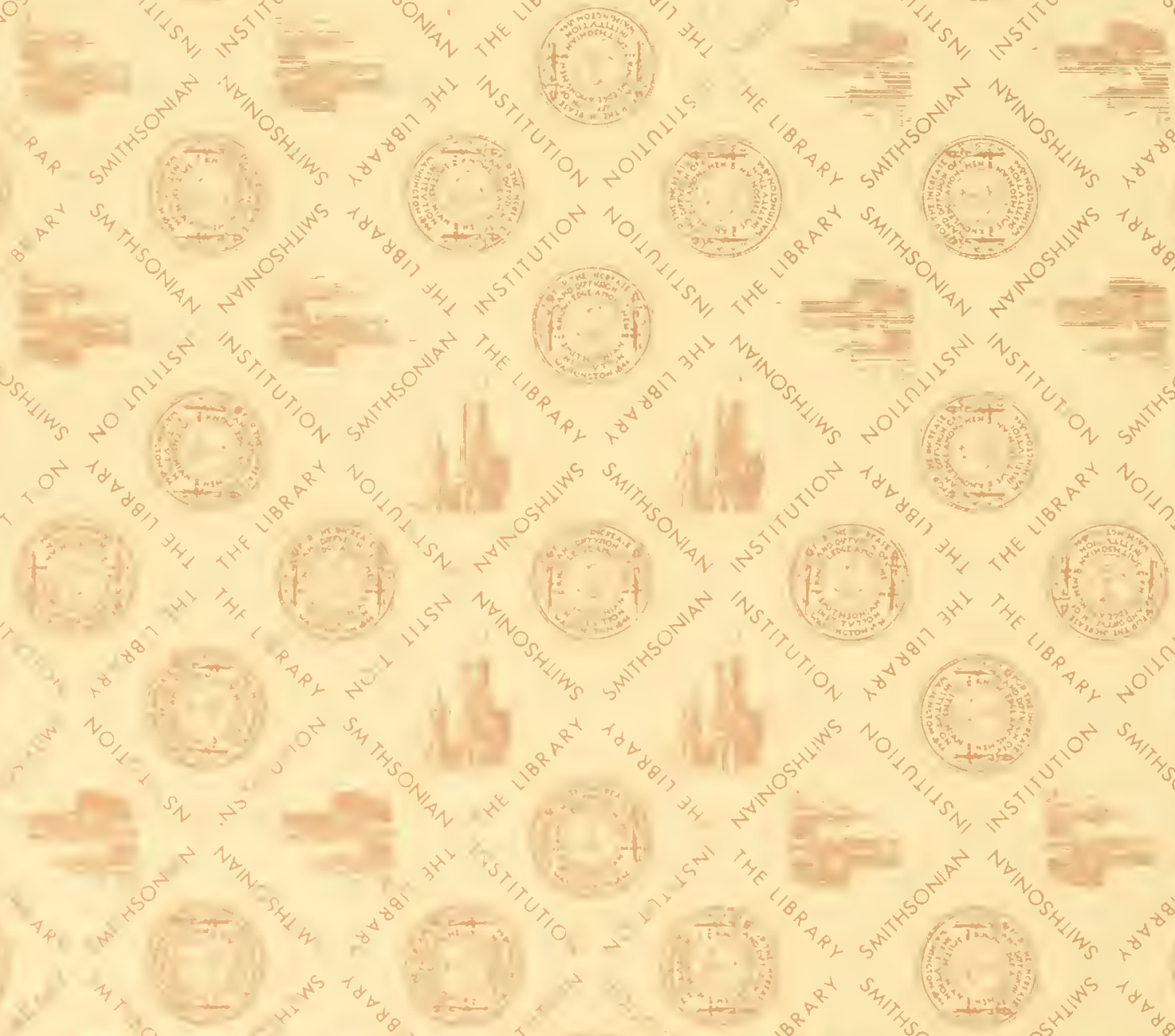
